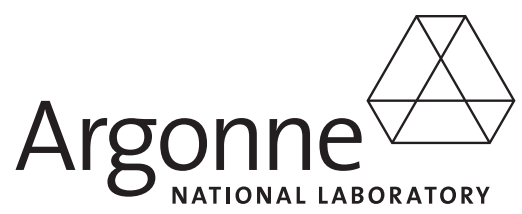

ANL-09/23

\title{
YALINA Analytical Benchmark Analyses Using the Deterministic ERANOS Code System
}

Nuclear Engineering Division 


\begin{abstract}
About Argonne National Laboratory
Argonne is a U.S. Department of Energy laboratory managed by UChicago Argonne, LLC under contract DE-AC02-06CH11357. The Laboratory's main facility is outside Chicago, at 9700 South Cass Avenue, Argonne, Illinois 60439. For information about Argonne and its pioneering science and technology programs, see www.anl.gov.
\end{abstract}

\title{
Availability of This Report
}

This report is available, at no cost, at http://www.osti.gov/bridge. It is also available on paper to the U.S. Department of Energy and its contractors, for a processing fee, from:

U.S. Department of Energy

Office of Scientific and Technical Information

P.O. Box 62

Oak Ridge, TN 37831-0062

phone (865) 576-8401

fax (865) 576-5728

reports@adonis.osti.gov

\begin{abstract}
Disclaimer
This report was prepared as an account of work sponsored by an agency of the United States Government. Neither the United States Government nor any agency thereof, nor UChicago Argonne, LLC, nor any of their employees or officers, makes any warranty, express or implied, or assumes any legal liability or responsibility for the accuracy, completeness, or usefulness of any information, apparatus, product, or process disclosed, or represents that its use would not infringe privately owned rights. Reference herein to any specific commercial product, process, or service by trade name, trademark, manufacturer, or otherwise, does not necessarily constitute or imply its endorsement, recommendation, or favoring by the United States Government or any agency thereof. The views and opinions of document authors expressed herein do not necessarily state or reflect those of the United States Government or any agency thereof, Argonne National Laboratory, or UChicago Argonne, LLC.
\end{abstract}




\title{
YALINA Analytical Benchmark Analyses Using the Deterministic ERANOS Code System
}

\author{
by \\ G. Aliberti and Y. Gohar \\ Nuclear Engineering Division, Argonne National Laboratory \\ work supported by the \\ Office of Global Nuclear Material Threat Reduction \\ U.S. Department of Energy \\ Under Contract DE-AC02-06CH11357
}

August 2009 


\title{
YALINA Analytical Benchmark Analyses Using the Deterministic ERANOS Code System
}

\author{
Table of Contents
}

Page

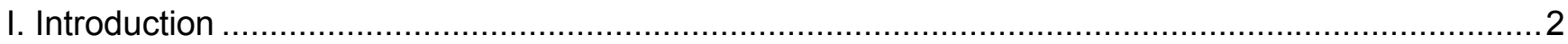

II. YALINA Benchmark Specifications of the IAEA Coordinated Research Projects...........................2

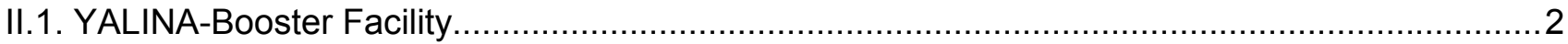

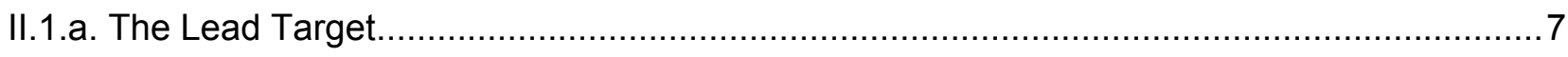

II.1.b. The Inner Part of the Fast Zone .......................................................................

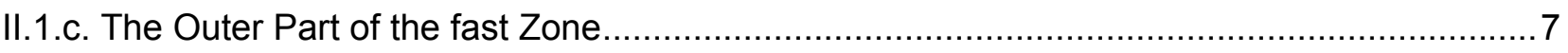

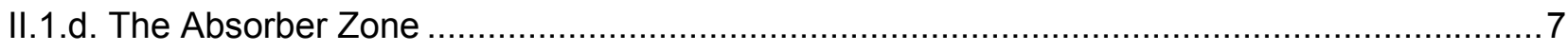

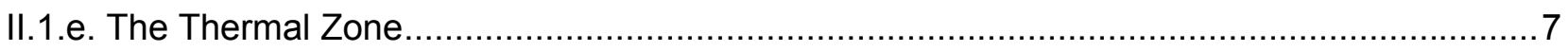

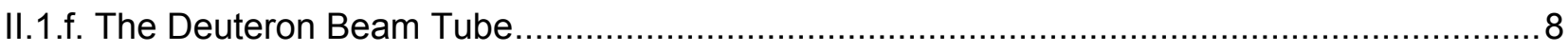

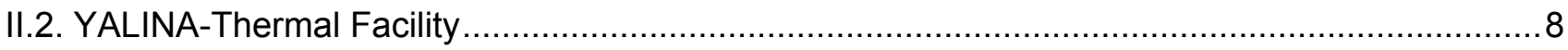

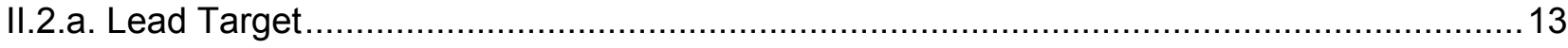

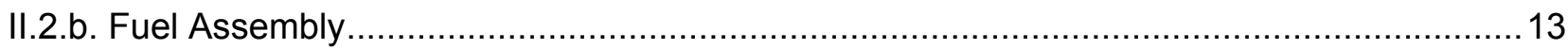

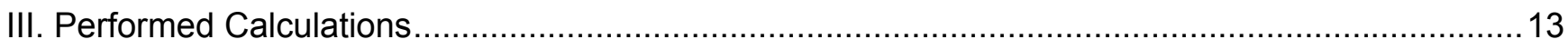

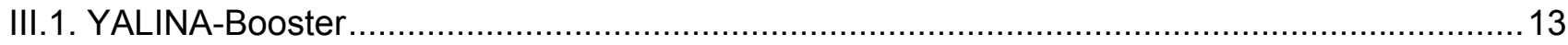

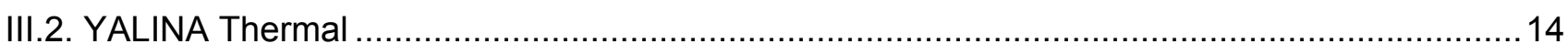

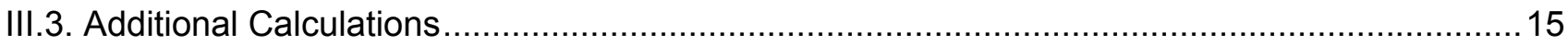

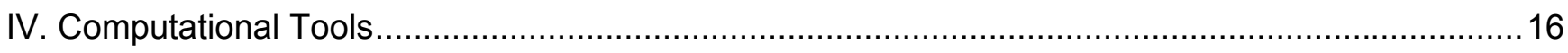

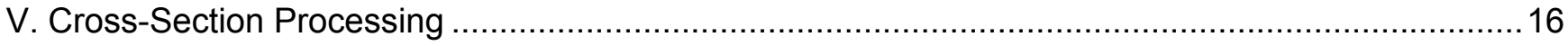

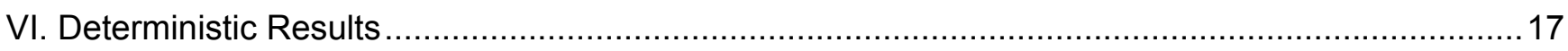

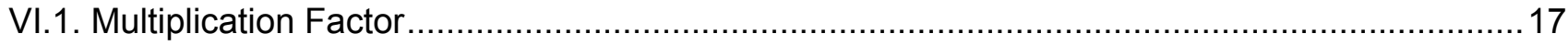

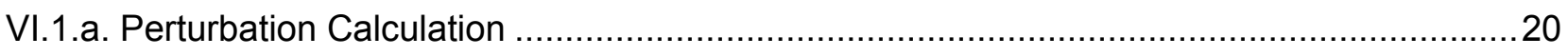

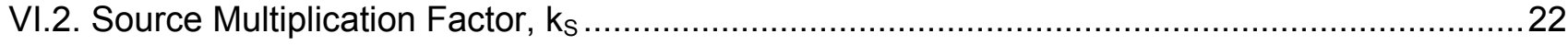

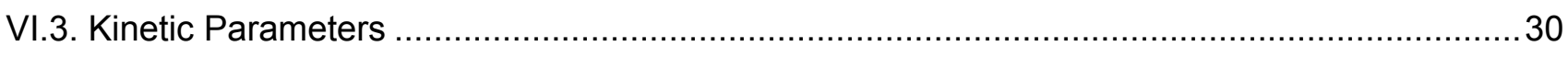

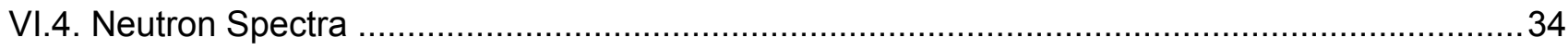




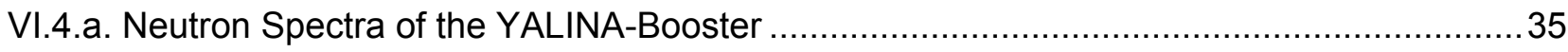

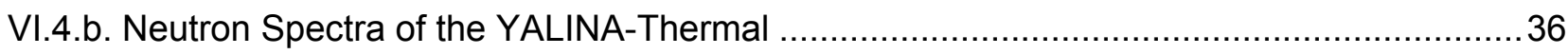

VI.4.c. Comparison of Neutron Spectra in the YALINA-Thermal Calculated with Different

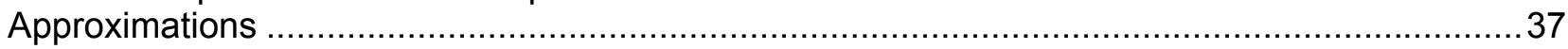

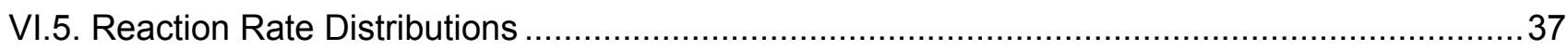

VI.5.a. Reaction Rate Distributions in the YALINA-Booster ...................................................39

VI.5.b. Reaction Rate Distributions in the YALINA-Thermal .......................................... 41

VI.5.c. Comparison of Reaction Rate Distributions in the YALINA-Booster .............................42

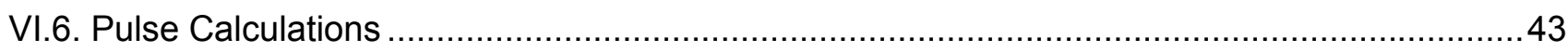

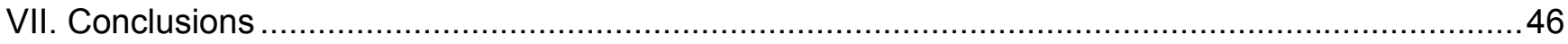

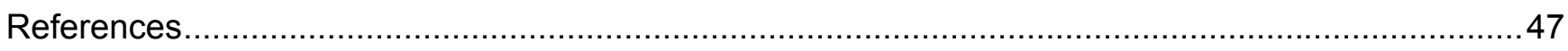

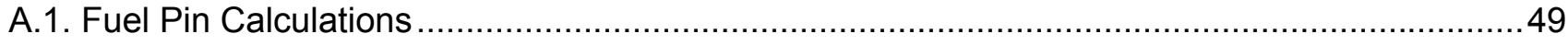

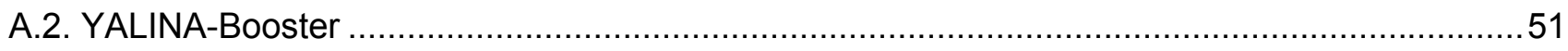

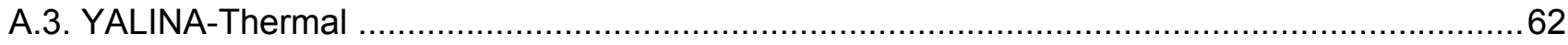

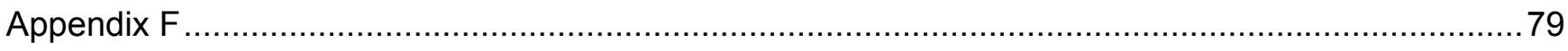

Comparison of Neutron Spectra Calculated with Different Nuclear Data Libraries ...........................79

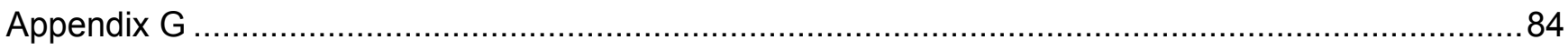

Comparison of Reaction Rates Calculated with Different Nuclear Data Libraries ............................84

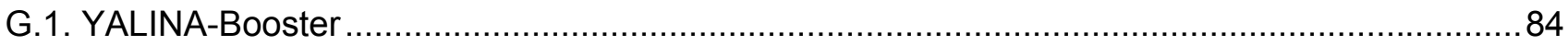

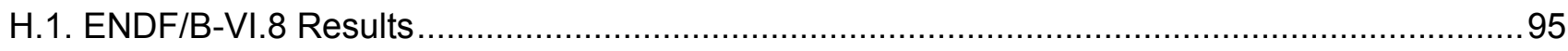




\title{
YALINA Analytical Benchmark Analyses Using the Deterministic ERANOS Code System
}

\author{
List of Figures
}

Page

Figure 1. XY Cross-Sectional View of the YALINA-Booster Assembly, Dimensions in $\mathrm{mm}$................4

Figure 2. Fuel Loading of the YALINA-Booster Configuration with 902 EK-10 Fuel Rods...................5

Figure 3. Fuel Loading of the YALINA-Booster Configuration with 1141 EK-10 Fuel Rods.................5

Figure 4. YZ Cross-Sectional View of the YALINA-Booster Assembly (at $X=4$ ), Dimensions in mm.....6

Figure 5. XZ Cross-Sectional View of the YALINA-Booster Assembly (at $Y=4$ ), Dimensions in mm.....6

Figure 6. XZ and XY Cross-Sectional Views of a Fuel Rod Inside the Steel Casing, Dimensions in cm 9

Figure 7. XZ and XY Cross-Sectional View of the Boron Carbide Rod, Dimensions in cm ..................9

Figure 8. XZ and XY Cross-Sectional Views of the EK-10 Fuel Rod, Dimensions in cm. ...................9

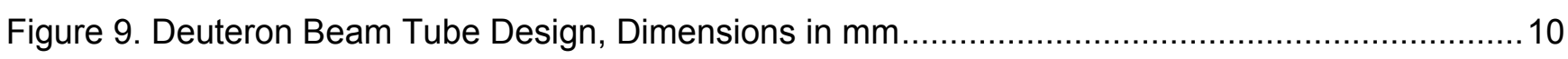

Figure 10. XY Cross-Sectional View of the YALINA-Thermal Assembly, Dimensions in mm.............10

Figure 11. XY Cross-Section of the YALINA-Thermal Assembly with 216 EK-10 Fuel Rods ..............11

Figure 12. XY Cross-Section of the YALINA-Thermal Assembly with 245 EK-10 Fuel Rods ..............11

Figure 13. XY Cross-Section of the YALINA-Thermal Assembly with 280 EK-10 Fuel Rods (Target

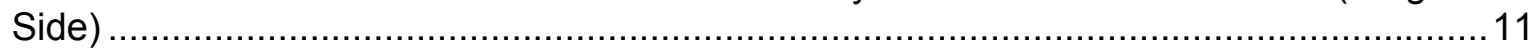

Figure 14. XY Cross-Section of the YALINA-Thermal Assembly with 280 EK-10 Fuel Rods (Beam

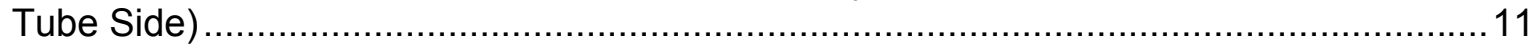

Figure 15. XZ Cross-Section of the YALINA-Thermal Assembly ( $\mathrm{Y}=0$ ), Dimensions in $\mathrm{mm}$...............12

Figure 16. YZ Cross-Section of the YALINA-Thermal Assembly $(X=0)$, Dimensions in $\mathrm{mm}$..............12

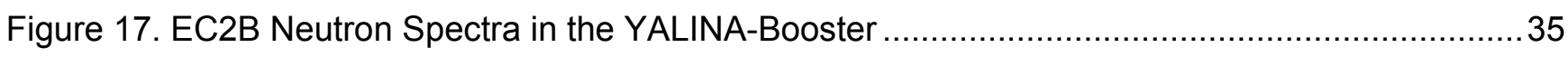

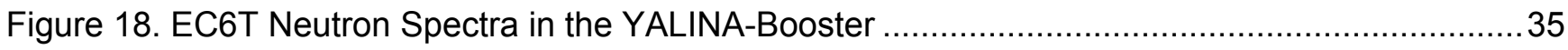

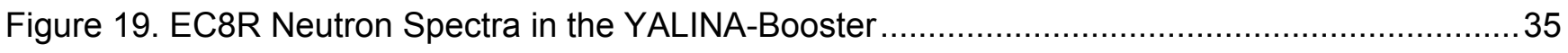

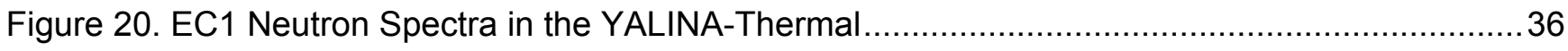

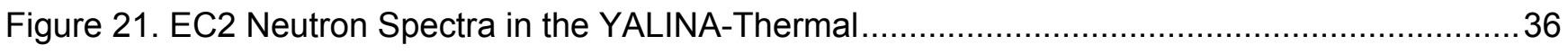

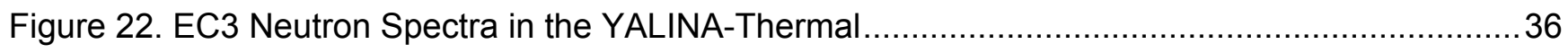

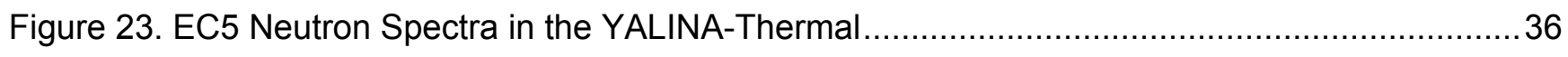

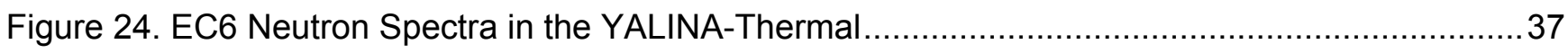


Figure 25. EC2 Neutron Spectra in the YALINA-Thermal with Different Approximations

Figure 26. EC6T He-3 (n,p) Reaction Rates 39

Figure 27. EC2B U-235 Fission Reaction Rates..... 39

Figure 28. EC6T U-235 fission Reaction Rates. 39

Figure 29. EC2B In-115 Capture Reaction Rates 39

Figure 30. EC5T In-115 Capture Reaction Rates 39

Figure 31. EC6T In-115 Capture Reaction Rates in the YALINA-Booster. Polyethylene Holder is Modeled.

Figure 32. EC7T In-115 Capture Reaction Rates

Figure 33. EC10R In-115 Capture Reaction Rates in the YALINA-Booster. Polyethylene Holder is Modeled....

Figure 34. EC2B Au-197 Capture Reaction Rates

Figure 35. EC6T Au-197 Capture Reaction Rates in the YALINA-Booster. Polyethylene Holder is Modeled.

Figure 36. EC2B Mn-55 Capture Reaction Rates

Figure 37. EC6T Mn-55 Capture Reaction Rates in the YALINA-Booster. Polyethylene Holder is Modeled.

Figure 38. EC1 He-3 (n,p) Reaction Rates

Figure 39. EC2 He-3 (n,p) Reaction Rates

Figure 40. EC3 He-3 (n,p) Reaction Rates

Figure 41. EC1 U-235 Fission Reaction Rates

Figure 42. EC2 U-235 Fission Reaction Rates

Figure 43. EC3 U-235 Fission Reaction Rates

Figure 44. EC2 In-115 Capture Reaction Rates

Figure 45. EC7 In-115 Capture Reaction Rates in the YALINA-Thermal. Polyethylene Holder is Modeled.

Figure 46. EC2 Au-197 Capture Reaction Rates.

Figure 47. EC2 Mn-55 Capture Reaction Rates in the YALINA-Thermal. Polyethylene Holder is Modeled.

Figure 48. EC6T He-3 (n,p) Reaction Rates

Figure 49. EC2B U-235 Fission Reaction Rates

Figure 50. JEF3.1 EC6T Detector Response with (d,t) Neutron Source for the YALINA-Booster.

Figure 51. JEF3.1 EC8R Detector Response with ( $d, t)$ Neutron Source for the YALINA-Booster. 43

Figure 52. JEF3.1 EC1B Detector Response with $(d, t)$ Neutron Source for the YALINA-Booster. 44 
Figure 53. JEF3.1 EC2B Detector Response with (d,t) Neutron Source for the YALINA-Booster........44

Figure 54. JEF3.1 EC3B Detector Response with $(\mathrm{d}, \mathrm{t})$ Neutron Source for the YALINA-Booster........44

Figure 55. JEF3.1 EC6T Detector Response with (d,d) Neutron Source for the YALINA-Booster .......44

Figure 56. JEF3.1 EC8R Detector Response with (d,d) Neutron Source for the YALINA-Booster.......44

Figure 57. JEF3.1 EC1B Detector Response with (d,d) Neutron Source for the YALINA-Booster.......44

Figure 58. JEF3.1 EC2B Detector Response with (d,d) Neutron Source for the YALINA-Booster .......45

Figure 59. JEF3.1 EC3B Detector Response with (d,d) Neutron Source for the YALINA-Booster.......45

Figure 60. JEF3.1 EC2 Detector Response with $(\mathrm{d}, \mathrm{t})$ Neutron Source for the YALINA-Thermal .........45

Figure 61. JEF3.1 EC5 Detector Response with $(\mathrm{d}, \mathrm{t})$ Neutron Source for the YALINA-Thermal .........45

Figure 62. JEF3.1 EC1 Detector Response with $(\mathrm{d}, \mathrm{t})$ Neutron Source for the YALINA-Thermal .........45

Figure 63. JEF3.1 EC2 Detector Response with $(d, d)$ Neutron Source for the YALINA-Thermal ........45

Figure 64. JEF3.1 EC5 Detector Response with (d,d) Neutron Source for the YALINA-Thermal ........46

Figure 65. JEF3.1 EC1 Detector Response with $(d, d)$ Neutron Source for the YALINA-Thermal ........46

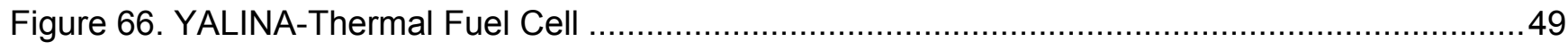

Figure 67. Comparison of MCNPX and ERANOS Averaged Fuel Cell Neutron Spectra ...................50

Figure 68. Comparison of MCNPX and ERANOS Averaged Fuel Pin Neutron Spectra ...................50

Figure 69. Comparison of MCNPX and ERANOS Averaged Aluminum Clad Neutron Spectra ...........50

Figure 70. Comparison of MCNPX and ERANOS Averaged Air Gap Neutron Spectra ....................50

Figure 71. Comparison of MCNPX and ERANOS Averaged Polyethylene Neutron Spectra ..............50

Figure 72. Comparison of MCNPX Fuel Pin Neutron Spectra and ERANOS Neutron Spectra from Different Fuel Pin regions .............................................................................. 50

Figure 73. Comparison of MCNPX Polyethylene Neutron Spectra and ERANOS Neutron Spectra from Different Polyethylene regions.....

Figure 74. XZ Layout of the YALINA-Booster Deterministic Model (Experimental Channels are not Represented).

Figure 75. YZ Layout of the YALINA-Booster Deterministic Model (Experimental Channels are not

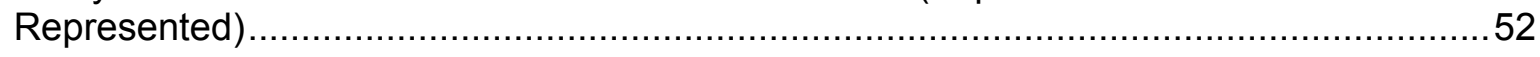

Figure 76. XY Layout of the YALINA-Booster Deterministic Model .........................................53

Figure 77. Homogenization of the Air Gap with the Graphite Reflector (Zones 24 and 26) and of the Air

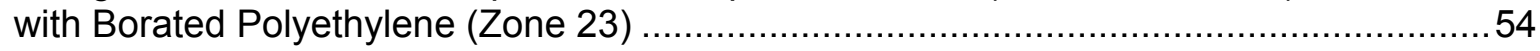

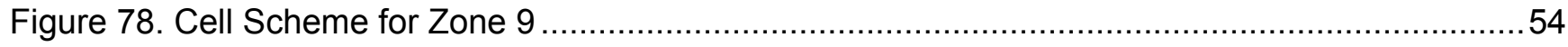

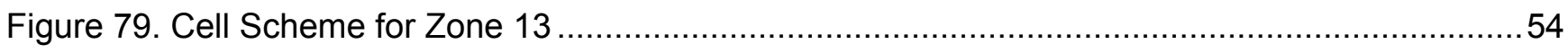

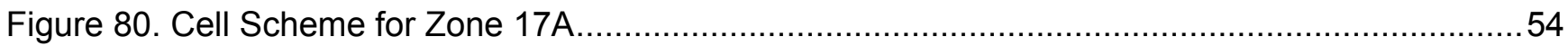




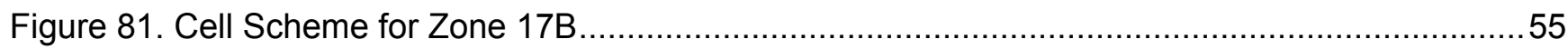

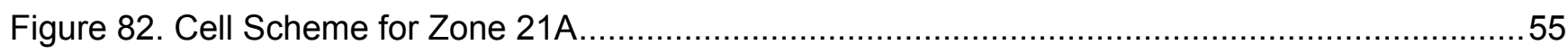

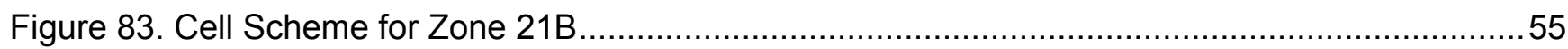

Figure 84. Cell Scheme and Representation of the Assembly Steel Structure................................55

Figure 85. Bottom Part of the 90\% U-235 Enriched Metallic, the 36\% U-235 Enriched Uranium Oxide,

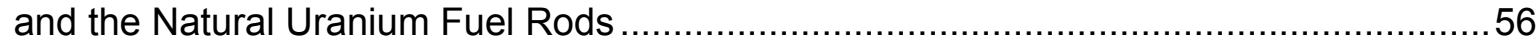

Figure 86. Top Part of the 90\% U-235 Enriched Metallic, the 36\% U-235 Enriched Uranium Oxide, and the Natural Uranium Fuel Rods ................................................................... 56

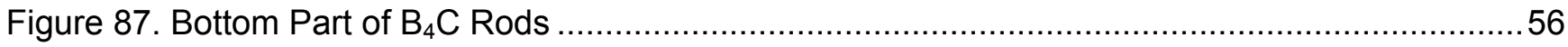

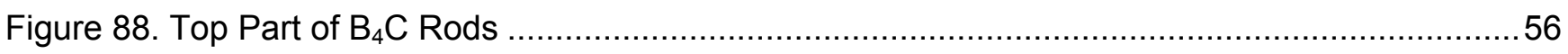

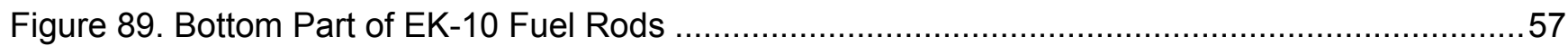

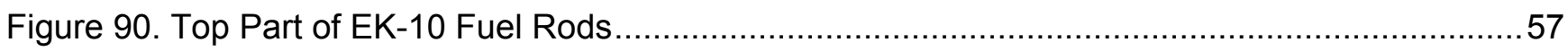

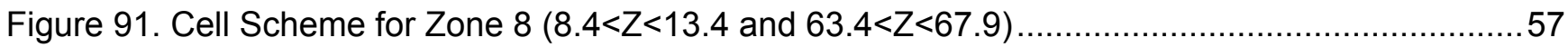

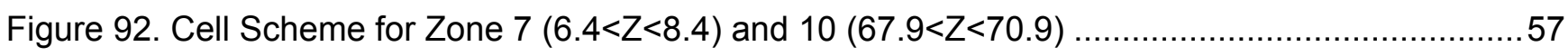

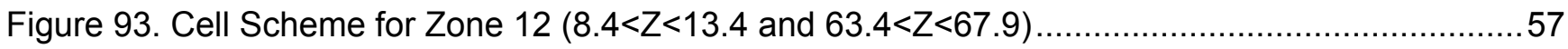

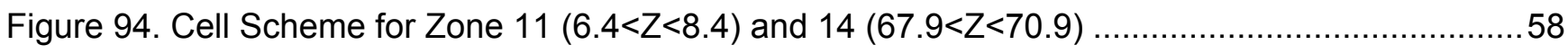

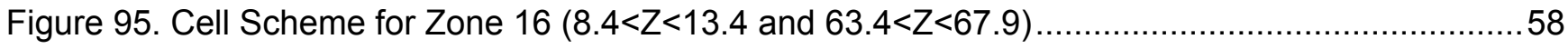

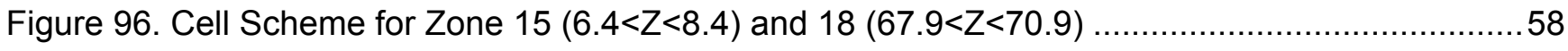

Figure 97. Cell Scheme for Zone $16(8.4<Z<13.4$ and $63.4<Z<67.9)$ at the Corner.........................58

Figure 98. Cell Scheme for Zone $15(6.4<Z<8.4)$ and $18(67.9<Z<70.9)$ at the Corner ...................58

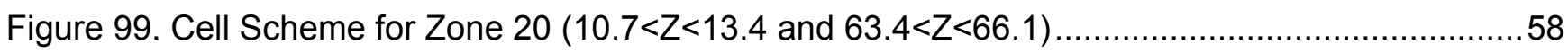

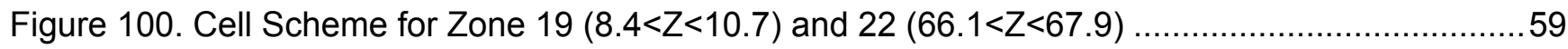

Figure 101. YALINA-Booster Calculational Models of the Central Assembly ................................60

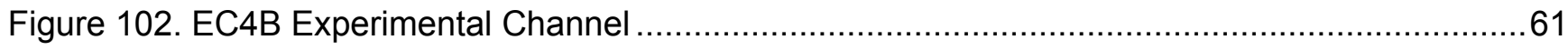

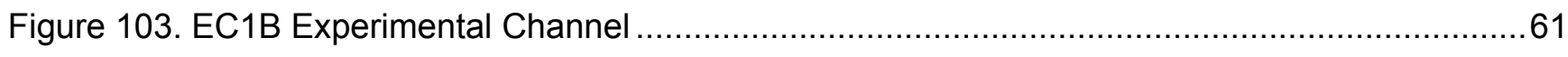

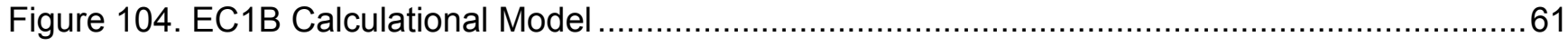

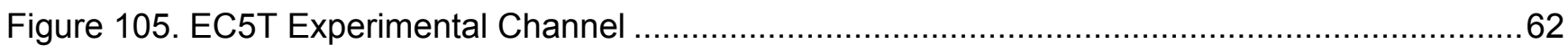

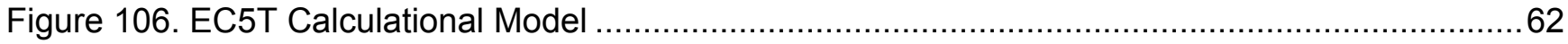

Figure 107. Three Void Channels for the Boron Carbide Rods ............................................62

Figure 108. The calculational model of the three Void Channels for the Boron Carbide Rods ............62

Figure 109. XZ Model for the YALINA-Thermal Deterministic Model (Experimental Channels are not Represented)... 
Figure 110. YZ Model for the YALINA-Thermal Deterministic Model (Experimental Channels are not Represented).

Figure 111. XY Layout of the YALINA-Thermal Deterministic Model 65

Figure 112. Homogenization of Air with Graphite Reflector of Zone 12. 65

Figure 113. Cell Scheme for Zone 9A. 66

Figure 114. Cell Scheme for Zone 9B 66

Figure 115. Cell Scheme for MC1 - MC4 Measurement Channels 66

Figure 116. Bottom Part of EK-10 Fuel Rods 66

Figure 117. Top Part of EK-10 Fuel Rods 66

Figure 118. Cell Scheme for Zone $20(2.2<Z<4.9$ and $54.9<Z<57.6)$. 67

Figure 119. Cell Scheme for Zone $19(0<Z<2.2)$ and $22(57.6<Z<59.5)$. 67

Figure 120. YALINA-Thermal Calculational Models of the Central Assembly 68

Figure 121. EC2 Experimental Channel 69

Figure 122.EC2 Experimental Channel Model. 69

Figure 123. Three Channel for the $\mathrm{B}_{4} \mathrm{C}$ Rods 69

Figure 124. Calculational Model of the Three Channels for the $B_{4} C$ Rods 69

Figure 125. RZ Geometrical Model of the YALINA-Booster...... 70

Figure 126. RZ Geometrical Model of the YALINA-Thermal... 71

Figure 127. EC2B Neutron Spectra of the YALINA-Booster with $(d, t)$ Neutron Source 79

Figure 128. EC6T Neutron Spectra of the YALINA-Booster with $(\mathrm{d}, \mathrm{t})$ Neutron Source 79

Figure 129. EC8R Neutron Spectra of the YALINA-Booster with (d,t) Neutron Source 79

Figure 130. EC2B Neutron Spectra of the YALINA-Booster with (d,d) Neutron Source. 79

Figure 131. EC6T Neutron Spectra of the YALINA-Booster with $(d, d)$ Neutron Source. 80

Figure 132. EC8R Neutron Spectra of the YALINA-Booster with $(d, d)$ Neutron Source. 80

Figure 133. EC2B Neutron Spectra of the YALINA-Booster with Cf Neutron Source. 80

Figure 134. EC6T Neutron Spectra of the YALINA-Booster with Cf Neutron Source...... 80

Figure 135. EC8R Neutron Spectra of the YALINA-Booster with Cf Neutron Source. 80

Figure 136. EC1 Neutron Spectra of the YALINA-Thermal with (d,t) Neutron Source. 81

Figure 137. EC2 Neutron Spectra of the YALINA-Thermal with (d,t) Neutron Source. 81

Figure 138. EC3 Neutron Spectra of the YALINA-Thermal with (d,t) Neutron Source. 81

Figure 139. EC5 Neutron Spectra of the YALINA-Thermal with (d,t) Neutron Source. 81

Figure 140. EC6 Neutron Spectra of the YALINA-Thermal with (d,t) Neutron Source. 81 
Figure 141. EC1 Neutron Spectra of the YALINA-Thermal with (d,d) Neutron Source. 81

Figure 142. EC2 Neutron Spectra of the YALINA-Thermal with (d,d) Neutron Source. 82

Figure 143. EC3 Neutron Spectra of the YALINA-Thermal with (d,d) Neutron Source. 82

Figure 144. EC5 Neutron Spectra of the YALINA-Thermal with (d,d) Neutron Source. 82

Figure 145. EC6 Neutron Spectra of the YALINA-Thermal with (d,d) Neutron Source..... 82

Figure 146. EC1 Neutron Spectra of the YALINA-Thermal with Cf Neutron Source 82

Figure 147. EC2 Neutron Spectra of the YALINA-Thermal with Cf Neutron Source 82

Figure 148. EC3 Neutron Spectra of the YALINA-Thermal with Cf Neutron Source 83

Figure 149. EC5 Neutron Spectra of the YALINA-Thermal with Cf Neutron Source 83

Figure 150. EC6 Neutron Spectra of the YALINA-Thermal with Cf Neutron Source 83

Figure 151. He-3(n,p) Reaction Rate in EC6T Experimental Channel of the YALINA-Booster with (d,t) Source

Figure 152. U-235 Fission Reaction Rate in EC2B Experimental Channel of the YALINA-Booster with $(d, t)$ Source. 84

Figure 153. U-235 Fission Reaction Rate in EC6T Experimental Channel of the YALINA-Booster with $(d, t)$ Source.

Figure 154. In-115 Capture Reaction Rate in EC2B Experimental Channel of the YALINA-Booster with $(d, t)$ Source. Lead Holder is Modeled.

Figure 155. In-115 Capture Reaction Rate in EC5T Experimental Channel of the YALINA-Booster with $(d, t)$ Source. Polyethylene Holder is Modeled

Figure 156. In-115 Capture Reaction Rate in EC6T Experimental Channel of the YALINA-Booster with $(d, t)$ Source. Polyethylene Holder is Modeled

Figure 157. In-115 Capture Reaction Rate in EC7T Experimental Channel of the YALINA-Booster with $(d, t)$ Source. Polyethylene Holder is Modeled

Figure 158. In-115 Capture Reaction Rate in EC10R Experimental Channel of the YALINA-Booster with $(d, t)$ Source. Polyethylene Holder is Modeled.....

Figure 159. Au-197 Capture Reaction Rate in EC2B Experimental Channel of the YALINA-Booster with $(d, t)$ Source. Lead Holder is Modeled

Figure 160. Au-197 Capture Reaction Rate in EC6T Experimental Channel of the YALINA-Booster with $(\mathrm{d}, \mathrm{t})$ Source. Polyethylene Holder is Modeled....

Figure 161. Mn-55 Capture Reaction Rate in EC2B Experimental Channel of the YALINA-Booster with $(d, t)$ Source. Lead Holder is Modeled.

Figure 162. Mn-55 Capture Reaction Rate in EC6T Experimental Channel of the YALINA-Booster with $(d, t)$ Source. Polyethylene Holder is Modeled

Figure 163. He-3(n,p) Capture Reaction Rate in EC6T Experimental Channel of the YALINA-Booster with $(d, d)$ Source 
Figure 164. U-235 Fission Capture Reaction Rate in EC2B Experimental Channel of the YALINABooster with $(d, d)$ Source

Figure 165. U-235 Fission Capture Reaction Rate in EC6T Experimental Channel of the YALINABooster with $(\mathrm{d}, \mathrm{d})$ Source

Figure 166. In-115 Capture Reaction Rate in EC2B Experimental Channel of the YALINA-Booster with (d,d) Source. Lead Holder is Modeled.

Figure 167. In-115 Capture Reaction Rate in EC5T Experimental Channel of the YALINA-Booster with $(d, d)$ Source. Polyethylene Holder is Modeled

Figure 168. In-115 Capture Reaction Rate in EC6T Experimental Channel of the YALINA-Booster with (d,d) Source. Polyethylene Holder is Modeled

Figure 169. In-115 Capture Reaction Rate in EC7T Experimental Channel of the YALINA-Booster with (d,d) Source. Polyethylene Holder is Modeled ...

Figure 170. In-115 Capture Reaction Rate in EC10R Experimental Channel of the YALINA-Booster with $(d, d)$ Source. Polyethylene Holder is Modeled.

Figure 171. Au-197 Capture Reaction Rate in EC2B Experimental Channel of the YALINA-Booster with (d,d) Source. Lead Holder is Modeled

Figure 172. Au-197 Capture Reaction Rate in EC6T Experimental Channel of the YALINA-Booster with $(\mathrm{d}, \mathrm{d})$ Source. Polyethylene Holder is Modeled.

Figure 173. Mn-55 Capture Reaction Rate in EC2B Experimental Channel of the YALINA-Booster with $(d, d)$ Source. Lead Holder is Modeled.

Figure 174. Mn-55 Capture Reaction Rate in EC6T Experimental Channel of the YALINA-Booster with (d,d) Source. Polyethylene Holder is Modeled

Figure 175. He-3(n,p) Reaction Rate in EC6T Experimental Channel of the YALINA-Booster with Cf Neutron Source

Figure 176. U-235 Fission Reaction Rate in EC2B Experimental Channel of the YALINA-Booster with Cf Neutron Source. 88

Figure 177. U-235 Fission Reaction Rate in EC6T Experimental Channel of the YALINA-Booster with Cf Neutron Source.

Figure 178. In-115 Capture Reaction Rate in EC2B Experimental Channel of the YALINA-Booster with Cf Neutron Source. Lead Holder is Modeled.

Figure 179. In-115 Capture Reaction Rate in EC5T Experimental Channel of the YALINA-Booster with Cf Neutron Source. Polyethylene Holder is Modeled

Figure 180. In-115 Capture Reaction Rate in EC6T Experimental Channel of the YALINA-Booster with Cf Neutron Source. Polyethylene Holder is Modeled

Figure 181. In-115 Capture Reaction Rate in EC7T Experimental Channel of the YALINA-Booster with Cf Neutron Source. Polyethylene Holder is Modeled

Figure 182. In-115 Capture Reaction Rate in EC10R Experimental Channel of the YALINA-Booster with Cf Neutron Source. Polyethylene Holder is Modeled....

Figure 183. Au-197 Capture Reaction Rate in EC2B Experimental Channel of the YALINA-Booster with Cf Neutron Source. Lead Holder is Modeled 
Figure 184. Au-197 Capture Reaction Rate in EC6T Experimental Channel of the YALINA-Booster with Cf Neutron Source. Polyethylene Holder is Modeled....

Figure 185. Mn-55 Capture Reaction Rate in EC2B Experimental Channel of the YALINA-Booster with Cf Neutron Source. Lead Holder is Modeled.

Figure 186. Mn-55 Capture Reaction Rate in EC6T Experimental Channel of the YALINA-Booster with Cf Neutron Source. Polyethylene Holder is Modeled

Figure 187. He-3(n,p) Reaction Rate in EC1 Experimental Channel of the YALINA-Thermal with $(d, t)$ Neutron Source

Figure 188. He-3(n,p) Reaction Rate in EC2 Experimental Channel of the YALINA-Thermal with $(d, t)$ Neutron Source .90

Figure 189. He-3(n,p) Reaction Rate in EC3 Experimental Channel of the YALINA-Thermal with $(d, t)$ Neutron Source

Figure 190. U-235 Fission Reaction Rate in EC1 Experimental Channel of the YALINA-Thermal with $(d, t)$ Neutron Source

Figure 191. U-235 Fission Reaction Rate in EC2 Experimental Channel of the YALINA-Thermal with $(d, t)$ Neutron Source

Figure 192. U-235 Fission Reaction Rate in EC3 Experimental Channel of the YALINA-Thermal with $(d, t)$ Neutron Source

Figure 193. In-115 Capture Reaction Rate in EC2 Experimental Channel of the YALINA-Thermal with $(d, t)$ Neutron Source. Polyethylene Holder is Modeled

Figure 194. In-115 Capture Reaction Rate in EC7 Experimental Channel of the YALINA-Thermal with $(d, t)$ Neutron Source. Polyethylene Holder is Modeled

Figure 195. Au-197 Capture Reaction Rate in EC2 Experimental Channel of the YALINA-Thermal with $(d, t)$ Neutron Source. Polyethylene Holder is Modeled

Figure 196. Mn-55 Capture Reaction Rate in EC2 Experimental Channel of the YALINA-Thermal with $(d, t)$ Neutron Source. Polyethylene Holder is Modeled

Figure 197. He-3(n,p) Reaction Rate in EC1 Experimental Channel of the YALINA-Thermal with (d,d) Neutron Source

Figure 198. He-3(n,p) Reaction Rate in EC2 Experimental Channel of the YALINA-Thermal with (d,d) Neutron Source

Figure 199. He-3(n,p) Reaction Rate in EC3 Experimental Channel of the YALINA-Thermal with (d,d) Neutron Source

Figure 200. U-235 Fission Reaction Rate in EC1 Experimental Channel of the YALINA-Thermal with $(d, d)$ Neutron Source.

Figure 201. U-235 Fission Reaction Rate in EC2 Experimental Channel of the YALINA-Thermal with $(d, d)$ Neutron Source.

Figure 202. U-235 Fission Reaction Rate in EC3 Experimental Channel of the YALINA-Thermal with (d,d) Neutron Source.

Figure 203. In-115 Capture Reaction Rate in EC2 Experimental Channel of the YALINA-Thermal with (d,d) Neutron Source. Polyethylene Holder is modeled 
Figure 204. In-115 Capture Reaction Rate in EC7 Experimental Channel of the YALINA-Thermal with (d,d) Neutron Source. Polyethylene Holder is modeled .92

Figure 205. Au-197 Capture Reaction Rate in EC2 Experimental Channel of the YALINA-Thermal with (d,d) Neutron Source. Polyethylene Holder is modeled

Figure 206. Mn-55 Capture Reaction Rate in EC2 Experimental Channel of the YALINA-Thermal with (d,d) Neutron Source. Polyethylene Holder is modeled

Figure 207. He-3(n,p) Reaction Rate in EC1 Experimental Channel of the YALINA-Thermal with Cf Neutron Source

Figure 208. He-3(n,p) Reaction Rate in EC2 Experimental Channel of the YALINA-Thermal with Cf Neutron Source

Figure 209. He-3(n,p) Reaction Rate in EC3 Experimental Channel of the YALINA-Thermal with Cf Neutron Source

Figure 210. U-235 Fission Reaction Rate in EC1 Experimental Channel of the YALINA-Thermal with Cf Neutron Source....

Figure 211. U-235 Fission Reaction Rate in EC2 Experimental Channel of the YALINA-Thermal with Cf Neutron Source.

Figure 212. U-235 Fission Reaction Rate in EC3 Experimental Channel of the YALINA-Thermal with Cf Neutron Source.

Figure 213. In-115 Capture Reaction Rate in EC2 Experimental Channel of the YALINA-Thermal with Cf Neutron Source. Polyethylene Holder is modeled

Figure 214. In-115 Capture Reaction Rate in EC7 Experimental Channel of the YALINA-Thermal with Cf Neutron Source. Polyethylene Holder is modeled .94

Figure 215. Au-197 Capture Reaction Rate in EC2 Experimental Channel of the YALINA-Thermal with Cf Neutron Source. Polyethylene Holder is modeled

Figure 216. Mn-55 Capture Reaction Rate in EC2 Experimental Channel of the YALINA-Thermal with Cf Neutron Source. Polyethylene Holder is modeled .94

Figure 217. He-3 Detector Response in EC6T Experimental Channel of the YALINA-Booster with $(d, t)$ Neutron Source

Figure 218. He-3 Detector Response in EC8R Experimental Channel of the YALINA-Booster with (d,t) Neutron Source

Figure 219. He-3 Detector Response in EC1B Experimental Channel of the YALINA-Booster with $(d, t)$ Neutron Source

Figure 220. He-3 Detector Response in EC2B Experimental Channel of the YALINA-Booster with $(d, t)$ Neutron Source

Figure 221. He-3 Detector Response in EC3B Experimental Channel of the YALINA-Booster with $(d, t)$ Neutron Source

Figure 222. He-3 Detector Response in EC6T Experimental Channel of the YALINA-Booster with (d,d) Neutron Source

Figure 223. He-3 Detector Response in EC8R Experimental Channel of the YALINA-Booster with (d,d) Neutron Source 
Figure 224. He-3 Detector Response in EC1B Experimental Channel of the YALINA-Booster with (d,d) Neutron Source

Figure 225. He-3 Detector Response in EC2B Experimental Channel of the YALINA-Booster with (d,d) Neutron Source

Figure 226. He-3 Detector Response in EC3B Experimental Channel of the YALINA-Booster with (d,d) Neutron Source

Figure 227. He-3 Detector Response in EC2 Experimental Channel of the YALINA-Thermal with (d,t) Neutron Source

Figure 228. He-3 Detector Response in EC5 Experimental Channel of the YALINA-Thermal with $(\mathrm{d}, \mathrm{t})$ Neutron Source

Figure 229. He-3 Detector Response in EC1 Experimental Channel of the YALINA-Thermal with (d,t) Neutron Source

Figure 230. He-3 Detector Response in EC2 Experimental Channel of the YALINA-Thermal with $(d, t)$ Neutron Source

Figure 231. He-3 Detector Response in EC5 Experimental Channel of the YALINA-Thermal with (d,d) Neutron Source

Figure 232. He-3 Detector Response in EC1 Experimental Channel of the YALINA-Thermal with (d,d) Neutron Source

Figure 233. He-3 Detector Response in EC1B Experimental Channel of the YALINA-Booster with $(d, t)$ Neutron Source

Figure 234. He-3 Detector Response in EC2B Experimental Channel of the YALINA-Booster with (d,t) Neutron Source

Figure 235. He-3 Detector Response in EC3B Experimental Channel of the YALINA-Booster with $(d, t)$ Neutron Source

Figure 236. He-3 Detector Response in EC1B Experimental Channel of the YALINA-Booster with $(\mathrm{d}, \mathrm{d})$ Neutron Source

Figure 237. He-3 Detector Response in EC2B Experimental Channel of the YALINA-Booster with (d,d) Neutron Source

Figure 238. He-3 Detector Response in EC3B Experimental Channel of the YALINA-Booster with (d,d) Neutron Source 


\title{
YALINA Analytical Benchmark Analyses Using the Deterministic ERANOS Code System
}

\author{
List of Tables
}

Page

Table 1. Calculated keff (Reactivity) with VARIANT for the YALINA-Booster................................18

Table 2. Calculated keff (Reactivity) with VARIANT for the YALINA-Thermal .............................. 18

Table 3. Calculated keff (Reactivity) with VARIANT for the YALINA-Booster...............................19

Table 4. Calculated keff (Reactivity) with VARIANT for the YALINA-Thermal ..............................19

Table 5. Final keff (Reactivity) with VARIANT fo $r$ the YALINA-Booster ....................................... 19

Table 6. Final keff (Reactivity) with VARIANT for the YALINA-Thermal .....................................20

Table 7. Calculated keff (Reactivity [pcm]) with RZ BISTRO Model for the YALINA-Booster............20

Table 8. Calculated keff (Reactivity [pcm]) with RZ BISTRO Model for the YALINA-Thermal ...........20

Table 9. Perturbation Components [pcm] for the YALINA-Booster .........................................21

Table 10. Perturbation Components [pcm] for the YALINA-Thermal .........................................22

Table 11. Neutron Balance per Neutron Source and kS for the YALINA-Booster ............................24

Table 12. Neutron Balance per Neutron Source and kS for the YALINA-Booster ...........................25

Table 13. Neutron Balance per Neutron Source and kS for the YALINA-Booster ............................26

Table 14. Neutron Balance per Neutron Source and kS for the YALINA-Thermal ...........................27

Table 15. Neutron Balance per Neutron Source and kS for the YALINA-Thermal ...........................28

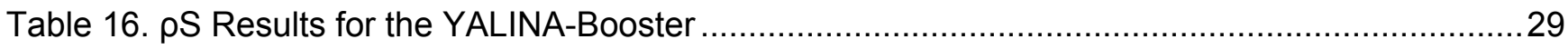

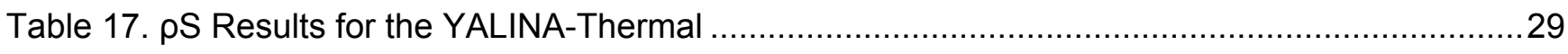

Table 18. kS $(\rho S)$ for the YALINA-Booster calculated with 172 Energy Group Set and P5P1

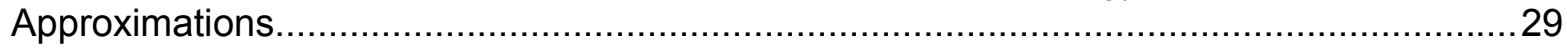

Table 19. kS $(\rho S)$ for the YALINA-Thermal calculated with 172 Energy Group Set and P5P1

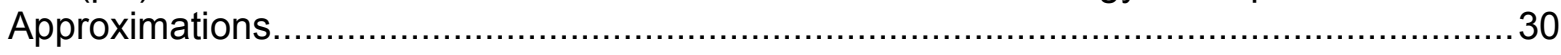

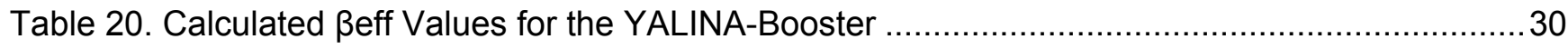

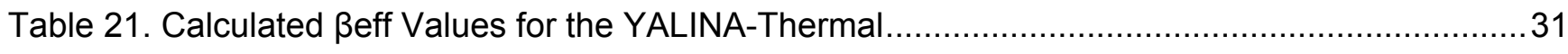

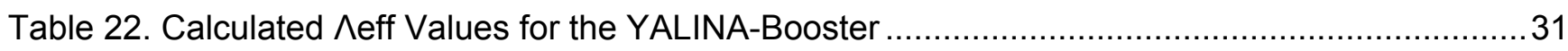

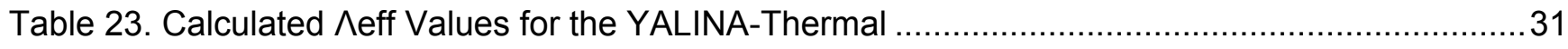

Table 24. Calculated $\beta$ eff $[\mathrm{pcm}]$ of the YALINA Configurations with RZ Geometry ..........................32 
Table 25. Calculated $\Lambda$ eff [ $\mu \mathrm{s}]$ for the YALINA Configuration in RZ Geometry

Table 26. $\Delta$ ßeff $[\mathrm{pcm}]$ Due to the Use of Different External Neutron Source Relative to the case without External Neutron Source with RZ Geometry....

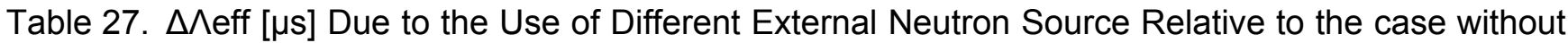
External Neutron Source with RZ Geometry ................................................................ 33

Table 28. ßeff [pcm] Adjoint Flux Weighted Values for the YALINA Configurations ............................33

Table 29. ^eff [ $\mu \mathrm{s}]$ Adjoint Flux Weighted Values for the YALINA Configurations.............................34

Table 30. keff Values Comparison between MCNPx and ERANOS .........................................49

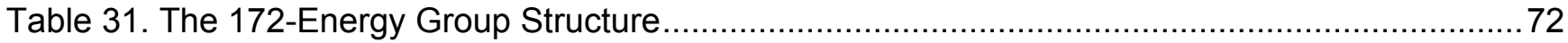

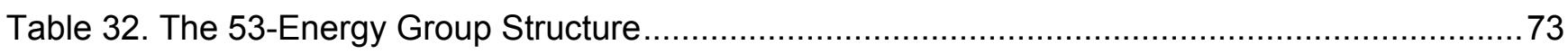

Table 33. 172 Energy Group Distribution of the Cf-252 Source .................................................74

Table 34. 53 Energy Group Distribution of the Cf-252 Source .............................................. 75

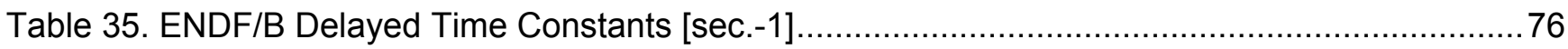

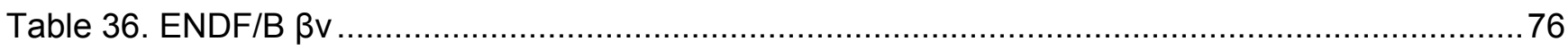

Table 37. Calculated ENDF/B Delayed Neutron Spectra for the YALINA-Booster ..........................77

Table 38. Calculated ENDF/B Delayed Neutron Spectra for the YALINA-Thermal .........................78 


\title{
YALINA Analytical Benchmark Analyses Using the Deterministic ERANOS Code System
}

\begin{abstract}
This report presents the analytical analyses obtained with the deterministic ERANOS code system for the YALINA facility within: a) the collaboration between Argonne National Laboratory (ANL) of USA and the Joint Institute for Power and Nuclear Research (JIPNR) Sosny of Belarus; and b) the IAEA coordinated research projects for accelerator driven systems (ADS). This activity is conducted as a part of the Russian Research Reactor Fuel Return (RRRFR) Program and the Global Threat Reduction Initiative (GTRI) of DOE/NNSA.
\end{abstract}




\section{YALINA Analytical Benchmark Analyses Using the Deterministic ERANOS Code System}

\section{Introduction}

The growing stockpile of nuclear waste constitutes a severe challenge for the mankind for more than hundred thousand years. To reduce the radiotoxicity of the nuclear waste, the Accelerator Driven System (ADS) has been proposed [1,2]. One of the most important issues of ADSs technology is the choice of the appropriate neutron spectrum for the transmutation of Minor Actinides (MA) and Long Lived Fission Products (LLFP).

An experimental program has been launched by the Joint Institute for Power and Nuclear Research - SOSNY (JIPNR-SOSNY), National Academy of Sciences of Belarus [3,4] with the purpose to study the ADS physics and to investigate the transmutation of MA and LLFP using the YALINA facility.

In order to construct an ADS, calculations methods have to be developed in order to predict the performance of such systems. The IAEA has taken the initiative to start a set of ADS benchmarks [5,6]. These benchmarks, are part of the IAEA Coordinated Research Projects (CRP): "Analytical and Experimental Analysis of Accelerator Driven Systems" and "Low Enriched Uranium Fuel Utilization in Accelerator Driven Sub-Critical Assembly Systems" [7,8]. The main purpose is to compare the results from different calculational methods, performed by different research institutes, with each other and with the experimental data. The benchmarks are based on the current YALINA facility configurations, which provide the opportunity to verify the prediction capability of the different calculational methods. The YALINA facility has two subcritical assemblies: the YALINA-Booster and -Thermal. The two configurations and their operating conditions define the benchmark specifications and the required calculations with Cf-252, $(d, d)$, and $(d, t)$ neutron sources.

\section{YALINA Benchmark Specifications of the IAEA Coordinated Research Projects}

The subcritical assemblies object of the benchmark are the YALINA-Booster and -Thermal. In this section, a short description of the two assemblies followed by the required benchmark calculations are presented.

\section{II.1. YALINA-Booster Facility}

The YALINA-Booster has been designed to have both fast and thermal neutron spectra in one configuration and to achieve neutron flux densities as high as possible in a subcritical configuration. In addition, the subcritical assembly together with the highly intensive neutron generator makes the YALINA-Booster assembly interesting for performing ADS kinetics research [9].

The YALINA-Booster operates with $k_{\text {eff }}<0.98$ under all conditions for safety purposes. The subcritical assembly is driven by an external neutron source: a Cf-252 neutron source or a deuteron accelerator with deuterium or tritium targets for neutron production. The YALINABooster shown in Figure 1 couples a fast zone ("booster") of two U-235 enrichments ( $90 \%$, and 
$36 \%$ ) in a lead lattice and a thermal zone with $10 \%$ enrichment of U-235 (EK-10 fuel rods) in a polyethylene moderator. The booster zone multiplies the external neutrons through the fission reactions of Uranium and $(n, x n)$ reactions of lead. The produced neutrons leak to the surrounding thermal zone. Between the two zones, there is an interface, called the "valve" zone, consisting of two layers. The inner layer has metallic natural uranium rods and the outer layer has boron carbide rods for absorbing the thermal neutrons. Such "valve" zone enables fast neutrons to scatter between the fast and the thermal zone and prevents thermal neutrons from entering the fast zone from the thermal zone.

The fast booster zone consists of 36 lead subassemblies. The thermal zone consists of 108 polyethylene subassemblies. For structural reasons, the subassemblies are encased into a stainless steel frame and nine subassemblies are arranged in each frame. The frame thickness is $4 \mathrm{~mm}$ and the total length along the z-axis is $771 \mathrm{~mm}$ in the thermal zone and $804 \mathrm{~mm}$ in the fast zone. The central part of the fast zone has highly enriched $(90 \%)$ metallic uranium fuel rods inserted in a lead block as shown in Figures 2 and 3.

The YALINA-Booster is radially surrounded by a graphite reflector and axially by borated polyethylene. The radial reflector and the backside of the thermal zone are covered by organic glass sheets. There are four axial experimental channels (EC1B, EC2B, EC3B, and EC4B) in the fast zone, three axial experimental channels in the thermal zone (EC5T, EC6T, and EC7T), two axial experimental channels (EC8R, located $32 \mathrm{~mm}$ below the assembly mid-plane and 520 $\mathrm{mm}$ left of the assembly center line, and EC9R, located $356 \mathrm{~mm}$ below the assembly mid-plane and $600 \mathrm{~mm}$ right of the assembly center line) and one radial experimental channel in the reflector zone (EC10R). All experimental channels are shown in Figure 1.

Two YALINA-Booster configurations are considered in the benchmark. The number of EK-10 fuel rods in the two configurations are 1141 and 902. Figures 2 and 3 show the core loading of these two configurations. The geometrical details used for generating the calculation models are presented in the $X Z$ and $Y Z$ cross-sectional views shown in Figures 4 and 5 . Additional information can be found in Ref. 5.

The subcritical assembly of the YALINA-Booster facility is made of rectangular parallelepiped sections. The central axis of the assembly is aligned horizontally. The deuteron target can be situated along the central axis at different distances from the assembly center. 


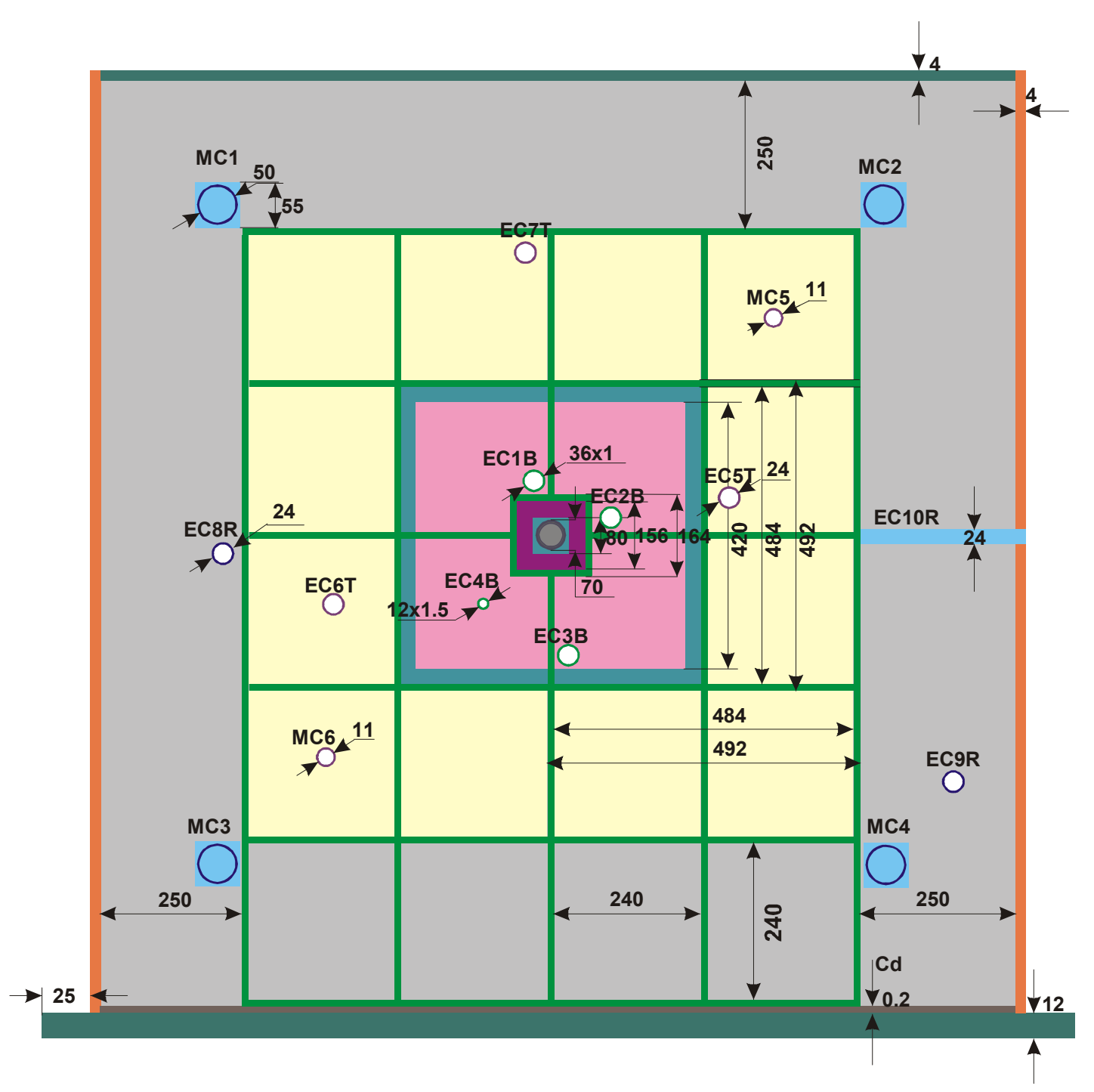

Umet. of $90 \%$ enrichment

Thermal neutron absorber Umet.(nat)+B4C

Air

Graphite reflector

Stainless steel frame

UO2 of $36 \%$ enrichment

Thermal zone

Organic glass

Cd layer

Mild (low carbon) steel

EC1B - EC4B - experimental channels in booster zone

EC5T - EC7T - experimental channels in thermal zone

EC8R - EC10R - experimental channels in reflector

MC1 - MC4 - measurement channels in reflector for neutron flux monitoring

MC5 - MC6 - experimental channels in the thermal zone for neutron flux monitoring

Figure 1. XY Cross-Sectional View of the YALINA-Booster Assembly, Dimensions in mm 

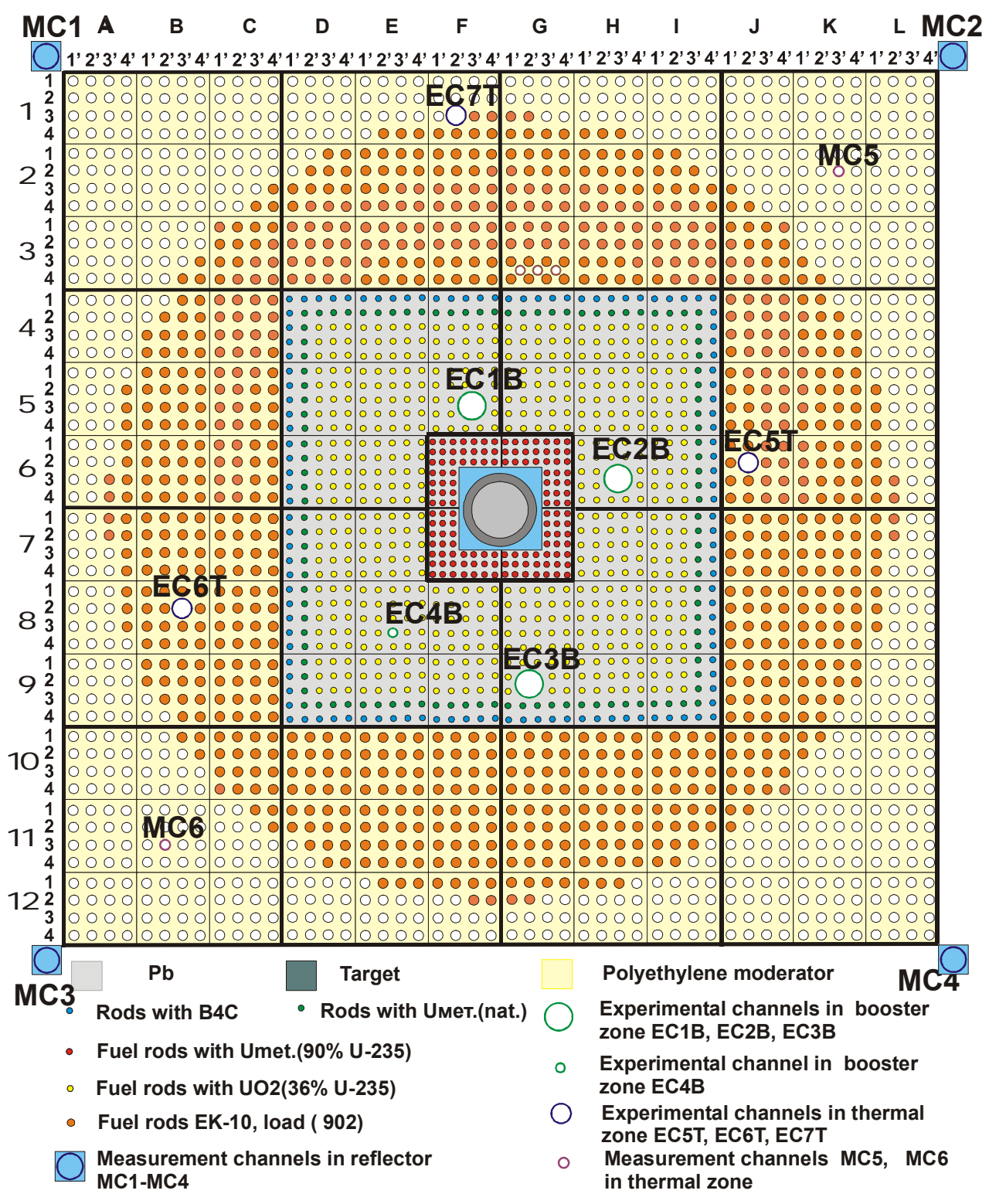

$\begin{array}{llllllllllllll}\text { MC1 } & \text { A } & \text { B } & \text { C } & \text { D } & \text { E } & \text { F } & \text { G } & \text { H } & \text { I } & \text { J } & \text { K } & \text { L } & \text { MC: }\end{array}$

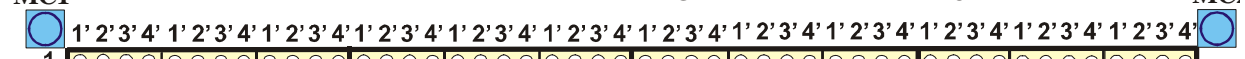

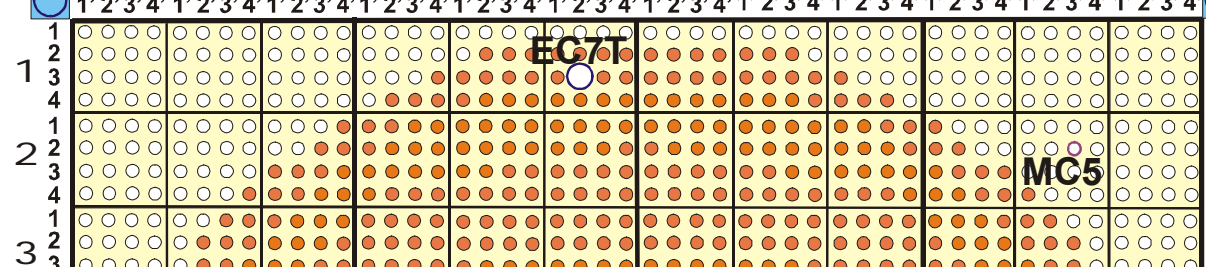

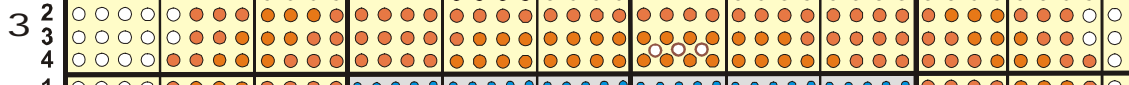

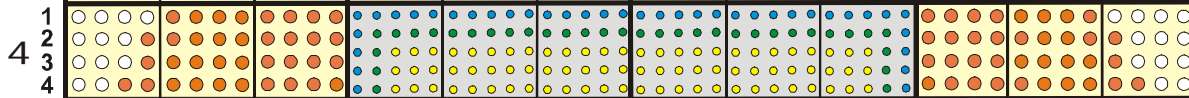

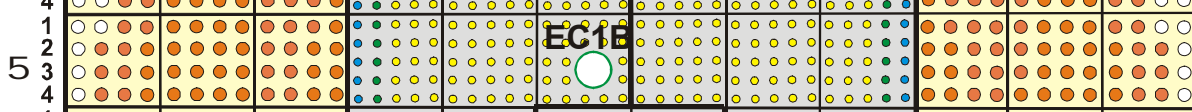

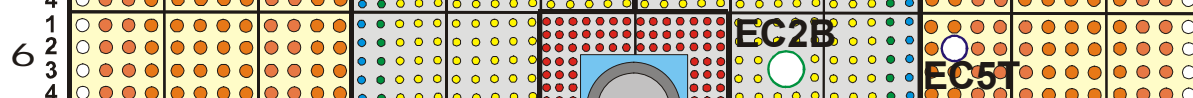

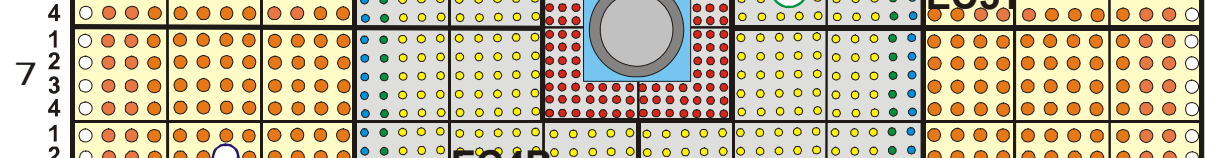

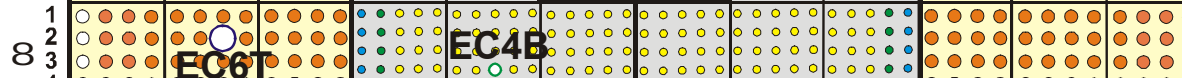

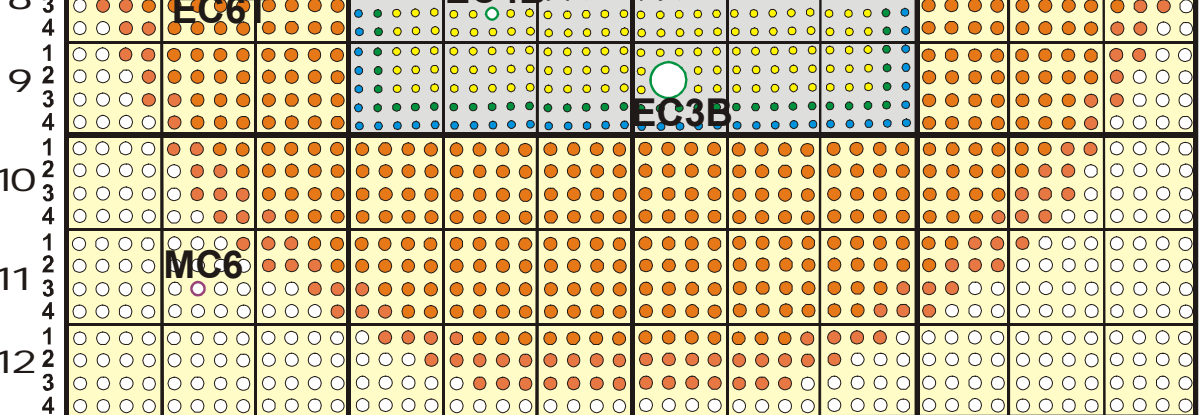

(1) MC3

- Rods with B4C Rods with Uмет.(nat.)

- Fuel pins with Umet.(90\% U-235)

- Fuel pins with U02(36\% U-235)

- Fuel pins EK-10, load ( 1141)

Measurement channels in reflector

- Holes for control rods (B4C) location
Polyethylene moderator

Experimental channels in booster zone EC1B, EC2B, EC3B

- Experimental channel in booster zone EC4B

Experimental channels in thermal zone EC5T, EC6T, EC7T

- Measurement channels MC5, MC6 in thermal zone

Holes in block G3 for control rods (B4C)

Figure 2. Fuel Loading of the YALINA-Booster Configuration with 902 EK-10 Fuel Rods

Figure 3. Fuel Loading of the YALINA-Booster Configuration with 1141 EK-10 Fuel Rods 


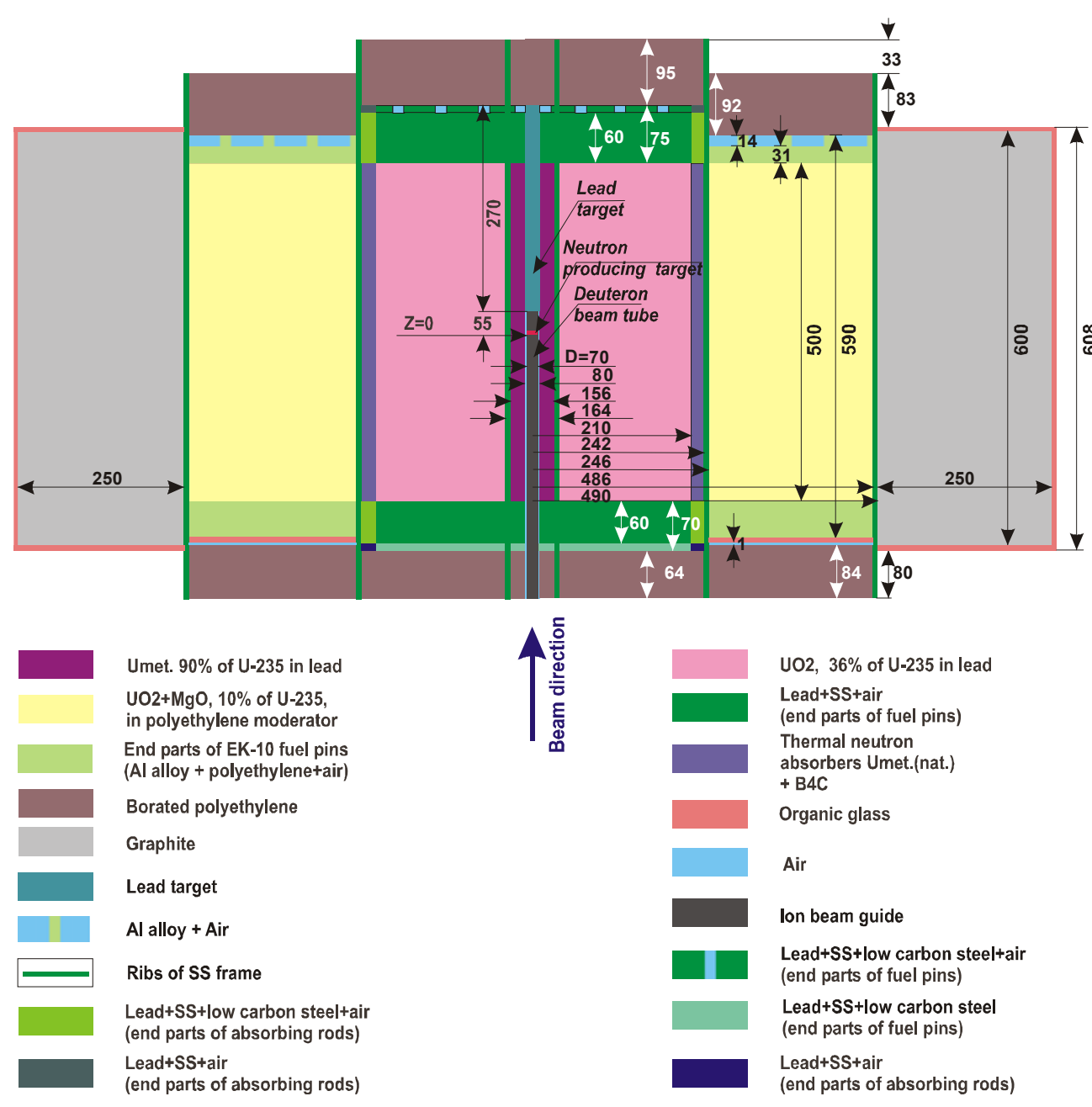

Figure 4. YZ Cross-Sectional View of the YALINA-Booster Assembly (at $X=4$ ), Dimensions in $\mathrm{mm}$.

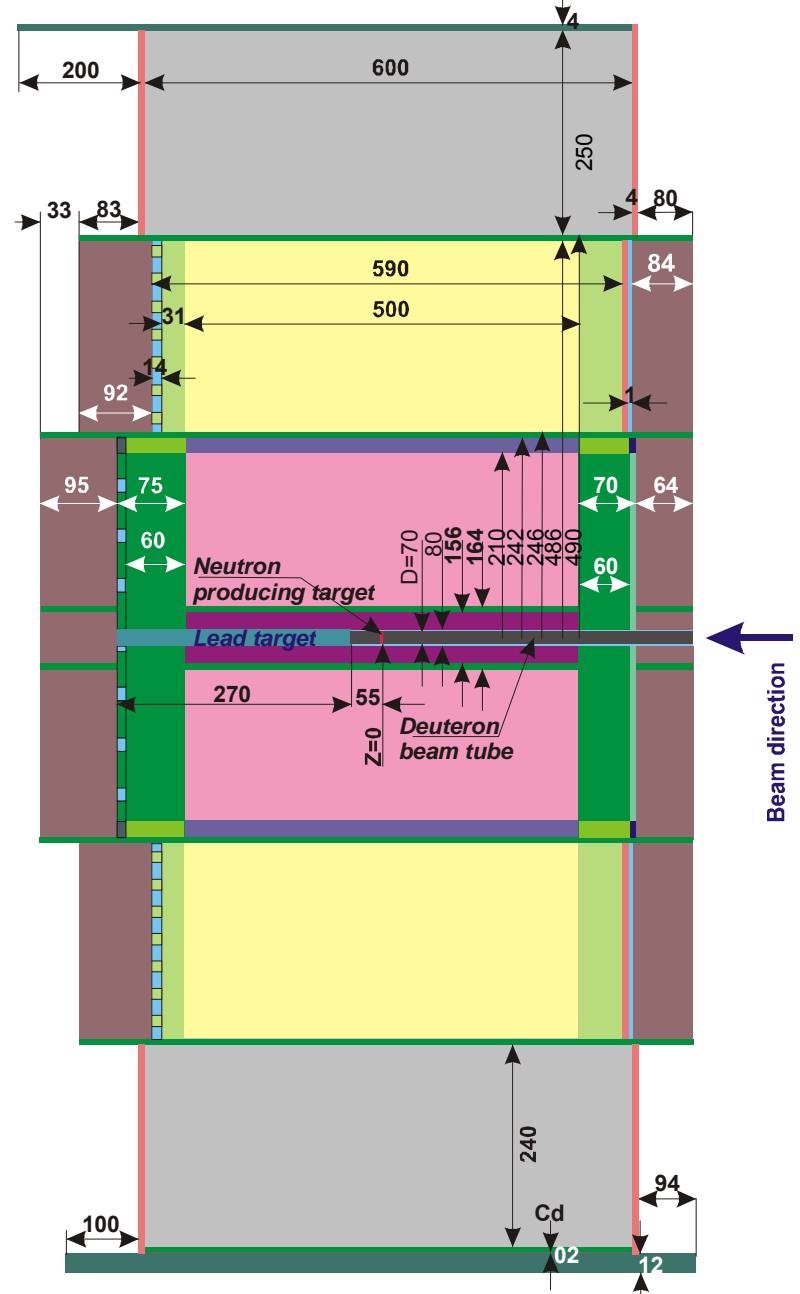

Figure 5. XZ Cross-Sectional View of the YALINA-Booster Assembly (at $Y=4$ ), Dimensions in $\mathrm{mm}$. 


\section{II.1.a. The Lead Target}

There is a hole with side dimensions of $80 \times 80 \mathrm{~mm}$ in the center of the fast zone formed by cutting out the inner corners of the four central lead blocks. In the axial direction, a lead zone consisting of 12 blocks with a total length of $645 \mathrm{~mm}$ is used and each block has $X-Y$ dimensions of $78 \times 78 \mathrm{~mm}$. When the deuteron accelerator is used for neutron production, part of the hole is occupied by the beam tube as shown in Figures 4 and 5.

\section{II.1.b. The Inner Part of the Fast Zone}

The innermost part of the fast zone surrounding the lead target contains 132 fuel rods in a lead block, which are marked by red color in Figures 2 and 3 . The fuel material is metallic uranium with $90 \% \mathrm{U}-235$ enrichment arranged in a square lattice. The fuel rod pitch is $11.143 \mathrm{~mm}$ and the lead block dimension is $78 \times 78 \mathrm{~mm}$. The total length of the lead subassembly is $645 \mathrm{~mm}$. A detailed description of the fuel rod design is shown in Figure 6.

\section{II.1.c. The Outer Part of the fast Zone}

The fast fuel zone surrounding the $90 \%$-enriched zone consists of 32 lead subassemblies with 563 fuel rods arranged in a square lattice having a $16 \mathrm{~mm}$ pitch. The fuel material is ceramic $\mathrm{UO}_{2}$ with $36 \% \mathrm{U}-235$ enrichment. The $\mathrm{UO}_{2}$ density is $9.694 \mathrm{~g} / \mathrm{cm}^{3}$. Each lead subassembly has 25 fuel rods and the fuel rod details are shown in Figure 6 . The clad material is stainless steel alloy $12 \mathrm{X} 18 \mathrm{H} 10 \mathrm{~T}$. All fuel rods in the booster zone are inserted into stainless steel tubes with 9 $\mathrm{mm}$ outer diameter and $0.7 \mathrm{~mm}$ wall thickness. In this zone, four experimental channels, EC1B, EC2B, EC3B, and EC4B are located as shown in Figures 2 and 3. The first three experimental channels have stainless steel alloy $12 \mathrm{X} 18 \mathrm{H} 10 \mathrm{~T}$ liner with $36 \mathrm{~mm}$ outer diameter and $1 \mathrm{~mm}$ wall thickness. The experimental channel EC4B has the same liner material but the outer diameter and the wall thickness are 12 and $1.5 \mathrm{~mm}$, respectively.

\section{II.1.d. The Absorber Zone}

The absorber zone surrounds the fast zone and consists of an inner layer of natural metallic uranium rods with stainless steel clad. The clad outer diameter is $9 \mathrm{~mm}$ with $0.7 \mathrm{~mm}$ thickness as shown in Figure 6 . The outer layer of the absorber zone consists of boron carbide $\left(\mathrm{B}_{4} \mathrm{C}\right)$ rods having $1.38 \mathrm{~g} / \mathrm{cm}^{3}$ density as shown in Figure 7 . The number of metallic natural uranium rods is 108 and the number of $B_{4} C$ rods is 116 . The $B_{4} C$ rods use the same lattice of the uranium fuel rods in the fast zone, which is $16 \mathrm{~mm}$ pitch. This absorber zone permits fast neutrons to scatter between the fast and thermal zones, and prevents thermal neutrons from entering the fast zone from the thermal zone. The result is a fast neutron coupling of the fast and the thermal zones. The $\mathrm{B}_{4} \mathrm{C}$ rods are constrained inside the assembly and cannot removed out accidentally, which prevents undesired reactivity insertion.

\section{II.1.e. The Thermal Zone}

The thermal zone surrounds the absorber zone and consists of 108 polyethylene subassemblies with 16 holes each for loading the EK-10 fuel rods. The holes are arranged in a square lattice with $20 \mathrm{~mm}$ pitch. The active fuel length is $500 \mathrm{~mm}$ and the average amount of U-235 is $7.73 \mathrm{~g}$ 
per rod. The total length of EK-10 fuel rods is $590 \mathrm{~mm}$ and the outer clad diameter is $10 \mathrm{~mm}$. Each polyethylene subassembly has a total length of $576 \mathrm{~mm}$ obtained by arranging twelve blocks in the axial direction. The block dimensions are $80 \times 80 \times 48 \mathrm{~mm}$ and the polyethylene density is $0.859 \mathrm{~g} / \mathrm{cm}^{3}$. The $20 \mathrm{~mm}$ lattice dimension is the optimum value for the neutron multiplication using the EK-10 fuel with polyethylene moderator in a square lattice. The detailed description of the EK-10 fuel rod is shown in Figure 8. Three experimental channels, EC5T, EC6T, and EC7T are inserted into the thermal zone as shown in Figures 2 and 3. Finally, the thermal zone is surrounded in the radial direction by a $250-\mathrm{mm}$ graphite reflector containing three experimental channels EC8R, EC9R, and EC10R as shown in Figure 1. In the axial directions, borated polyethylene shields are used as shown in Figures 4 and 5 . In the thermal zone and close to the fast zone, it is possible to insert three small $\mathrm{B}_{4} \mathrm{C}$ rods as shown in Figures 2 and 3. During operation these rods are not inserted and, consequently, the holes are filled with air. The diameter of each hole is $11 \mathrm{~mm}$ with an aluminum alloy liner of $0.5 \mathrm{~mm}$ thickness.

\section{II.1.f. The Deuteron Beam Tube}

The detailed design of the deuteron beam tube is shown in Figure 9.

\section{II.2. YALINA-Thermal Facility}

The YALINA-Thermal has been designed to have a thermal neutron spectrum and to achieve neutron flux densities as high as possible in a subcritical configuration. In addition, the subcritical assembly together with the highly intensive neutron generator makes the YALINA-Thermal assembly interesting for performing ADS kinetics research [9].

The YALINA-Thermal operates with $k_{\text {eff }}<0.98$ under all conditions for safety reasons. The assembly is driven by an external neutron source: a Cf-252 neutron source or a deuteron accelerator with deuterium or tritium targets for neutron production. The deuteron energy is $240 \mathrm{keV}$ impinging on the target located at the center of the subcritical assembly.

The YALINA-Thermal consists of uranium dioxide nuclear fuel rods and polyethylene moderator. The assembly is surrounded by a graphite reflector in the radial direction. The fuel rods are arranged horizontally. The front side of the assembly opposite to the beam entrance is covered by borated polyethylene. The backside is covered by organic glass sheets where the entrance of the deuteron beam tube is located. Three axial experimental channels (EC1, EC2, and EC3) are located in the fuel zone and they are parallel to the fuel rods. One axial experimental channel (EC4) is positioned in the target zone and two axial experimental channels (EC5, EC6) are included in the reflector zone. One radial experimental channel EC7 is inserted in the reflector zone at the fuel midplane. The experimental channels are shown in Figure 10.

Three YALINA-Thermal configurations are considered for the benchmark. The number of EK-10 fuel rods are 216, 245 and 280. Figures 11 to 14 show the core loading of the three configurations. The geometrical details for generating the calculation models are presented in the $X Z$ and $Y Z$ cross-sectional views shown in Figures 15 and 16. Additional information can be found in Ref. 6.

The subcritical assembly of the YALINA-Thermal facility is made of rectangular parallelepiped sections. The central axis of the assembly is aligned horizontally. The target can be situated along the central axis at different distances from the assembly center. 

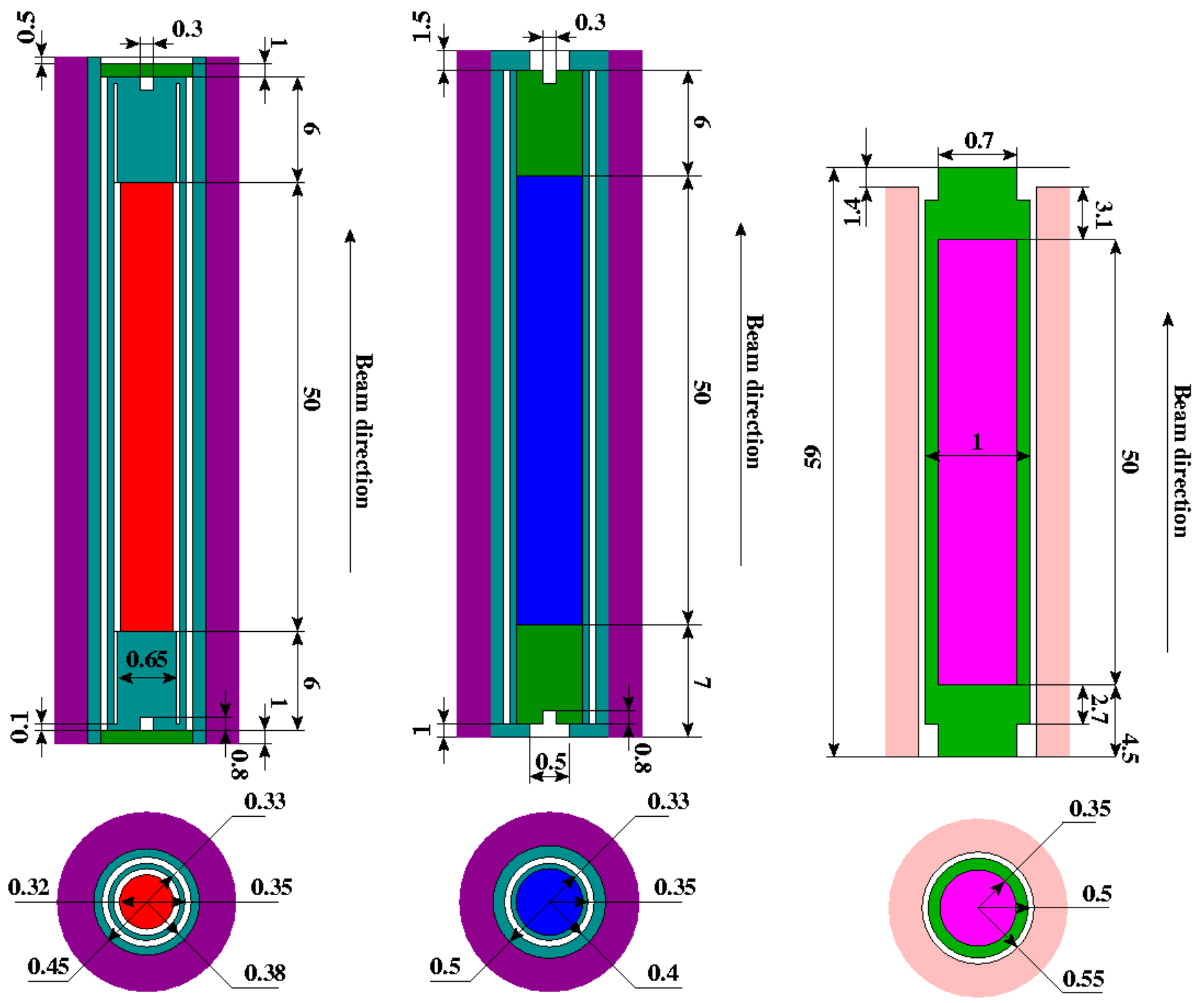

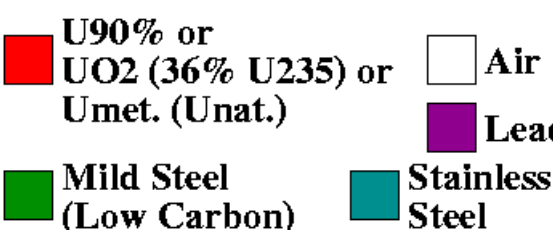

Figure 6. XZ and XY CrossSectional Views of a Fuel Rod Inside the Steel Casing, Dimensions in $\mathrm{cm}$

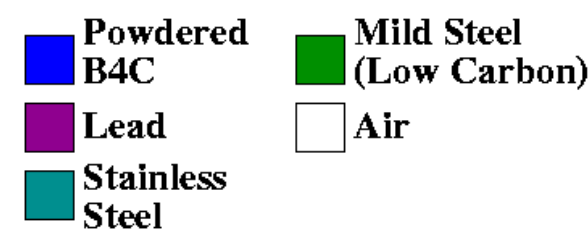

Figure 7. $X Z$ and $X Y$ CrossSectional View of the Boron Carbide Rod, Dimensions in $\mathrm{cm}$

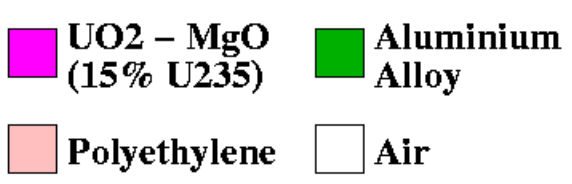

Figure 8. $X Z$ and $X Y$ CrossSectional Views of the EK-10 Fuel Rod, Dimensions in $\mathrm{cm}$. 


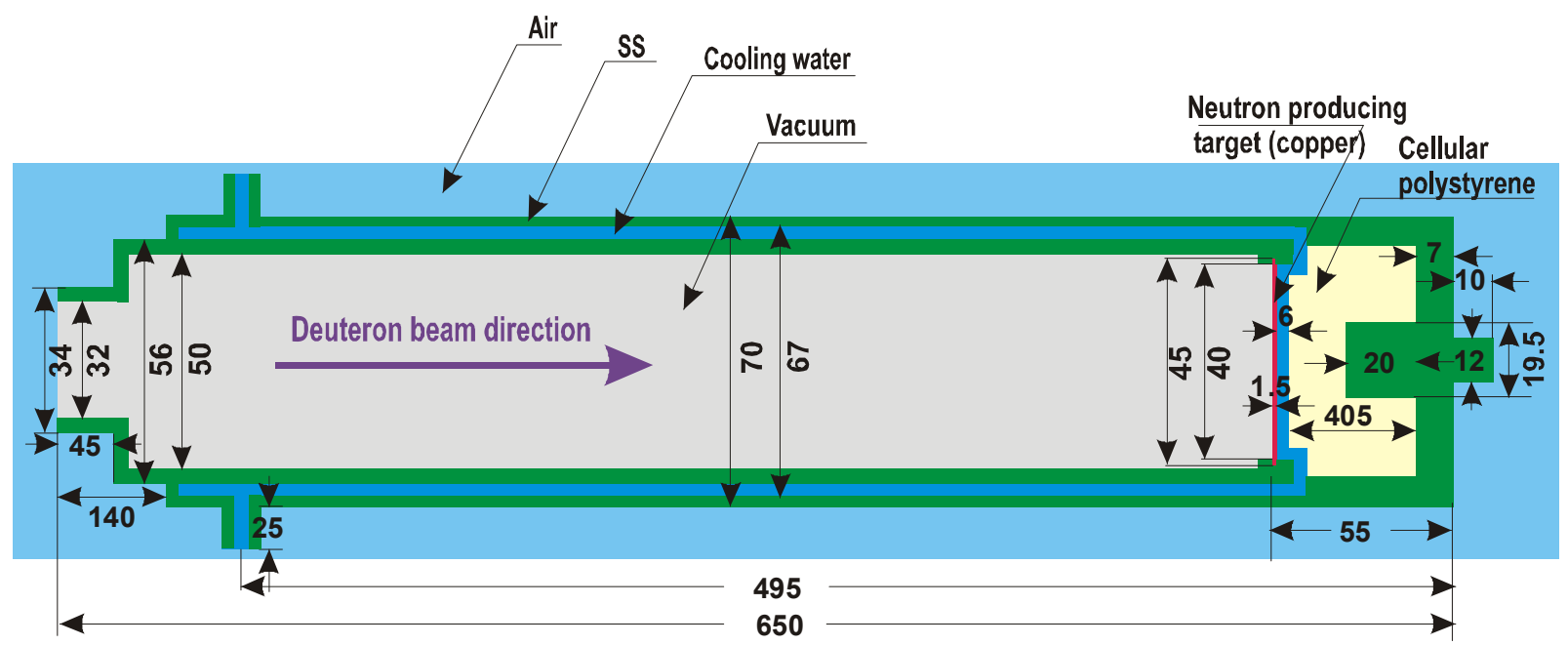

Figure 9. Deuteron Beam Tube Design, Dimensions in $\mathrm{mm}$

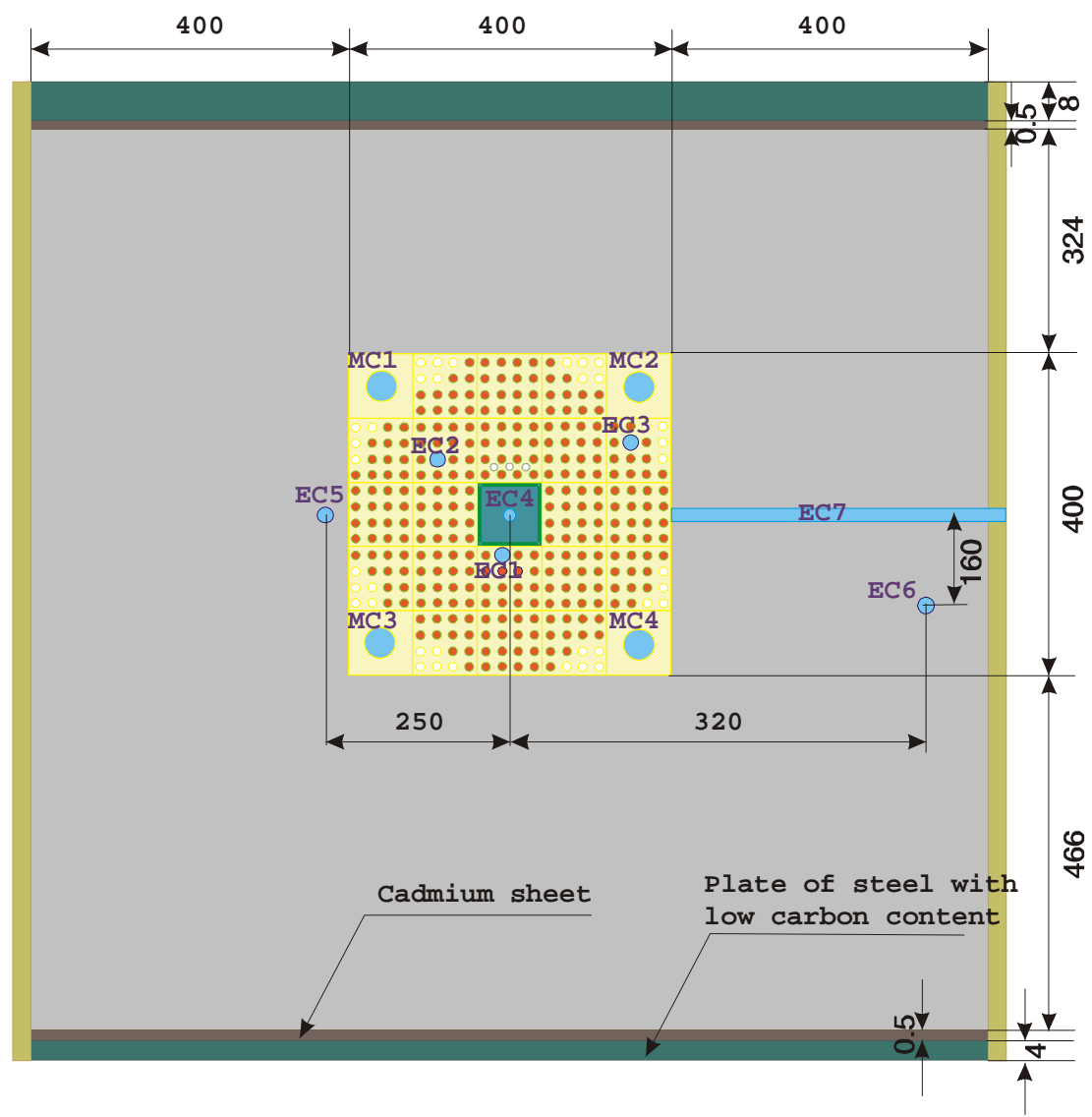

$\because$ Fuel rods EK-10 in

$\because \because:$ polyethylene subassembly

Holes for control rods with B4C

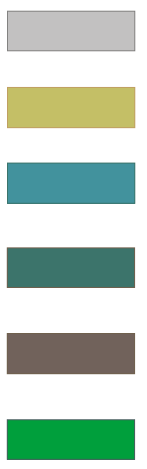

Graphite reflector

Organic glass sheet, $4 \mathrm{~mm}$

Lead

Steel with low carbon content (from above and below)

Cadmium sheet, $0.5 \mathrm{~mm}$ (from above and below)

Stainless steel frame of lead target

Measurement channels in the core (MC1-MC4) Experimental channels in the core and reflector (EC1-EC7)

Figure 10. XY Cross-Sectional View of the YALINA-Thermal Assembly, Dimensions in mm 
Polyethylene

Fuel rod EK-10

Hole for control rod B4C location
Lead

Vacuum

Measurement

channels

(MC1 - MC4)
Experimental channels

in the core (EC1-EC3)

Experimental channel in the target hole (EC4)

Stainless steel casing

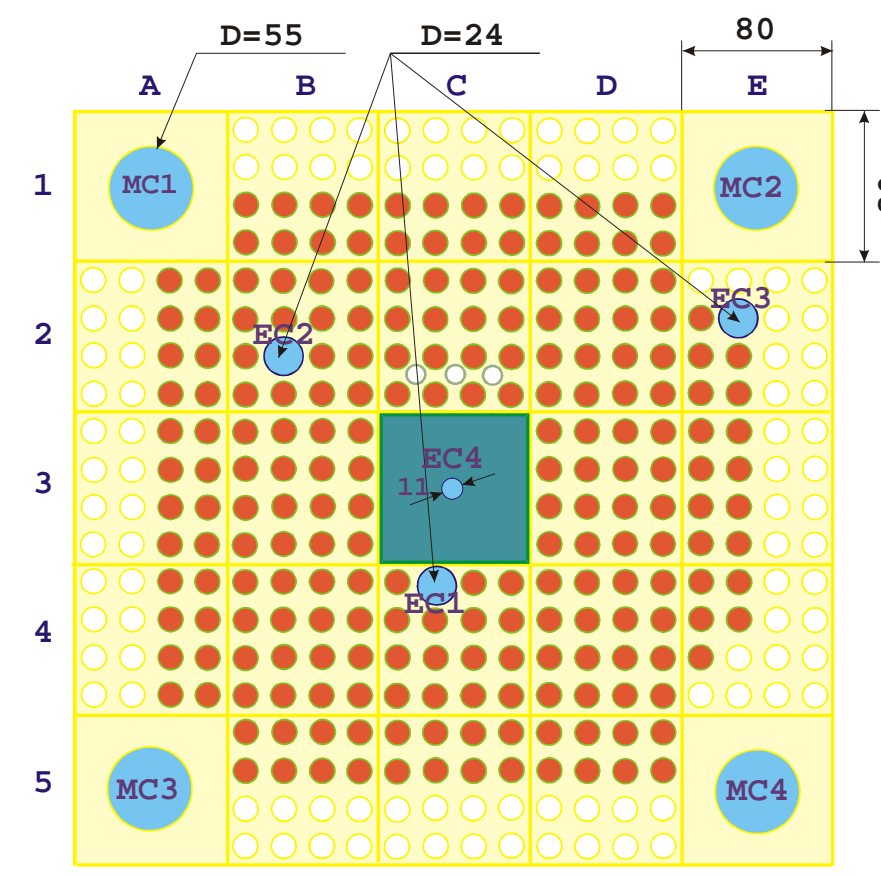

Figure 11. XY Cross-Section of the YALINAThermal Assembly with 216 EK-10 Fuel Rods

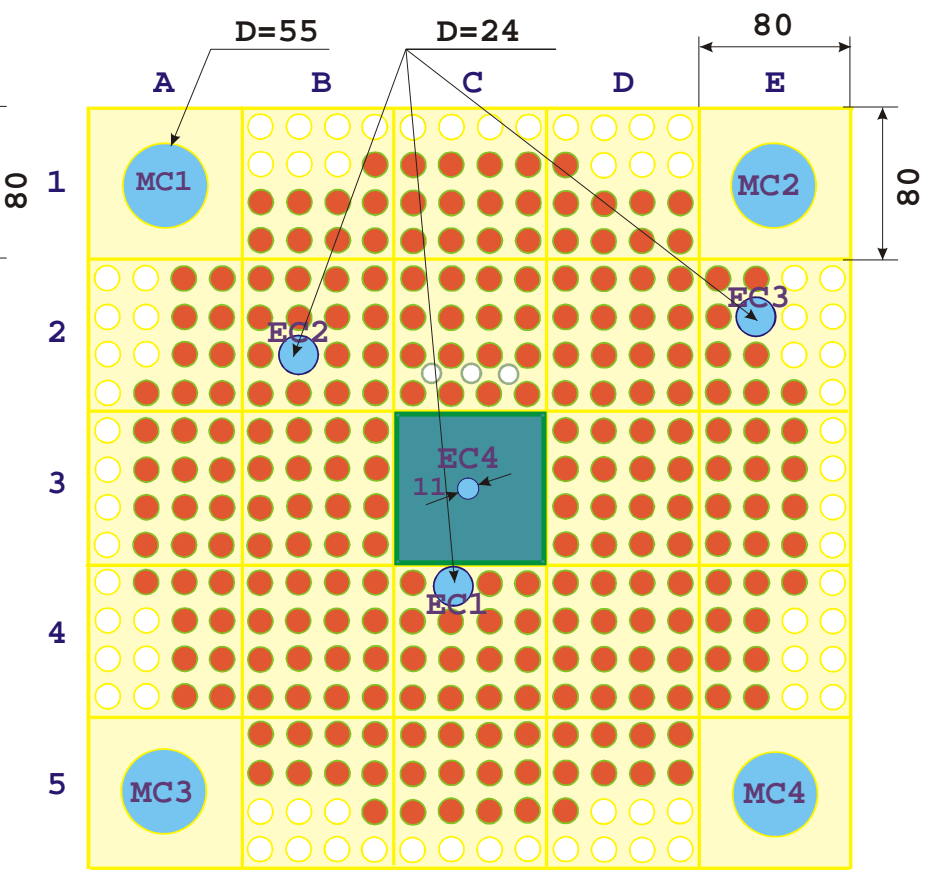

Figure 12. XY Cross-Section of the YALINAThermal Assembly with 245 EK-10 Fuel Rods

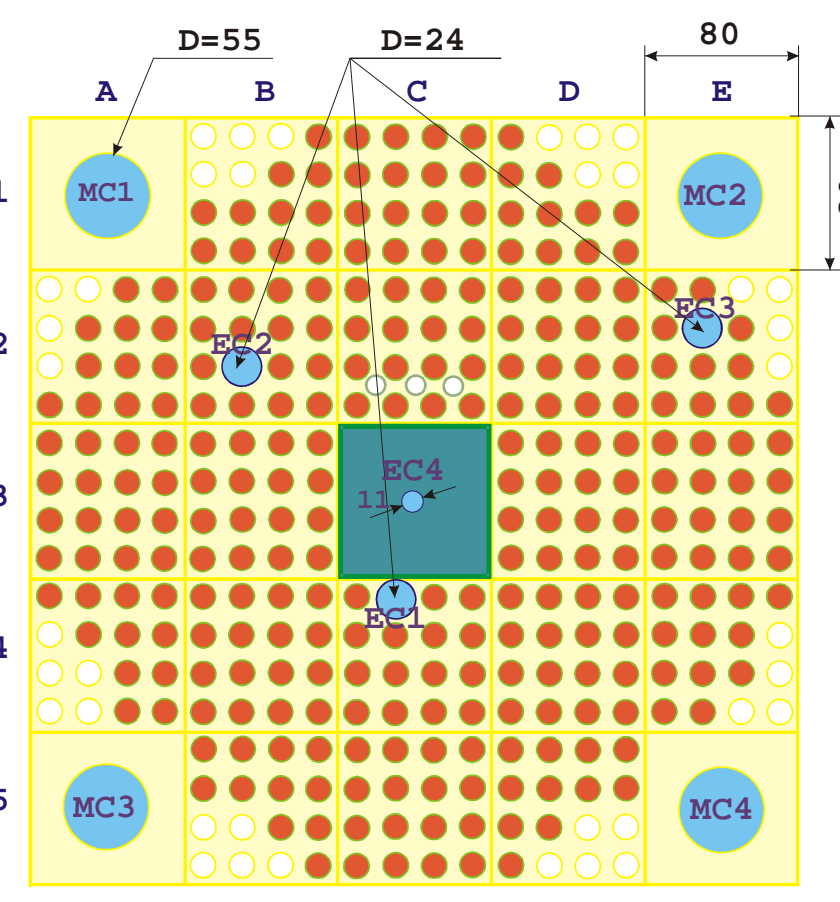

Figure 13. XY Cross-Section of the YALINAThermal Assembly with 280 EK-10 Fuel Rods (Target Side)

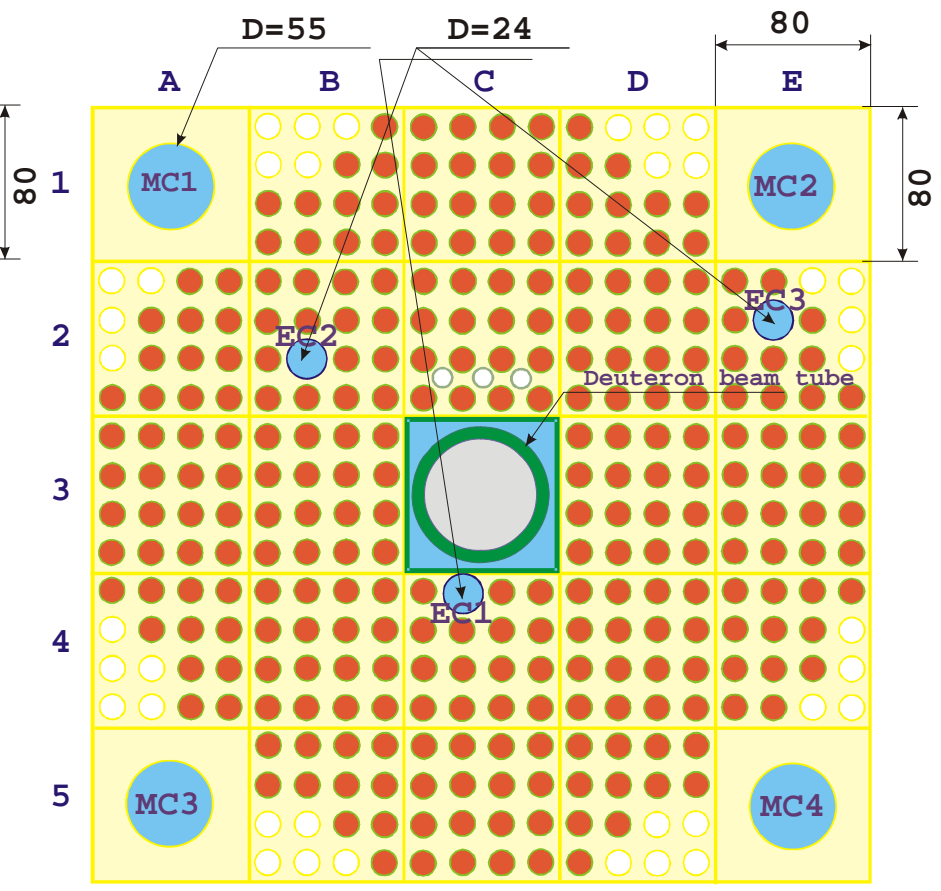

Figure 14. XY Cross-Section of the YALINAThermal Assembly with 280 EK-10 Fuel Rods (Beam Tube Side) 


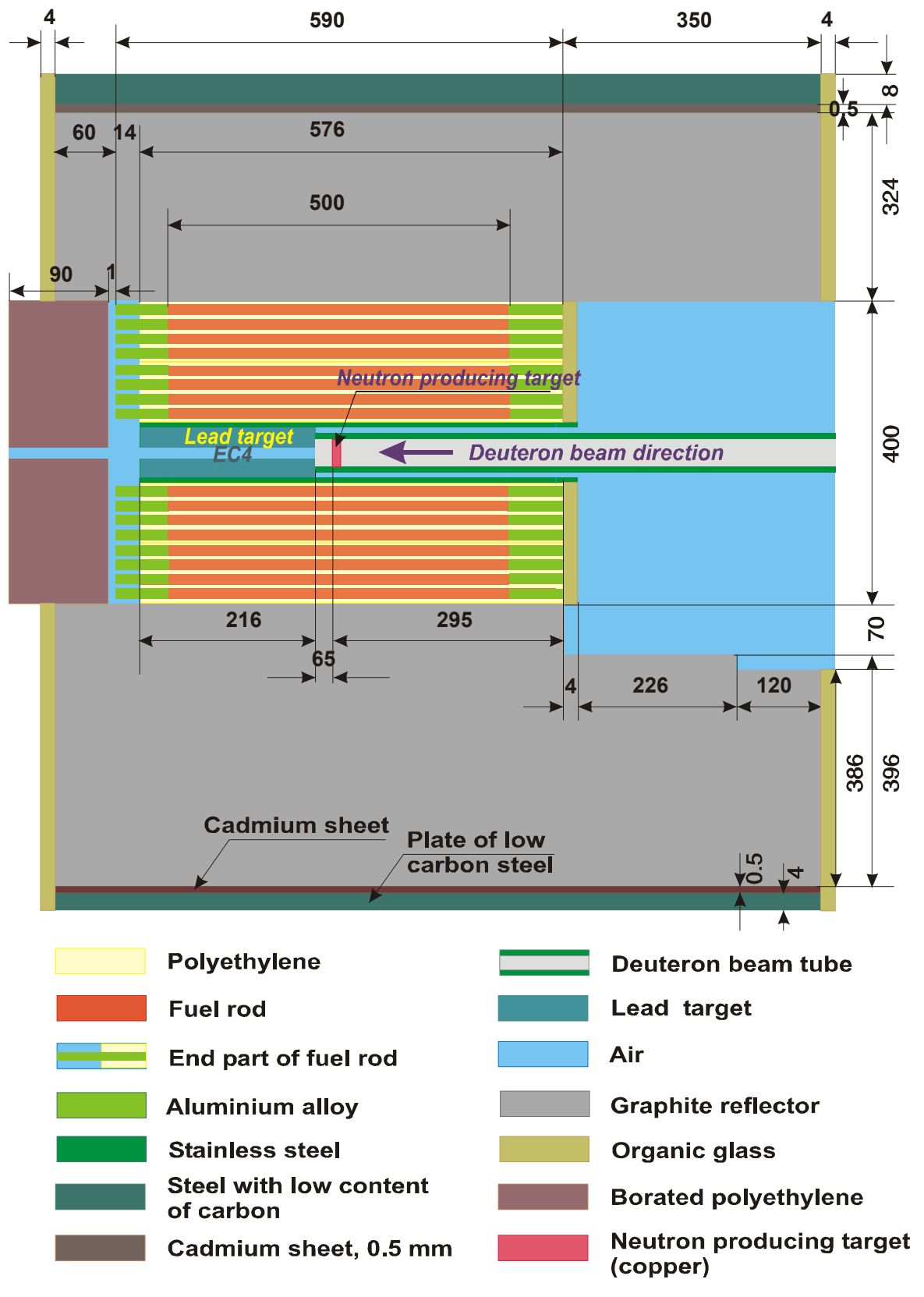

Figure 15. XZ Cross-Section of the YALINA-Thermal Assembly $(Y=0)$, Dimensions in $\mathrm{mm}$

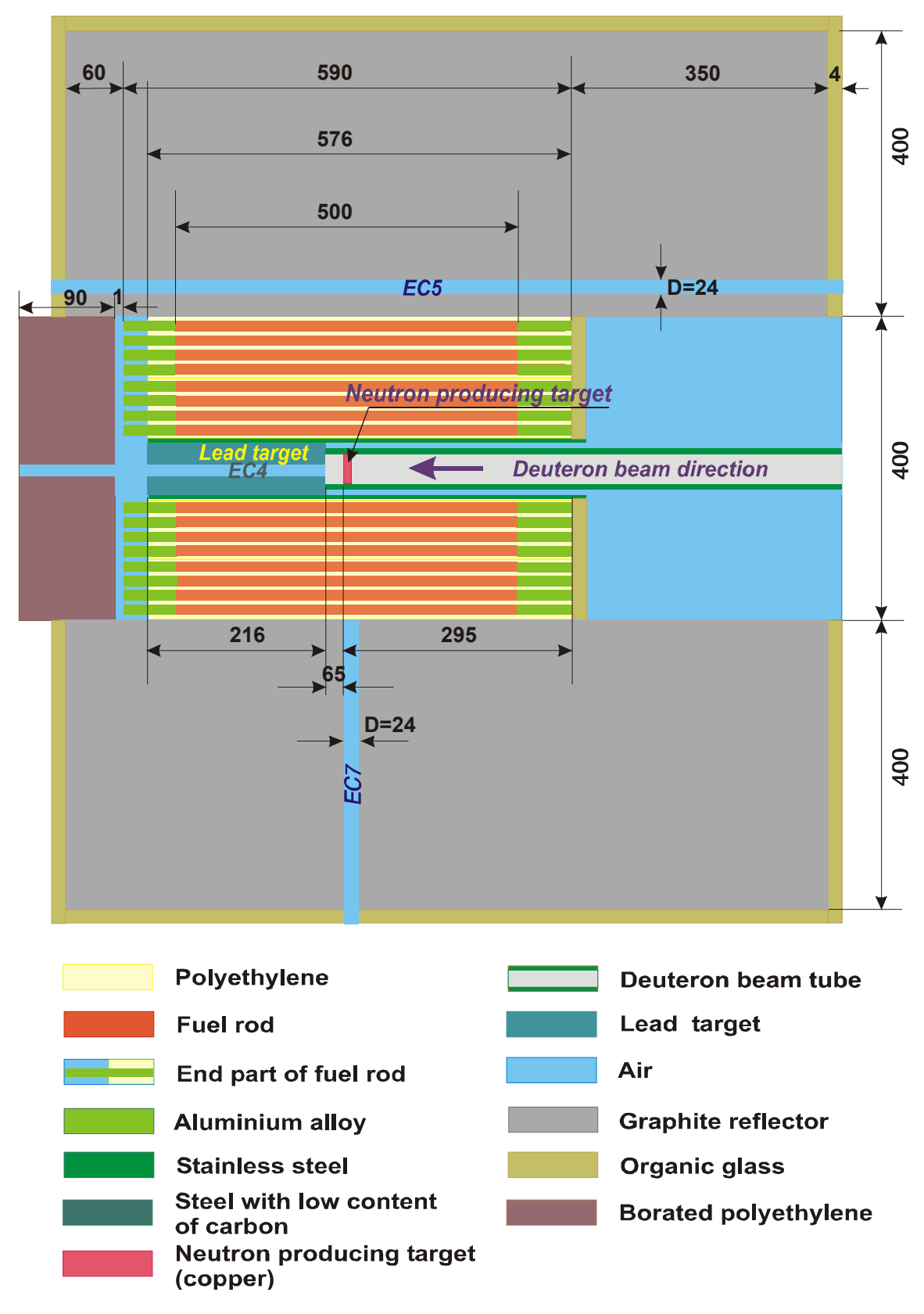

Figure 16. YZ Cross-Section of the YALINA-Thermal Assembly $(X=0)$, Dimensions in $\mathrm{mm}$ 


\section{II.2.a. Lead Target}

There is a hole with side dimensions of $80 \times 80 \mathrm{~mm}$ in the assembly center with a stainless steel frame. A lead zone consisting of 12 blocks with a total length of $576 \mathrm{~mm}$ in the axial direction is used, and each block has $X-Y$ dimensions of $78 \times 78 \mathrm{~mm}$. When the deuteron accelerator is used for neutron production, part of the hole is occupied by the beam tube as shown in Figures 15 and 16.

\section{II.2.b. Fuel Assembly}

The assembly consists of 20 polyethylene subassemblies with 16 holes each for the loading of 16 EK-10 fuel rods. The holes are arranged in a square lattice with $20 \mathrm{~mm}$ pitch as shown in Figures 11 to 14 . The active fuel length is $500 \mathrm{~mm}$ and the average amount of $U-235$ is $7.73 \mathrm{~g}$ per rod. The total length of EK-10 fuel rod is $590 \mathrm{~mm}$ and the outer and inner clad diameters are 10 and $7 \mathrm{~mm}$ respectively. Each subassembly has a total length of $576 \mathrm{~mm}$ obtained by arranging twelve blocks in the axial direction. The block dimensions are $80 \times 80 \times 48 \mathrm{~mm}$ and the polyethylene density is 0.923 $\mathrm{g} / \mathrm{cm}^{3}$. The $20 \mathrm{~mm}$ lattice dimension is the optimum configuration for neutron multiplication using the EK-10 fuel with polyethylene moderator in a square lattice. The detailed description of the EK-10 fuel rods is shown in Figure 8.

Three experimental channels, EC1, EC2, and EC3 are embedded in the fuel zone, while the experimental channel EC4 is located inside the lead target zone. The fuel zone is surrounded in the radial direction by a graphite reflector, whose dimensions are shown in Figures 10, 15, and 16. There are two axial experimental channels, EC5 and EC6, and one radial experimental channel, EC7, in the graphite reflector. Borated polyethylene blocks are used in the front section of the fuel zone and organic glass sheets are used at the backside of the assembly and in the front section of the graphite reflector as shown in Figures 15 and 16.

In the fuel zone and close to the target zone, it is possible to insert three small $\mathrm{B}_{4} \mathrm{C}$ rods as shown in Figures 11 to 14 . During the operation these rods are not inserted and, consequently, the holes are filled with air. The diameter of each hole is $11 \mathrm{~mm}$ with aluminum alloy linear of $0.5 \mathrm{~mm}$ thickness.

\section{Performed Calculations}

Several calculations were performed for the YALINA-Booster and -Thermal using different nuclear data files. The following three sections describe the performed calculations.

\section{III.1. YALINA-Booster}

Two subcritical configurations are considered in the YALINA-Booster benchmark. These configurations have different fuel loadings in the thermal zone: 902 and $1141 \mathrm{EK}-10$ fuel rods as shown in Figures 2 and 3 respectively. In both configurations, the booster zone is fully loaded. The deuterons are accelerated to $240 \mathrm{keV}$ and the target is located at the center of the subcritical assembly. The neutron source is $(\mathrm{d}, \mathrm{t}),(\mathrm{d}, \mathrm{d})$, or Cf-252 neutrons. The Cf-252 neutron source is located at $(x, y, z)=(0,0,62) \mathrm{mm}$ with the deuteron beam tube still in place. The assembly center corresponds to the point $(x, y, z)=(0,0,0)$. For each configuration, the following results are obtained (see Ref. 5 for additional details):

1. Axial distribution of the following nuclear reaction rates:

a. He-3(n,p) reaction rate in the EC6T experimental channel, normalized to one external neutron source and one He-3 atom. The reaction rate values are calculated using the average neutron 
flux, $\varphi(E)$, in cylindrical cells from $Z=-250 \mathrm{~mm}$ to $Z=250 \mathrm{~mm}$ in steps of $50 \mathrm{~mm}$. The cells description is given in Ref. 5 . The detector is not modeled in the calculation.

b. $U-235(n, f)$ reaction rate in the EC2B and EC6T experimental channels, normalized to one external neutron source and one U-235 atom. In both channels, the reaction rate values are calculated using the average neutron flux, $\varphi(E)$, in cylindrical cells from $Z=-250 \mathrm{~mm}$ to $Z=$ $250 \mathrm{~mm}$ in steps of $50 \mathrm{~mm}$. The cells description is given in Ref. 5. The U-235 material is not modeled in the calculation.

c. In-115(n,y) reaction rate in the EC2B, EC5T, EC6T, and EC7T experimental channels, normalized to one external neutron source and one In-115 atom. Values are to be calculated in the In-115 samples located from $Z=-242 \mathrm{~mm}$ to $Z=208 \mathrm{~mm}$ in steps of $50 \mathrm{~mm}$. The In-115 samples are explicitly simulated together with their polyethylene holder, without loading any other isotopes in the holder. The description of the polyethylene holder is given in Ref. 5 .

2. Radial distribution of the $\operatorname{In}-115(n, y)$ reaction rate in the $E C 10 R$ radial experimental channel at the radial distances of $480,530,580,630,680$ and $730 \mathrm{~mm}$. All reaction rate values are normalized to one neutron source and one In-115 atom. The samples are simulated together with their polyethylene holder. The description of the polyethylene holder is given in Ref. 5.

3. Au-197(n,y) and Mn-55(n,y) reaction rates in the EC2B, EC6T experimental channels, normalized to one external neutron source and one isotope atom. The samples are simulated together with their holder, as done in the previous calculations. The calculation is performed with the holder containing only Au-197 or Mn-55.

4. Neutron energy spectra in the EC2B, EC6T and EC8R experimental channels, calculated at $Z=0$ with the 172 energy groups structure given in Appendix $C$. The integral of the neutron spectrum over the total energy range is normalized to $1.0\left(\int \Phi(E) d E=1.0\right)$.

5. The neutron flux is calculated as a function of time after a neutron pulse insertion. The pulse consists of $(d, t)$ or $(d, d)$ neutrons at $Z=0$ with $5 \mu$ s duration. The neutron flux calculations are performed for a period of $20 \mathrm{~ms}$ with two different detectors:

a. He-3(n,p) detector in the EC6T and EC8R experimental channels without explicit modeling of the detector. The results are normalized to the maximum value in the EC6T experimental channel.

b. U-235(n,f) detector in the EC1B, EC2B, and EC3B experimental channels without explicit modeling of the detector. The results are normalized to the maximum value in the EC1B experimental channel.

The calculations are done using a $10 \mu$ s time step from 0 to $1 \mathrm{~ms}$ and a $100 \mu$ s time step from 1 $\mathrm{ms}$ to $20 \mathrm{~ms}$.

6. The static and the kinetic neutronic parameters for both configurations:
a. Effective multiplication factor, $k_{\text {eff }}$.
b. Source multiplication factor, $k_{s}$.
c. Mean neutron generation time, $\wedge$.
d. Effective delayed neutron fraction, $\beta_{\text {eff. }}$

\section{III.2. YALINA Thermal}

Three different fuel loadings are considered for the YALINA-Thermal benchmark. These loadings have 216, 245 and $280 \mathrm{EK}-10$ fuel rods and the corresponding U-235 masses are 1.67, 1.89, $2.16 \mathrm{~kg}$, respectively. The fuel loadings are shown in Figures 11 to 14. The neutron source is (d,t), (d,d), or Cf-252 neutrons. For each configuration the following results are obtained, as explained in Ref. 6 :

1. Axial distribution of the following reaction rates:

a. He-3(n,p) reaction rate in the EC1, EC2, and EC3 experimental channels, normalized to one external neutron source and one $\mathrm{He}-3$ atom. The reaction values are calculated using the 
average neutron flux, $\varphi(E)$, in cylindrical cells from $Z=-250 \mathrm{~mm}$ to $Z=250 \mathrm{~mm}$ in steps of 50 $\mathrm{mm}$. The cells description is given in Ref. 6 . The detector is not modeled in the calculation.

b. U-235(n,f) reaction rate in the EC1, EC2, and EC3 experimental channels, normalized to one external neutron source and one U-235 atom. In all the channels, the reaction rate values are calculated using the average neutron flux, $\varphi(E)$, in cylindrical cells from $Z=-250 \mathrm{~mm}$ to $Z=$ $250 \mathrm{~mm}$ in steps of $50 \mathrm{~mm}$. The cells description is given in Ref. 6 . The U-235 material is not modeled in the calculation.

c. In-115(n,y) reaction rate in the EC2 experimental channel, normalized to one external neutron source and one $\mathrm{In}-115$ atom. Reaction rate values are calculated in the In-115 samples located from $Z=-242 \mathrm{~mm}$ to $Z=208 \mathrm{~mm}$ in steps of $50 \mathrm{~mm}$. The In-115 samples are simulated together with their polyethylene holder, without loading any other isotopes in the holder. The description of the polyethylene holder is explained in Ref. 6.

2. Radial distribution of the $\operatorname{In}-115(\mathrm{n}, \mathrm{y})$ reaction rate in the $E C 7$ radial experimental channel at the radial distances of $200,250,300,350,400,450,500,550$ and $600 \mathrm{~mm}$. All reaction rate values are normalized to one neutron source and one In-115 atom. The samples are simulated together with their polyethylene holder. The description of the polyethylene holder is explained in Ref. 6.

3. Au-197(n,y) and Mn-55(n,y) reaction rates in the EC2 experimental channel, normalized to one external neutron source and one isotope atom. The samples are simulated together with their holder, as done in the above calculation. The calculation has performed with the holder containing only Au-197 or Mn-55.

4. Neutron energy spectra in the EC1, EC2, EC3, EC5, and EC6 experimental channels, calculated at $Z=0$ with the 172 energy groups structure given in Appendix $C$. The integral of the neutron spectrum over the total energy range is normalized to $1.0\left(\int \Phi(\mathrm{E}) \mathrm{dE}=1.0\right)$.

5. Neutron flux calculated as a function of time after a neutron pulse insertion. The pulse consists of $(d, t)$ or $(d, d)$ neutrons at $Z=0$ with $5 \mu$ s duration. The neutron flux calculations are performed for a period of $20 \mathrm{~ms}$ with two different detectors:

a. He-3(n,p) detector in the EC2 and EC5 experimental channels without explicit modeling of the detector. The results are normalized to the maximum value in the EC2 experimental channel.

b. U-235(n,f) detector in the EC1 experimental channels without explicit modeling of the detector.

The results are normalized to the maximum value in the EC1 experimental channel.

The calculations are done using a $10 \mu$ s time step from 0 to $1 \mathrm{~ms}$ and a $100 \mu \mathrm{s}$ time step from $1 \mathrm{~ms}$ to $20 \mathrm{~ms}$.

6. The static and the kinetic neutronic parameters for the three configurations:

a. Effective multiplication factor, $k_{\text {eff }}$.

b. Source multiplication factor, $k_{s}$.

c. Mean neutron generation time, $\Lambda$.

d. Effective delayed neutron fraction, $\beta_{\text {eff }}$.

Some of the YALINA-Thermal results have been also presented in Ref. 10.

\section{III.3. Additional Calculations}

An additional study was performed to calculate the kinetic parameters of the YALINA-Booster and -Thermal according to the following formulations:

$$
\begin{aligned}
& \beta_{\text {eff }}=\sum_{\mathrm{i}=1}^{\mathrm{NF}} \frac{1}{\left\langle\Phi_{\mathrm{S}}^{*}, \mathrm{~F} \Phi_{\mathrm{S}}\right\rangle} \cdot \iint \chi_{\mathrm{d}, \mathrm{i}}\left(\mathrm{E}^{\prime}\right) \Phi_{\mathrm{S}}^{*}\left(\overrightarrow{\mathrm{r}}, \mathrm{E}^{\prime}\right) \mathrm{d} E^{\prime} \int \beta_{\mathrm{i}} v \Sigma_{\mathrm{f}}(\mathrm{E}) \Phi_{\mathrm{S}}(\overrightarrow{\mathrm{r}}, \mathrm{E}) \mathrm{dEd} \overrightarrow{\mathrm{r}} \\
& \Lambda_{\mathrm{eff}}=\frac{1}{\left\langle\Phi_{\mathrm{S}}^{*}, \mathrm{~F} \Phi_{\mathrm{S}}\right\rangle} \cdot \iint \Phi_{\mathrm{S}}^{*}\left(\overrightarrow{\mathrm{r}}, \mathrm{E}^{\prime}\right) \mathrm{d} E^{\prime} \int \frac{1}{\mathrm{v}(\mathrm{E})} \Phi_{\mathrm{S}}(\overrightarrow{\mathrm{r}}, \mathrm{E}) \mathrm{dEd} \overrightarrow{\mathrm{r}}
\end{aligned}
$$

where:

- $\mathrm{X}_{\mathrm{d}, \mathrm{i}}$ are the delayed neutron spectra for the group family $\mathrm{i}=1, \ldots, \mathrm{NF}$; 
- $\quad \beta_{\mathrm{i}}$ are the delayed neutron fraction for the $\mathrm{i}^{\text {th }}$ group family;

- $v(E)$ is the neutron velocity;

- $\mathrm{F}$ is the fission production operator of the Boltzmann equation.

Generally, the kinetic parameters are obtained with homogeneous (source-free) fluxes, $\Phi^{*}$ and $\Phi$, solutions of the equations: $A \Phi^{*}=\left(1 / \mathrm{k}_{\text {eff }}\right) F \Phi^{*}$ and $A \Phi=\left(1 / \mathrm{k}_{\text {eff }}\right) F \Phi$.

In Eqs. 1 and 2, $\Phi_{\mathrm{S}}^{*}$ and $\Phi_{\mathrm{S}}$ are inhomogeneous (source-driven) fluxes, adjoint and direct respectively, solution of the transport equations: $A \Phi_{S}^{*}=F \Phi_{S}^{*}+v \Sigma_{f}$ and $A \Phi_{S}=F \Phi_{S}+S$, where $v \Sigma_{f}$ is the macroscopic cross-section associated to the assembly fission source and $S$ is the external source driving the subcritical system, $(d, t),(d, d)$ or Cf-252 neutron source.

\section{Computational Tools}

Considerable efforts have been made in order to create a deterministic model using the ERANOS (European Reactor ANalysis Optimized code System) code package [11] for the analysis of the YALINA configurations. ERANOS, essentially developed for the analysis of fast neutron systems, with extended capabilities for the slowing down treatment with up to 1968 energy groups, is also used for the analysis of thermal reactors. Cross-sections have been processed with the ECCO code [12] of ERANOS using JEF2.2 [13], JEF3.1 [14] and ENDF/B-VI.8 [15] nuclear data. The VARIANT module [16] of ERANOS has been used to perform reactivity and flux calculations. The kinetic study is carried out with the KIN3D module [17]. For complementary studies, the 2D $S_{n}$ code BISTRO [18] of ERANOS has been also used. All calculations have been performed with the ERANOS version 2.0, except the VARIANT and KIN3D calculations that have been carried out with the version 2.1 recently available at ANL.

In the present report, the YALINA-Booster and -Thermal with 1141 and 280 EK-10 fuel rods have been considered.

\section{Cross-Section Processing}

The cross-sections have been processed with the ECCO code using the nuclear data from the JEF2.2, JEF3.1 and ENDF/B-VI.8 libraries. The cell calculations are performed for each zone assumed to be infinite. The ECCO code utilizes the sub-group method for the treatment of the resonances and performs cell calculations in homogeneous (OD) and heterogeneous geometry (1D: cylindrical or slab; 2D: $X Y$ or hexagonal) using the collision probability method. In the YALINA configurations, heterogeneous effects are quite important, as consequence, the cross-sections have been processed for most zones in XY geometry. The cross-sections are calculated over a fine energy group structure (up to 1968 energy groups) and collapsed to a broader energy group structure specified by the user using the cell flux as a weighting function. For the present work, the condensation has been performed over the 172 group structure according to the benchmark specifications. However, deterministic calculations for reactivity or neutron flux determination of the YALINA configurations with 172 energy groups require significant computational resources. As consequence, the cross-sections have been also processed with a lower number of energy groups. A 53 energy group structure was derived from the standard 33 group structure used for fast reactor analysis. Two energy groups have been added at the highest energy to represent the $14 \mathrm{MeV}(\mathrm{d}, \mathrm{t})$ neutron source and the lowest two energy groups of the original 33 group structure have been replaced by 20 energy groups for a more appropriate treatment of the thermal part of the neutron spectrum. The 53 and 172 energy group structures are given in Appendix C. After the individual material cross-sections are condensed using the heterogeneous geometry, a homogeneous cross- 
section is generated over the cell volume. For structural zone, the cell flux is calculated by introducing a source term given by the neutron leakage from the neighbour zone. The term $D^{2}$, where $D$ is the diffusion coefficient and B is the buckling value, of the ECCO calculation is given by a semi-empirical formula ( $B^{2}=\frac{5}{8}\left(\frac{\pi}{h}\right)^{2}$, where $\mathrm{h}$ is the zone thickness). This formula has been historically developed for the treatment of fertile blankets and, as consequence, it could be inappropriate in other cases. In the absence of appropriate information, in the present study it has been assigned $\mathrm{B}^{2}=0$. However, the dependence of the results on the value provided for the buckling has been investigated. The results indicate that the effect of this term is negligible: for instance, the change in reactivity for the YALINABooster between the cases $B^{2}=\frac{5}{8}\left(\frac{\pi}{h}\right)^{2}$ and $B^{2}=0$ is about 10 to $20 \mathrm{pcm}$. The differences decreases as the number of energy groups increases. Appendix $A$ contains all the geometrical details for the cross-sections processing used for the deterministic model of the YALINA configurations. A particular attention has been devoted to the calculation of the thermal cells, as explained in Appendix A.1.

\section{Deterministic Results}

Reactivity and flux calculations have been performed in XYZ geometry with the VARIANT code implemented in the new ERANOS version 2.1, using JEF2.2, JEF3.1, and ENDF/B-VI.8 nuclear data. In the VARIANT code, the transport equation is derived in terms of an "even" and an "odd" fluxes, expanded in Legendre's polynomials and in spherical harmonics for the spatial and angular variables respectively, as shown in the following equations:

$$
\begin{aligned}
& \Phi_{\mathrm{S}}^{+}(\overrightarrow{\mathrm{r}}, \vec{\Omega})=\frac{1}{2}\left[\Phi_{\mathrm{S}}(\overrightarrow{\mathrm{r}}, \vec{\Omega})+\Phi_{\mathrm{S}}(\overrightarrow{\mathrm{r}},-\vec{\Omega})\right]=\sum_{\mathrm{i}, \mathrm{m}} \mathrm{f}_{\mathrm{i}}(\overrightarrow{\mathrm{r}}) \mathrm{g}_{\mathrm{m}}(\vec{\Omega}) \zeta_{\mathrm{i}, \mathrm{m}} \\
& \Phi_{\mathrm{S}, \gamma}^{-}(\overrightarrow{\mathrm{r}}, \vec{\Omega})=\frac{1}{2}\left[\Phi_{\mathrm{S}}(\overrightarrow{\mathrm{r}}, \vec{\Omega})-\Phi_{\mathrm{S}}(\overrightarrow{\mathrm{r}},-\vec{\Omega})\right]=\sum_{\mathrm{j}, \mathrm{n}} \mathrm{h}_{\mathrm{j}}(\overrightarrow{\mathrm{r}}) \mathrm{k}_{\mathrm{n}}(\vec{\Omega}) \chi_{\mathrm{j}, \mathrm{n}, \gamma}
\end{aligned}
$$

VARIANT uses the nodal variational method. This implies that the solutions of the equation are integrated over the mesh volumes and they are obtained by the minimization of a function, that contains the total cross-section, $\Sigma_{\mathrm{t}}$, at the denominator. Due to these features, the VARIANT code does not work properly with fine meshes. Moreover, difficulties are encountered in presence of void regions, characterized by low values of $\Sigma_{\mathrm{t}}$. Therefore, the void zones of the original YALINA configurations were homogenized with other neighbor zones as shown in Appendix A.

The VARIANT method is also the basis of the time-dependent ERANOS calculation modules, implemented in the KIN3D code, used for the kinetic studies presented in this report.

\section{VI.1. Multiplication Factor}

The impact of the number of energy groups, the angular flux expansion order, and the anisotropic scattering expansion order on the calculated $k_{\text {eff }}$ values has been investigated for the YALINA-Booster and -Thermal. Concerning the number of energy groups used, the obtained results in Tables 1 and 2 show that increasing the energy group number from 53 to 172 results in a negligible impact on the calculated reactivity values. The obtained effect is less than $50 \mathrm{pcm}$ for the YALINA-Booster and -Thermal, depending on the used nuclear data files. Therefore, it is concluded that the 53 energy group structure is adequate for the analyses of the current configurations. 
Table 1. Calculated $k_{\text {eff }}$ (Reactivity) with VARIANT for the YALINA-Booster

\begin{tabular}{||c|c|c|c||}
\hline $\begin{array}{c}\text { Number of Energy } \\
\text { Groups }\end{array}$ & JEF2.2 & JEF3.1 & ENDF/B-VI.8 \\
\hline \hline $53^{\text {(a) }}$ & $0.96235(-3912 \mathrm{pcm})$ & $0.95983(-4185 \mathrm{pcm})$ & $0.95895(-4281 \mathrm{pcm})$ \\
\hline $172^{(\mathrm{a})}$ & $0.96246(-3900 \mathrm{pcm})$ & $0.95998(-4169 \mathrm{pcm})$ & $0.95915(-4259 \mathrm{pcm})$ \\
\hline
\end{tabular}

(a) Results obtained in $\mathrm{SP}_{3} \mathrm{P}_{0}$ approximation: full $\mathrm{P}_{3}$ angular flux expansion with simplified spherical harmonics; anisotropic scattering order 0

Table 2. Calculated $k_{\text {eff }}$ (Reactivity) with VARIANT for the YALINA-Thermal

\begin{tabular}{|c|c|c|c||}
\hline $\begin{array}{c}\text { Number of Energy } \\
\text { Groups }\end{array}$ & JEF2.2 & JEF3.1 & ENDF/B-VI.8 \\
\hline \hline $53^{\text {(a) }}$ & $0.91002(-9888 \mathrm{pcm})$ & $0.94170(-6191 \mathrm{pcm})$ & $0.93994(-6390 \mathrm{pcm})$ \\
\hline $172^{\text {(a) }}$ & $0.91042(-9840 \mathrm{pcm})$ & $0.94180(-6180 \mathrm{pcm})$ & $0.94004(-6379 \mathrm{pcm})$ \\
\hline $53^{(\mathrm{b})}$ & $0.91276(-9558 \mathrm{pcm})$ & $0.94476(-5847 \mathrm{pcm})$ & $0.94294(-6051 \mathrm{pcm})$ \\
\hline $172^{\text {(b) }}$ & $0.91341(-9480 \mathrm{pcm})$ & $0.94514(-5804 \mathrm{pcm})$ & $0.94333(-6008 \mathrm{pcm})$ \\
\hline
\end{tabular}

(a) Results obtained in $\mathrm{SP}_{3} \mathrm{P}_{0}$ approximation: full $\mathrm{P}_{3}$ angular flux expansion with simplified spherical harmonics; anisotropic scattering order 0

(b) Results obtained in $\mathrm{SP}_{3} \mathrm{P}_{1}$ approximation: full $\mathrm{P}_{3}$ angular flux expansion with simplified spherical harmonics; anisotropic scattering order 1

Tables 3 and 4 show the calculated reactivity values with different angular flux expansion or anisotropic scattering order approximations. The use of the 53 energy group structure is used for obtaining these results.

In Table 3, the first four sets of calculations (A, B, C, and D) used heterogeneous cell calculations for obtaining the zone average cross-section for each zone of the YALINA-Booster geometrical model. The fifth calculational set $(F)$ was obtained by applying a correction factor to the fourth calculation set since the current computational resources do not permit the use of the heterogeneous cell calculations for $\mathrm{SP}_{3} \mathrm{P}_{3}$ zone average cross-sections. The correction factor was obtained by performing $\mathrm{SP}_{3} \mathrm{P}_{1}$ and $\mathrm{SP}_{3} \mathrm{P}_{3}$ simulations using homogenous cell calculations based on the number densities of each isotope averaged over the volume of the cell. In Table 4 , similar approach was performed for the YALINAThermal. The first five calculational sets utilized heterogeneous cell calculations for getting average cross-sections sets for the different zones and the sixth calculation set obtained by using a correction factor.

The obtained results for the two assemblies suggest that the angular expansion of the flux and the anisotropic scattering should be increased to the orders 5 and 3 respectively or more. The $P_{5} P_{3}$ calculation is not possible with the current computer resources. Therefore, the results for the desired approximation orders have been obtained by separate investigations for angular flux and the anisotropic scattering orders. This kind of analysis is commonly performed when deterministic codes are used. 
Table 3. Calculated $k_{\text {eff }}$ (Reactivity) with VARIANT for the YALINA-Booster

\begin{tabular}{||l||c|c|c||}
\hline Calculation & JEF2.2 & JEF3.1 & ENDF/B-VI.8 \\
\hline \hline $\mathrm{A}: \mathrm{SP}_{3}^{(\mathrm{a})} \mathrm{P}_{0}{ }^{(\mathrm{b})}$ & $0.96235(-3912 \mathrm{pcm})$ & $0.95983(-4185 \mathrm{pcm})$ & $0.95895(-4281 \mathrm{pcm})$ \\
\hline $\mathrm{B}: \mathrm{P}_{3} \mathrm{P}_{0}$ & $0.96388(-3747 \mathrm{pcm})$ & $0.96089(-4070 \mathrm{pcm})$ & $0.96002(-4165 \mathrm{pcm})$ \\
\hline $\mathrm{C}: \mathrm{P}_{5} \mathrm{P}_{0}$ & $0.96516(-3610 \mathrm{pcm})$ & $0.96211(-3938 \mathrm{pcm})$ & $0.96123(-4033 \mathrm{pcm})$ \\
\hline $\mathrm{D}: \mathrm{SP}_{3} \mathrm{P}_{1}$ & $0.96877(-3224 \mathrm{pcm})$ & $0.96620(-3498 \mathrm{pcm})$ & $0.96537(-3587 \mathrm{pcm})$ \\
\hline $\mathrm{F}^{(\mathrm{c})}: \mathrm{SP}_{3} \mathrm{P}_{3}$ & $0.97329(-2744 \mathrm{pcm})$ & $0.97069(-3019 \mathrm{pcm})$ & $0.96989(-3104 \mathrm{pcm})$ \\
\hline
\end{tabular}

(a) Angular flux expansion $\left(\mathrm{SP}_{3}\right.$ : full $\mathrm{P}_{3}$ angular flux expansion with simplified spherical harmonics, $\mathrm{P}_{3}$ : angular flux expansion order 3);

(b) Anisotropic scattering order;

(c) Simplified geometrical model is used

Table 4. Calculated $k_{\text {eff }}$ (Reactivity) with VARIANT for the YALINA-Thermal

\begin{tabular}{l||c|c|c||}
\hline Calculation & JEF2.2 & JEF3.1 & ENDF/B-VI.8 \\
\hline \hline $\mathrm{A}: \mathrm{SP}_{3}{ }^{(\mathrm{a})} \mathrm{P}_{0}{ }^{(\mathrm{b})}$ & $0.91002(-9888 \mathrm{pcm})$ & $0.94170(-6191 \mathrm{pcm})$ & $0.93994(-6390 \mathrm{pcm})$ \\
\hline $\mathrm{B}: \mathrm{P}_{3} \mathrm{P}_{0}$ & $0.91634(-9130 \mathrm{pcm})$ & $0.94421(-5909 \mathrm{pcm})$ & $0.94242(-6110 \mathrm{pcm})$ \\
\hline $\mathrm{C}: \mathrm{P}_{5} \mathrm{P}_{0}$ & $0.91897(-8818 \mathrm{pcm})$ & $0.94611(-5696 \mathrm{pcm})$ & $0.94431(-5897 \mathrm{pcm})$ \\
\hline $\mathrm{D}: \mathrm{SP}_{3} \mathrm{P}_{1}$ & $0.91276(-9558 \mathrm{pcm})$ & $0.94476(-5847 \mathrm{pcm})$ & $0.94294(-6051 \mathrm{pcm})$ \\
\hline $\mathrm{E}: \mathrm{P}_{3} \mathrm{P}_{1}$ & $0.92107(-8569 \mathrm{pcm})$ & $0.94923(-5349 \mathrm{pcm})$ & $0.94739(-5553 \mathrm{pcm})$ \\
\hline $\mathrm{F}^{(\mathrm{c})}: \mathrm{SP}_{3} \mathrm{P}_{3}$ & $0.91533(-9250 \mathrm{pcm})$ & $0.94758(-5532 \mathrm{pcm})$ & $0.94570(-5742 \mathrm{pcm})$ \\
\hline
\end{tabular}

The reactivity change due to increasing the angular flux expansion is obtained with $\mathrm{P}_{0}$ anisotropic scattering; similarly, the correction due higher anisotropic scattering order is obtained with $\mathrm{SP}_{3}$ expansion for the neutron flux. From the results of Tables 3 and 4, for instance, the reactivity results assuming $\mathrm{P}_{5} \mathrm{P}_{3}$ approximation are given in Tables 5 and 6 . In the case of the YALINA-Booster, a quite good agreement in the reactivity values is observed for the three different nuclear data libraries, the obtained results vary within a range of $\sim 400 \mathrm{pcm}$. Regarding the YALINA-Thermal, JEF3.1 and ENDF/B-VI.8 provide comparable results, but JEF2.2 gives a lower reactivity value of $\sim 3000 \mathrm{pcm}$. The calculated reactivity differences from different data libraries will be discussed further in the next Section.

Table 5. Final $k_{\text {eff }}$ (Reactivity) with VARIANT for the YALINA-Booster

\begin{tabular}{|c|c|c|c|}
\hline Calculation & JEF2.2 & JEF3.1 & ENDF/B-VI.8 \\
\hline $\mathrm{SP}_{3} \mathrm{P}_{1}$ & $0.96877(-3224 \mathrm{pcm})$ & $0.96620(-3498 \mathrm{pcm})$ & $0.96537(-3587 \mathrm{pcm})$ \\
\hline Correction $^{(\mathrm{a})}: \mathrm{P}_{5} \mathrm{P}_{0}-\mathrm{SP}_{3} \mathrm{P}_{0}$ & $302 \mathrm{pcm}$ & $247 \mathrm{pcm}$ & $248 \mathrm{pcm}$ \\
\hline Correction ${ }^{(\mathrm{a})}: \mathrm{SP}_{3} \mathrm{P}_{3}-\mathrm{SP}_{3} \mathrm{P}_{1}$ & $480 \mathrm{pcm}$ & 479 pcm & $483 \mathrm{pcm}$ \\
\hline $\mathrm{P}_{5} \mathrm{P}_{3}$ & $0.97616(-2442 \mathrm{pcm})$ & $0.97303(-2772 \mathrm{pcm})$ & $0.97223(-2856 \mathrm{pcm})$ \\
\hline
\end{tabular}


Table 6. Final $k_{\text {eff }}$ (Reactivity) with VARIANT for the YALINA-Thermal

\begin{tabular}{||c||c|c|c||}
\hline Calculation & JEF2.2 & JEF3.1 & ENDF/B-VI.8 \\
\hline \hline $\mathrm{P}_{3} \mathrm{P}_{1}$ & $0.92107(-8569 \mathrm{pcm})$ & $0.94923(-5349 \mathrm{pcm})$ & $0.94739(-5553 \mathrm{pcm})$ \\
\hline Correction $^{(\mathrm{a})}: \mathrm{P}_{5} \mathrm{P}_{0}-\mathrm{P}_{3} \mathrm{P}_{0}$ & $312 \mathrm{pcm}$ & $213 \mathrm{pcm}$ & $213 \mathrm{pcm}$ \\
\hline Correction $^{(\mathrm{a})}: \mathrm{SP}_{3} \mathrm{P}_{3}-\mathrm{SP}_{3} \mathrm{P}_{1}$ & $308 \mathrm{pcm}$ & $315 \mathrm{pcm}$ & $309 \mathrm{pcm}$ \\
\hline $\mathrm{P}_{5} \mathrm{P}_{3}$ & $0.92636(-7949 \mathrm{pcm})$ & $0.95401(-4821 \mathrm{pcm})$ & $0.95210(-5031 \mathrm{pcm})$ \\
\hline
\end{tabular}

\section{VI.1.a. Perturbation Calculation}

Perturbation calculations were performed to examine the reactivity differences obtained from the use of different nuclear data libraries. Since the ERANOS perturbation modules are only available in two dimensional geometry, an RZ model has been developed for the YALINA-Booster and -Thermal as shown in Appendix B.

The reactivity values obtained for the $\mathrm{RZ}$ model with the BISTRO code using $\mathrm{S}_{4} \mathrm{P}_{1}$ approximation are presented in Tables 7 and 8 for the YALINA-Booster and -Thermal, respectively. Using the same library, the difference between the BISTRO and VARIANT reactivity results shown in Tables 5 and 6 compared to Tables 7 and 8 are essentially due to the omission of the YALINA experimental channels from the RZ model. These channels are included in the three dimensional model of the VARIANT calculations.

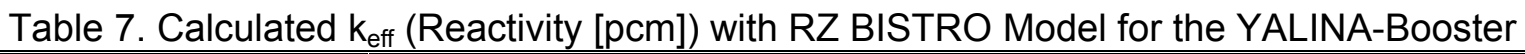

\begin{tabular}{|c|c|c|c|}
\hline \hline Model-Calculation & JEF2.2 & JEF3.1 & ENDF/B-VI.8 \\
\hline \hline RZ-S ${ }_{4} \mathrm{P}_{1}$ & $0.980579(-1980.6 \mathrm{pcm})$ & $0.974383(-2629.0 \mathrm{pcm})$ & $0.973531(-2718.9 \mathrm{pcm})$ \\
\hline
\end{tabular}

Table 8. Calculated $\mathrm{k}_{\text {eff }}$ (Reactivity [pcm]) with RZ BISTRO Model for the YALINA-Thermal

\begin{tabular}{|c|c|c|c|}
\hline Model-Calculation & JEF2.2 & JEF3.1 & ENDF/B-VI.8 \\
\hline \hline RZ-S $\mathrm{P}_{1}$ & $0.941637(-6198.0 \mathrm{pcm})$ & $0.958009(-4383.2 \mathrm{pcm})$ & $0.955992(-4603.4 \mathrm{pcm})$ \\
\hline
\end{tabular}

Table 9 gives the perturbation components of the observed BISTRO reactivity change due to the use of different nuclear data libraries for the YALINA-Booster. Isotopes that produce $\Delta \rho$ of less than $0.05 \mathrm{pcm}$ are not listed in the table. It can be seen that the total reactivity change is $+670 \mathrm{pcm}$ for the (JEF2.2 - JEF3.1) results and $-90 \mathrm{pcm}$ for (ENDF/B-VI.8 - JEF3.1). The difference is consistent with the Table 7 results. $\mathrm{U}-235, \mathrm{~Pb}, \mathrm{C}, \mathrm{Al}, \mathrm{U}-238$ isotopes are the main contributors to the $\Delta \rho$ for the (JEF2.2 - JEF3.1) case. U-238, $\mathrm{H}$ and $\mathrm{Pb}$ isotopes are the main contributors to the $\Delta \rho$ for (ENDF/B-VI.8 - JEF3.1) case. However, it is important to notice that the perturbation components have different signs, which reduce the net reactivity difference. 
Table 9. Perturbation Components [pcm] for the YALINA-Booster

\begin{tabular}{|c|c|c|c|c|c|c|c|c|c|c|c|c|c|c|c|}
\hline \multicolumn{8}{|c|}{$\Delta \rho(\mathrm{JEF} 2.2-\mathrm{JEF} 3.1)$} & \multicolumn{8}{|c|}{$\Delta \rho($ ENDF/B-VI.8 - JEF3.1) } \\
\hline Isotope & Capture & Fission & $\overline{\text { Leakage }}$ & Elastic & Inelastic & $\mathrm{N}, \mathrm{xN}$ & Total & Isotope & Capture & Fission & Leakage & Elastic & Inelastic & $\mathrm{N}, \mathrm{xN}$ & Total \\
\hline U235 & 113.4 & 262.7 & 2.1 & -0.1 & -0.9 & - & 377.3 & U235 & -6.3 & 34.7 & -0.2 & -0.2 & - & - & 28.1 \\
\hline U238 & -45.6 & -14.3 & -16.5 & -0.9 & -6.3 & -4.1 & -87.7 & $\mathrm{U} 238$ & -40.0 & -12.4 & -6.4 & -0.6 & -45.8 & -0.3 & -105.4 \\
\hline Fe54 & -49.3 & - & 1.1 & - & -0.5 & - & -48.7 & Fe54 & -1.8 & - & -3.5 & -0.3 & -0.5 & - & -6.1 \\
\hline Fe56 & -3.3 & - & 54.9 & 1.0 & 16.1 & - & 68.7 & Fe56 & -15.7 & - & 19.6 & -0.4 & 5.0 & - & 8.4 \\
\hline Fe57 & -5.7 & - & -0.4 & -0.5 & -1.5 & - & -8.1 & Fe57 & 0.6 & - & -6.5 & -0.7 & -2.1 & - & -8.7 \\
\hline Fe58 & 0.1 & - & -1.2 & -0.1 & -0.1 & - & -1.2 & Fe58 & 0.7 & - & -1.6 & -0.1 & -0.1 & - & -1.1 \\
\hline Cr50 & 1.0 & - & -0.4 & -0.1 & - & - & 0.5 & Cr50 & -0.2 & - & - & - & - & - & -0.2 \\
\hline Cr52 & -2.6 & - & 38.2 & 3.6 & 2.6 & - & 41.9 & Cr52 & 7.7 & - & 14.4 & 1.3 & 4.7 & - & 28.1 \\
\hline Cr53 & -11.4 & - & 3.7 & 0.9 & -0.4 & - & -7.0 & Cr53 & -0.2 & - & - & - & - & - & -0.2 \\
\hline Cr54 & 0.1 & - & -0.6 & -0.1 & -0.1 & - & -0.6 & Ni58 & -0.3 & - & - & -0.4 & 0.8 & - & 0.1 \\
\hline $\mathrm{Ni58}$ & 0.5 & - & 0.6 & -0.4 & 0.8 & - & 1.5 & $\mathrm{Ni60}$ & 0.6 & - & 0.7 & 0.1 & 0.1 & - & 1.5 \\
\hline $\mathrm{Ni60}$ & 0.9 & - & 0.8 & - & 0.1 & - & 1.8 & B10 & -0.6 & - & - & - & - & - & -0.6 \\
\hline Ni61 & -0.2 & - & 0.1 & - & - & - & -0.1 & Pb207 & -19.8 & - & 46.8 & 1.0 & 4.4 & -2.1 & 30.3 \\
\hline Ni62 & -0.1 & - & - & - & - & - & -0.1 & Pb208 & -0.3 & - & -22.9 & -0.8 & 5.7 & -2.0 & -20.3 \\
\hline B10 & -1.1 & - & 0.2 & - & - & - & -0.9 & $\mathrm{Al} 27$ & 1.5 & - & -1.0 & -0.1 & - & - & 0.4 \\
\hline B11 & - & - & 0.1 & -0.1 & - & - & - & P31 & -0.3 & - & 0.2 & - & - & - & -0.2 \\
\hline P31 & -0.1 & - & 0.7 & - & - & - & 0.7 & Sb121 & 2.4 & - & 0.1 & - & - & - & 2.5 \\
\hline Sb121 & 1.4 & - & 1.0 & - & -0.1 & - & 2.3 & Sb123 & $\begin{array}{l}-1.3 \\
\end{array}$ & - & - & - & - & - & -1.3 \\
\hline Sb123 & -1.1 & - & 0.8 & - & -0.2 & - & -0.5 & As75 & -0.1 & - & - & - & - & - & -0.1 \\
\hline $\mathrm{H}^{(\mathrm{a})}$ & -7.8 & - & 18.6 & 5.4 & - & - & 16.2 & Mn55 & -0.1 & - & 0.1 & - & - & - & - \\
\hline$C^{(b)}$ & -2.1 & - & -111.1 & -1.5 & -0.6 & - & -115.5 & $\mathrm{Na} 23$ & - & - & -0.1 & - & - & - & -0.1 \\
\hline $\mathrm{Pb}$ & -5.7 & - & 317.5 & 15.4 & -14.1 & -3.1 & 310.1 & O16 & -0.1 & - & 0.1 & -0.1 & - & - & -0.1 \\
\hline $\mathrm{Ca}$ & 0.8 & - & - & - & - & - & 0.8 & $\mathrm{H}^{(c)}$ & -9.6 & - & -62.0 & -29.3 & - & - & -100.9 \\
\hline $\mathrm{Cu}$ & -0.5 & - & 0.1 & - & - & - & -0.4 & C & - & - & - & -0.2 & - & - & -0.3 \\
\hline $\mathrm{Mg}$ & 1.3 & - & -11.3 & 0.9 & -0.8 & - & -10.0 & graphite & - & - & -0.1 & -0.1 & - & - & -0.1 \\
\hline $\mathrm{Ti}$ & -0.1 & - & - & 0.1 & -0.1 & - & -0.2 & Mo & -2.2 & - & 0.1 & - & -0.1 & - & -2.2 \\
\hline $\mathrm{Si}$ & - & - & 0.1 & - & - & - & 0.1 & $\mathrm{Ca}$ & 0.8 & - & - & - & - & - & 0.8 \\
\hline $\mathrm{O}$ & -1.7 & - & 5.7 & 1.0 & - & - & 5.0 & $\mathrm{Mg}$ & 1.4 & - & -9.2 & -1.6 & -2.1 & - & -11.5 \\
\hline $\mathrm{Al}$ & 96.2 & - & 34.6 & 4.6 & -20.3 & - & 115.1 & $\mathrm{Ti}$ & - & - & -0.4 & - & -0.1 & - & -0.6 \\
\hline $\mathrm{Mn}$ & -8.9 & - & 0.4 & 0.1 & 0.5 & - & 8.0 & $\mathrm{~S}$ & 0.2 & - & -0.1 & - & 0.1 & - & 0.3 \\
\hline $\mathrm{Zn}$ & 1.1 & - & 0.1 & - & 0.1 & - & 1.3 & Pb204, & 194 & & 183 & 08 & 03 & 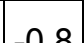 & 679 \\
\hline Total & 69.6 & 248.5 & 340.1 & 29.2 & -25.8 & -7.2 & 670.4 & $\mathrm{~Pb} 206^{(\mathrm{d}}$ & 19.4 & - & 48.3 & 0.8 & 0.3 & -0.8 & 67.9 \\
\hline & & & & & & & & $\mathrm{Zn}$ & 4.6 & - & -1.6 & -0.1 & -0.1 & - & 2.7 \\
\hline & & & & & & & & Total & -59.0 & 22.3 & 14.8 & $\mid-31.8$ & -30.0 & \begin{tabular}{|l|}
-5.3 \\
\end{tabular} & -89.0 \\
\hline
\end{tabular}

(a) For JEF2.2 the isotope "bdH" is used for each hydrogenated material;

For JEF3.1 the isotope "HCH2" is used for polyethylene; "HH2O" for water; "H1" for other hydrogenated materials.

(b) For JEF2.2 the isotope "C" is used for the graphite reflector;

For JEF3.1 the isotope "Cgra" is used for the graphite reflector.

(c) For ENDF/B-VI.8 the isotope "POLY" is used for polyethylene; "H2OL" for water; "H1" for other hydrogenated materials;

For JEF3.1 the isotope "HCH2" is used for polyethylene; "HH2O" for water; "H1" for other hydrogenated materials.

(d) In ENDF/B-VI.8 the isotope Pb-204 is absent: the Pb-206 density is Pb-204 + Pb-206.

Table 10 shows the perturbation components for the observed BISTRO reactivity change when different data libraries are used for the case of the YALINA-Thermal. Isotopes not presented in the table contribute to the $\Delta \rho$ for less than $0.05 \mathrm{pcm}$ !

The total reactivity variation is of the order of $-1800 \mathrm{pcm}$ for the (JEF2.2 - JEF3.1) results and of -210 pcm for (ENDF/B-VI.8 - JEF3.1). The results provided in Table 10 show that $U-238$ and $\mathrm{H}$ are the main contributors to the $\Delta \rho$ (ENDF/B-VI.8 - JEF3.1), while the $\Delta \rho$ (JEF2.2 - JEF3.1) is essentially caused by the carbon. This study demonstrates that the carbon is inadequate to represent the graphite reflector and consequently it is decided to avoid the use of the JEF2.2 library for the calculations of the YALINA-Thermal. 
Table 10. Perturbation Components [pcm] for the YALINA-Thermal

\begin{tabular}{|c|c|c|c|c|c|c|c|c|c|c|c|c|c|c|c|}
\hline \multicolumn{8}{|c|}{$\Delta \rho($ JEF2.2 - JEF3.1) } & \multicolumn{8}{|c|}{$\Delta \rho($ ENDF/B-VI.8 - JEF3.1) } \\
\hline Isotope & Capture & Fission & Leakage & Elastic & Inelastic & $\mathrm{N}, \mathrm{xN}$ & Total & Isotope & Capture & Fission & Leakage & Elastic & Inelastic & $\mathrm{N}, \mathrm{xN}$ & Total \\
\hline U235 & 25.0 & 334.2 & -1.1 & - & -0.1 & - & 358.0 & U235 & -1.0 & 25.6 & -0.3 & - & - & - & 24.3 \\
\hline U238 & -57.5 & -11.8 & -10.5 & -0.2 & -19.2 & -3.8 & -103.0 & U238 & -43.1 & -9.8 & -5.0 & - & -46.7 & -0.3 & -104.8 \\
\hline Fe54 & -7.5 & - & - & - & -0.3 & - & -7.8 & Fe54 & -0.2 & - & -0.2 & - & -0.2 & - & -0.6 \\
\hline Fe56 & -1.5 & - & 1.8 & 0.4 & 2.3 & - & 3.0 & Fe56 & -1.5 & - & 0.9 & - & 1.1 & - & 0.5 \\
\hline Fe57 & -0.7 & - & 0.2 & - & -0.2 & - & -0.8 & Fe57 & 0.2 & - & - & - & -0.2 & - & -0.1 \\
\hline Fe58 & - & - & -0.2 & - & - & - & -0.2 & Fe58 & 0.1 & - & -0.1 & - & - & - & -0.1 \\
\hline Cr50 & -0.1 & - & -0.1 & - & - & - & -0.1 & Cr52 & 1.2 & - & 0.8 & - & 1.1 & - & 3.1 \\
\hline Cr52 & -0.4 & - & 1.7 & 0.2 & 0.3 & - & 1.9 & Ni58 & -0.1 & - & - & - & 0.2 & - & 0.1 \\
\hline Cr53 & -2.0 & - & - & - & -0.2 & - & -2.2 & Ni60 & - & - & - & - & 0.1 & - & 0.1 \\
\hline Cr54 & - & - & - & - & - & - & -0.1 & Pb207 & -0.6 & - & 2.4 & 0.1 & -0.1 & -0.3 & 1.5 \\
\hline Ni58 & -0.1 & - & -0.2 & - & 0.2 & - & -0.2 & Pb208 & - & - & $\begin{array}{l}-1.3 \\
\end{array}$ & -0.1 & 3.1 & -0.2 & 1.5 \\
\hline Ni60 & - & - & - & - & 0.1 & - & 0.1 & $\mathrm{Al} 27$ & 3.7 & - & -1.4 & -0.1 & - & - & 2.3 \\
\hline B10 & -0.9 & - & - & - & - & - & -0.9 & P31 & -0.1 & - & - & - & - & - & - \\
\hline P31 & - & - & 0.1 & - & - & - & 0.1 & Sb121 & 0.6 & - & - & - & - & - & 0.6 \\
\hline Sb121 & 0.5 & - & 0.1 & - & - & - & 0.5 & Sb123 & -0.3 & - & - & - & - & - & -0.3 \\
\hline Sb123 & -0.3 & - & - & - & - & - & -0.3 & As75 & - & - & - & - & - & - & - \\
\hline $\mathrm{H}^{(\mathrm{a})}$ & 3.1 & - & 9.6 & 48.5 & - & - & 61.2 & O16 & - & - & 0.2 & -0.1 & - & - & 0.1 \\
\hline$C^{(b)}$ & -2.9 & - & -2137.0 & -3.9 & -1.1 & - & -2145.0 & $\mathrm{H}^{\odot}$ & -16.5 & - & -84.4 & -25.9 & - & - & -126.7 \\
\hline Total & 79.3 & 322.4 & -2186.1 & 47.1 & -55.7 & -4.6 & -1797.5 & $C^{(d)}$ & -0.1 & - & 0.3 & -0.1 & - & - & 0.2 \\
\hline & & & & & & & & Total & -50.1 & 15.8 & -97.9 & -30.1 & -46.9 & \begin{tabular}{|c|}
-1.0 \\
\end{tabular} & -210.2 \\
\hline
\end{tabular}

(a) For JEF2.2 the isotope "bdH" is used for each hydrogenated material;

For JEF3.1 the isotope "HCH2" is used for polyethylene; "HH2O" for water; "H1" for other hydrogenated materials.

(b) For JEF2.2 the isotope " $\mathrm{C}$ " is used for the graphite reflector;

For JEF3.1 the isotope "cgra" is used for the graphite reflector.

(c) For ENDF/B-VI.8 the isotope "POLY" is used for polyethylene; "H2OL" for water; "H1" for other hydrogenated materials: $\mathrm{H} 1$ gives 0 contribution;

For JEF3.1 the isotope "HCH2" is used for polyethylene; "HH2O" for water; "H1" for other hydrogenated materials: $\mathrm{H} 1$ gives 0 contribution.

(d) "C" is not used in graphite reflector. For the graphite reflector "cgra" and "graphl" are used for JEF3.1 and ENDF/B-VI.8 respectively: the graphite gives 0 contribution.

\section{VI.2. Source Multiplication Factor, $\mathbf{k}_{\mathrm{s}}$}

Calculations have been performed to determine the source multiplication factor, $\mathrm{k}_{\mathrm{s}}$, of the YALINABooster and -Thermal configurations. Two formulations for the $\mathrm{k}_{\mathrm{s}}$ have been considered:

$$
\mathrm{k}_{\mathrm{S}}=\frac{\left\langle\mathrm{F} \Phi_{\mathrm{S}}\right\rangle}{\left\langle\mathrm{A} \Phi_{\mathrm{S}}\right\rangle-\left\langle\mathrm{P}_{\mathrm{n}, \mathrm{xn}} \Phi_{\mathrm{S}}\right\rangle}
$$

and

$$
\mathrm{k}_{\mathrm{S}}=\frac{\left\langle\mathrm{F} \Phi_{\mathrm{S}}\right\rangle+\left\langle\mathrm{P}_{\mathrm{n}, \mathrm{xn}} \Phi_{\mathrm{S}}\right\rangle}{\left\langle\mathrm{A} \Phi_{\mathrm{S}}\right\rangle}
$$

where:

$\Phi_{S}$ is the inhomogeneous (source-driven) flux, solution of the transport equation $\mathrm{A} \Phi_{\mathrm{S}}=\mathrm{F} \Phi_{\mathrm{S}}+\mathrm{P}_{\mathrm{N}, \mathrm{xN}} \Phi_{\mathrm{S}}+\mathrm{S}$;

A is the loss term (absorption + leakage) of the Boltzmann operator;

$F$ is the fission production term;

$P_{n, x n}$ is the $(n, x n)$ production term;

$S$ is the external source driving the subcritical system. 
For similarity with the multiplication factor, an inhomogeneous reactivity can be defined: $\rho_{\mathrm{S}}=1-\frac{1}{\mathrm{k}_{\mathrm{S}}}$.

The $\mathrm{k}_{\mathrm{s}}$ has been calculated for the three external sources considered by the YALINA benchmark: the $(d, t),(d, d)$ and Cf-252 sources. For this purpose, the external sources had to be represented in the deterministic model. The $(\mathrm{d}, \mathrm{t})$ and $(\mathrm{d}, \mathrm{d})$ sources have been modeled as mono-energetic $(14.1 \mathrm{MeV}$ and $2.45 \mathrm{MeV}$ respectively) and uniformly distributed in an opportune volume at the assembly center of both YALINA configurations. Point neutron source cannot be represented explicitly in deterministic calculational models. The JEF3.1 energy spectrum of the Cf-252 source is used in the calculations, which is shown in Appendix D. The use of the Cf-252 fission spectrum from the JEF2.2 or the ENDF/B-VI.8 nuclear data files results in negligible differences relative to the spectrum from JEF3.1. The Cf-252 source has been distributed in an opportune volume located at the assembly center similar to the $(\mathrm{d}, \mathrm{t})$ and $(\mathrm{d}, \mathrm{d})$ neutron sources in the YALINA-Thermal and at $Z=6.2 \mathrm{~cm}$ in the YALINABooster, assuming that $Z=0$ corresponds to the assembly midplane. The $k_{S}$ calculations have been performed using the JEF2.2, JEF3.1 and ENDF/B-VI.8 data libraries for the YALINA-Booster and JEF3.1 and ENDF/B-VI.8 for the YALINA-Thermal.

As in the case of the multiplication factor, the impact on the calculated $k_{s}$ values due to the number of energy groups, the angular flux expansion and the anisotropic scattering orders has been investigated. The results of the neutron balance and the corresponding $\mathrm{k}_{\mathrm{s}}$ calculated with both Eqs. 5 and 6 have been presented in Tables 11 to 13 for the YALINA-Booster and in Tables 14 and 15 for the YALINA-Thermal.

Tables 11 to 15 give the calculated neutron balance per neutron source for the YALINA-Booster and -Thermal using different nuclear data files with different group structure sets and approximations. The approximations were imposed by the available computer resources for performing the calculations. For the same flux and cross-sections approximations, increasing the energy group number from 53 to 172 results in negligible change in the calculated $\rho_{S}$ values. This change is about 10 pcm except for the YALINA-Thermal with $(\mathrm{d}, \mathrm{t})$ neutron source, where the effect is of the range of $100 \mathrm{pcm}$. In fact, the slowing down of the $14 \mathrm{MeV}$ neutrons requires fine group structure for accurately presenting the neutron spectrum. For the same energy group structure, increasing the anisotropic scattering order results in less effect on the $\mathrm{k}_{\mathrm{S}}$ values compared to the obtained effect for the multiplication factor.

The results presented in Tables 11 to 15 were used to obtain $k_{S}$ with $P_{5} P_{1}$ approximation using 172 energy groups. For this purpose, as already done for the multiplication factor, the results with 53-energy group structure have been corrected as indicated in Tables 16 and 17 for the YALINABooster and -Thermal respectively. The obtained results are compiled in Tables 18 and 19.

For $(\mathrm{d}, \mathrm{t})$ neutron source, the highest $\mathrm{k}_{\mathrm{S}}$ values are obtained in the YALINA-Booster and the lowest values are instead obtained in the YALINA-Thermal. The $\mathrm{k}_{\mathrm{S}}$ value is lower than the $\mathrm{k}_{\text {eff }}$ value for the YALINA-Thermal as shown in Tables 5 and 6 . Because the neutron leakage per fission neutron is increased and the number of fission reaction per source neutron is decreased as shown in Tables 14 and 15 , which explains the lower $k_{s}$ values. Equations. 5 and 6 do practically yield the same values for $\mathrm{k}_{\mathrm{s}}$ as the $\mathrm{k}_{\text {eff }}$ of the assembly approach criticality. 
Table 11.: Neutron Balance per Neutron Source and $k_{S}$ for the YALINA-Booster Using JEF2.2 Nuclear Data Files

\begin{tabular}{|c|c|c|c|c|c|c|}
\hline \multicolumn{7}{|c|}{$(d, t)$ Source } \\
\hline $53 \mathrm{gr}$ & Leakage & Absorption & $(n, x n)$ & $\begin{array}{l}\text { Fission } \\
\text { Source }\end{array}$ & $\mathbf{k}_{\mathrm{s}}\left(\rho_{\mathrm{s}}[\mathrm{pcm}]\right)^{(1)}$ & $\mathrm{k}_{\mathrm{s}}\left(\rho_{\mathrm{s}}[\mathrm{pcm}]\right)^{(2)}$ \\
\hline $\mathrm{SP}_{3} \mathrm{P}_{0}$ & 4.515 & 69.294 & 0.520 & 72.288 & $0.98635(-1384 \mathrm{pcm})$ & $0.98644(-1374 \mathrm{pcm})$ \\
\hline $\mathrm{P}_{3} \mathrm{P}_{0}$ & 4.253 & 67.227 & 0.525 & 70.171 & $0.98894(-1118 \mathrm{pcm})$ & $0.98902(-1110 \mathrm{pcm})$ \\
\hline $\mathrm{P}_{5} \mathrm{P}_{0}$ & 4.676 & 73.513 & 0.515 & 76.706 & $0.98755(-1261 \mathrm{pcm})$ & $0.98763(-1252 \mathrm{pcm})$ \\
\hline $\mathrm{SP}_{3} \mathrm{P}_{1}$ & 4.890 & 84.470 & 0.535 & 87.826 & $0.98875(-1137 \mathrm{pcm})$ & $0.98882(-1131 \mathrm{pcm})$ \\
\hline $172 \mathrm{gr}$ & Leakage & Absorption & $(n, x n)$ & $\begin{array}{l}\text { Fission } \\
\text { Source } \\
\end{array}$ & $k_{s}\left(\rho_{s}[p c m]\right)^{(1)}$ & $k_{s}\left(\rho_{s}[p c m]\right)^{(2)}$ \\
\hline $\mathrm{SP}_{3} \mathrm{P}_{0}$ & 4.714 & 72.403 & 0.580 & 75.538 & $0.98694(-1324 \mathrm{pcm})$ & $0.98703(-1314 \mathrm{pcm})$ \\
\hline \multicolumn{7}{|c|}{ (d,d) Source } \\
\hline $53 \mathrm{gr}$ & Leakage & Absorption & $(n, x n)$ & $\begin{array}{l}\text { Fission } \\
\text { Source }\end{array}$ & $k_{s}\left(\rho_{s}[p c m]\right)^{(1)}$ & $k_{s}\left(\rho_{s}[p c m]\right)^{(2)}$ \\
\hline $\mathrm{SP}_{3} \mathrm{P}_{0}$ & 2.843 & 43.823 & 0.025 & 45.644 & $0.97861(-2186 \mathrm{pcm})$ & $0.97862(-2185 \mathrm{pcm})$ \\
\hline $\mathrm{P}_{3} \mathrm{P}_{0}$ & 2.890 & 45.590 & 0.025 & 47.456 & $0.97939(-2105 \mathrm{pcm})$ & $0.97940(-2104 \mathrm{pcm})$ \\
\hline $\mathrm{P}_{5} \mathrm{P}_{0}$ & 2.999 & 47.277 & 0.020 & 49.252 & $0.98001(-2040 \mathrm{pcm})$ & $0.98002(-2039 \mathrm{pcm})$ \\
\hline $\mathrm{SP}_{3} \mathrm{P}_{1}$ & 3.076 & 53.275 & 0.025 & 55.324 & $0.98220(-1812 \mathrm{pcm})$ & $0.98221(-1811 \mathrm{pcm})$ \\
\hline $172 \mathrm{gr}$ & Leakage & Absorption & $(n, x n)$ & $\begin{array}{l}\text { Fission } \\
\text { Source }\end{array}$ & $\mathbf{k}_{\mathrm{s}}\left(\rho_{\mathrm{s}}[\mathrm{pcm}]\right)^{(1)}$ & $k_{s}\left(\rho_{s}[p c m]\right){ }^{(2)}$ \\
\hline $\mathrm{SP}_{3} \mathrm{P}_{0}$ & 2.854 & 44.022 & 0.025 & 45.854 & $0.97870(-2176 \mathrm{pcm})$ & $0.97871(-2175 \mathrm{pcm})$ \\
\hline \multicolumn{7}{|c|}{ Cf-252 Source } \\
\hline $53 \mathrm{gr}$ & Leakage & Absorption & $(n, x n)$ & $\begin{array}{l}\text { Fission } \\
\text { Source }\end{array}$ & $\mathbf{k}_{\mathrm{S}}\left(\rho_{\mathrm{s}}[\mathrm{pcm}]\right)^{(1)}$ & $k_{S}\left(\rho_{s}[p c m]\right)^{(2)}$ \\
\hline $\mathrm{SP}_{3} \mathrm{P}_{0}$ & 2.753 & 42.743 & 0.020 & 44.471 & $0.97789(-2261 \mathrm{pcm})$ & $0.97790(-2260 \mathrm{pcm})$ \\
\hline $\mathrm{P}_{3} \mathrm{P}_{0}$ & 2.808 & 44.626 & 0.030 & 46.408 & $0.97898(-2147 \mathrm{pcm})$ & $0.97899(-2146 \mathrm{pcm})$ \\
\hline $\mathrm{P}_{5} \mathrm{P}_{0}$ & 2.910 & 46.207 & 0.020 & 48.090 & $0.97949(-2094 \mathrm{pcm})$ & $0.97950(-2093 \mathrm{pcm})$ \\
\hline $\mathrm{SP}_{3} \mathrm{P}_{1}$ & 2.984 & 52.032 & 0.030 & 53.986 & $0.98181(-1853 \mathrm{pcm})$ & $0.98182(-1852 \mathrm{pcm})$ \\
\hline $172 \mathrm{gr}$ & Leakage & Absorption & $(n, x n)$ & $\begin{array}{l}\text { Fission } \\
\text { Source } \\
\end{array}$ & $k_{s}\left(\rho_{s}[p c m]\right)^{(1)}$ & $\mathrm{k}_{\mathrm{s}}\left(\rho_{\mathrm{s}}[\mathrm{pcm}]\right)^{(2)}$ \\
\hline $\mathrm{SP}_{3} \mathrm{P}_{0}$ & 2.759 & 42.871 & 0.030 & 44.604 & $0.97816(-2233 \mathrm{pcm})$ & $0.97818(-2231 \mathrm{pcm})$ \\
\hline
\end{tabular}

(1) Formulation according to Eq. 5; ${ }^{(2)}$ Formulation according to Eq. 6. 
Table 12. Neutron Balance per Neutron Source and $k_{S}$ for the YALINA-Booster Using JEF3.1 Nuclear Data Files

\begin{tabular}{|c|c|c|c|c|c|c|}
\hline \multicolumn{7}{|c|}{$(d, t)$ Source } \\
\hline $53 \mathrm{gr}$ & Leakage & Absorption & $(n, x n)$ & $\begin{array}{l}\text { Fission } \\
\text { Source }\end{array}$ & $\mathrm{k}_{\mathrm{s}}\left(\rho_{\mathrm{s}}[\mathrm{pcm}]\right)^{(1)}$ & $k_{s}\left(\rho_{s}[p c m]\right)^{(2)}$ \\
\hline $\mathrm{SP}_{3} \mathrm{P}_{0}$ & 3.579 & 64.661 & 0.570 & 66.668 & $0.98519(-1503 \mathrm{pcm})$ & $0.98532(-1490 \mathrm{pcm})$ \\
\hline $\mathrm{P}_{3} \mathrm{P}_{0}$ & 3.342 & 62.102 & 0.570 & 64.073 & $0.98765(-1251 \mathrm{pcm})$ & $0.98776(-1240 \mathrm{pcm})$ \\
\hline $\mathrm{P}_{5} \mathrm{P}_{0}$ & 3.644 & 67.336 & 0.565 & 69.447 & $0.98626(-1393 \mathrm{pcm})$ & $0.98637(-1382 \mathrm{pcm})$ \\
\hline $\mathrm{SP}_{3} \mathrm{P}_{1}$ & 3.731 & 77.444 & 0.585 & 79.590 & $0.98760(-1255 \mathrm{pcm})$ & $0.98769(-1246 \mathrm{pcm})$ \\
\hline $172 \mathrm{gr}$ & Leakage & Absorption & $(n, x n)$ & $\begin{array}{l}\text { Fission } \\
\text { Source } \\
\end{array}$ & $k_{s}\left(\rho_{s}[p c m]\right)^{(1)}$ & $k_{s}\left(\rho_{s}[p c m]\right)^{(2)}$ \\
\hline $\mathrm{SP}_{3} \mathrm{P}_{0}$ & 3.675 & 66.374 & 0.600 & 68.447 & $0.98557(-1465 \mathrm{pcm})$ & $0.98569(-1452 \mathrm{pcm})$ \\
\hline \multicolumn{7}{|c|}{ (d,d) Source } \\
\hline $53 \mathrm{gr}$ & Leakage & Absorption & $(n, x n)$ & $\begin{array}{l}\text { Fission } \\
\text { Source }\end{array}$ & $k_{s}\left(\rho_{s}[p c m]\right)^{(1)}$ & $k_{s}\left(\rho_{s}[p c m]\right)^{(2)}$ \\
\hline $\mathrm{SP}_{3} \mathrm{P}_{0}$ & 2.184 & 39.689 & 0.020 & 40.850 & $0.97605(-2454 \mathrm{pcm})$ & $0.97606(-2453 \mathrm{pcm})$ \\
\hline $\mathrm{P}_{3} \mathrm{P}_{0}$ & 2.191 & 40.702 & 0.020 & 41.870 & $0.97660(-2396 \mathrm{pcm})$ & $0.97661(-2395 \mathrm{pcm})$ \\
\hline $\mathrm{P}_{5} \mathrm{P}_{0}$ & 2.264 & 42.022 & 0.025 & 43.262 & $0.97744(-2309 \mathrm{pcm})$ & $0.97745(-2307 \mathrm{pcm})$ \\
\hline $\mathrm{SP}_{3} \mathrm{P}_{1}$ & 2.280 & 47.530 & 0.030 & 48.783 & $0.97997(-2044 \mathrm{pcm})$ & $0.97999(-2042 \mathrm{pcm})$ \\
\hline $172 \mathrm{gr}$ & Leakage & Absorption & $(n, x n)$ & $\begin{array}{l}\text { Fission } \\
\text { Source }\end{array}$ & $\mathbf{k}_{\mathrm{s}}\left(\rho_{\mathrm{s}}[\mathrm{pcm}]\right)^{(1)}$ & $k_{s}\left(\rho_{s}[p c m]\right)^{(2)}$ \\
\hline $\mathrm{SP}_{3} \mathrm{P}_{0}$ & 2.198 & 39.963 & 0.020 & 41.139 & $0.97621(-2437 \mathrm{pcm})$ & $0.97622(-2436 \mathrm{pcm})$ \\
\hline \multicolumn{7}{|c|}{ Cf-252 Source } \\
\hline $53 \mathrm{gr}$ & Leakage & Absorption & $(n, x n)$ & $\begin{array}{l}\text { Fission } \\
\text { Source }\end{array}$ & $k_{s}\left(\rho_{s}[p c m]\right)^{(1)}$ & $\mathrm{k}_{\mathrm{s}}\left(\rho_{\mathrm{s}}[\mathrm{pcm}]\right)^{(2)}$ \\
\hline $\mathrm{SP}_{3} \mathrm{P}_{0}$ & 2.106 & 38.609 & 0.020 & 39.689 & $0.97529(-2533 \mathrm{pcm})$ & $0.97531(-2532 \mathrm{pcm})$ \\
\hline $\mathrm{P}_{3} \mathrm{P}_{0}$ & 2.118 & 39.706 & 0.030 & 40.798 & $0.97617(-2441 \mathrm{pcm})$ & $0.97618(-2440 \mathrm{pcm})$ \\
\hline $\mathrm{P}_{5} \mathrm{P}_{0}$ & 2.186 & 40.939 & 0.020 & 42.098 & $0.97665(-2391 \mathrm{pcm})$ & $0.97666(-2390 \mathrm{pcm})$ \\
\hline $\mathrm{SP}_{3} \mathrm{P}_{1}$ & 2.201 & 46.277 & 0.030 & 47.448 & $0.97936(-2107 \mathrm{pcm})$ & $0.97937(-2106 \mathrm{pcm})$ \\
\hline $172 \mathrm{gr}$ & Leakage & Absorption & $(n, x n)$ & $\begin{array}{l}\text { Fission } \\
\text { Source } \\
\end{array}$ & $k_{s}\left(\rho_{s}[p c m]\right){ }^{(1)}$ & $k_{S}\left(\rho_{s}[p c m]\right)^{(2)}$ \\
\hline $\mathrm{SP}_{3} \mathrm{P}_{0}$ & 2.114 & 38.782 & 0.020 & 39.871 & $0.97540(-2522 \mathrm{pcm})$ & $0.97541(-2521 \mathrm{pcm})$ \\
\hline
\end{tabular}

(1) Formulation according to Eq. 5; ${ }^{(2)}$ Formulation according to Eq. 6. 
Table 13. Neutron Balance per Neutron Source and $k_{S}$ for the YALINA-Booster Using ENDF/B-VI.8 Nuclear Data Files

\begin{tabular}{|c|c|c|c|c|c|c|}
\hline \multicolumn{7}{|c|}{$(d, t)$ Source } \\
\hline $53 \mathrm{gr}$ & Leakage & Absorption & $(n, x n)$ & $\begin{array}{l}\text { Fission } \\
\text { Source }\end{array}$ & $\mathbf{k}_{\mathrm{s}}\left(\rho_{\mathrm{s}}[\mathrm{pcm}]\right)^{(1)}$ & $k_{S}\left(\rho_{s}[p c m]\right)^{(2)}$ \\
\hline $\mathrm{SP}_{3} \mathrm{P}_{0}$ & 3.495 & 63.209 & 0.545 & 65.157 & $0.98485(-1538 \mathrm{pcm})$ & $0.98497(-1526 \mathrm{pcm})$ \\
\hline $\mathrm{P}_{3} \mathrm{P}_{0}$ & 3.276 & 60.935 & 0.550 & 62.852 & $0.98728(-1288 \mathrm{pcm})$ & $0.98739(-1277 \mathrm{pcm})$ \\
\hline $\mathrm{P}_{5} \mathrm{P}_{0}$ & 3.554 & 65.755 & 0.545 & 67.800 & $0.98598(-1422 \mathrm{pcm})$ & $0.98609(-1411 \mathrm{pcm})$ \\
\hline $\mathrm{SP}_{3} \mathrm{P}_{1}$ & 3.633 & 75.507 & 0.555 & 77.581 & $0.98722(-1294 \mathrm{pcm})$ & $0.98731(-1285 \mathrm{pcm})$ \\
\hline $172 \mathrm{gr}$ & Leakage & Absorption & $(n, x n)$ & $\begin{array}{l}\text { Fission } \\
\text { Source }\end{array}$ & $k_{s}\left(\rho_{s}[p c m]\right)^{(1)}$ & $\mathbf{k}_{\mathrm{s}}\left(\rho_{\mathrm{s}}[\mathrm{pcm}]\right)^{(2)}$ \\
\hline $\mathrm{SP}_{3} \mathrm{P}_{0}$ & 3.601 & 65.110 & 0.580 & 67.129 & $0.98530(-1492 \mathrm{pcm})$ & $0.98542(-1479 \mathrm{pcm})$ \\
\hline \multicolumn{7}{|c|}{$(d, d)$ Source } \\
\hline $53 \mathrm{gr}$ & Leakage & Absorption & $(n, x n)$ & $\begin{array}{c}\text { Fission } \\
\text { Source }\end{array}$ & $k_{s}\left(\rho_{s}[p c m]\right)^{(1)}$ & $k_{s}\left(\rho_{s}[p c m]\right)^{(2)}$ \\
\hline $\mathrm{SP}_{3} \mathrm{P}_{0}$ & 2.157 & 39.264 & 0.020 & 40.401 & $0.97584(-2476 \mathrm{pcm})$ & $0.97585(-2475 \mathrm{pcm})$ \\
\hline $\mathrm{P}_{3} \mathrm{P}_{0}$ & 2.164 & 40.248 & 0.020 & 41.391 & $0.97639(-2419 \mathrm{pcm})$ & $0.97640(-2417 \mathrm{pcm})$ \\
\hline $\mathrm{P}_{5} \mathrm{P}_{0}$ & 2.234 & 41.529 & 0.020 & 42.742 & $0.97710(-2344 \mathrm{pcm})$ & $0.97711(-2342 \mathrm{pcm})$ \\
\hline $\mathrm{SP}_{3} \mathrm{P}_{1}$ & 2.248 & 46.943 & 0.025 & 48.167 & $0.97967(-2075 \mathrm{pcm})$ & $0.97968(-2074 \mathrm{pcm})$ \\
\hline $172 \mathrm{gr}$ & Leakage & Absorption & $(n, x n)$ & $\begin{array}{l}\text { Fission } \\
\text { Source }\end{array}$ & $k_{S}\left(\rho_{s}[p c m]\right)^{(1)}$ & $\mathrm{k}_{\mathrm{s}}\left(\rho_{\mathrm{s}}[\mathrm{pcm}]\right)^{(2)}$ \\
\hline $\mathrm{SP}_{3} \mathrm{P}_{0}$ & 2.174 & 39.570 & 0.020 & 40.723 & $0.97602(-2457 \mathrm{pcm})$ & $0.97603(-2456 \mathrm{pcm})$ \\
\hline \multicolumn{7}{|c|}{ Cf-252 Source } \\
\hline $53 \mathrm{gr}$ & Leakage & Absorption & $(n, x n)$ & $\begin{array}{l}\text { Fission } \\
\text { Source }\end{array}$ & $k_{s}\left(\rho_{s}[p c m]\right)^{(1)}$ & $k_{s}\left(\rho_{s}[p c m]\right)^{(2)}$ \\
\hline $\mathrm{SP}_{3} \mathrm{P}_{0}$ & 2.079 & 38.175 & 0.020 & 39.231 & $0.97507(-2557 \mathrm{pcm})$ & $0.97508(-2556 \mathrm{pcm})$ \\
\hline $\mathrm{P}_{3} \mathrm{P}_{0}$ & 2.091 & 39.256 & 0.020 & 40.324 & $0.97571(-2489 \mathrm{pcm})$ & $0.97572(-2488 \mathrm{pcm})$ \\
\hline $\mathrm{P}_{5} \mathrm{P}_{0}$ & 2.156 & 40.439 & 0.020 & 41.570 & $0.97641(-2416 \mathrm{pcm})$ & $0.97642(-2415 \mathrm{pcm})$ \\
\hline $\mathrm{SP}_{3} \mathrm{P}_{1}$ & 2.170 & 45.683 & 0.020 & 46.825 & $0.97895(-2151 \mathrm{pcm})$ & $0.97895(-2150 \mathrm{pcm})$ \\
\hline $172 \mathrm{gr}$ & Leakage & Absorption & $(n, x n)$ & $\begin{array}{l}\text { Fission } \\
\text { Source }\end{array}$ & $\mathbf{k}_{\mathrm{s}}\left(\rho_{\mathrm{s}}[\mathrm{pcm}]\right)^{(1)}$ & $k_{s}\left(\rho_{s}[p c m]\right){ }^{(2)}$ \\
\hline $\mathrm{SP}_{3} \mathrm{P}_{0}$ & 2.091 & 38.400 & 0.020 & 39.467 & $0.97520(-2543 \mathrm{pcm})$ & $0.97522(-2541 \mathrm{pcm})$ \\
\hline
\end{tabular}

(1) Formulation according to Eq. 5; ${ }^{(2)}$ Formulation according to Eq. 6. 
Table 14. Neutron Balance per Neutron Source and $k_{s}$ for the YALINA-Thermal Using JEF3.1 Nuclear Data Files

\begin{tabular}{|c|c|c|c|c|c|c|}
\hline \multicolumn{7}{|c|}{$(d, t)$ Source } \\
\hline $53 \mathrm{gr}$ & Leakage & Absorption & $(n, x n)$ & $\begin{array}{l}\text { Fission } \\
\text { Source }\end{array}$ & $k_{s}\left(\rho_{s}[p c m]\right)^{(1)}$ & $k_{s}\left(\rho_{s}[p c m]\right)^{(2)}$ \\
\hline $\mathrm{SP}_{3} \mathrm{P}_{0}$ & 2.698 & 13.531 & 0.070 & 15.158 & $0.93806(-6603 \mathrm{pcm})$ & $0.93832(-6573 \mathrm{pcm})$ \\
\hline $\mathrm{P}_{3} \mathrm{P}_{0}$ & 2.787 & 14.196 & 0.070 & 15.911 & $0.94077(-6296 \mathrm{pcm})$ & $0.94101(-6269 \mathrm{pcm})$ \\
\hline $\mathrm{P}_{5} \mathrm{P}_{0}$ & 2.890 & 14.837 & 0.075 & 16.654 & $0.94345(-5994 \mathrm{pcm})$ & $0.94369(-5967 \mathrm{pcm})$ \\
\hline $\mathrm{SP}_{3} \mathrm{P}_{1}$ & 2.774 & 14.331 & 0.080 & 16.023 & $0.94118(-6249 \mathrm{pcm})$ & $0.94146(-6218 \mathrm{pcm})$ \\
\hline $\mathrm{P}_{3} \mathrm{P}_{1}$ & 2.930 & 15.532 & 0.085 & 17.380 & $0.94579(-5732 \mathrm{pcm})$ & $0.94604(-5704 \mathrm{pcm})$ \\
\hline $172 \mathrm{gr}$ & Leakage & Absorption & $(n, x n)$ & $\begin{array}{l}\text { Fission } \\
\text { Source }\end{array}$ & $k_{S}\left(\rho_{s}[p c m]\right)^{(1)}$ & $k_{S}\left(\rho_{s}[p c m]\right)^{(2)}$ \\
\hline $\mathrm{SP}_{3} \mathrm{P}_{0}$ & 2.674 & 13.355 & 0.075 & 14.952 & $0.93719(-6702 \mathrm{pcm})$ & $0.93748(-6668 \mathrm{pcm})$ \\
\hline $\mathrm{SP}_{3} \mathrm{P}_{1}$ & 2.759 & 14.224 & 0.085 & 15.896 & $0.94072(-6302 \mathrm{pcm})$ & $0.94101(-6268 \mathrm{pcm})$ \\
\hline \multicolumn{7}{|c|}{$(d, d)$ Source } \\
\hline $53 \mathrm{gr}$ & Leakage & Absorption & $(n, x n)$ & $\begin{array}{l}\text { Fission } \\
\text { Source } \\
\end{array}$ & $k_{s}\left(\rho_{s}[p c m]\right)^{(1)}$ & $k_{s}\left(\rho_{s}[p c m]\right)^{(2)}$ \\
\hline $\mathrm{SP}_{3} \mathrm{P}_{0}$ & 3.477 & 18.994 & 0.000 & 21.468 & $0.95534(-4675 \mathrm{pcm})$ & $0.95534(-4675 \mathrm{pcm})$ \\
\hline $\mathrm{P}_{3} \mathrm{P}_{0}$ & 3.571 & 19.727 & 0.000 & 22.294 & $0.95692(-4502 \mathrm{pcm})$ & $0.95692(-4502 \mathrm{pcm})$ \\
\hline $\mathrm{P}_{5} \mathrm{P}_{0}$ & 3.651 & 20.226 & 0.000 & 22.872 & $0.95796(-4389 \mathrm{pcm})$ & $0.95796(-4389 \mathrm{pcm})$ \\
\hline $\mathrm{SP}_{3} \mathrm{P}_{1}$ & 3.617 & 20.389 & 0.005 & 23.001 & $0.95838(-4343 \mathrm{pcm})$ & $0.95839(-4342 \mathrm{pcm})$ \\
\hline $\mathrm{P}_{3} \mathrm{P}_{1}$ & 3.830 & 22.036 & 0.005 & 24.861 & $0.96136(-4020 \mathrm{pcm})$ & $0.96136(-4019 \mathrm{pcm})$ \\
\hline $172 \mathrm{gr}$ & Leakage & Absorption & $(n, x n)$ & $\begin{array}{l}\text { Fission } \\
\text { Source }\end{array}$ & $k_{s}\left(\rho_{s}[p c m]\right){ }^{(1)}$ & $k_{s}\left(\rho_{s}[p c m]\right){ }^{(2)}$ \\
\hline $\mathrm{SP}_{3} \mathrm{P}_{0}$ & 3.493 & 19.098 & 0.000 & 21.587 & $0.95558(-4649 \mathrm{pcm})$ & $0.95558(-4649 \mathrm{pcm})$ \\
\hline $\mathrm{SP}_{3} \mathrm{P}_{1}$ & 3.650 & 20.629 & 0.005 & 23.275 & $0.95885(-4292 \mathrm{pcm})$ & $0.95886(-4291 \mathrm{pcm})$ \\
\hline \multicolumn{7}{|c|}{ Cf-252 Source } \\
\hline $53 \mathrm{gr}$ & Leakage & Absorption & $(n, x n)$ & $\begin{array}{l}\text { Fission } \\
\text { Source }\end{array}$ & $k_{s}\left(\rho_{s}[p c m]\right)^{(1)}$ & $k_{s}\left(\rho_{s}[p c m]\right){ }^{(2)}$ \\
\hline $\mathrm{SP}_{3} \mathrm{P}_{0}$ & 3.636 & 20.100 & 0.004 & 22.732 & $0.95786(-4400 \mathrm{pcm})$ & $0.95786(-4399 \mathrm{pcm})$ \\
\hline $\mathrm{P}_{3} \mathrm{P}_{0}$ & 3.741 & 20.910 & 0.005 & 23.647 & $0.95945(-4226 \mathrm{pcm})$ & $0.95946(-4225 \mathrm{pcm})$ \\
\hline $\mathrm{P}_{5} \mathrm{P}_{0}$ & 3.837 & 21.512 & 0.005 & 24.344 & $0.96056(-4106 \mathrm{pcm})$ & $0.96057(-4105 \mathrm{pcm})$ \\
\hline $\mathrm{SP}_{3} \mathrm{P}_{1}$ & 3.798 & 21.653 & 0.004 & 24.446 & $0.96067(-4094 \mathrm{pcm})$ & $0.96068(-4093 \mathrm{pcm})$ \\
\hline $\mathrm{P}_{3} \mathrm{P}_{1}$ & 4.034 & 23.460 & 0.005 & 26.489 & $0.96362(-3776 \mathrm{pcm})$ & $0.96362(-3775 \mathrm{pcm})$ \\
\hline $172 \mathrm{gr}$ & Leakage & Absorption & $(n, x n)$ & $\begin{array}{l}\text { Fission } \\
\text { Source }\end{array}$ & $k_{s}\left(\rho_{s}[p c m]\right)^{(1)}$ & $k_{s}\left(\rho_{s}[p c m]\right)^{(2)}$ \\
\hline $\mathrm{SP}_{3} \mathrm{P}_{0}$ & 3.640 & 20.124 & 0.000 & 22.759 & $0.95775(-4412 \mathrm{pcm})$ & $0.95775(-4412 \mathrm{pcm})$ \\
\hline $\mathrm{SP}_{3} \mathrm{P}_{1}$ & 3.818 & 21.801 & 0.000 & 24.614 & $0.96079(-4081 \mathrm{pcm})$ & $0.96079(-4081 \mathrm{pcm})$ \\
\hline
\end{tabular}

(1) Formulation according to Eq. 5; ${ }^{(2)}$ Formulation according to Eq. 6. 
Table 15. Neutron Balance per Neutron Source and $k_{S}$ for the YALINA-Thermal Using ENDF/B-VI.8 Nuclear Data Files

\begin{tabular}{|c|c|c|c|c|c|c|}
\hline \multicolumn{7}{|c|}{$(d, t)$ Source } \\
\hline $53 \mathrm{gr}$ & Leakage & Absorption & $(n, x n)$ & $\begin{array}{l}\text { Fission } \\
\text { Source }\end{array}$ & $k_{s}\left(\rho_{s}[p c m]\right)^{(1)}$ & $k_{s}\left(\rho_{s}[p c m]\right)^{(2)}$ \\
\hline $\mathrm{SP}_{3} \mathrm{P}_{0}$ & 2.606 & 13.000 & 0.065 & 14.538 & $0.93551(-6894 \mathrm{pcm})$ & $0.93578(-6863 \mathrm{pcm})$ \\
\hline $\mathrm{P}_{3} \mathrm{P}_{0}$ & 2.689 & 13.625 & 0.065 & 15.245 & $0.93826(-6581 \mathrm{pcm})$ & $0.93850(-6553 \mathrm{pcm})$ \\
\hline $\mathrm{P}_{5} \mathrm{P}_{0}$ & 2.783 & 14.210 & 0.070 & 15.924 & $0.94094(-6277 \mathrm{pcm})$ & $0.94118(-6249 \mathrm{pcm})$ \\
\hline $\mathrm{SP}_{3} \mathrm{P}_{1}$ & 2.672 & 13.725 & 0.080 & 15.319 & $0.93887(-6511 \mathrm{pcm})$ & $0.93917(-6477 \mathrm{pcm})$ \\
\hline $\mathrm{P}_{3} \mathrm{P}_{1}$ & 2.808 & 14.806 & 0.075 & 16.538 & $0.94287(-6059 \mathrm{pcm})$ & $0.94312(-6032 \mathrm{pcm})$ \\
\hline $172 \mathrm{gr}$ & Leakage & Absorption & $(n, x n)$ & $\begin{array}{l}\text { Fission } \\
\text { Source }\end{array}$ & $k_{s}\left(\rho_{s}[p c m]\right)^{(1)}$ & $k_{S}\left(\rho_{s}[p c m]\right)^{(2)}$ \\
\hline $\mathrm{SP}_{3} \mathrm{P}_{0}$ & 2.579 & 12.811 & 0.075 & 14.317 & $0.93482(-6973 \mathrm{pcm})$ & $0.93514(-6936 \mathrm{pcm})$ \\
\hline $\mathrm{SP}_{3} \mathrm{P}_{1}$ & 2.652 & 13.594 & 0.080 & 15.164 & $0.93798(-6612 \mathrm{pcm})$ & $0.93829(-6577 \mathrm{pcm})$ \\
\hline \multicolumn{7}{|c|}{$(d, d)$ Source } \\
\hline $53 \mathrm{gr}$ & Leakage & Absorption & $(n, x n)$ & $\begin{array}{l}\text { Fission } \\
\text { Source } \\
\end{array}$ & $k_{s}\left(\rho_{s}[p c m]\right)^{(1)}$ & $k_{s}\left(\rho_{s}[p c m]\right)^{(2)}$ \\
\hline $\mathrm{SP}_{3} \mathrm{P}_{0}$ & 3.375 & 18.410 & 0.000 & 20.781 & $0.95394(-4828 \mathrm{pcm})$ & $0.95394(-4828 \mathrm{pcm})$ \\
\hline $\mathrm{P}_{3} \mathrm{P}_{0}$ & 3.460 & 19.086 & 0.000 & 21.542 & $0.95549(-4658 \mathrm{pcm})$ & $0.95549(-4658 \mathrm{pcm})$ \\
\hline $\mathrm{P}_{5} \mathrm{P}_{0}$ & 3.533 & 19.546 & 0.005 & 22.076 & $0.95672(-4523 \mathrm{pcm})$ & $0.95673(-4522 \mathrm{pcm})$ \\
\hline $\mathrm{SP}_{3} \mathrm{P}_{1}$ & 3.502 & 19.718 & 0.005 & 22.216 & $0.95699(-4495 \mathrm{pcm})$ & $0.95699(-4494 \mathrm{pcm})$ \\
\hline $\mathrm{P}_{3} \mathrm{P}_{1}$ & 3.696 & 21.237 & 0.005 & 23.929 & $0.95992(-4175 \mathrm{pcm})$ & $0.95993(-4174 \mathrm{pcm})$ \\
\hline $172 \mathrm{gr}$ & Leakage & Absorption & $(n, x n)$ & $\begin{array}{l}\text { Fission } \\
\text { Source }\end{array}$ & $k_{s}\left(\rho_{s}[p c m]\right){ }^{(1)}$ & $k_{s}\left(\rho_{s}[p c m]\right){ }^{(2)}$ \\
\hline $\mathrm{SP}_{3} \mathrm{P}_{0}$ & 3.388 & 18.500 & 0.000 & 20.885 & $0.95417(-4803 \mathrm{pcm})$ & $0.95417(-4803 \mathrm{pcm})$ \\
\hline $\mathrm{SP}_{3} \mathrm{P}_{1}$ & 3.532 & 19.934 & 0.000 & 22.462 & $0.95723(-4468 \mathrm{pcm})$ & $0.95723(-4468 \mathrm{pcm})$ \\
\hline \multicolumn{7}{|c|}{ Cf-252 Source } \\
\hline $53 \mathrm{gr}$ & Leakage & Absorption & $(n, x n)$ & $\begin{array}{l}\text { Fission } \\
\text { Source }\end{array}$ & $k_{s}\left(\rho_{s}[p c m]\right)^{(1)}$ & $k_{s}\left(\rho_{s}[p c m]\right)^{(2)}$ \\
\hline $\mathrm{SP}_{3} \mathrm{P}_{0}$ & 3.530 & 19.493 & 0.004 & 22.019 & $0.95656(-4541 \mathrm{pcm})$ & $0.95657(-4541 \mathrm{pcm})$ \\
\hline $\mathrm{P}_{3} \mathrm{P}_{0}$ & 3.625 & 20.244 & 0.004 & 22.865 & $0.95809(-4374 \mathrm{pcm})$ & $0.95810(-4373 \mathrm{pcm})$ \\
\hline $\mathrm{P}_{5} \mathrm{P}_{0}$ & 3.714 & 20.797 & 0.004 & 23.507 & $0.95919(-4255 \mathrm{pcm})$ & $0.95919(-4254 \mathrm{pcm})$ \\
\hline $\mathrm{SP}_{3} \mathrm{P}_{1}$ & 3.677 & 20.948 & 0.004 & 23.621 & $0.95937(-4235 \mathrm{pcm})$ & $0.95937(-4235 \mathrm{pcm})$ \\
\hline $\mathrm{P}_{3} \mathrm{P}_{1}$ & 3.894 & 22.623 & 0.004 & 25.513 & $0.96226(-3923 \mathrm{pcm})$ & $0.96226(-3922 \mathrm{pcm})$ \\
\hline $172 \mathrm{gr}$ & Leakage & Absorption & $(n, x n)$ & $\begin{array}{l}\text { Fission } \\
\text { Source }\end{array}$ & $k_{s}\left(\rho_{s}[p c m]\right)^{(1)}$ & $\mathrm{k}_{\mathrm{s}}\left(\rho_{\mathrm{s}}[\mathrm{pcm}]\right)^{(2)}$ \\
\hline $\mathrm{SP}_{3} \mathrm{P}_{0}$ & 3.533 & 19.515 & 0.010 & 22.044 & $0.95686(-4509 \mathrm{pcm})$ & $0.95688(-4507 \mathrm{pcm})$ \\
\hline $\mathrm{SP}_{3} \mathrm{P}_{1}$ & 3.696 & 21.085 & 0.000 & 23.777 & $0.95947(-4224 \mathrm{pcm})$ & $0.95947(-4224 \mathrm{pcm})$ \\
\hline
\end{tabular}

(1) Formulation according to Eq. 5; ${ }^{(2)}$ Formulation according to Eq. 6. 
Table 16. $\rho_{S}$ Results for the YALINA-Booster

\begin{tabular}{|c|c|c|c|c|c|c|c|}
\hline \multirow{2}{*}{ Source } & \multirow{2}{*}{ Calculation Parameters } & \multicolumn{2}{|c|}{ JEF2.2 } & \multicolumn{2}{|c|}{ JEF3.1 } & \multicolumn{2}{|c|}{ ENDF/B-VI.8 } \\
\hline & & $\rho_{\mathrm{s}}[\mathrm{pcm}]^{(1)}$ & $\rho_{\mathrm{s}}[\mathrm{pcm}]^{(2)}$ & $\rho_{\mathrm{s}}[\mathrm{pcm}]^{(1)}$ & $\rho_{\mathrm{s}}[\mathrm{pcm}]^{(2}$ & $\rho_{s}[p c m]^{(1)}$ & $\rho_{s}[p c m]^{(2)}$ \\
\hline \multirow{4}{*}{$(d, t)$} & $53 g r-S_{3} P_{1}$ & -1137 & -1131 & -1255 & -1246 & -1294 & -1285 \\
\hline & $172 \mathrm{gr} \mathrm{SP}{ }_{3} \mathrm{P}_{0}-53 \mathrm{gr} \mathrm{SP_{3 } \mathrm { P } _ { 0 }}$ & 60 & 61 & 38 & 38 & 46 & 46 \\
\hline & $53 g r P_{5} P_{0}-53 g r P_{3} P_{0}$ & 123 & 122 & 110 & 108 & 116 & 115 \\
\hline & 172gr $P_{5} P_{1}$ & -954 & -948 & -1107 & -1100 & -1132 & -1124 \\
\hline \multirow{4}{*}{$(d, d)$} & Calculated: $53 \mathrm{gr}-\mathrm{SP}_{3} \mathrm{P}_{1}$ & -1812 & -1811 & -2044 & -2042 & -2075 & -2074 \\
\hline & $172 \mathrm{gr} \mathrm{SP}{ }_{3} \mathrm{P}_{0}-53 \mathrm{gr} \mathrm{SP_{3 } \mathrm { P } _ { 0 }}$ & 10 & 10 & 17 & 17 & 19 & 19 \\
\hline & 53gr $\mathrm{P}_{5} \mathrm{P}_{0}-53 \mathrm{gr} \mathrm{SP}_{3} \mathrm{P}_{0}$ & 146 & 146 & 145 & 146 & 133 & 133 \\
\hline & 172gr $P_{5} P_{1}$ & -1656 & -1655 & -1881 & -1880 & -1923 & -1922 \\
\hline \multirow{4}{*}{ Cf-252 } & Calculated: $53 \mathrm{gr}-\mathrm{SP}_{3} \mathrm{P}_{1}$ & -1853 & -1852 & -2107 & -2106 & -2151 & -2150 \\
\hline & $172 \mathrm{gr} \mathrm{SP}{ }_{3} \mathrm{P}_{0}-53 \mathrm{gr} \mathrm{SP_{3 } \mathrm { P } _ { 0 }}$ & 28 & 29 & 11 & 11 & 14 & 14 \\
\hline & $53 g r P_{5} P_{0}-53 g r P_{3} P_{0}$ & 167 & 167 & 142 & 142 & 141 & 141 \\
\hline & 172gr $P_{5} P_{1}$ & -1658 & -1656 & -1954 & -1953 & -1995 & -1994 \\
\hline
\end{tabular}

(1) Formulation according to Eq. 5; (2) Formulation according to Eq. 6.

Table 17. $\rho_{\mathrm{S}}$ Results for the YALINA-Thermal

\begin{tabular}{|c|c|c|c|c|c|}
\hline \multirow{2}{*}{ Source } & \multirow{2}{*}{ Calculation Parameters } & \multicolumn{2}{|c|}{\begin{tabular}{|l|} 
JEF3.1 \\
\end{tabular}} & \multicolumn{2}{|c|}{ ENDF/B-VI.8 } \\
\hline & & $\rho_{\mathrm{s}}[\mathrm{pcm}]^{(1)}$ & $\rho_{\mathrm{s}}[\mathrm{pcm}]^{(2)}$ & $\rho_{\mathrm{s}}[\mathrm{pcm}]^{(1)}$ & $\rho_{\mathrm{s}}[\mathrm{pcm}]^{(2)}$ \\
\hline \multirow{4}{*}{$(d, t)$} & $53 g r-P_{3} P_{1}$ & -5732 & -5704 & -6059 & -6032 \\
\hline & $172 \mathrm{gr} \mathrm{SP} \mathrm{P}_{1}-53 \mathrm{gr} \mathrm{SP_{3 } \mathrm { P } _ { 1 }}$ & -53 & -50 & -101 & -100 \\
\hline & $53 g r P_{5} P_{0}-53 g r P_{3} P_{0}$ & 302 & 302 & 304 & 303 \\
\hline & 172gr $P_{5} P_{1}$ & -5482 & -5453 & -5856 & -5828 \\
\hline \multirow{4}{*}{$(d, d)$} & Calculated: 53gr $-\mathrm{P}_{3} \mathrm{P}_{1}$ & -4020 & -4019 & -4175 & -4174 \\
\hline & $172 \mathrm{gr} \mathrm{SP}{ }_{3} \mathrm{P}_{1}-53 \mathrm{gr} \mathrm{SP_{3 } \mathrm { P } _ { 1 }}$ & 51 & 51 & 27 & 26 \\
\hline & $53 g r P_{5} P_{0}-53 g r P_{3} P_{0}$ & 113 & 113 & 135 & 136 \\
\hline & 172gr $P_{5} P_{1}$ & -3855 & -3854 & -4014 & -4013 \\
\hline \multirow{4}{*}{ Cf-252 } & $53 g r-P_{3} P_{1}$ & -3776 & -3775 & -3923 & -3922 \\
\hline & $172 \mathrm{gr} \mathrm{SP} \mathrm{P}_{1}-53 \mathrm{gr} \mathrm{SP_{3 } \mathrm { P } _ { 1 }}$ & 12 & 12 & 11 & 10 \\
\hline & $53 g r P_{5} P_{0}-53 g r P_{3} P_{0}$ & 120 & 120 & 119 & 119 \\
\hline & $172 \mathrm{gr} \mathrm{P}_{5} \mathrm{P}_{1}$ & -3643 & -3643 & -3793 & -3793 \\
\hline
\end{tabular}

(1) Formulation according to Eq. 5; ${ }^{(2)}$ Formulation according to Eq. 6.

Table 18.: $\mathrm{k}_{\mathrm{S}}\left(\rho_{\mathrm{S}}\right)$ for the YALINA-Booster calculated with 172 Energy Group Set and $\mathrm{P}_{5} \mathrm{P}_{1}$ Approximations

Using Different Nuclear Data Files

\begin{tabular}{|c|c|c|c|c|c|c|}
\hline \multirow{2}{*}{ Source } & \multicolumn{2}{|c|}{ JEF2.2 } & \multicolumn{2}{|c|}{ JEF3.1 } & \multicolumn{2}{|c|}{ ENDF/B-VI.8 } \\
\hline & $\mathbf{k}_{\mathrm{S}}\left(\rho_{\mathrm{S}}\right)^{(1)}$ & $k_{S}\left(\rho_{S}\right)^{(2)}$ & $k_{S}\left(\rho_{S}\right)^{(1)}$ & $k_{\mathrm{S}}\left(\rho_{\mathrm{S}}\right)^{(2)}$ & $k_{S}\left(\rho_{S}\right)^{(1)}$ & $k_{S}\left(\rho_{S}\right)^{(2)}$ \\
\hline$(d, t)$ & $\begin{array}{c}0.99055 \\
(-954 \mathrm{pcm})\end{array}$ & $\begin{array}{c}0.99061 \\
(-948 \mathrm{pcm})\end{array}$ & $\begin{array}{c}0.98905 \\
(-1107 \mathrm{pcm})\end{array}$ & $\begin{array}{c}0.98912 \\
(-1100 \mathrm{pcm})\end{array}$ & $\begin{array}{c}0.98881 \\
(-1132 \mathrm{pcm})\end{array}$ & $\begin{array}{c}0.98889 \\
(-1124 \mathrm{pcm})\end{array}$ \\
\hline$(\mathrm{d}, \mathrm{d})$ & $\begin{array}{c}0.98371 \\
(-1656 \mathrm{pcm}) \\
\end{array}$ & $\begin{array}{c}0.98372 \\
(-1655 \mathrm{pcm}) \\
\end{array}$ & $\begin{array}{c}0.98153 \\
(-1881 \mathrm{pcm}) \\
\end{array}$ & $\begin{array}{c}0.98155 \\
(-1880 \mathrm{pcm}) \\
\end{array}$ & $\begin{array}{c}0.98113 \\
(-1923 \mathrm{pcm}) \\
\end{array}$ & $\begin{array}{c}0.98114 \\
(-1922 \mathrm{pcm}) \\
\end{array}$ \\
\hline Cf-252 & $\begin{array}{c}0.98369 \\
(-1658 \mathrm{pcm})\end{array}$ & $\begin{array}{c}0.98371 \\
(-1656 \mathrm{pcm})\end{array}$ & $\begin{array}{c}0.98083 \\
(-1954 \mathrm{pcm})\end{array}$ & $\begin{array}{c}0.98084 \\
(-1953 \mathrm{pcm})\end{array}$ & $\begin{array}{c}0.98044 \\
(-1995 \mathrm{pcm})\end{array}$ & $\begin{array}{c}0.98045 \\
(-1994 \mathrm{pcm})\end{array}$ \\
\hline
\end{tabular}

(1) Formulation according to Eq. 5; ${ }^{(2)}$ Formulation according to Eq. 6. 
Table 19. $k_{\mathrm{S}}\left(\rho_{\mathrm{S}}\right)$ for the YALINA-Thermal calculated with 172 Energy Group Set and $\mathrm{P}_{5} \mathrm{P}_{1}$ Approximations

Using Different Nuclear Data Files

\begin{tabular}{|c|c|c|c|c|}
\hline \multirow{2}{*}{ Source } & \multicolumn{2}{|c|}{ JEF3.1 } & \multicolumn{2}{|c|}{ ENDF/B-VI.8 } \\
\hline & $\mathrm{k}_{\mathrm{S}}\left(\rho_{\mathrm{S}}\right)^{(1)}$ & $k_{\mathrm{S}}\left(\rho_{\mathrm{S}}\right)^{(2)}$ & $\mathrm{k}_{\mathrm{S}}\left(\rho_{\mathrm{s}}\right)^{(1)}$ & $\mathrm{k}_{\mathrm{S}}\left(\rho_{\mathrm{S}}\right)^{(2)}$ \\
\hline$(d, t)$ & $\begin{array}{c}0.94803 \\
(-5482 \mathrm{pcm})\end{array}$ & $\begin{array}{c}0.94829 \\
(-5453 \mathrm{pcm})\end{array}$ & $\begin{array}{c}0.94468 \\
(-5856 \mathrm{pcm})\end{array}$ & $\begin{array}{c}0.94493 \\
(-5828 \mathrm{pcm})\end{array}$ \\
\hline$(d, d)$ & $\begin{array}{c}0.96288 \\
(-3855 \mathrm{pcm})\end{array}$ & $\begin{array}{c}0.96289 \\
(-3854 \mathrm{pcm})\end{array}$ & $\begin{array}{c}0.96141 \\
(-4014 \mathrm{pcm})\end{array}$ & $\begin{array}{c}0.96142 \\
(-4013 \mathrm{pcm})\end{array}$ \\
\hline Cf-252 & $\begin{array}{c}0.96485 \\
(-3643 \mathrm{pcm})\end{array}$ & $\begin{array}{c}0.96485 \\
(-3643 \mathrm{pcm})\end{array}$ & $\begin{array}{c}0.96346 \\
(-3793 \mathrm{pcm})\end{array}$ & $\begin{array}{c}0.96346 \\
(-3793 \mathrm{pcm})\end{array}$ \\
\hline
\end{tabular}

(1) Formulation according to Eq. 5 ; ${ }^{(2)}$ Formulation according to Eq. 6.

\section{VI.3. Kinetic Parameters}

The KIN3D module implemented in the ERANOS version 2.1 has been used to determine the kinetic parameters $\beta_{\text {eff }}$ and $\Lambda_{\text {eff }}$ using the three dimensional geometrical model according to Eqs. 1 and 2 . In the present study, the unweighted kinetic parameters have been also calculated by setting $\Phi^{*}=1$ in Eqs. 1 and 2. First, the kinetic parameters have been determined using only neutron fluxes calculated in absence of the source term and obtained with the JEF2.2, JEF3.1 and ENDF/B-VI.8 data libraries for the YALINA-Booster and JEF3.1 and ENDF/B-VI.8 for the YALINA-Thermal.

The delayed neutron data were taken from ENDF/B nuclear data files. These data are given in Appendix E, which include the decay constants, the delayed neutron number per fission reaction $\left(\beta^{v}\right)$, and the delayed neutron spectrum. ERANOS inputs require to provide the total spectra of the delayed neutrons, while ENDF/B data provide delayed neutron spectrum by family group per each isotope. As consequence, the spectra presented in Tables 37 and 38 of Appendix $E$ are obtained by combining the U-235 and U-238 delayed neutron spectra with the respective fission reaction fraction in the YALINA configurations under consideration.

The obtained results for the kinetic parameters are presented in Tables 20 to 23 for the YALINABooster and -Thermal. For comparison, the values obtained in RZ geometry with the $S_{n}$ code BISTRO of ERANOS, are also presented. Decimals are reported only for distinguishing the results.

Table 20. Calculated $\beta_{\text {eff }}$ Values for the YALINA-Booster

\begin{tabular}{|c|c|c|c|}
\hline Nuclear Data Library & JEF2.2 & JEF3.1 & ENDF/B-VI.8 \\
\hline$\beta^{(a)}[p c m]-R Z$ & 695.4 & 695.6 & 695.6 \\
\hline$\beta_{\text {eff }}^{(b)}[p c m]-K I N 3 D$ & 752.8 & 753.3 & 753.4 \\
\hline$\beta_{\text {eff }}^{(b)}[p c m]-R Z$ & 751.1 & 752.1 & 752.2 \\
\hline
\end{tabular}


Table 21. Calculated $\beta_{\text {eff }}$ Values for the YALINA-Thermal

\begin{tabular}{|c|c|c|}
\hline Nuclear Data Library & JEF3.1 & ENDF/B-VI.8 \\
\hline$\beta^{(a)}[p c m]-R Z$ & 692.1 & 692.0 \\
\hline$\beta_{\text {eff }}^{(b)}[p c m]-$ KIN3D & 779.1 & 779.2 \\
\hline$\beta_{\text {eff }}^{(b)}[p c m]-R Z$ & 775.2 & 775.3 \\
\hline
\end{tabular}

(a) Unweighted;

(b) Weighted by the homogeneous adjoint flux.

Table 22. Calculated $\Lambda_{\text {eff }}$ Values for the YALINA-Booster

\begin{tabular}{|c||c|c|c|}
\hline Nuclear Data Library & JEF2.2 & JEF3.1 & ENDF/B-VI.8 \\
\hline \hline$\wedge^{(\mathrm{a})}[\mu \mathrm{s}]-\mathrm{RZ}$ & 62.6 & 70.2 & 70.3 \\
\hline \hline$\wedge_{\mathrm{eff}}^{(\mathrm{b})}[\mu \mathrm{s}]-\mathrm{KIN} 3 \mathrm{D}$ & 47.4 & 50.4 & 50.3 \\
\hline$\wedge_{\mathrm{eff}}^{(\mathrm{b})}[\mu \mathrm{s}]-\mathrm{RZ}$ & 45.9 & 47.9 & 47.7 \\
\hline
\end{tabular}

(a) Unweighted;

(b) Weighted by the homogeneous adjoint flux.

Table 23. Calculated $\Lambda_{\text {eff }}$ Values for the YALINA-Thermal

\begin{tabular}{|c|c|c|}
\hline \multicolumn{1}{|c||}{ Nuclear Data Library } & JEF3.1 & ENDF/B-VI.8 \\
\hline \hline$\wedge^{(\mathrm{a})}[\mu \mathrm{s}]-\mathrm{RZ}$ & 206.3 & 207.7 \\
\hline$\wedge_{\mathrm{eff}}^{(\mathrm{b})}[\mu \mathrm{s}]-\mathrm{KIN} 3 \mathrm{D}$ & 87.0 & 87.5 \\
\hline$\wedge_{\mathrm{eff}}^{(\mathrm{b})}[\mu \mathrm{s}]-\mathrm{RZ}$ & 79.0 & 79.4 \\
\hline
\end{tabular}

(a) Unweighted;

(b) Weighted by the homogeneous adjoint flux.

The obtained results of Tables 20 to 23 show the following conclusions:

- The use of the three libraries JEF2.2, JEF3.1 and ENDFB-VI.8 produce similar results for the calculated kinetic parameter values;

- As expected, the RZ model is able to provide an accurate estimation of $\beta_{\text {eff }}$ and $\Lambda_{\text {eff }}$.

As previously discussed, the above results have been obtained using direct and adjoint neutron fluxes calculated in absence of the source term in the equations for $\beta_{\text {eff }}$ and $\Lambda_{\text {eff. }}$ The kinetic parameters have also obtained using a direct flux from the solution of the source driven equation $A \Phi_{S}=F \Phi_{S}+S$ and an adjoint flux solution of the transport equation $\mathrm{A} \Phi_{\mathrm{S}}^{*}=\mathrm{F} \Phi_{\mathrm{S}}^{*}+v \Sigma_{\mathrm{f}}$ as a weighting function. VARIANT computer code has the capability to solve a direct equation with external neutron source but it does not have the capability to solve an adjoint equation with external neutron source. It is possible with the BISTRO computer code to obtain the adjoint flux with an external neutron source. As a consequence, the RZ model is used to obtain the kinetic parameters with different external neutron sources. The previous results showed that the kinetic parameters from the use of the three dimensional model (XYZ geometry) and the two dimensional model (RZ geometry) are similar. 
Table 24. Calculated $\beta_{\text {eff }}[\mathrm{pcm}$ ] of the YALINA Configurations with RZ Geometry

\begin{tabular}{|c|c|c|c|c|c|}
\hline YALINA Configuration & \multicolumn{3}{|c|}{ Booster } & \multicolumn{2}{|c|}{ Thermal } \\
\hline Nuclear Data Library & JEF2.2 & JEF3.1 & $\begin{array}{l}\text { ENDF/B- } \\
\text { VI.8 }\end{array}$ & JEF3.1 & $\begin{array}{l}\text { ENDF/B- } \\
\text { VI.8 }\end{array}$ \\
\hline A - No external neutron source - Unweighted & 695.4 & 695.6 & 695.6 & 692.1 & 692.0 \\
\hline $\begin{array}{l}\text { B - No external neutron source - Weighted } \\
\text { with Homogeneous Adjoint Flux }\end{array}$ & 751.1 & 752.1 & 752.2 & 775.2 & 775.3 \\
\hline C - $(\mathrm{d}, \mathrm{t})$ neutron source - Unweighted & 694.7 & 694.7 & 694.7 & 692.9 & 692.8 \\
\hline $\begin{array}{l}D \text { - }(\mathrm{d}, \mathrm{t}) \text { neutron source - Weighted with } \\
\text { Homogeneous Adjoint Flux }\end{array}$ & 749.0 & 749.3 & 749.3 & 776.5 & 776.7 \\
\hline $\begin{array}{l}\mathrm{E}-(\mathrm{d}, \mathrm{t}) \text { neutron source }- \text { Weighted with } \\
\text { Inhomogeneous Adjoint Flux }\end{array}$ & 749.0 & 749.3 & 749.3 & 776.0 & 776.1 \\
\hline F - $(d, d)$ neutron source - Unweighted & 695.5 & 695.7 & 695.7 & 692.2 & 692.1 \\
\hline $\begin{array}{l}\text { G - (d,d) neutron source - Weighted with } \\
\text { Homogeneous Adjoint Flux }\end{array}$ & 750.4 & 751.1 & 751.2 & 775.9 & 776.1 \\
\hline $\begin{array}{l}\mathrm{H}-(\mathrm{d}, \mathrm{d}) \text { neutron source }- \text { Weighted with } \\
\text { Inhomogeneous Adjoint Flux }\end{array}$ & 750.4 & 751.0 & 751.1 & 775.3 & 775.4 \\
\hline I - Cf neutron source - Unweighted & 695.3 & 695.5 & 695.6 & 692.1 & 692.0 \\
\hline $\begin{array}{l}\mathrm{J} \text { - Cf neutron source }- \text { Weighted with } \\
\text { Homogeneous Adjoint Flux }\end{array}$ & 750.1 & 750.8 & 750.9 & 775.8 & 775.9 \\
\hline $\begin{array}{l}\text { K - Cf neutron source }- \text { Weighted with } \\
\text { Inhomogeneous Adjoint Flux }\end{array}$ & 750.1 & 750.7 & 750.8 & 775.1 & 775.3 \\
\hline
\end{tabular}

Table 25. Calculated $\Lambda_{\text {eff }}[\mu \mathrm{s}]$ for the YALINA Configuration in RZ Geometry

\begin{tabular}{|c|c|c|c|c|c|}
\hline YALINA Configuration & \multicolumn{3}{|c|}{ YALINA-Booster } & \multicolumn{2}{|c|}{ YALINA-Thermal } \\
\hline Nuclear Data Library & JEF2.2 & JEF3.1 & $\begin{array}{l}\text { ENDF/B- } \\
\text { VI.8 } \\
\end{array}$ & JEF3.1 & $\begin{array}{l}\text { ENDF/B- } \\
\text { VI.8 } \\
\end{array}$ \\
\hline A - No external neutron source - Unweighted & 62.6 & 70.2 & 70.3 & 206.3 & 207.7 \\
\hline $\begin{array}{l}\text { B - No external neutron source - Weighted } \\
\text { with Homogeneous Adjoint Flux }\end{array}$ & 45.9 & 47.9 & 47.7 & 79.0 & 79.4 \\
\hline$C$ - $(d, t)$ neutron source - Unweighted & 60.4 & 66.9 & 66.9 & 204.7 & 206.1 \\
\hline $\begin{array}{l}D-(d, t) \text { neutron source - Weighted with } \\
\text { Homogeneous Adjoint Flux }\end{array}$ & 44.2 & 45.6 & 45.4 & 78.4 & 78.8 \\
\hline $\begin{array}{l}\mathrm{E}-(\mathrm{d}, \mathrm{t}) \text { neutron source }- \text { Weighted with } \\
\text { Inhomogeneous Adjoint Flux }\end{array}$ & 44.4 & 45.9 & 45.7 & 78.8 & 79.3 \\
\hline F - $(d, d)$ neutron source - Unweighted & 60.4 & 67.0 & 66.9 & 200.7 & 201.8 \\
\hline $\begin{array}{l}\text { G - (d,d) neutron source - Weighted with } \\
\text { Homogeneous Adjoint Flux }\end{array}$ & 44.3 & 45.7 & 45.5 & 78.2 & 78.5 \\
\hline $\begin{array}{l}\mathrm{H}-(\mathrm{d}, \mathrm{d}) \text { neutron source }- \text { Weighted with } \\
\text { Inhomogeneous Adjoint Flux }\end{array}$ & 44.5 & 46.0 & 45.8 & 78.5 & 78.9 \\
\hline I - Cf neutron source - Unweighted & 60.4 & 66.9 & 66.9 & 199.3 & 200.3 \\
\hline $\begin{array}{l}\text { J - Cf neutron source - Weighted with } \\
\text { Homogeneous Adjoint Flux }\end{array}$ & 44.3 & 45.7 & 45.5 & 78.0 & 78.3 \\
\hline $\begin{array}{l}\text { K - Cf neutron source - Weighted with } \\
\text { Inhomogeneous Adjoint Flux }\end{array}$ & 44.5 & 46.0 & 45.8 & 78.3 & 78.7 \\
\hline
\end{tabular}


The results of Tables 24 and 25 show that the use of source dependent fluxes to calculate the kinetic parameters has a small impact on their values. This implies that the external neutron sources in the YALINA configurations do not excite the high order harmonics especially in the case of the adjoint solution because the source term is distributed like the fission neutron source, $v \Sigma_{\mathrm{f}}$. The change in the kinetic parameter values due to the use of external neutron source are given in Tables 26 and 27 . By applying the corrections listed in Tables 26 and 27 to the values calculated in 3D geometry with KIN3D from Tables 20 to 23, the final results are listed in Tables 28 and 29.

Table 26. $\Delta \beta_{\text {eff }}$ [pcm] Due to the Use of Different External Neutron Source Relative to the case without External Neutron Source with RZ Geometry

\begin{tabular}{|c||c|c|c||c|c||}
\hline YALINA Configuration & \multicolumn{3}{|c||}{ YALINA-Booster } & \multicolumn{2}{c||}{ YALINA-Thermal } \\
\hline \hline Nuclear Data Library & JEF2.2 & JEF3.1 & ENDF/B-VI.8 & JEF3.1 & ENDF/B-VI.8 \\
\hline \hline$\Delta \beta_{\text {eff }}[\mathrm{pcm}]$ (case E - caseB) & -2.1 & -2.8 & -3.0 & 0.8 & 0.8 \\
\hline \hline$\Delta \beta_{\text {eff }}[\mathrm{pcm}]$ (case H - caseB) & -0.7 & -1.1 & -1.1 & 0.1 & 0.1 \\
\hline \hline$\Delta \beta_{\text {eff }}[\mathrm{pcm}]$ (case $\mathrm{K}-$ caseB) & -1.0 & -1.4 & -1.5 & -0.1 & -0.1 \\
\hline \hline
\end{tabular}

Table 27. $\Delta \bigwedge_{\text {eff }}[\mu \mathrm{s}]$ Due to the Use of Different External Neutron Source Relative to the case without External Neutron Source with RZ Geometry

\begin{tabular}{|c||c|c|c||c|c||}
\hline \multicolumn{1}{|c||}{ YALINA Configuration } & \multicolumn{3}{|c||}{ YALINA-Booster } & \multicolumn{2}{c||}{ YALINA-Thermal } \\
\hline \hline Nuclear Data Library & JEF2.2 & JEF3.1 & ENDF/B-VI.8 & JEF3.1 & ENDF/B-VI.8 \\
\hline \hline$\wedge_{\text {eff }}[\mu \mathrm{s}]$ (case E - caseB) & -1.5 & -1.9 & -2.0 & -0.2 & -0.2 \\
\hline$\Delta \wedge_{\text {eff }}[\mu \mathrm{s}]$ (case H - caseB) & -1.4 & -1.9 & -2.0 & -0.5 & -0.5 \\
\hline \hline$\Delta \wedge_{\text {eff }}[\mu \mathrm{s}]$ (case K- caseB) & -1.4 & -1.9 & -2.0 & -0.6 & -0.7 \\
\hline
\end{tabular}

Table 28. ßeff [pcm] Adjoint Flux Weighted Values for the YALINA Configurations

\begin{tabular}{|c||c|c|c||c|c||}
\hline \multicolumn{1}{||c||}{ YALINA Configuration } & \multicolumn{3}{|c||}{ Booster } & \multicolumn{2}{c||}{ Thermal } \\
\hline \hline Nuclear Data Library & JEF2.2 & JEF3.1 & ENDF/B-VI.8 & JEF3.1 & ENDF/B-VI.8 \\
\hline \hline (d,t) neutron source & 750.7 & 750.4 & 750.4 & 779.8 & 780.0 \\
\hline (d,d) neutron source & 752.0 & 752.2 & 752.2 & 779.2 & 779.3 \\
\hline Cf neutron source & 751.8 & 751.8 & 751.9 & 779.0 & 779.2 \\
\hline
\end{tabular}


Table 29. $\wedge_{\text {eff }}[\mu \mathrm{s}]$ Adjoint Flux Weighted Values for the YALINA Configurations

\begin{tabular}{|c||c|c|c||c|c||}
\hline \multicolumn{1}{||||}{ YALINA Configuration } & \multicolumn{3}{|c||}{ Booster } & \multicolumn{2}{c||}{ Thermal } \\
\hline \hline Nuclear Data Library & JEF2.2 & JEF3.1 & ENDF/B-VI.8 & JEF3.1 & ENDF/B-VI.8 \\
\hline \hline$(\mathrm{d}, \mathrm{t})$ neutron source & 45.9 & 48.5 & 48.3 & 86.9 & 87.30 \\
\hline (d,d) neutron source & 46.0 & 48.5 & 48.3 & 86.6 & 87.0 \\
\hline Cf neutron source & 46.0 & 48.5 & 48.3 & 86.4 & 86.8 \\
\hline
\end{tabular}

\section{VI.4. Neutron Spectra}

Neutron spectra have been calculated at the center of the experimental channels EC2B (fast zone), EC6T (thermal zone), EC8R (reflector) for the YALINA-Booster configuration, and EC1 (fuel zone), EC2 (fuel zone), EC3 (fuel zone), EC5 (reflector), EC6 (reflector) for the YALINA-Thermal configuration. The channel locations in the YALINA-Booster and -Thermal are shown in Figures 1 and 10 , respectively. The calculations have been performed for three external neutron sources $(d, t),(d, d)$ and Cf-252 using the JEF2.2, JEF3.1 and ENDF/B-VI.8 data libraries for the YALINA-Booster and JEF3.1 and ENDF/B-VI.8 for the YALINA-Thermal. In the present Section, the JEF3.1 results will be presented, while the comparison of the neutron spectra obtained with different libraries is shown in Appendix F.

The neutron spectra have been calculated in the 172 energy group structure with $\mathrm{SP}_{3} \mathrm{P}_{0}\left(\mathrm{P}_{3}\right.$ angular flux expansion with simplified spherical harmonics and anisotropic scattering order 0$)$ and $\mathrm{SP}_{3} \mathrm{P}_{1}\left(\mathrm{P}_{3}\right.$ angular flux expansion with simplified spherical harmonics and anisotropic scattering order 1) for the YALINA-Booster and -Thermal respectively, as shown in Figures 17 through 24. The angular flux expansion and the anisotropic scattering order cannot be increased further because of the limitations of the computer resources when using 172 energy groups. However, the neutron spectra for the YALINA-Thermal with (d,d) neutron source calculated in 172 energy group structure with $\mathrm{SP}_{3} \mathrm{P}_{0}$ and $\mathrm{SP}_{3} \mathrm{P}_{1}$ approximations have been compared in Figure 25. The two spectra show a good agreement and minor differences are observed at high neutron energy. This indicates that the flux spectra obtained in $\mathrm{SP}_{3} \mathrm{P}_{0}$ approximation is adequate. 


\section{VI.4.a. Neutron Spectra of the YALINA-Booster}

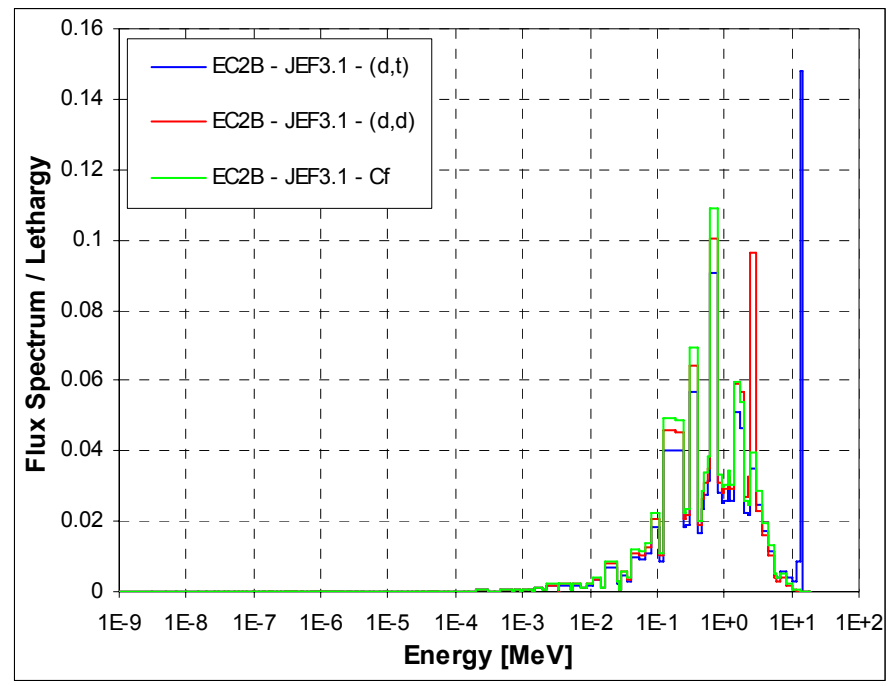

Figure 17. EC2B Neutron Spectra in the YALINABooster

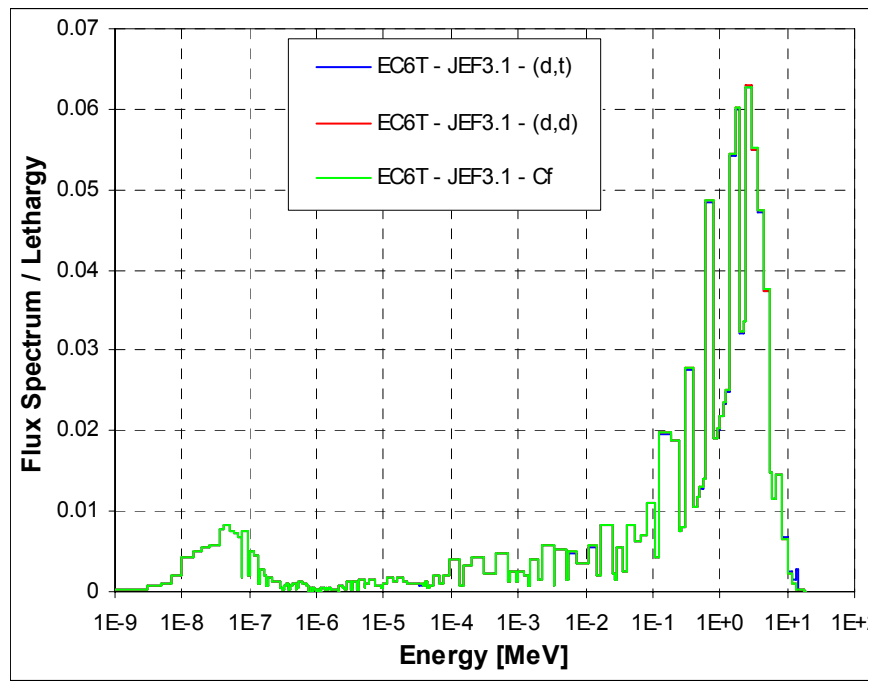

Figure 18. EC6T Neutron Spectra in the YALINABooster

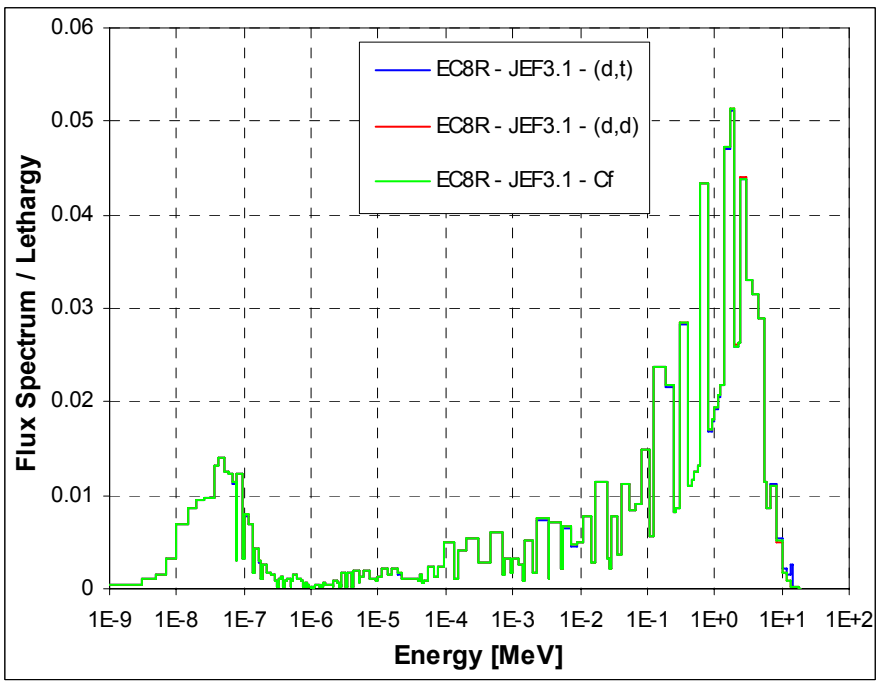

Figure 19. EC8R Neutron Spectra in the YALINA-Booster 
VI.4.b. Neutron Spectra of the YALINA-Thermal

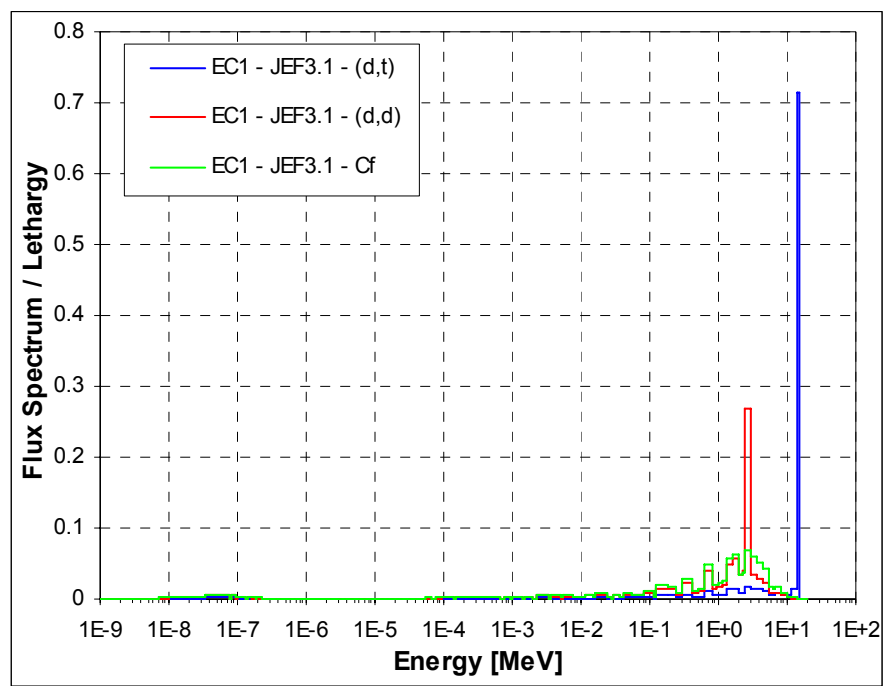

Figure 20. EC1 Neutron Spectra in the YALINAThermal

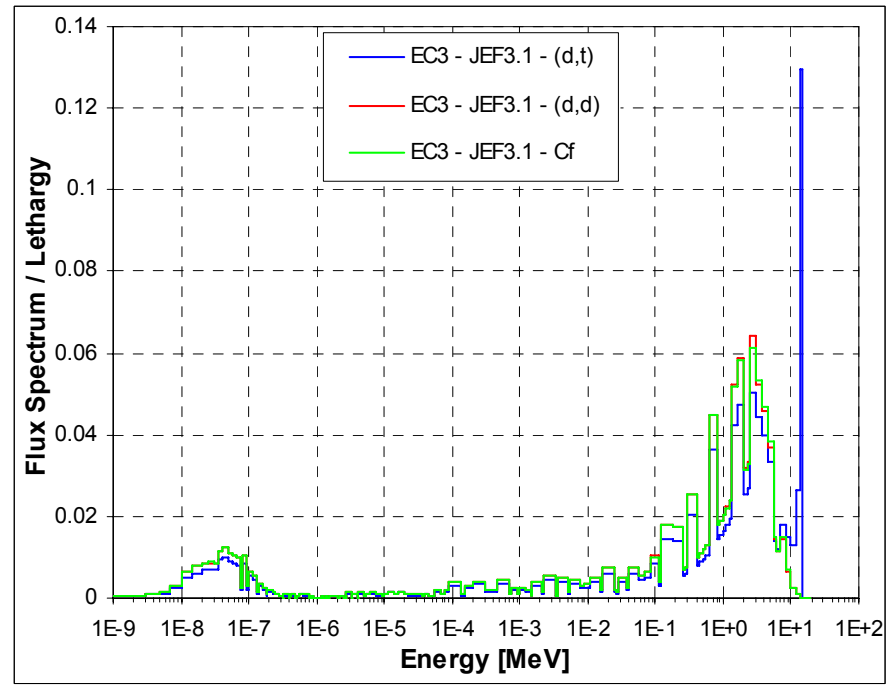

Figure 22. EC3 Neutron Spectra in the YALINAThermal

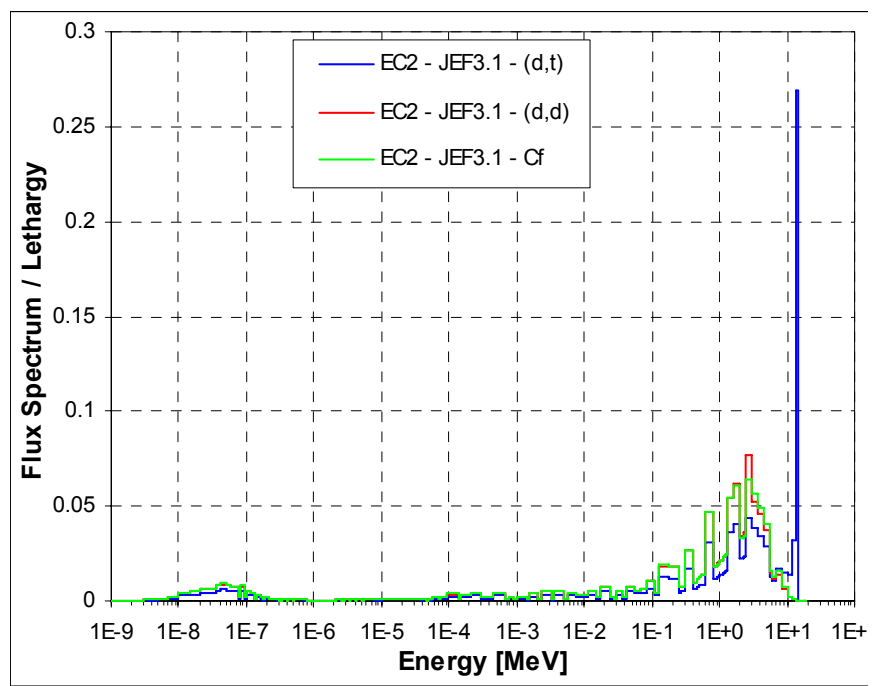

Figure 21. EC2 Neutron Spectra in the YALINAThermal

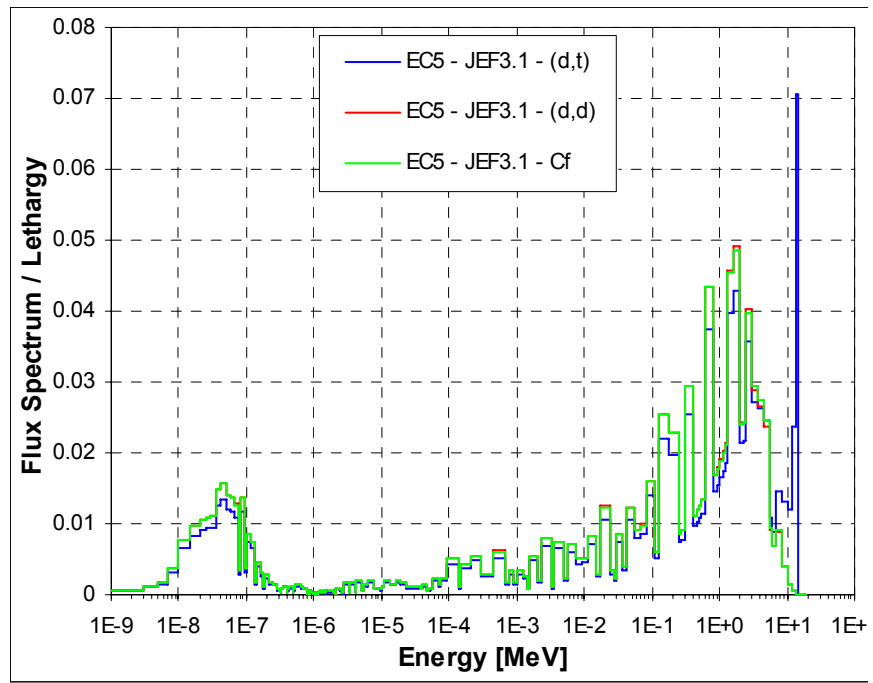

Figure 23. EC5 Neutron Spectra in the YALINAThermal 
ANL-09-23

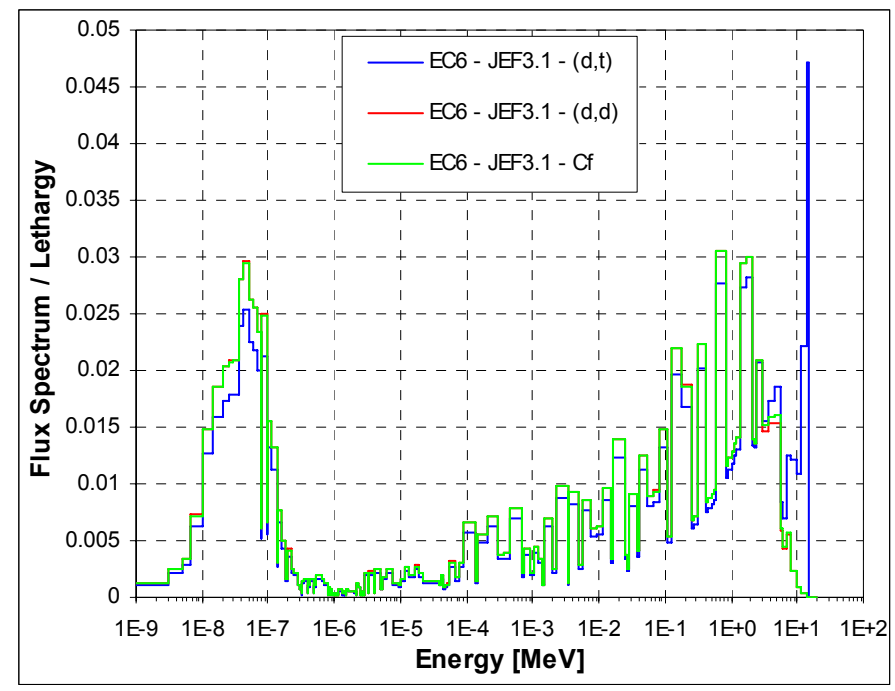

Figure 24. EC6 Neutron Spectra in the YALINA-Thermal

\section{VI.4.c. Comparison of Neutron Spectra in the YALINA-Thermal Calculated with Different Approximations}

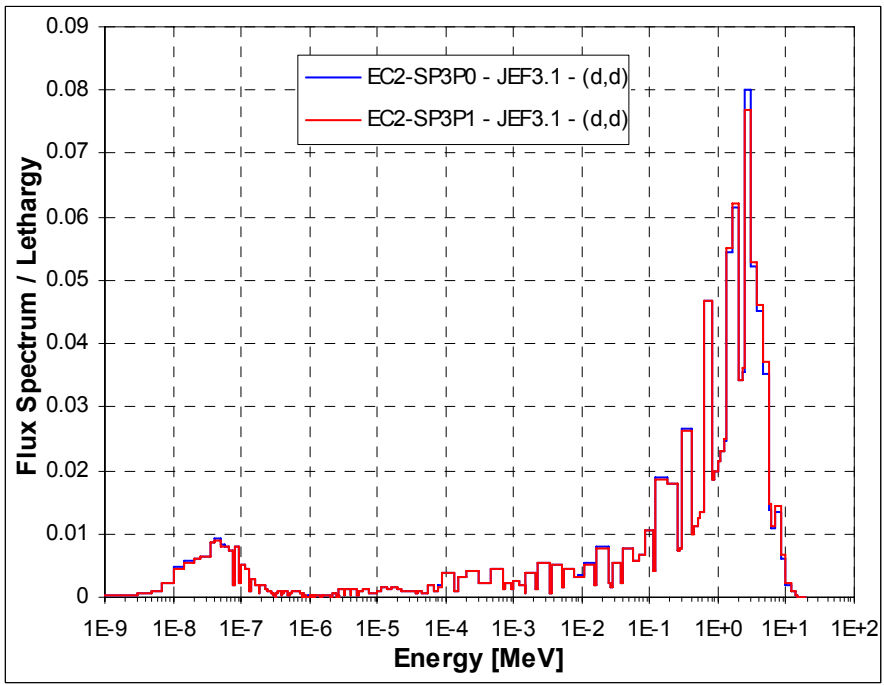

Figure 25. EC2 Neutron Spectra in the YALINA-Thermal with Different Approximations

\section{VI.5. Reaction Rate Distributions}

Reaction rates have been calculated along the experimental channels in presence of the three external neutron sources (d,t), (d,d) and Cf-252, using JEF2.2, JEF3.1 and ENDF/B-VI.8 for the YALINA-Booster, and JEF3.1 and ENDF/B-VI.8 for the YALINA-Thermal. The reaction rates have been obtained using the 53 energy groups fluxes with the most accurate approximation orders possible by the present computational resources: $\mathrm{SP}_{3} \mathrm{P}_{1}$ for the YALINA-Booster and $\mathrm{P}_{3} \mathrm{P}_{1}$ for the YALINA-Thermal. As discussed in Section VI.1, the final calculated reactivity values have been derived at higher approximation orders by applying appropriate correction factors. The absolute reaction rate values are function of the assembly reactivity since the neutron multiplication and consequently the neutron flux are function of the reactivity. It is assumed that the reaction rate value is inversely proportional to the associated reactivity. For this reason, the fluxes have been calculated 
with the highest possible expansion orders allowed by the computer resources and an appropriate correction factor has been applied to $v$. This factor is the ratio between the final $k_{\text {eff }}$ value and the $k_{\text {eff }}$ normally calculated without any correction on $v$. So that, the neutron flux is corresponding to the most accurate reactivity value calculated for the subcritical assembly. As an alternative solution, the $v$ could have been normalized to the measured reactivity rather than the calculated value. In addition, separate fluxes calculations have been performed for the cases where the reaction rates are required to be determined with the explicit modeling of the experimental channel holders. The other calculations assume air in the experimental channels.

In addition, the neutron detector cross-sections have been calculated in a separate cell calculation. For some reaction rates, the detectors are explicitly described along the experimental channel with their materials and geometrical details. In the deterministic calculation, often it is quite difficult to model the detector with accurate details, particularly due to the restrictions imposed by the cell code for the geometrical description. In this calculation, the detector cross-sections have been obtained with a single homogeneous cell calculation, where the detector compositions are "infinitely diluted". This solution could affect the calculated results since the detector cross-sections do not account for the self-shielding effects associated with the detector material. After comparing the calculated reaction rates with the results obtained from Monte-Carlo calculations where the detectors can be explicitly described and the experimental measurements, further investigation could be performed in the attempt to quantify possible effects neglected in the present calculations.

In the present Section, the JEF3.1 results are presented, while the comparison of the reaction rates obtained with different nuclear data files is shown in Appendix G. For demonstration purpose, the He-3 $(n, p)$ and $U-235$ fission reaction rates in the EC6T and EC2B experimental channels with (d,t) neutron source, respectively, have been calculated with and without correction on $v$ as shown in Figures 48 and 49. The obtained values are approximately consistent with the previously mentioned formula:

$$
\begin{aligned}
& \frac{\mathrm{T}_{\text {without_v_correction }}}{\mathrm{T}_{\text {with_v }} v_{\text {c correction }}} \cong \frac{\rho_{\text {with_v_correction }}}{\rho_{\text {without_v_correction }}} \text {. From Tables } 3 \text { and } 5, \rho_{\text {without_v_correction }}=-3498 \text { pcm and } \\
& \rho_{\text {with_v_correction }}=-2772 \mathrm{pcm}, \frac{\rho_{\text {with_v_correction }}}{\rho_{\text {without_v_correction }}}=\frac{2772}{3498}=0.79 \text {, which corresponds approximately to the }
\end{aligned}
$$

ratio of the reaction rates shown in Figures 48 and 49.

In Appendix G, the He-3 (n,p) reaction rates for the YALINA-Booster have not been calculated with JEF2.2 nuclear data because He-3 is missing in this library. The JEF2.2 reaction rate values are higher values than the corresponding values from the other nuclear data libraries. This is due to the higher multiplication factor obtained with JEF2.2 relative to the other libraries, as discussed before. 


\section{VI.5.a. Reaction Rate Distributions in the YALINA-Booster}

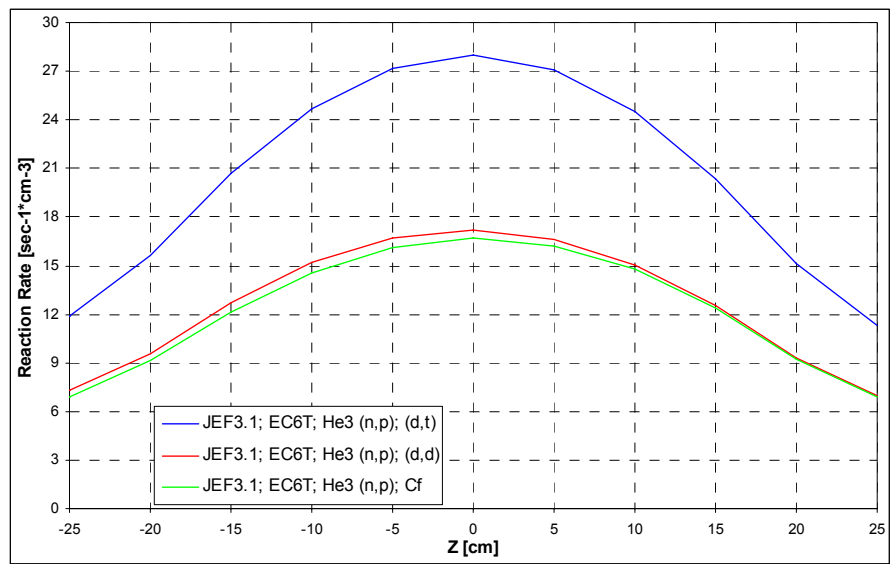

Figure 26. EC6T He-3 (n,p) Reaction Rates in the YALINA-Booster

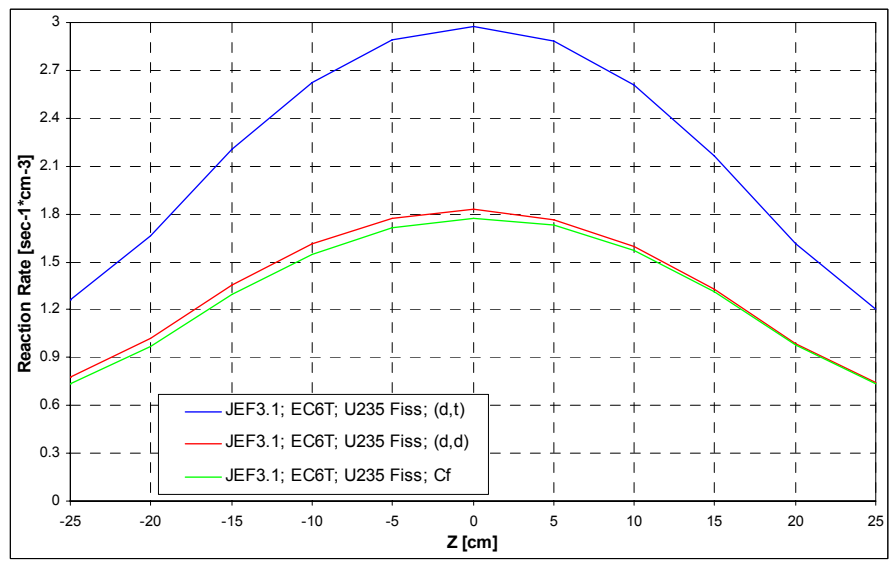

Figure 28. EC6T U-235 fission Reaction Rates in the YALINA-Booster

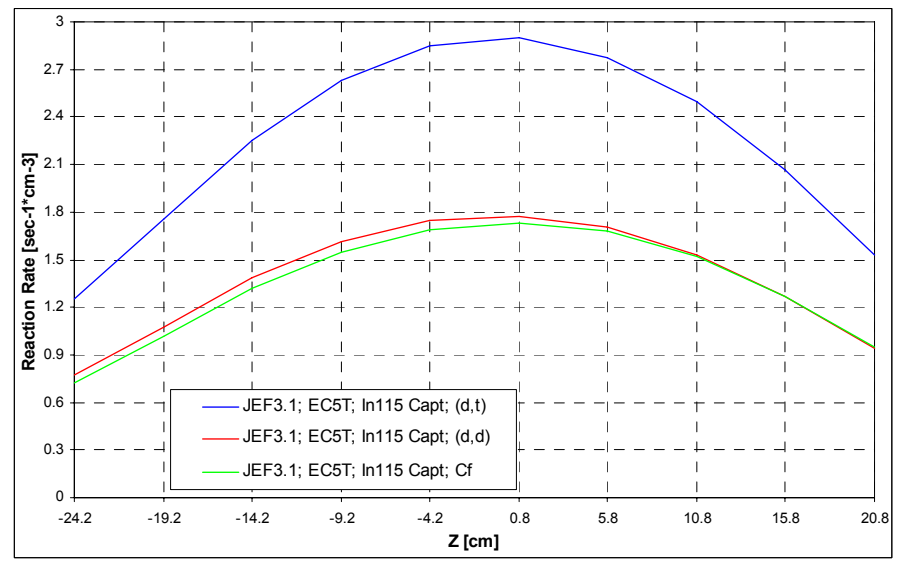

Figure 30. EC5T In-115 Capture Reaction Rates in the YALINA-Booster. Polyethylene Holder is Modeled

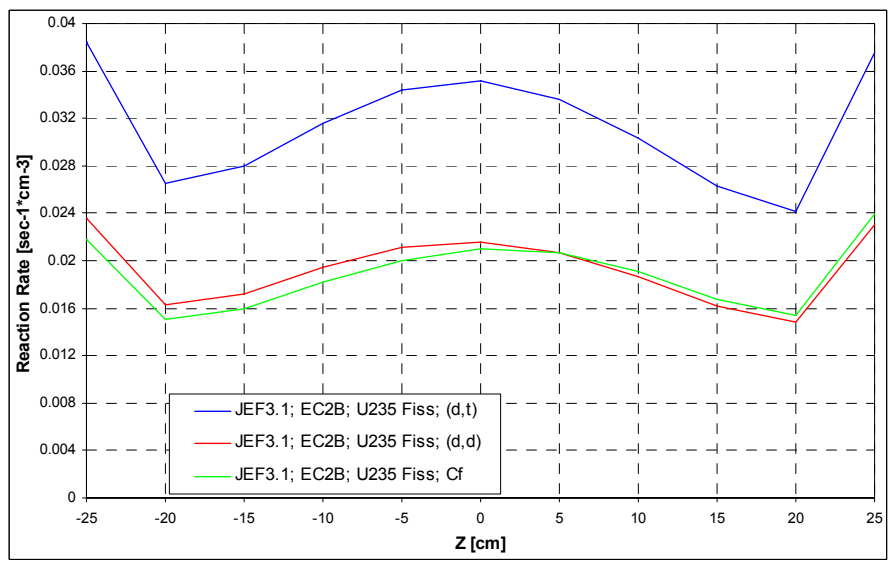

Figure 27. EC2B U-235 Fission Reaction Rates in the YALINA-Booster

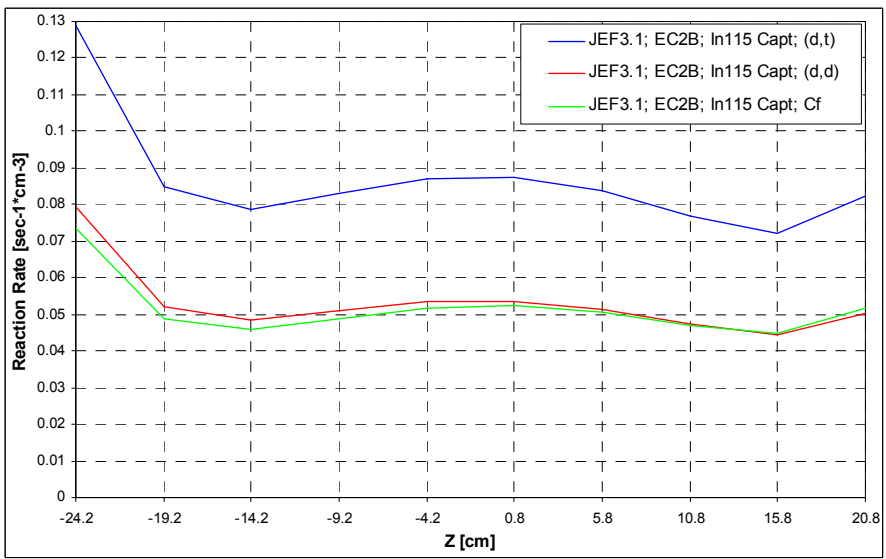

Figure 29. EC2B In-115 Capture Reaction Rates in the YALINA-Booster. Lead Holder is Modeled

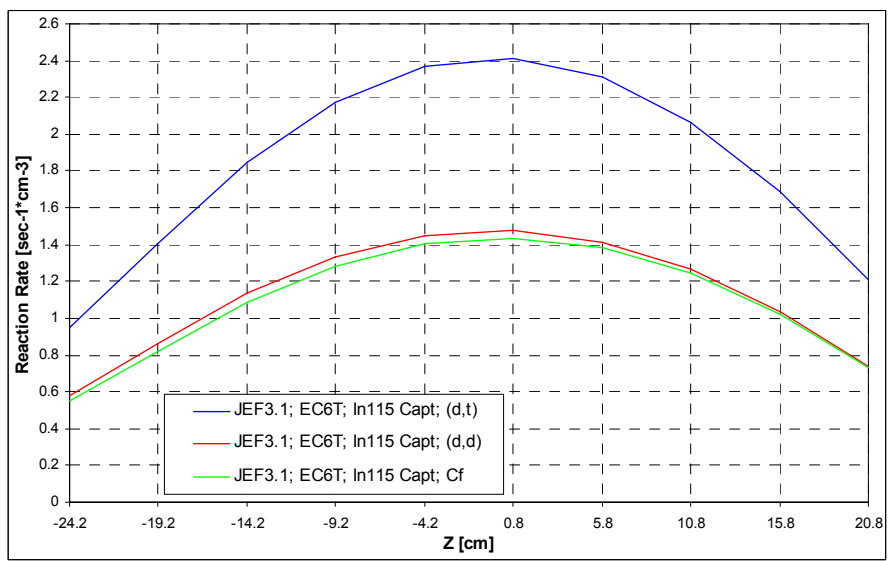

Figure 31. EC6T In-115 Capture Reaction Rates in the YALINA-Booster. Polyethylene Holder is Modeled 
ANL-09-23

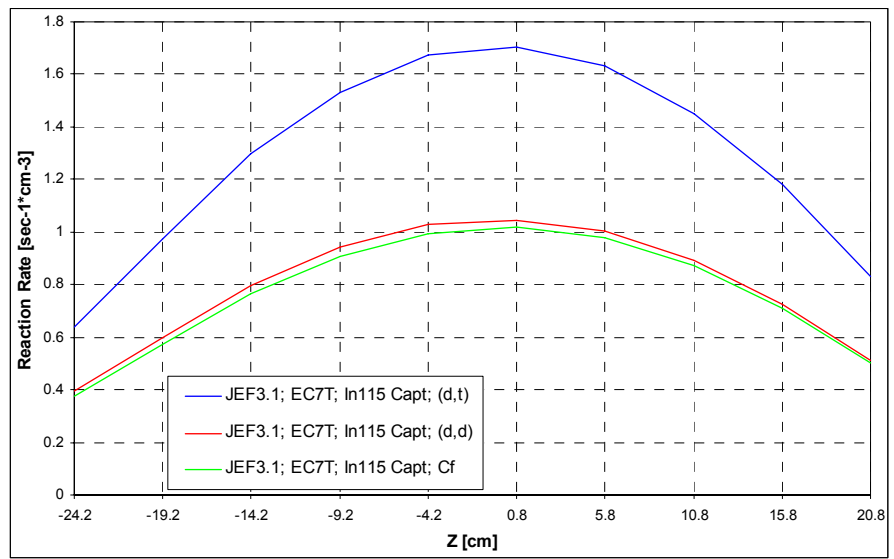

Figure 32. EC7T In-115 Capture Reaction Rates in the YALINA-Booster. Polyethylene Holder is Modeled

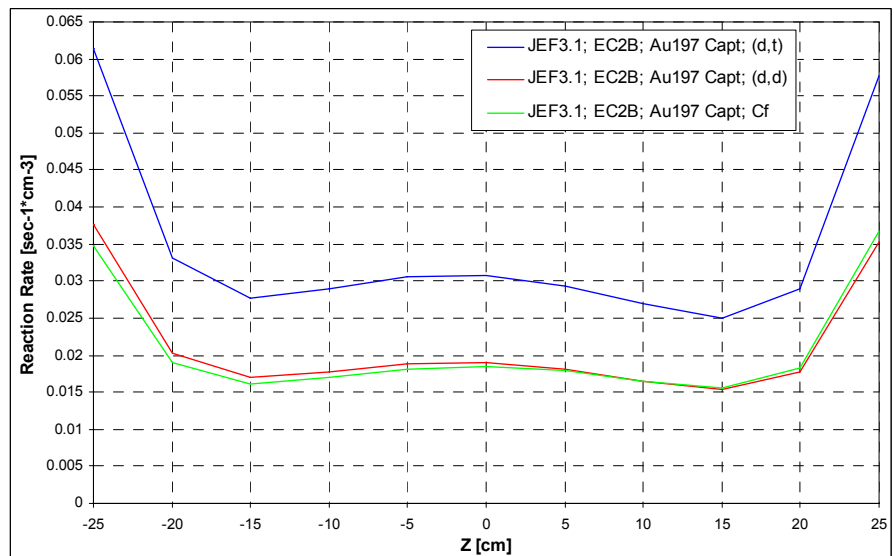

Figure 34. EC2B Au-197 Capture Reaction Rates in the YALINA-Booster. Lead Holder is Modeled

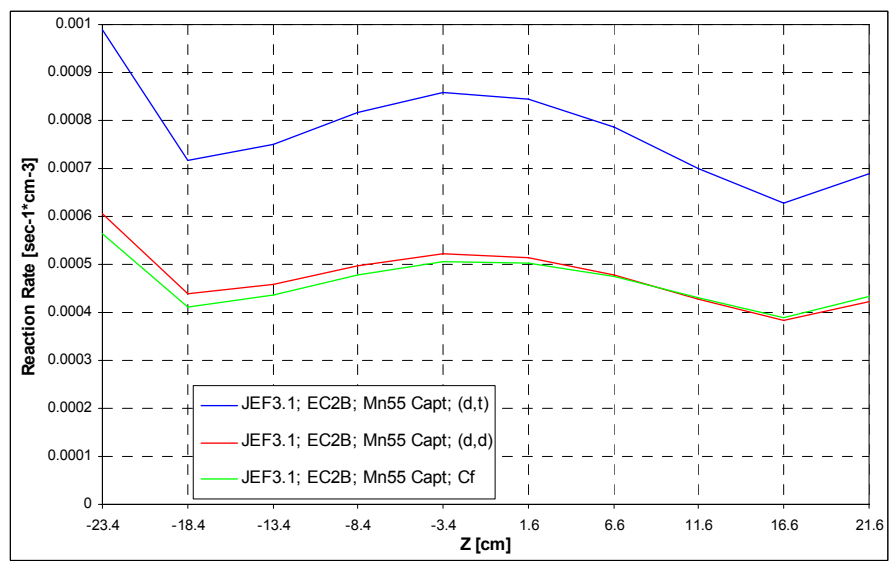

Figure 36. EC2B Mn-55 Capture Reaction Rates in the YALINA-Booster. Lead Holder is in Modeled

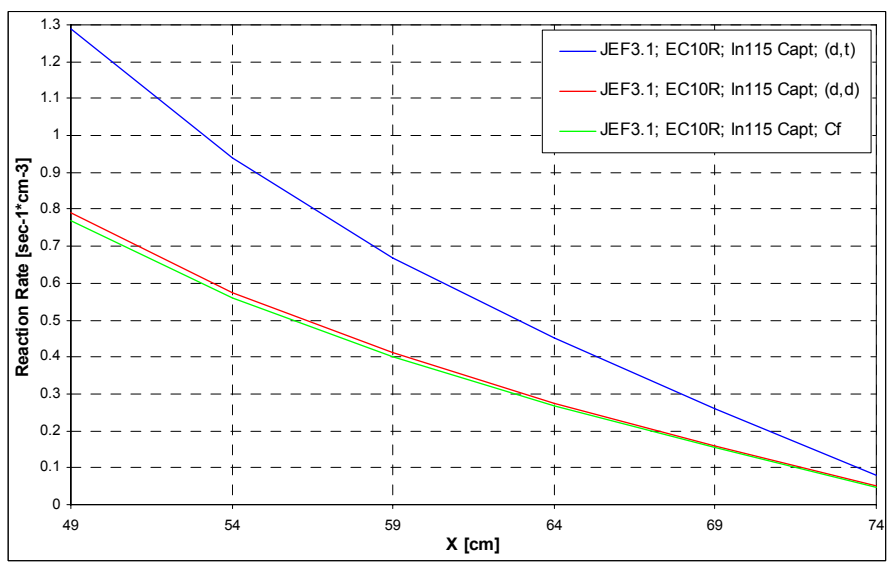

Figure 33. EC10R In-115 Capture Reaction Rates in the YALINA-Booster. Polyethylene Holder is Modeled

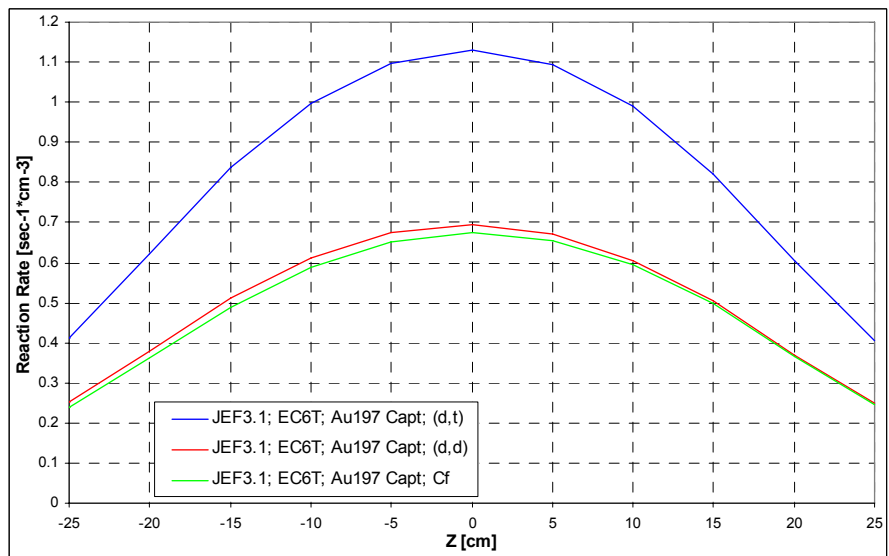

Figure 35. EC6T Au-197 Capture Reaction Rates in the YALINA-Booster. Polyethylene Holder is Modeled

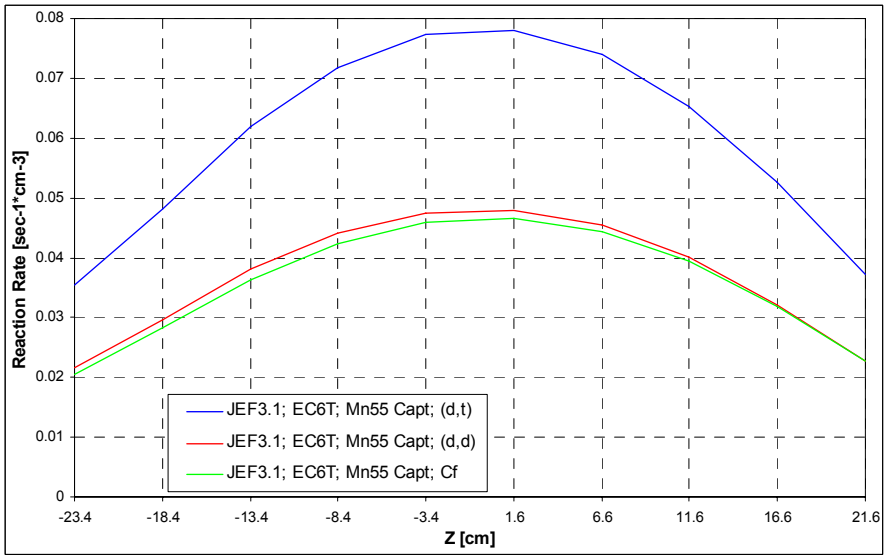

Figure 37. EC6T Mn-55 Capture Reaction Rates in the YALINA-Booster. Polyethylene Holder is Modeled 


\section{VI.5.b. Reaction Rate Distributions in the YALINA-Thermal}

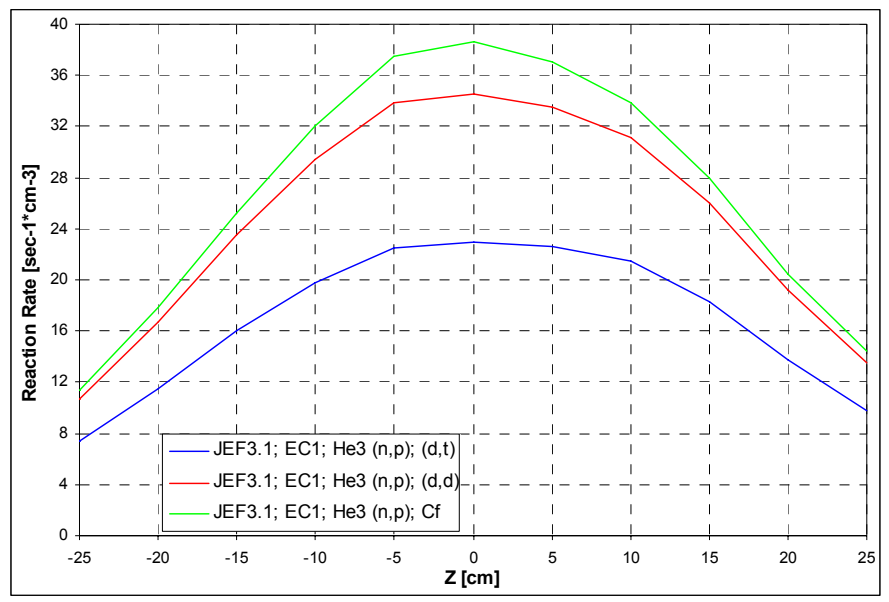

Figure 38. EC1 He-3 (n,p) Reaction Rates in the YALINA-Thermal

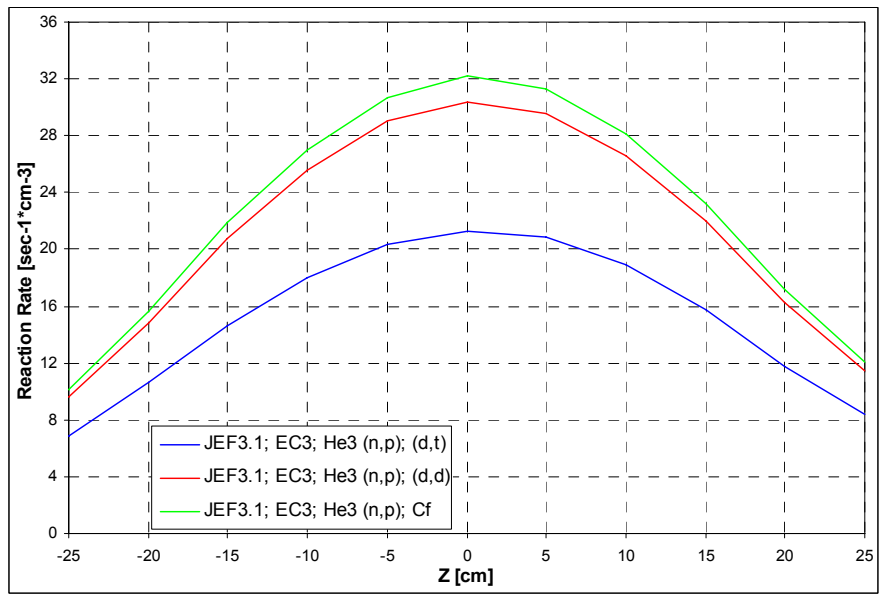

Figure 40. EC3 He-3 (n,p) Reaction Rates in the YALINA-Thermal

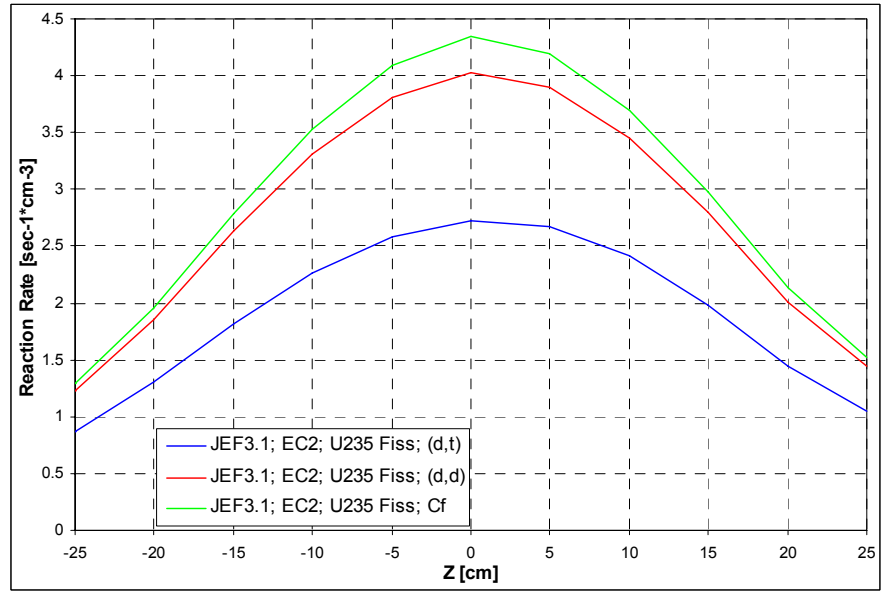

Figure 42. EC2 U-235 Fission Reaction Rates in the YALINA-Thermal

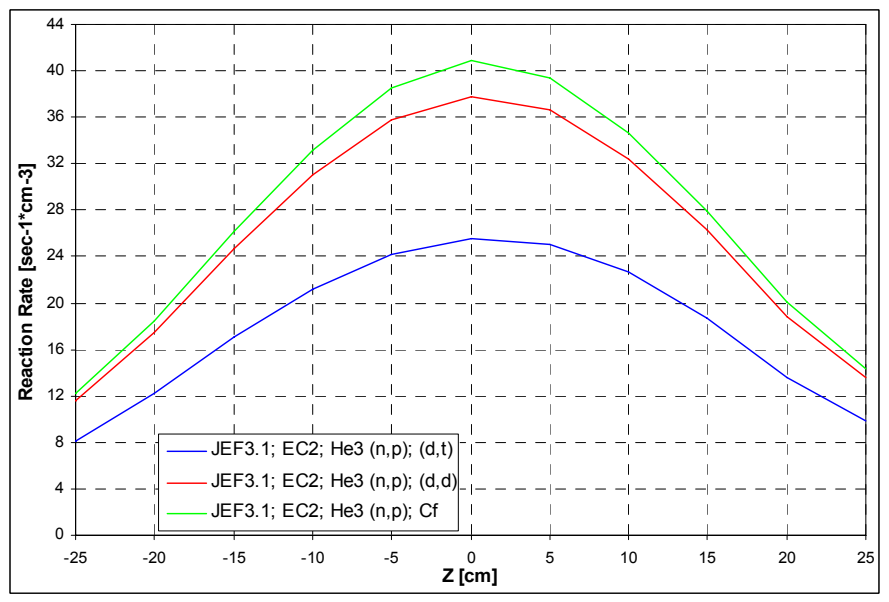

Figure 39. EC2 He-3 $(n, p)$ Reaction Rates in the YALINA-Thermal

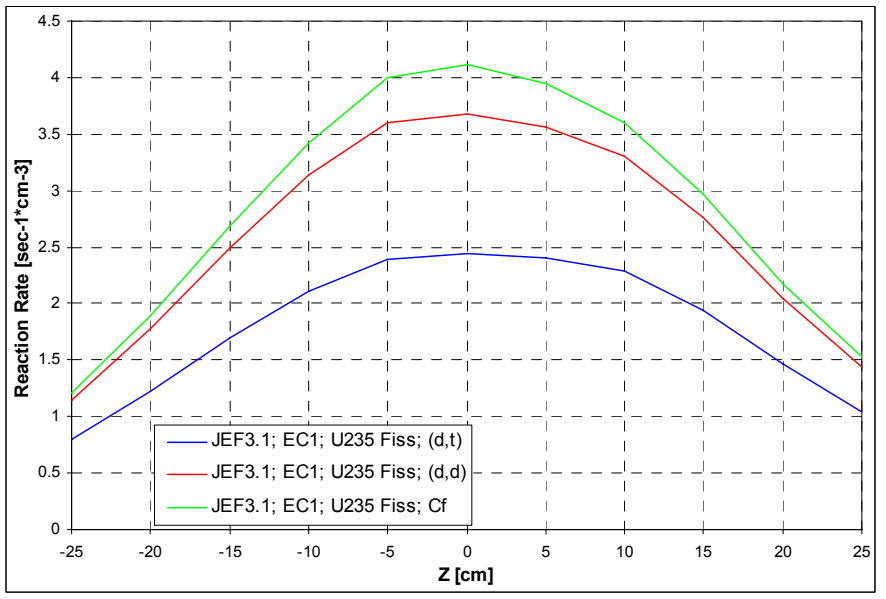

Figure 41. EC1 U-235 Fission Reaction Rates in the YALINA-Thermal

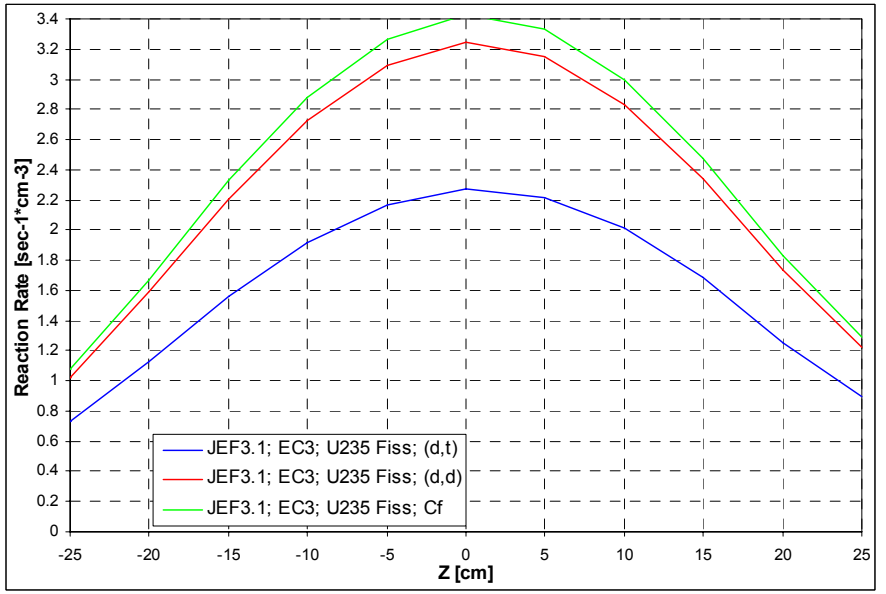

Figure 43. EC3 U-235 Fission Reaction Rates in the YALINA-Thermal 


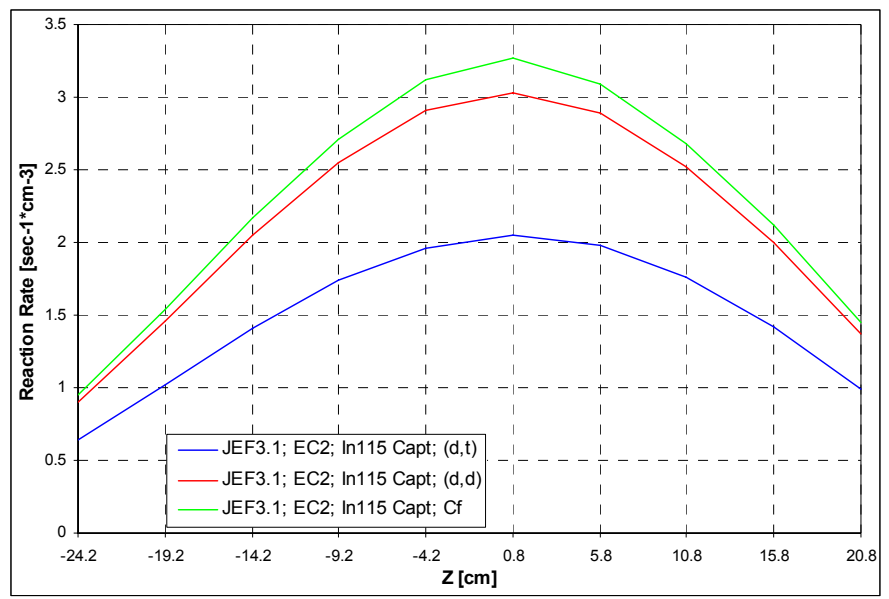

Figure 44. EC2 In-115 Capture Reaction Rates in the YALINA-Thermal. Polyethylene Holder is Modeled

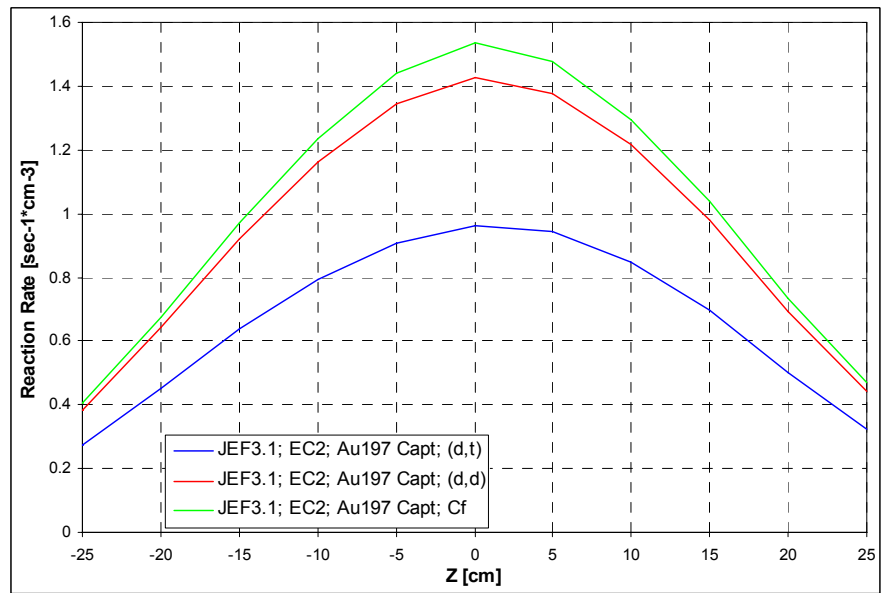

Figure 46. EC2 Au-197 Capture Reaction Rates in the YALINA-Thermal. Polyethylene Holder is Modeled

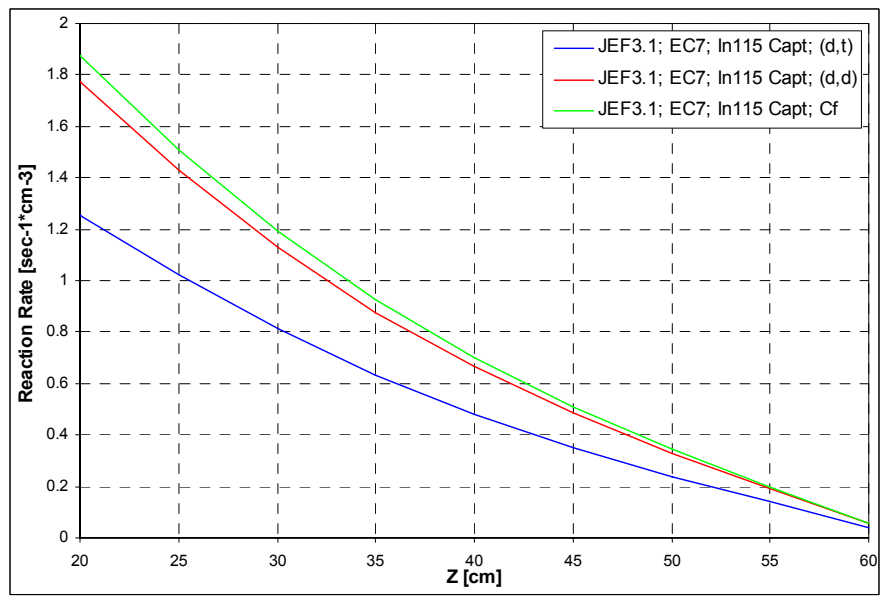

Figure 45. EC7 In-115 Capture Reaction Rates in the YALINA-Thermal. Polyethylene Holder is Modeled

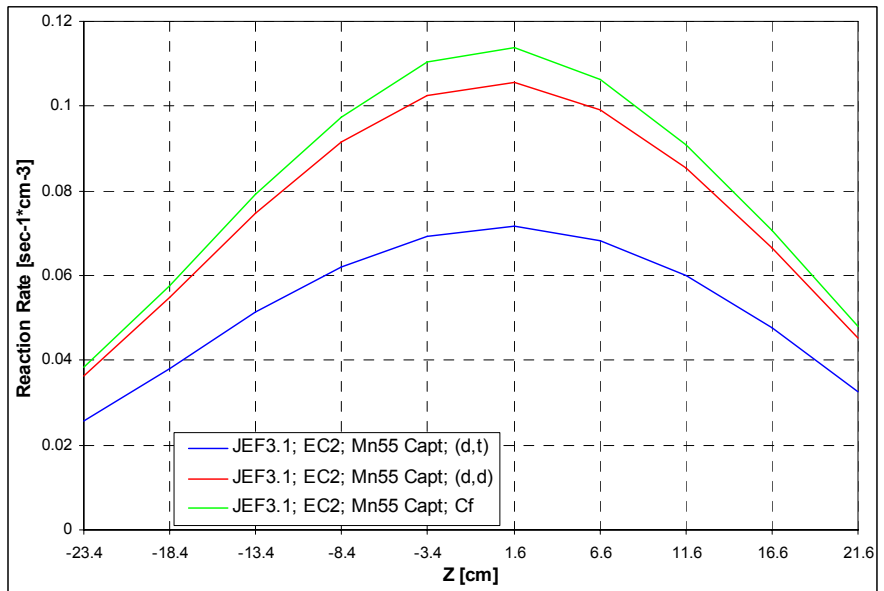

Figure 47. EC2 Mn-55 Capture Reaction Rates in the YALINA-Thermal. Polyethylene Holder is Modeled

\section{VI.5.c. Comparison of Reaction Rate Distributions in the YALINA-Booster}

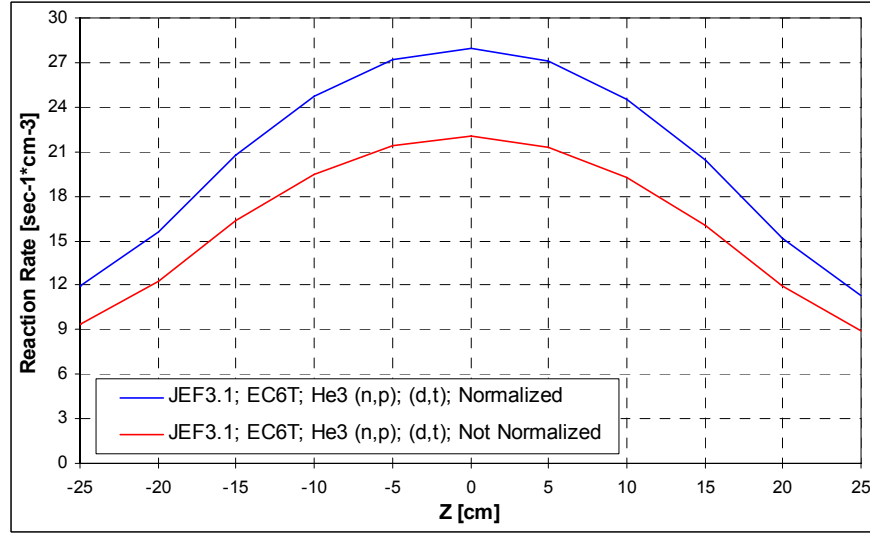

Figure 48. EC6T He-3 (n,p) Reaction Rates in the YALINA-Booster

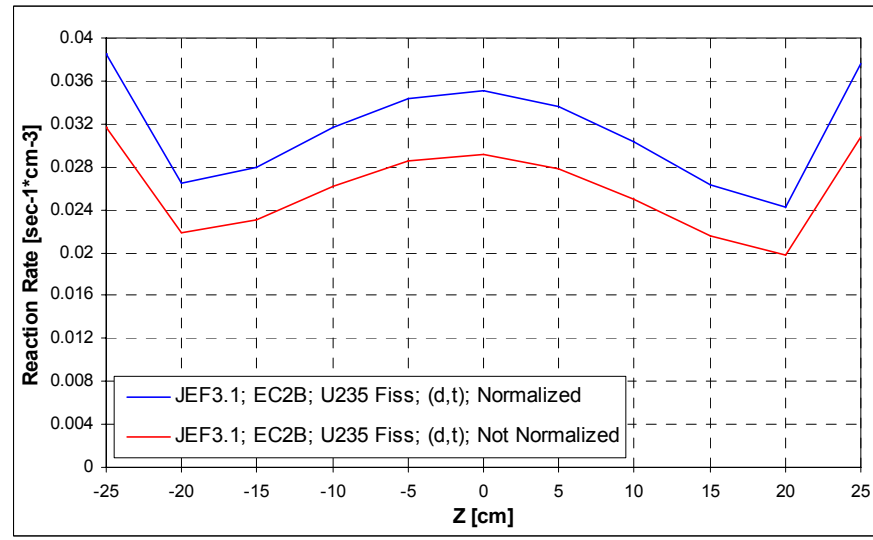

Figure 49. EC2B U-235 Fission Reaction Rates in the YALINA-Booster 


\section{VI.6. Pulse Calculations}

The KIN3D code of ERANOS has been used to perform pulse calculations. The goal is to calculate the neutron detector response in the subcritical YALINA configurations to repeated neutron pulses with a very short pulse duration of $5 \mu \mathrm{s}$. In the calculations, the neutron pulse is simulated as having a triangular shape, with the intensity linearly increasing from 0 to a maximum value (MV) in the time interval $0<t<2.5 \mu \mathrm{s}$, then linearly decreasing from $M V$ to 0 in $2.5<t<5 \mu \mathrm{s}$. The maximum amplitude, MV, reached by the neutron pulse in the calculations has been arbitrary fixed to 1000 . Then, the calculated response is then normalized according to the benchmark specifications (see Section III).

KIN3D has capabilities to perform the calculations in transport and diffusion approximations. In this analyses, the simulation has been carried out with the diffusion approximation. Since the decay slope of the detector response is strictly dependent on the reactivity value of the calculated model, the multiplication factor has been normalized to the most accurate value obtained from the transport calculation. The normalization is made by multiplying $v$ by an appropriate constant, which is the ratio between the desired multiplication factor and the $k_{\text {eff }}$ value normally obtained by the calculation without introducing any change on $\mathrm{v}$.

Kinetic calculations have been performed for the YALINA-Booster using the JEF2.2, JEF3.1 and ENDF/B-VI.8 and for the YALINA-Thermal using JEF3.1 and ENDF/B-VI.8. Results obtained with JEF3.1 are presented in this Section and Appendix $\mathrm{H}$ gives the results from the use of the other nuclear data files. The results show that the use of the two external sources $(d, t)$ or $(d, d)$ has only an effect on the amplitude of the detector response but not on the decay slope that remains practically the same.

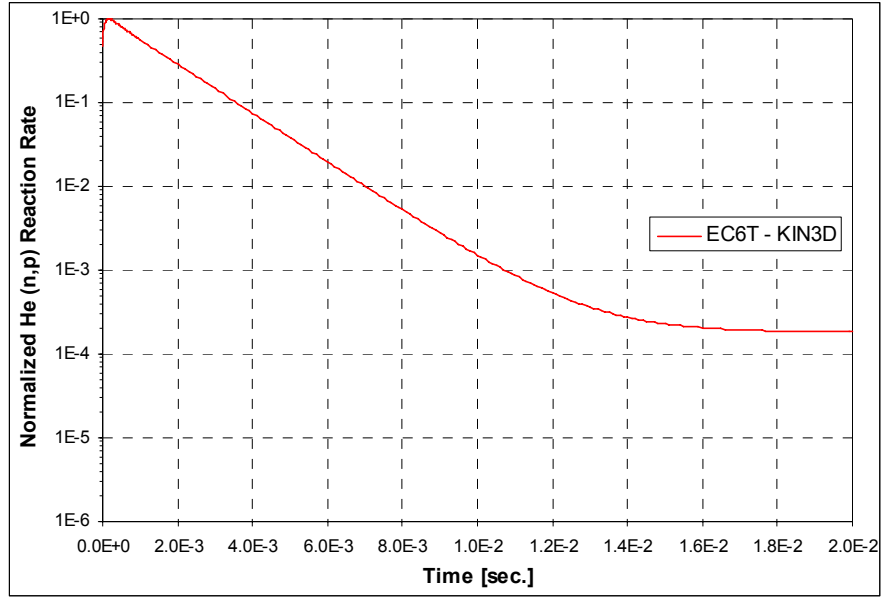

Figure 50. JEF3.1 EC6T Detector Response with $(d, t)$ Neutron Source for the YALINA-Booster

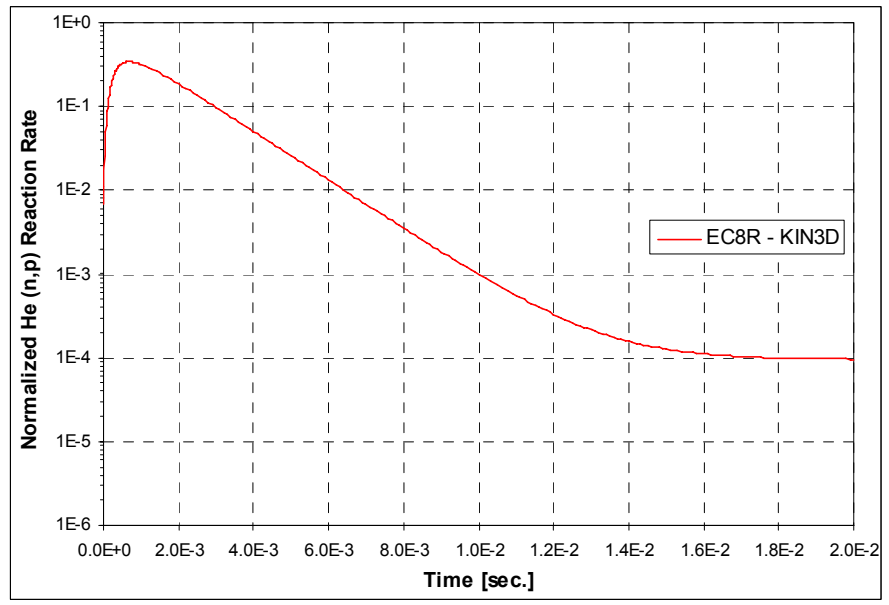

Figure 51. JEF3.1 EC8R Detector Response with $(d, t)$ Neutron Source for the YALINA-Booster 


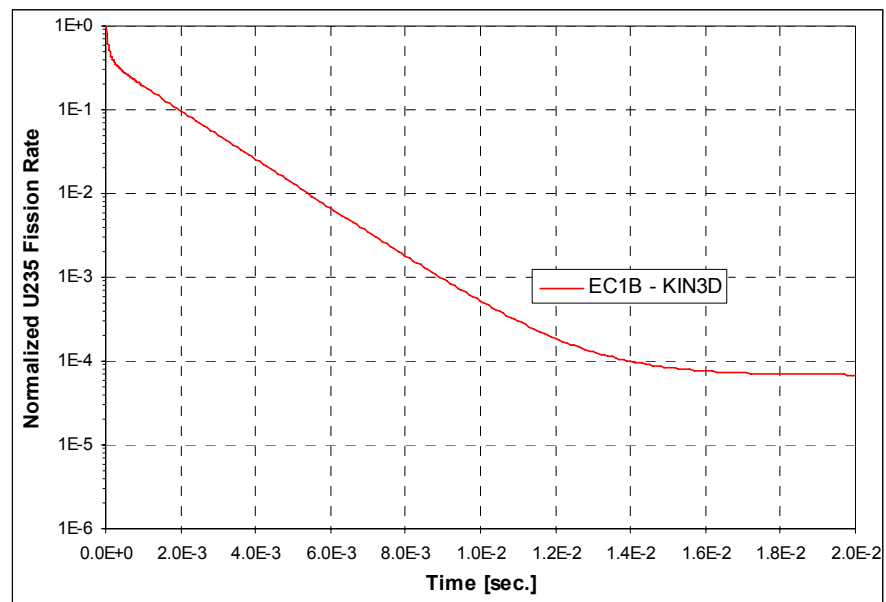

Figure 52. JEF3.1 EC1B Detector Response with $(d, t)$ Neutron Source for the YALINA-Booster

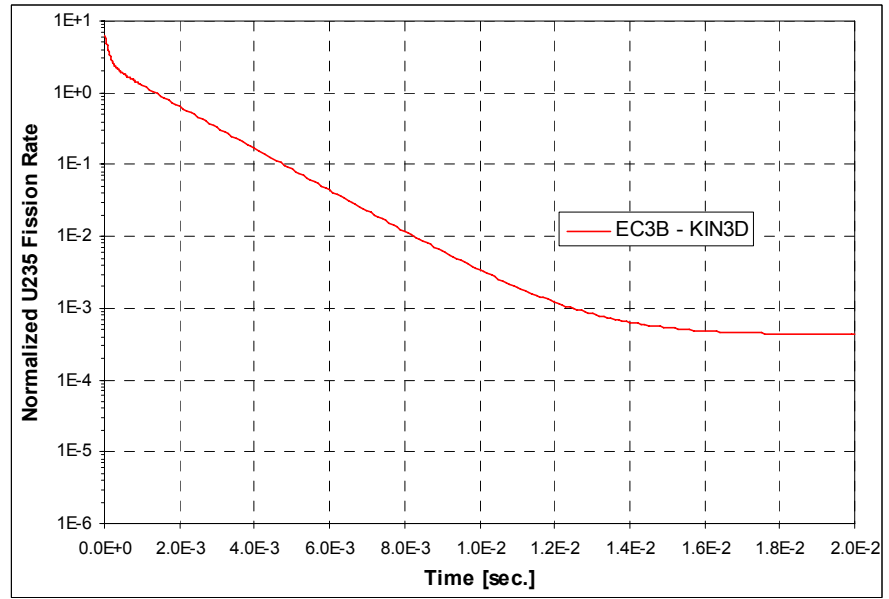

Figure 54. JEF3.1 EC3B Detector Response with $(d, t)$ Neutron Source for the YALINA-Booster

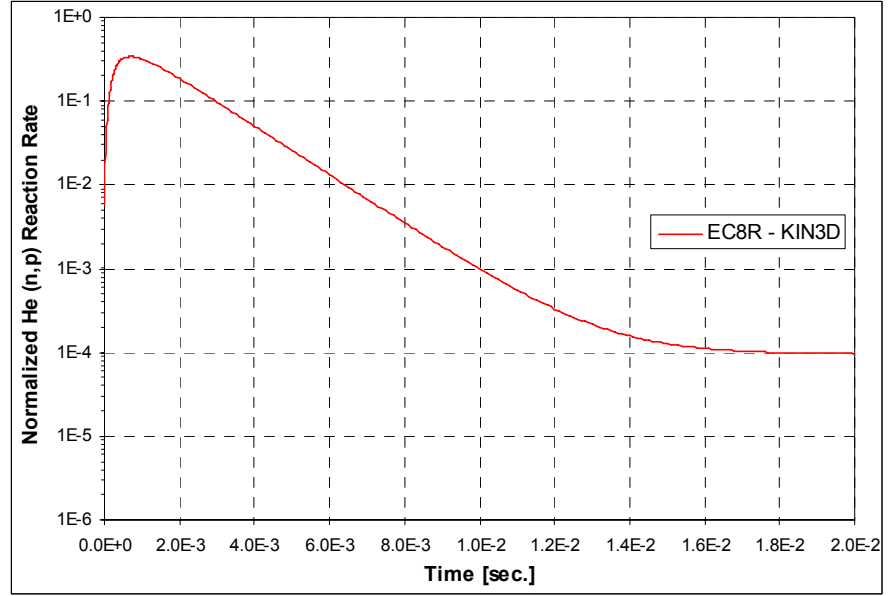

Figure 56. JEF3.1 EC8R Detector Response with $(d, d)$ Neutron Source for the YALINA-Booster

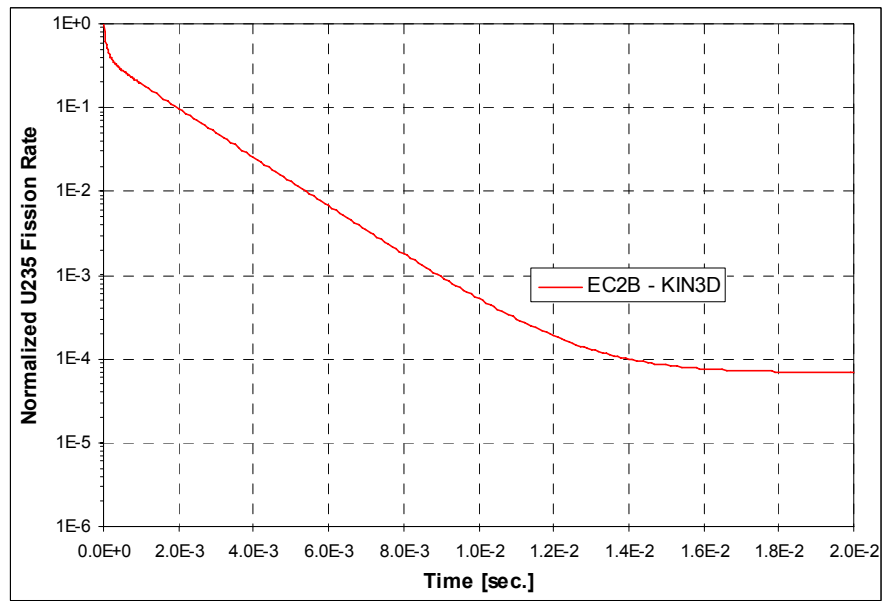

Figure 53. JEF3.1 EC2B Detector Response with $(d, t)$ Neutron Source for the YALINA-Booster

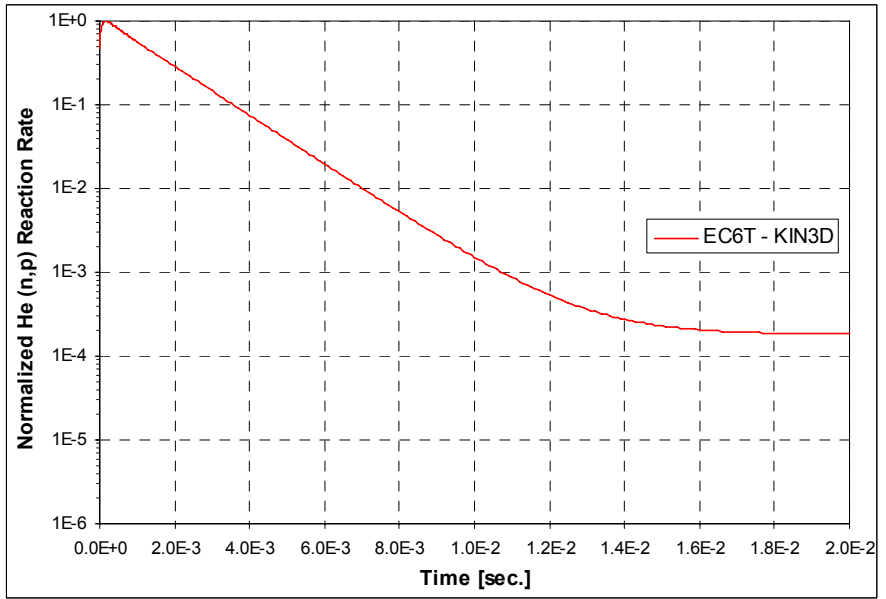

Figure 55. JEF3.1 EC6T Detector Response with (d,d) Neutron Source for the YALINA-Booster

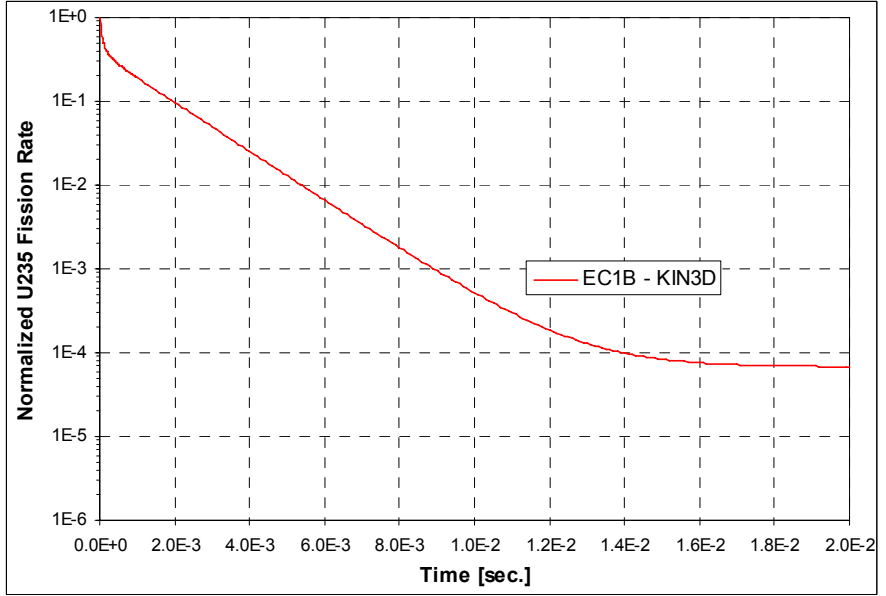

Figure 57. JEF3.1 EC1B Detector Response with $(d, d)$ Neutron Source for the YALINA-Booster 


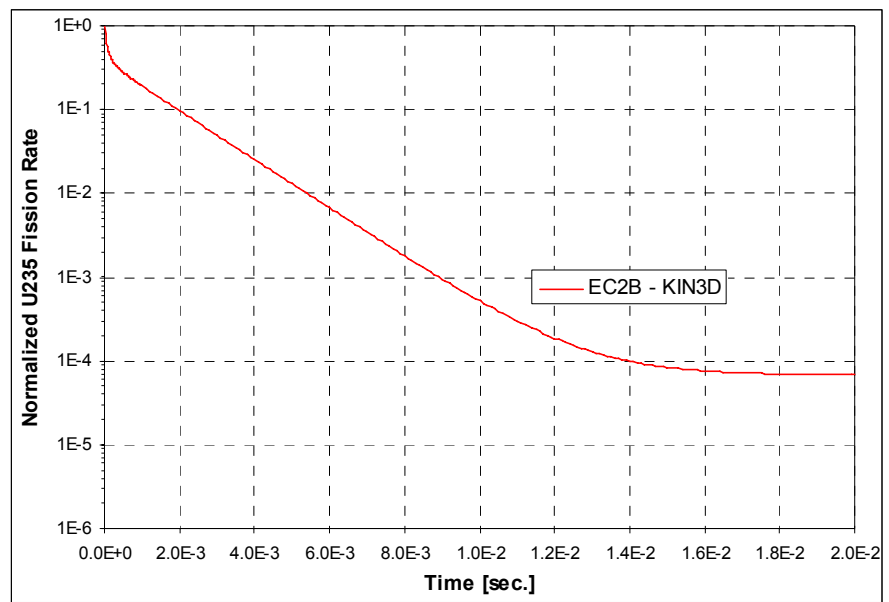

Figure 58. JEF3.1 EC2B Detector Response with (d,d) Neutron Source for the YALINA-Booster

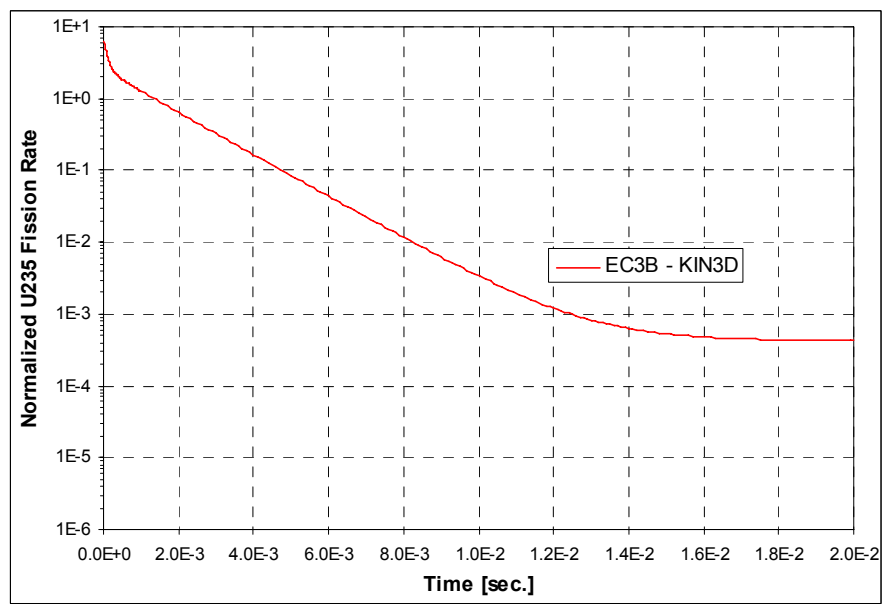

Figure 59. JEF3.1 EC3B Detector Response with $(d, d)$ Neutron Source for the YALINA-Booster
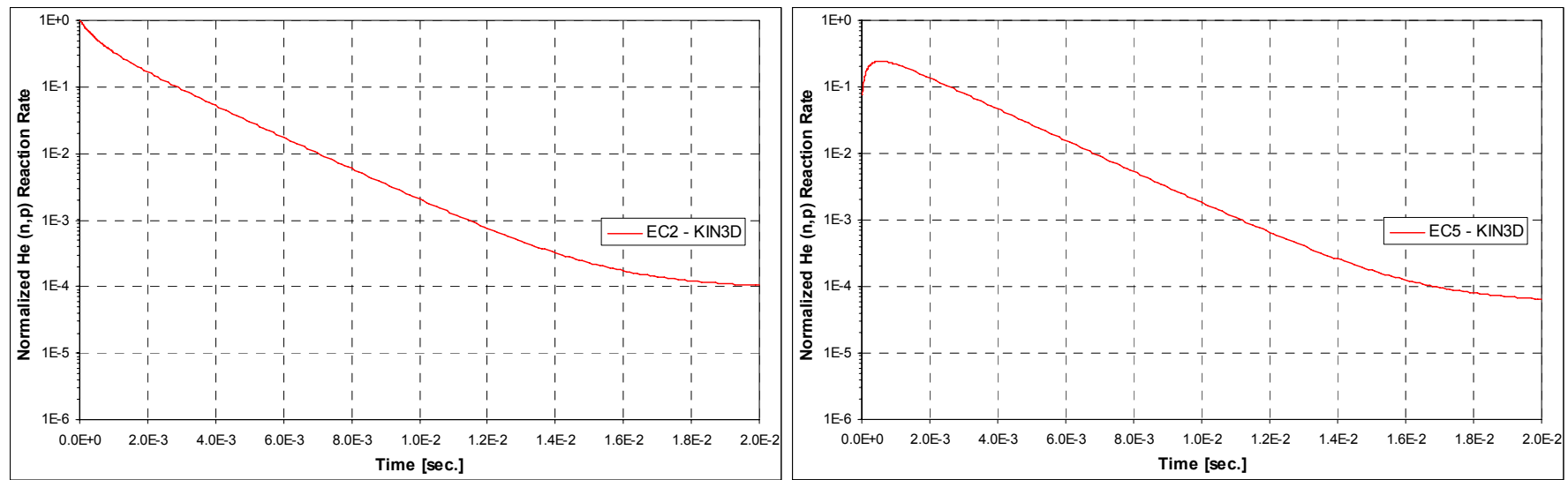

Figure 60. JEF3.1 EC2 Detector Response with (d,t)Figure 61. JEF3.1 EC5 Detector Response with $(\mathrm{d}, \mathrm{t})$ Neutron Source for the YALINA-Thermal Neutron Source for the YALINA-Thermal

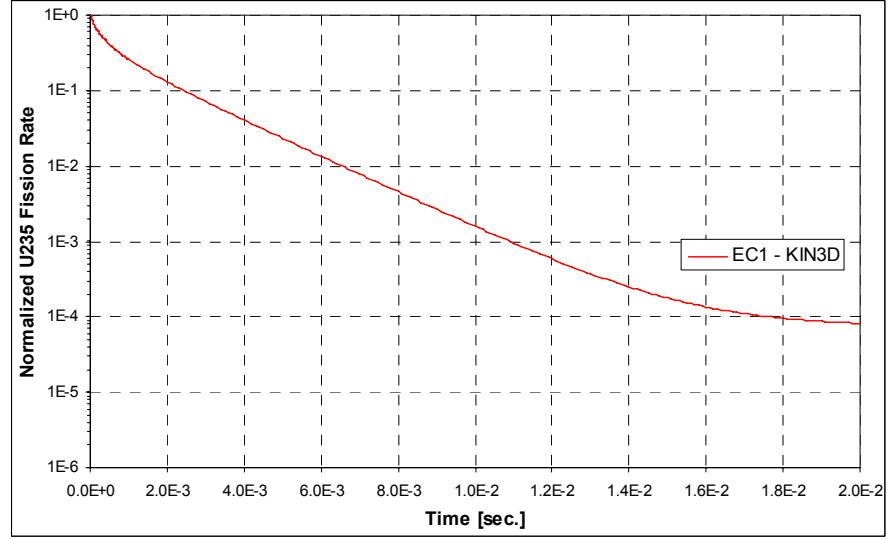

Figure 62. JEF3.1 EC1 Detector Response with $(\mathrm{d}, \mathrm{t})$ Neutron Source for the YALINA-Thermal

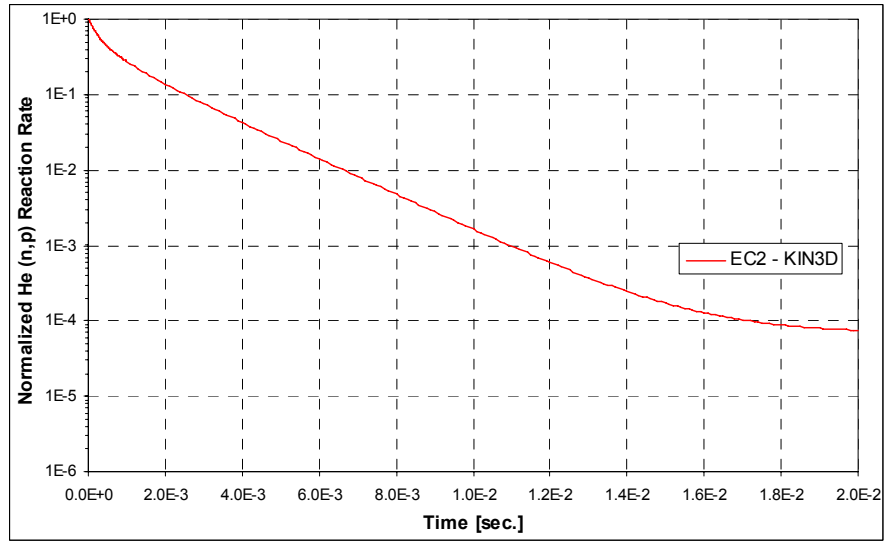

Figure 63. JEF3.1 EC2 Detector Response with (d,d) Neutron Source for the YALINA-Thermal 


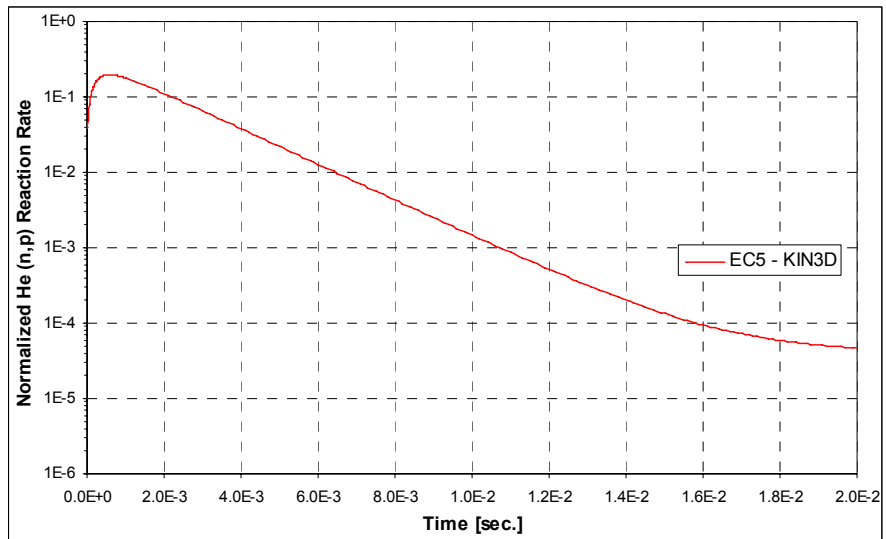

Figure 64. JEF3.1 EC5 Detector Response with (d,d) Neutron Source for the YALINA-Thermal

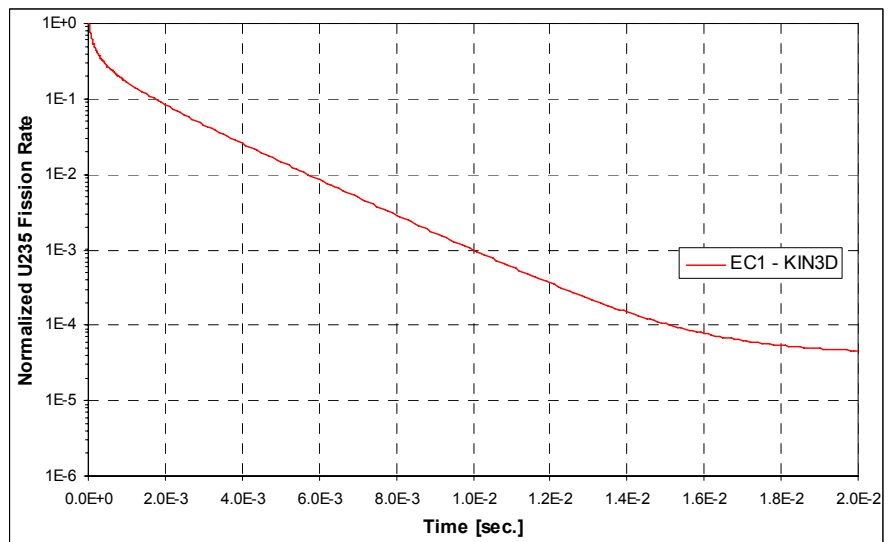

Figure 65. JEF3.1 EC1 Detector Response with (d,d) Neutron Source for the YALINA-Thermal

\section{Conclusions}

This report presents the obtained results for the YALINA-Booster loaded with $1141 \mathrm{EK}-10$ rods and the YALINA-Thermal loaded with 280 EK-10 rods using the deterministic ERANOS code system. Considerable efforts have been made for creating deterministic models for the two assemblies using JEF2.2, JEF3.1, and ENDF/B-VI.8 nuclear data files.

The obtained reactivity values for the YALINA-Booster show a quite good agreement with the use of the three different nuclear data libraries. The calculated reactivity is $-2700 \mathrm{pcm}$ with variations of less than $250 \mathrm{pcm}$ depending on the selected nuclear data files. Regarding the YALINA-Thermal, JEF3.1 and ENDF/B-VI.8 provide comparable results of $\sim-4900 \mathrm{pcm}$. JEF2.2 gives a lower reactivity value of $\sim 3000 \mathrm{pcm}$ for YALINA-Thermal. Perturbation calculations demonstrated that the use of the JEF2.2 library is inappropriate for the YALINA-Thermal calculations because of the use of carbon instead of the missing graphite for the reflector.

The source multiplication factor is also calculated for the two assemblies. The use of $(d, t)$ neutron source produces the highest $k_{s}$ value for YALINA-Booster, the lowest value for YALINA-Thermal. The source multiplication factor is even lower than the corresponding $k_{\text {eff }}$ value for the YALINA-Thermal. In YALINA-Thermal, the $(d, t)$ neutron source significantly increases the neutron leakage relative to the induced fission reaction rate.

The kinetic parameters, effective fraction of delayed neutrons $\beta_{\text {eff }}$ and mean generation time $\Lambda_{\text {eff, }}$, have been calculated with the KIN3D module of ERANOS in 3D geometry. The use of the different nuclear data libraries (JEF2.2, JEF3.1 and ENDFB-VI.8) does not change the obtained results. The $\beta_{\text {eff }}$ values are $753 \mathrm{pcm}$ for the YALINA-Booster and $779 \mathrm{pcm}$ for the YALINA-Thermal. The values for $\Lambda_{\text {eff }}$ are 50 $\mu$ s for the YALINA-Booster and $87 \mu$ s for the YALINA-Thermal.

Neutron spectra have been obtained in specific locations for the two assemblies as specified by the IAEA benchmark. In presence of $(\mathrm{d}, \mathrm{t})$ and $(\mathrm{d}, \mathrm{d})$ neutron sources, peaks in the neutron spectra are observed at the neutron source energy especially in the experimental channels close to the target for the two YALINA configurations. These peaks decrease with the distance from the source location and the peak values are significantly reduced in the reflector zone. The obtained neutron spectrum in the fast zone of the YALINA-Booster is typical of fast reactor systems, the highest fraction of neutrons being located at $\sim 1 \mathrm{MeV}$. Similarly, in the fuel zone of YALINA-Thermal the neutron spectrum is typical of thermal reactors, with a large fraction of neutrons located below $1 \mathrm{eV}$. 
The KIN3D code of ERANOS has been used to determine the response of the YALINA configurations to a very short neutron pulse, $5 \mu$ s width. The neutron pulse is simulated with a triangular shape, with intensity linearly increasing from 0 to a Maximum Value (MV) in the time interval $0<t<2.5 \mu \mathrm{s}$, then linearly decreasing from $\mathrm{MV}$ to 0 in $2.5<\mathrm{t}<5 \mu \mathrm{s}$. The simulation is carried out with the diffusion approximation. The decay slope of the detector response is strictly dependent on the reactivity value associated with the calculated model for $(d, d)$ and $(d, t)$ pulses.

The YALINA-Booster and -Thermal configurations have been successfully analyzed using the ERANOS modules, both steady-state and time dependent with different neutron sources.

\section{References}

1. D.G. Foster (ed.), Review of PNL study on transmutation processing of high level waste, LA-UR 74-74, Los Alamos National Laboratory (1974).

2. M. Salvatores et al., "Long-lived, radioactive waste transmutation and the role of accelerator driven (hybrid) systems", Nuclear Instruments and Methods in Physics Research, A 414 5-20, 1998.

3. S.E. Chigrinov et al., "Booster Subcritical Assembly, Driven by a Neutron Generator" (in Russian), JIPNR 14, Preprint of National Academy of Sciences of Belarus, Joint Institute for Power and Nuclear Research - Sosny, Minsk (2004).

4. S.E. Chigrinov et al., "Experimental Investigations on Neutronics of the Accelerator Driven Transmutation Technologies at the Subcritical Facility "YALINA" Proceedings of the ANA/ADTTA, Reno, Nevada, 11-15 November 2001. CD-ROM.

5. V. Bournos, A. Fokov, Y. Fokov, H. Kiyavitskaya, B. Martsynkevich, C. Routkovskaia, Y. Gohar, CM Persson, W. Gudowski, "YALINA-Booster Benchmark Specifications for the IAEA Coordinated Research Projects on Analytical and Experimental Benchmark Analysis on Accelerator Driven Systems, and Low Enriched Uranium Fuel Utilization in Accelerator Driven Sub-Critical Assembly Systems", February 2007.

6. V. Bournos, I. Serafimovich, A. Fokov, Y. Fokov, H. Kiyavitskaya, A. Khilmanovich, B. Martsynkevich, C. Routkovskaia, Y. Gohar, C-M Persson, W. Gudowski, "YALINA-Thermal Benchmark Specifications for the IAEA Coordinated Research Projects on Analytical and Experimental Benchmark Analysis on Accelerator Driven Systems, and Low Enriched Uranium Fuel Utilization in Accelerator Driven Sub-Critical Assembly Systems", March 2007.

7. IAEA, Working Material, Research Coordinated Meeting of the Coordinated Research Project on "Analytical and Experimental Benchmark Analyses of Accelerator Driven Systems", 5-9 Dec 2005 Minsk, Belarus, IAEA-RC-1003.1, TWG-FR/127, Vienna (2006).

8. IAEA, Working Material, Workshop Meeting of the Coordinated Research Project on "Low Enriched Uranium Fuel Utilization in Accelerator Driven Sub-Critical Assembly Systems," 6-9 November 2006 Vienna, Austria.

9. C.-M. Persson et al., "Comparison of Neutron Kinetic Parameters of the Subcritical ADS Experiments Yalina and Yalina Booster", 12th International Conference on Emerging Nuclear Energy Systems (ICENES'2005), Brussels, Belgium, August 21-26, 2005, on CD-ROM, SCK•CEN, Mol, Belgium (2005).

10. G. Aliberti, Y. Gohar, F. Kondev, A. Talamo, H. Kiyavitskaya, V. Bournos, Y. Fokov, C. Routkovskaya, and I. Serafimovich, "YALINA-Thermal Experiment Analysis with the Deterministic Code System ERANOS",ANS Winter Meeting, Rene, NV, USA, November 2008.

11. G. Rimpault, et al., "The ERANOS Code and Data System for Fast Reactor Neutronic Analyses", in Proceedings of PHYSOR 2002 Conference (Seoul, South Korea, October 2002).

12. G. Rimpault, "Algorithmic Features of the ECCO Cell Code for treating Heterogeneous Fast Reactor Assemblies", International Topical Meeting on Reactor Physics and Computation, Portland - Oregon, May 1-5, 1995.

13. OECD/NEA Report 17, "The JEF-2.2 Nuclear Data Library", April 2000.

14. Bernard, D., et al., "Present Status of JEFF-3.1 Qualification for LWR. Reactivity and Fuel 
Inventory Prediction", JEFF Meeting, Paris, France, 28-30 November 2005, JEFDOC-1122.

15. ENDF-102 Data Formats and Procedures for the Evaluated Nuclear Data File ENDF-6. BNL-NCS44945, Rev. 10/91 (ENDF/B-VI), Brookhaven National Laboratory, October 1991.

16. G. Palmiotti, C.B. Carrico and E.E. Lewis, "Variational Nodal Transport Methods with Anisotropic Scattering", Nucl. Sc. Eng., 115, p.233 (1993).

17. A. Rineiski, W. Mashek, G. Rimpault, "Performance of Neutron Kinetics Models for ADS Transient Analyses", AccAPP/ADTTA'01, ANS 2001 Winter Meeting November 11-15, 2001, Reno, Nevada, U.S.A.

18. G. Palmiotti, J.M. Rieunier, C. Gho, M. Salvatores, "BISTRO Optimized Two Dimensional Sn Transport Code", Nucl. Sc. Eng. 104, 26 (1990).

19. G. Aliberti, Y. Gohar, F. Kondev, A. Talamo, H. Kiyavitskaya, V. Bournos, Y. Fokov, C. Routkovskaya, I. Serafimovich, "Deterministic Model for the Analysis of YALINA-Booster Experiments with the ERANOS Code System", International Conference AccApp09, Vienna, Austria, May 2009. 


\section{Appendix A}

\section{Deterministic Model Details}

\section{A.1. Fuel Pin Calculations}

The ERANOS code system initially developed for the analysis of fast systems with extended capabilities for the slowing down treatment with up to 1968 energy groups and it can be used for the analysis of thermal reactors. In order to investigate the ERANOS performance when calculating thermal systems, calculations have been performed for the single fuel cell used in the YALINAThermal of Figure 66 and the obtained results have been compared with MCNPX results. The cell is assumed infinite in the axial direction ( $Z$ direction) with reflected boundary conditions in $X$ and $Y$. The $\mathrm{k}_{\text {eff }}$ results of Table 30 and the neutron flux spectra of Figures 67 to 73 show excellent agreements between ERANOS and MCNPX if the polyethylene region is subdivided in an appropriate number of sub-regions in ERANOS calculations. Table 30 shows that subdividing the fuel region in ERANOS calculation does not play an important role: the use of three sub-regions for the fuel pin produces practically the same results of a single fuel region.

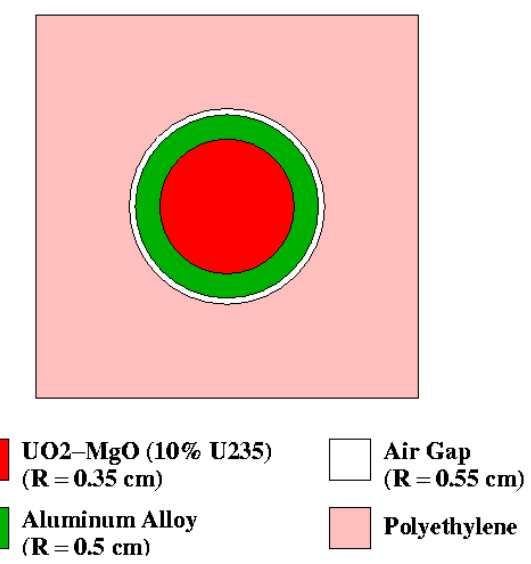

Figure 66. YALINA-Thermal Fuel Cell

Table 30. $\mathrm{k}_{\text {eff }}$ Values Comparison between MCNPx and ERANOS

\begin{tabular}{|c||c|}
\hline Computer code and Nuclear Data Library & $\mathrm{k}_{\mathrm{eff}}$ \\
\hline MCNPX - ENDF/B-VI.6 & $1.36510 \pm 0.00012$ \\
\hline $\begin{array}{c}\text { ERANOS - ENDF/B-VI.8 } \\
\text { (1 Region Fuel; 1 Region Polyethylene) }\end{array}$ & 1.37993 \\
\hline $\begin{array}{c}\text { ERANOS - ENDF/B-VI.8 } \\
\text { (3 Subregions Fuel; 4 Subregions Polyethylene) }\end{array}$ & 1.37021 \\
(3 Subregions Fuel; 5 Subregions Polyethylene) & 1.36640 \\
\hline $\begin{array}{c}\text { ERANOS - ENDF/B-VI.8 } \\
\text { (3 Subregions Fuel; 6 Subregions Polyethylene) }\end{array}$ & 1.36451 \\
\hline $\begin{array}{c}\text { ERANOS - ENDF/B-VI.8 } \\
\text { (3 Subregions Fuel; 7 Subregions Polyethylene) }\end{array}$ & 1.36347 \\
\hline $\begin{array}{c}\text { ERANOS - ENDF/B-VI.8 } \\
\text { (1 Region Fuel; 7 Subregions Polyethylene) }\end{array}$ & 1.36347 \\
\hline
\end{tabular}




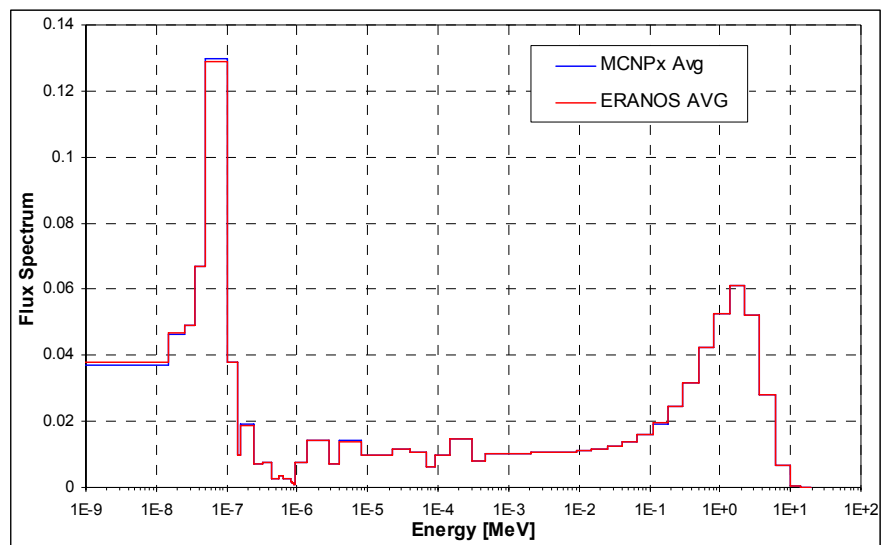

Figure 67. Comparison of MCNPX and ERANOS Averaged Fuel Cell Neutron Spectra

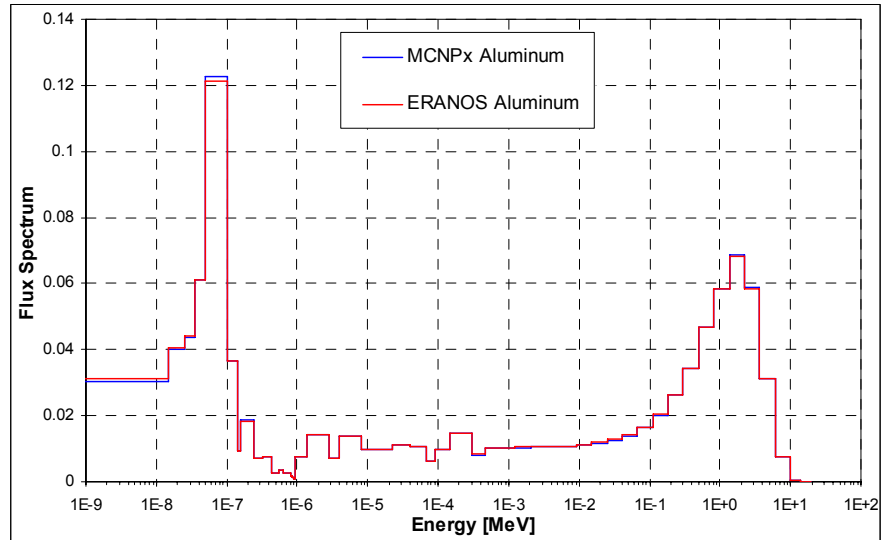

Figure 69. Comparison of MCNPX and ERANOS Averaged Aluminum Clad Neutron Spectra

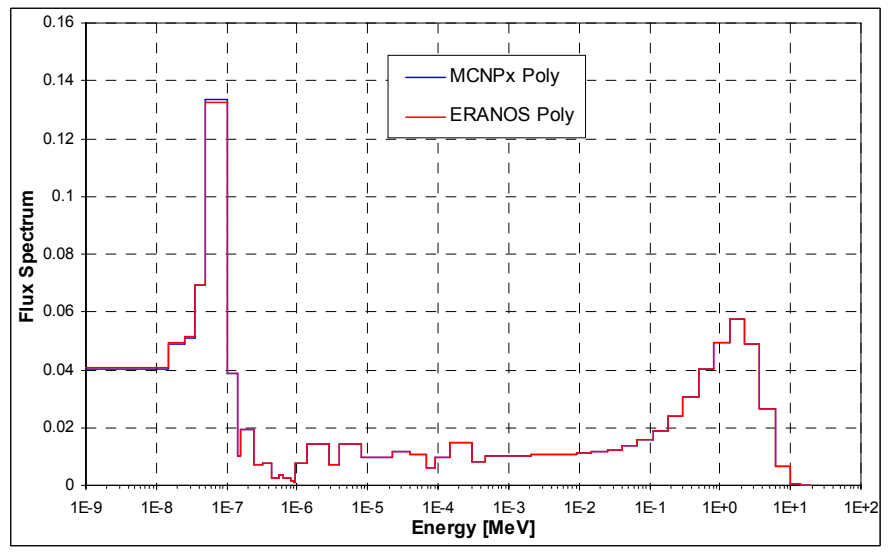

Figure 71. Comparison of MCNPX and ERANOS Averaged Polyethylene Neutron Spectra

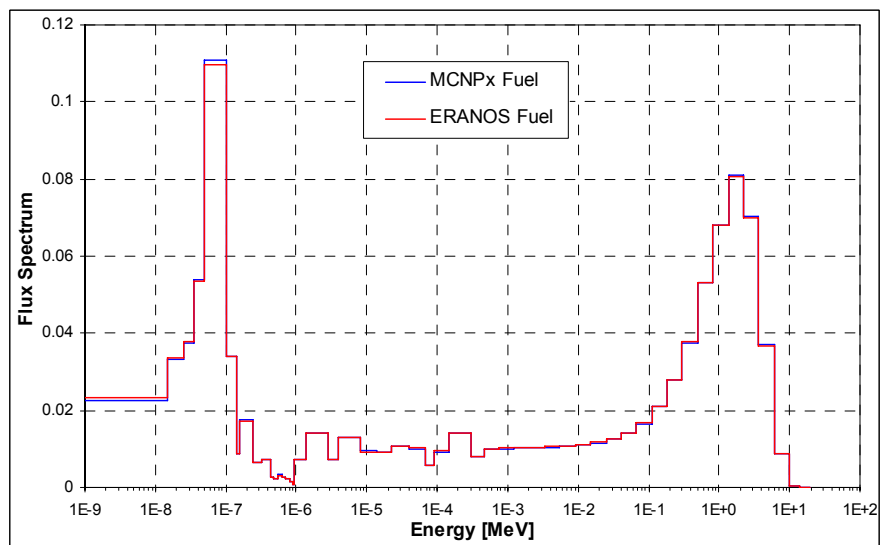

Figure 68. Comparison of MCNPX and ERANOS Averaged Fuel Pin Neutron Spectra

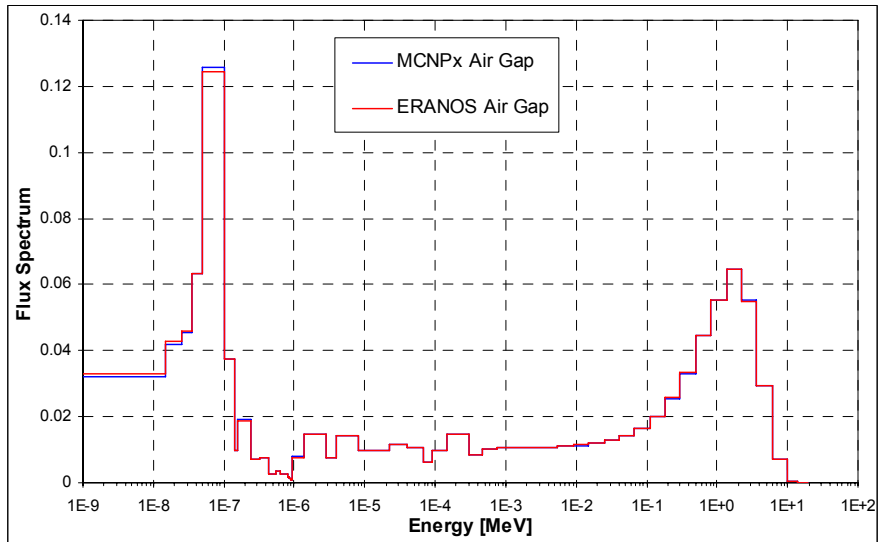

Figure 70. Comparison of MCNPX and ERANOS Averaged Air Gap Neutron Spectra

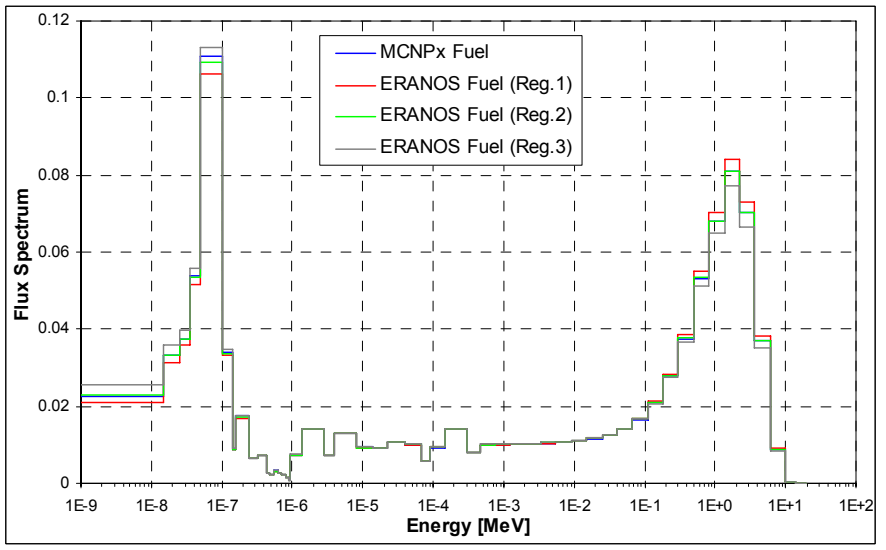

Figure 72. Comparison of MCNPX Fuel Pin Neutron Spectra and ERANOS Neutron Spectra from Different Fuel Pin regions 
ANL-09-23

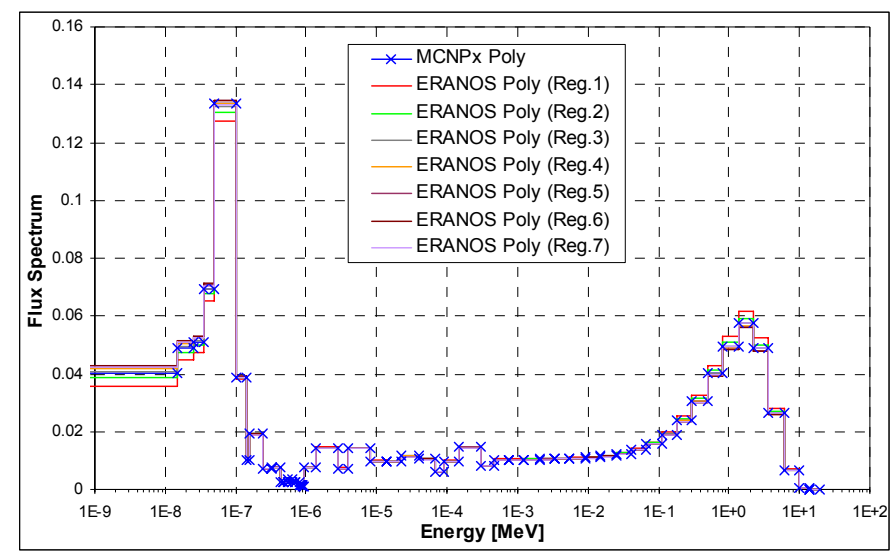

Figure 73. Comparison of MCNPX Polyethylene Neutron Spectra and ERANOS Neutron Spectra from Different Polyethylene regions

\section{A.2. YALINA-Booster}

The deterministic calculational model [19] developed for the YALINA-Booster is shown in Figures 74 and 75 (the axial views) and in Figure 76 (the $X Y$ view). Figures 74 to 76 show the zones where the cross-sections have been separately processed: e.g., a homogeneous set of cross-sections is associated to each zone number. The zones containing experimental channels have not been represented in Figures 74 and 75 . Taking into consideration the zones with experimental channels, a total of 113 cell calculations were performed to describe the deterministic model of the YALINABooster.

As explained before, void regions should be avoided in the geometrical model. Therefore, the void regions are homogenized with the neighbor regions. For instance, zones 24 and 26 have been obtained from the homogenization of the graphite reflector and the air gap as shown in Figure 77. Similarly, zone 23 is the result of homogenizing the borated polyethylene blocks and the air gap. Additional homogenizations have been performed for the end part of the fuel rods and for the experimental channels, details will be discussed later.

Heterogeneity effects are very important for the YALINA configurations, as consequence, the crosssections of most of the regions have been processed with heterogeneous cell calculations. Figures 78 to 83 and 91 to 100 , show the cell configurations used to process the cross-sections of the separate assembly regions. 


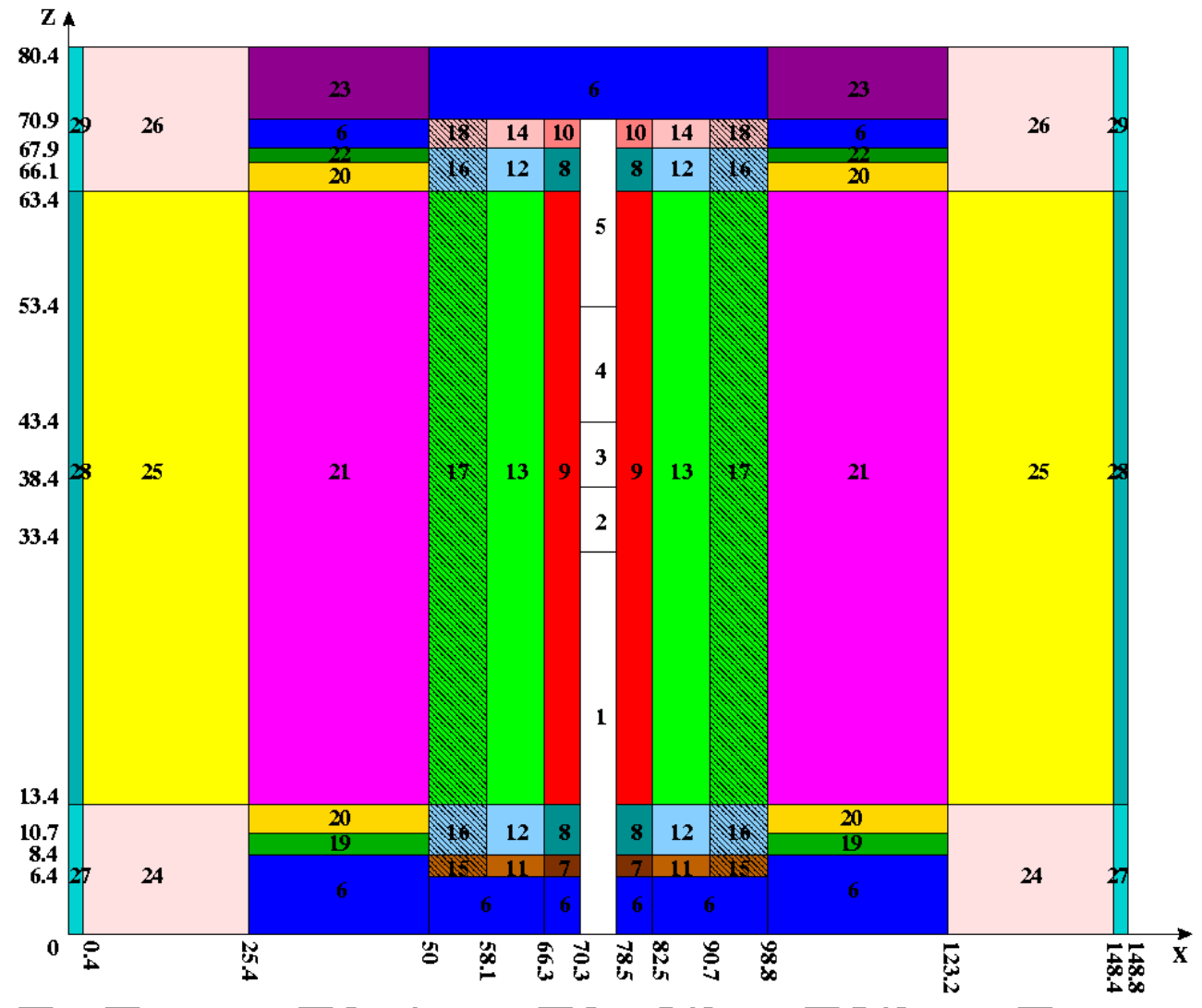

1 To 5 Beam Tube

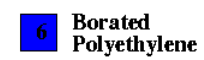

7 Bottom End Part

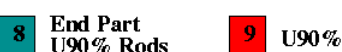

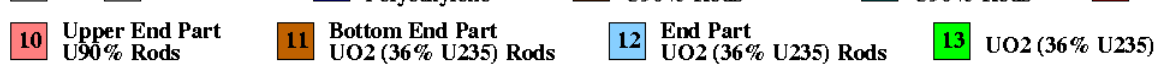

14 Upper End Part $\begin{aligned} & \text { Bottom End Part } \\ & \text { UO2 (U36) Rods }\end{aligned}$ Absorber Subassembly $\begin{aligned} & \text { End Part } \\ & \text { Absorber Subassembly Absorber Subassembly }\end{aligned}$

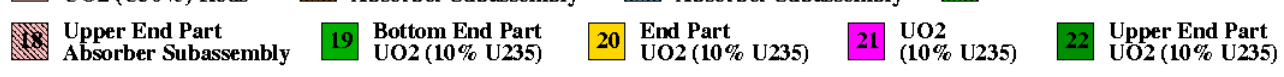

\begin{tabular}{lll|lllll}
23 & $\begin{array}{l}\text { Mixture of Borated } \\
\text { Polyethylene and Air }\end{array} 24$ & 26 & Mixture of \\
Reflector and Air & 25 & Reflector & 28 & Glass & 27 & 29 & Mixture of \\
Glass and Air
\end{tabular} Figure 74. XZ Layout of the YALINA-Booster Deterministic Model (Experimental Channels are not Represented)

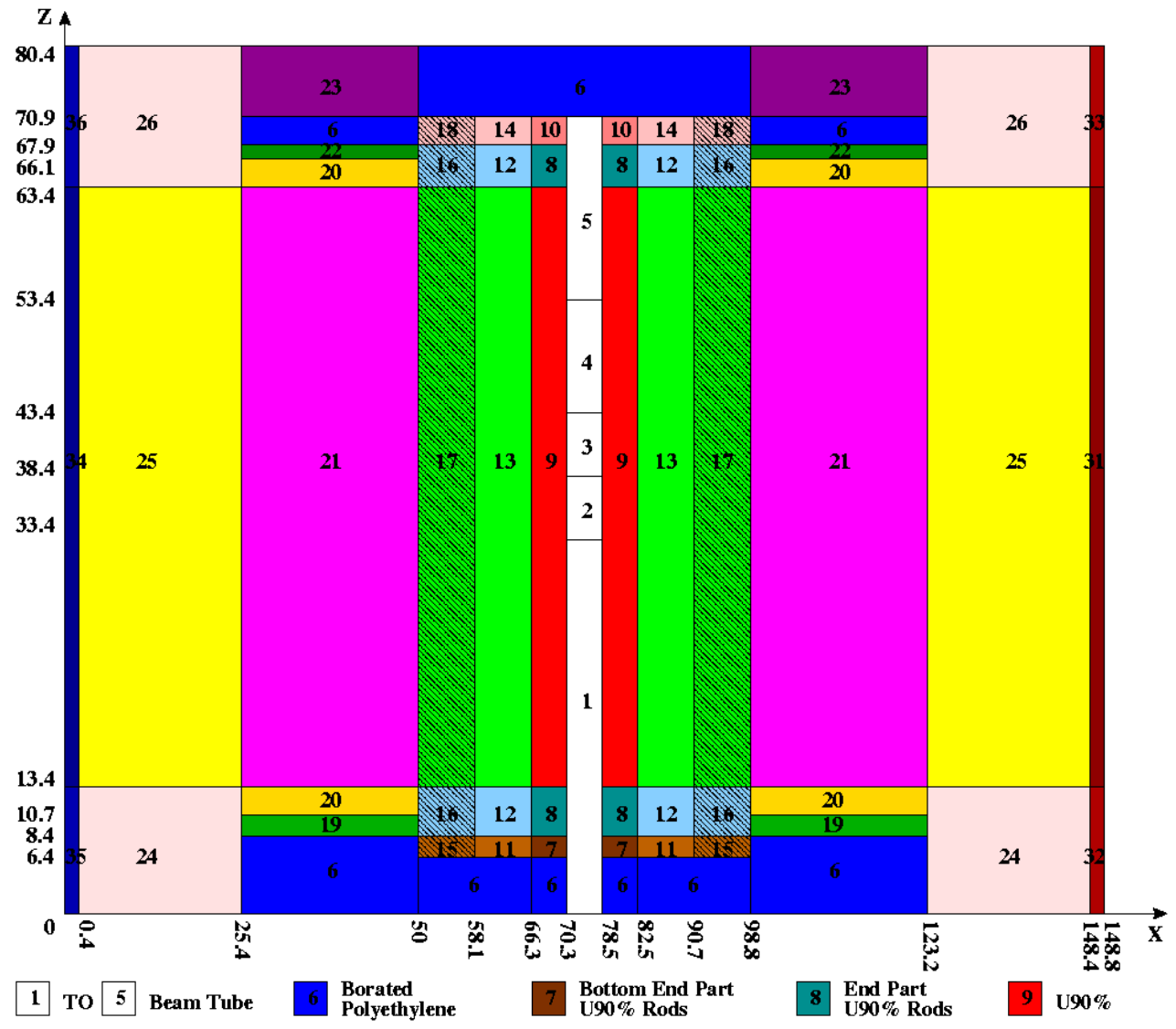

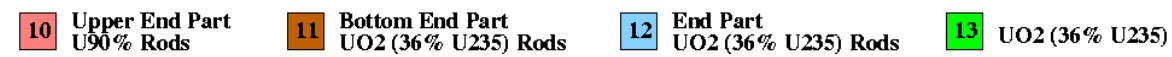

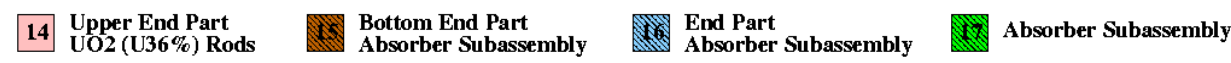

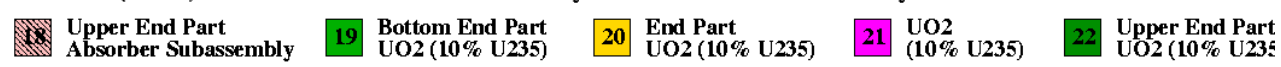

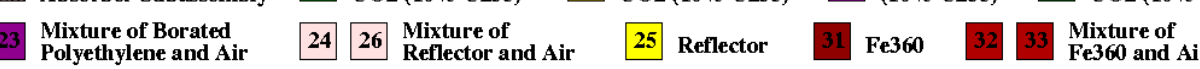

Fe360 + Cadmium 3536 Mixture of Fe360,

Figure 75. YZ Layout of the YALINA-Booster Deterministic Model (Experimental Channels are not Represented) 
147.8

147.4

122.2

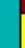

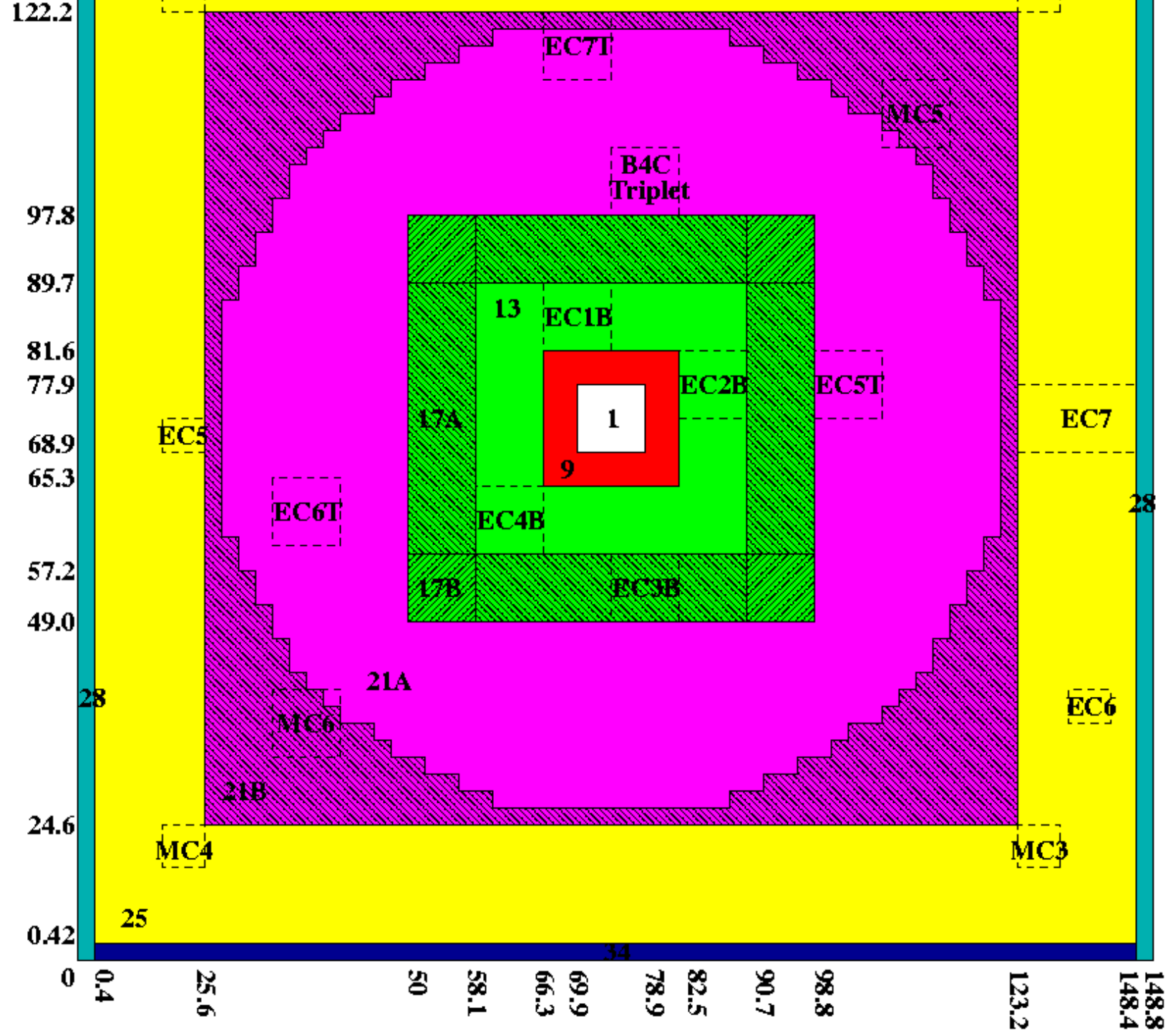

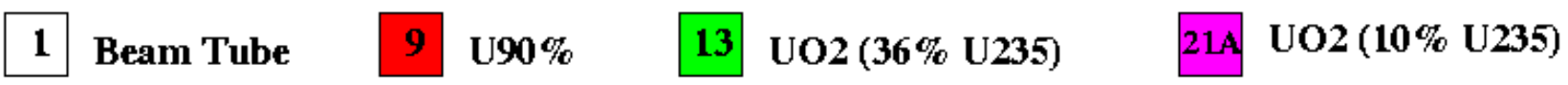

Absorber Subassembly

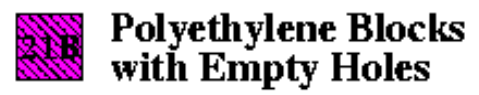

25 Reflector
28 Glass

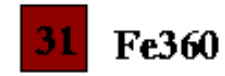
Fe360
Fe360 + Cadmium

Denotes the Location of the Cells for the Experimental Channel Modelization

Figure 76. XY Layout of the YALINA-Booster Deterministic Model 


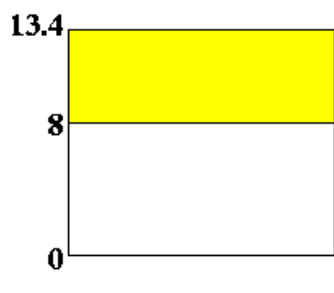

$\square$ Air $\square$ Reflector

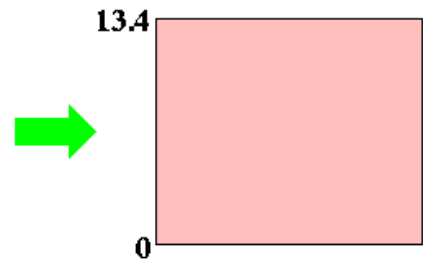

Mixture of Air and Reflector

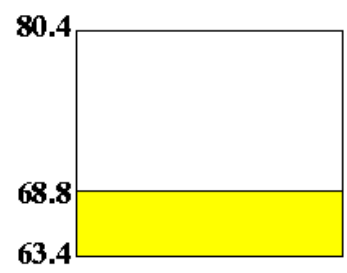

Air $\square$ Reflector

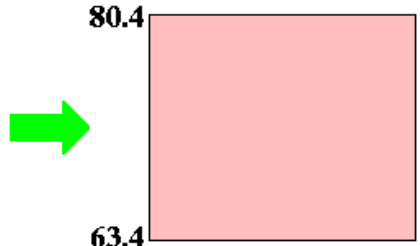

Mixture of Air and Reflector

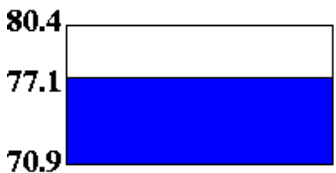

$\square$ Air $\square$ Borated Polyethylene

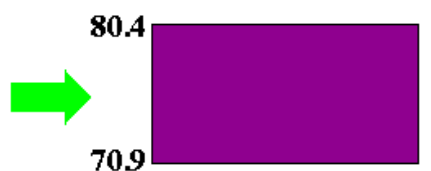

Mixture of Borated

Polyethylene and Air

Figure 77. Homogenization of the Air Gap with the Graphite Reflector (Zones 24 and 26) and of the Air with Borated Polyethylene (Zone 23)

\section{Fuel Regions}

Generally, the cells are chosen to represent the $X Y$ cut of the lead or polyethylene blocks shown in Figures 78 to 83. A particular attention has been devoted to the absorber subassemblies with the $\mathrm{B}_{4} \mathrm{C}$ pins. For these subassemblies, the cross-sections have been processed according to the schemes indicated in Figures 80 and 81, depending on the cell position in the subcritical assembly, whether it is located at the corner or not; the cell calculations have been performed with neutron leakage from the thermal zone. The stainless steel frame surrounds nine blocks of polyethylene or lead in the YALINABooster assembly as shown in Figure 84. The heterogeneous cell calculation conserve the stainless steel volume and each block has its share of stainless steel as shown on the right of Figure 84 . The heterogeneous cell model includes explicit representation for each fuel pin. YALINA-Thermal does not have a stainless steel frame.

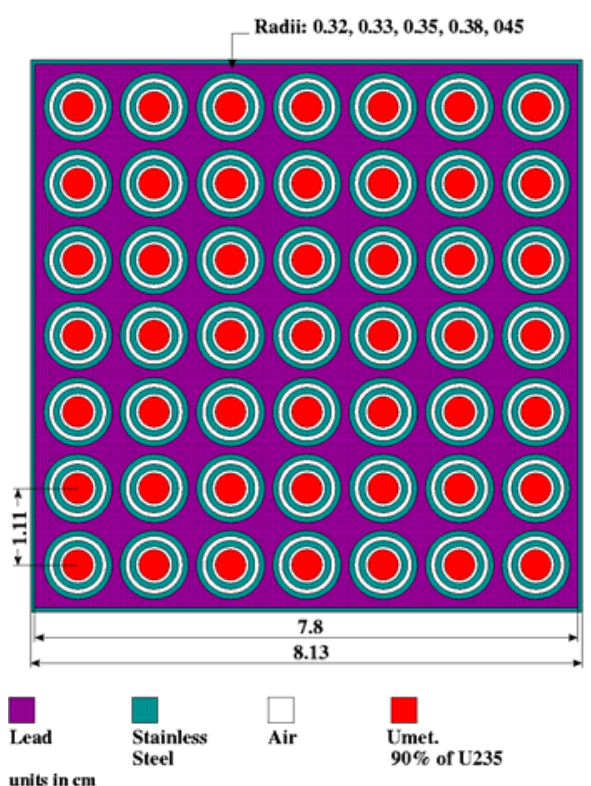

Figure 78. Cell Scheme for Zone 9

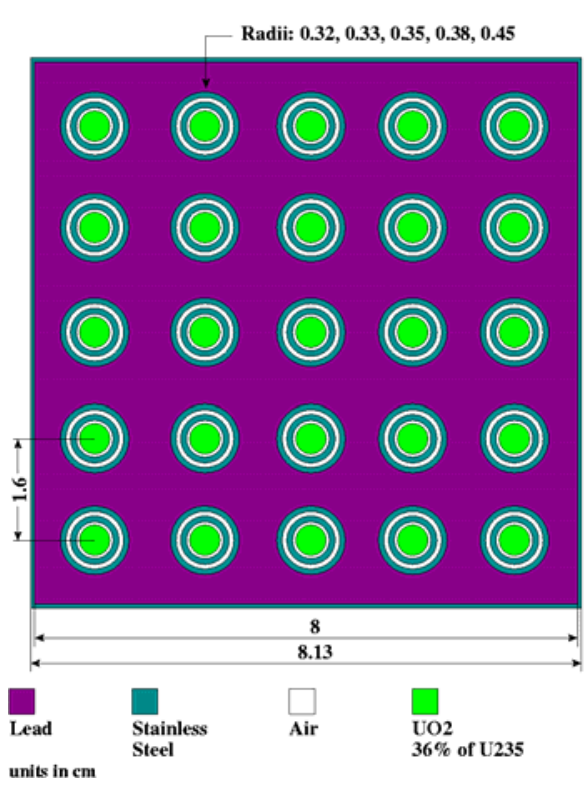

Figure 79. Cell Scheme for Zone 13

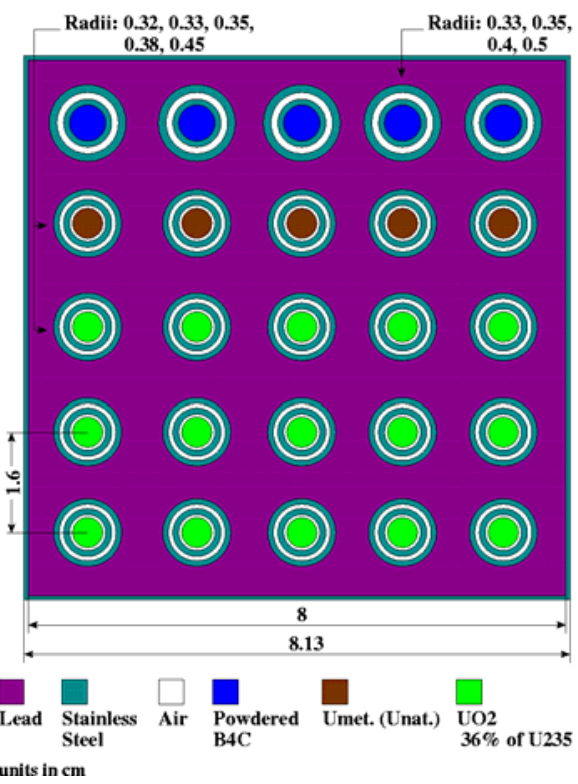

Figure 80. Cell Scheme for Zone 17A 


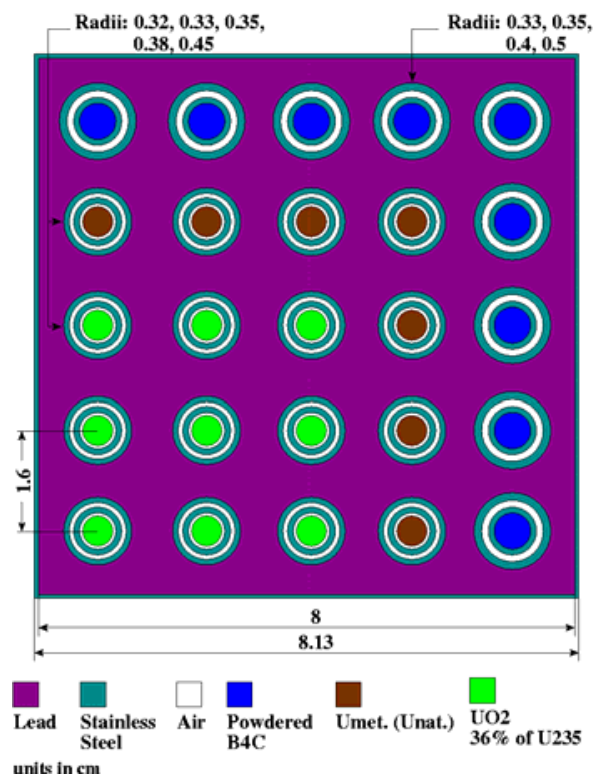

Figure 81. Cell Scheme for Zone 17B

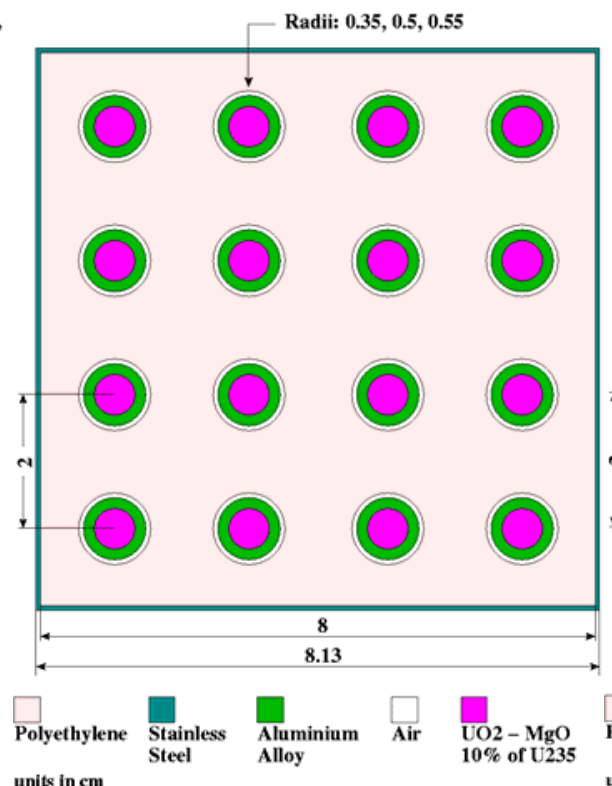

Figure 82. Cell Scheme for Zone 21A

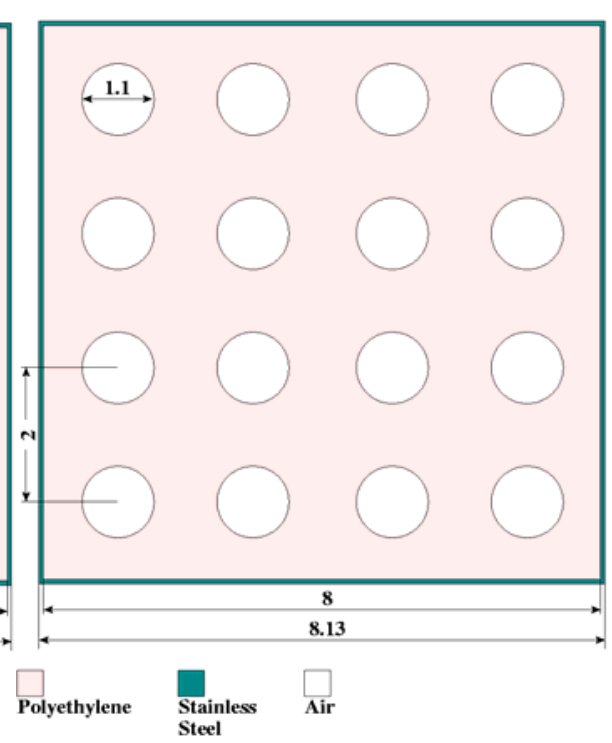

Figure 83. Cell Scheme for Zone 21B
Booster Assembly

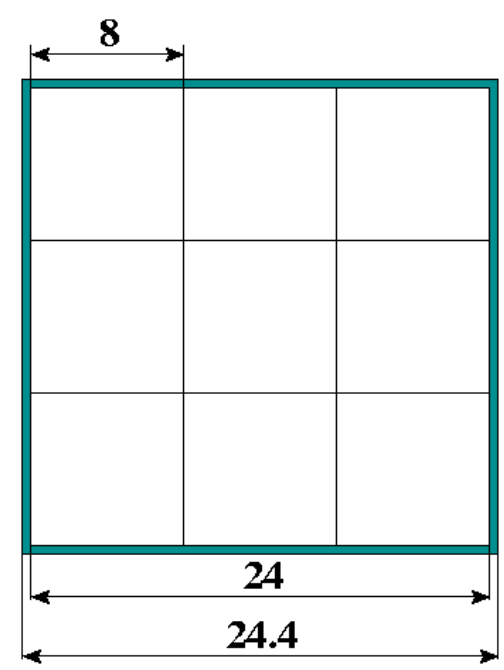

Cell

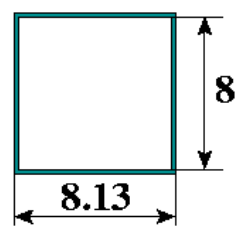

\section{Lead or}

Polyethylene

Stainless

Steel

Figure 84. Cell Scheme and Representation of the Assembly Steel Structure

\section{End Part of the Fuel and Absorber Rods}

The selected axial meshes match the geometries of the fuel rods shown in Figures 6 to 8 . The following are the axial boundaries used for each fuel rod design:

- Bottom part of the 90\% U-235 enriched metallic fuel rods, the $36 \%$ U-235 enriched uranium oxide fuel rods, and the natural uranium fuel rods: $Z=6.4,8.4$, and $13.4 \mathrm{~cm}$ as shown in Figure 85:;

- Top part of the $90 \%$ U-235 enriched metallic fuel rods, the $36 \% \mathrm{U}-235$ enriched uranium oxide fuel rods, and the natural uranium fuel rods: $Z=63.4,67.9$, and $70.9 \mathrm{~cm}$ as shown in Figure 86 ;

- Bottom part of the boron carbide rods: $Z=6.4,8.4$, and $13.4 \mathrm{~cm}$ as shown in Figure 87 ;

- Top part of the boron carbide rods: $Z=63.4,67.9$, and $70.9 \mathrm{~cm}$ as shown in Figure 88;

- Bottom part of EK-10 fuel rods: $Z=8.4,10.7$, and $13.4 \mathrm{~cm}$ as shown in Figure 89;

- Top part of EK-10 fuel rods: $Z=63.4,66.1$, and $67.9 \mathrm{~cm}$ as shown in Figure 90. 
For these regions, the cross-sections have been obtained with heterogeneous geometry, as shown in Figures 91 to 100. However, for some zones material homogenization were used as shown in Figures 85 to 90 .

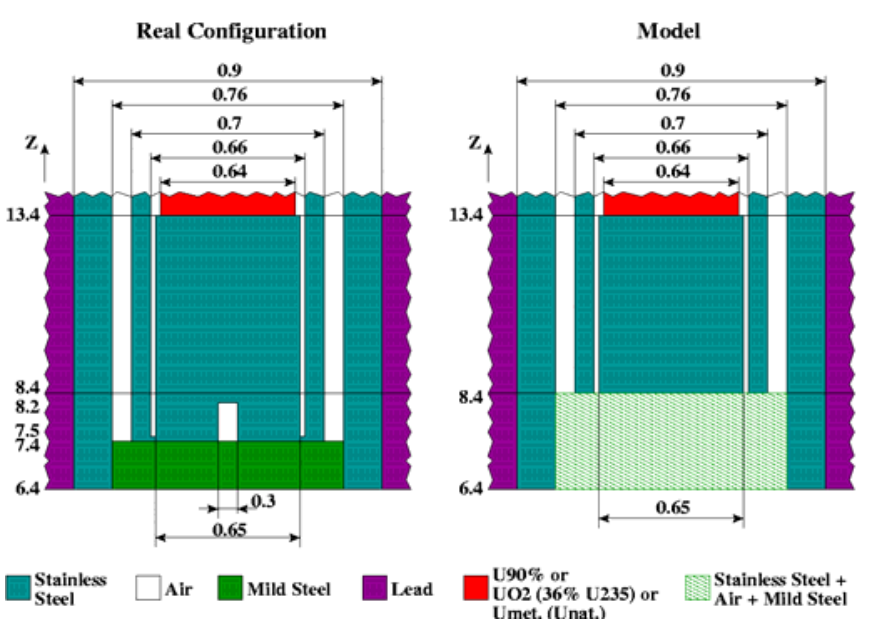

Figure 85. Bottom Part of the $90 \%$ U-235 Enriched Metallic, the $36 \%$ U-235 Enriched Uranium Oxide, and the Natural Uranium Fuel Rods

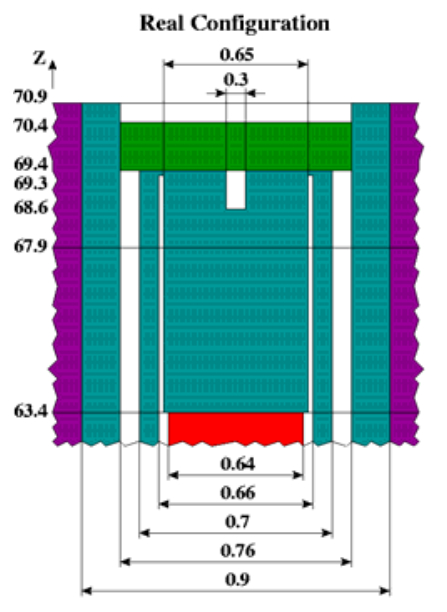

$\square_{\text {Steel }}^{\text {Stainles }}$

Mild Steel Lead (36\% U235) or 1 Air + Mild Ste

Figure 86. Top Part of the $90 \%$ U-235 Enriched Metallic, the $36 \%$ U-235 Enriched Uranium Oxide, and the Natural Uranium Fuel Rods

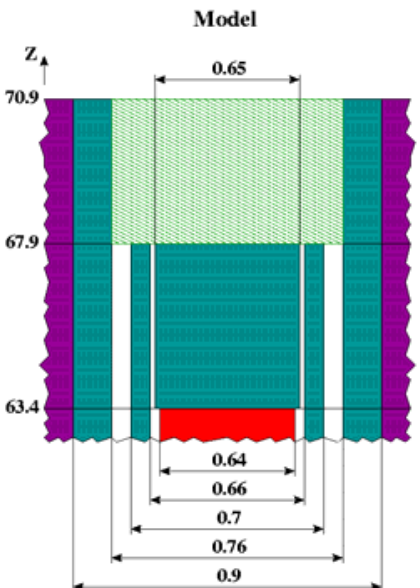

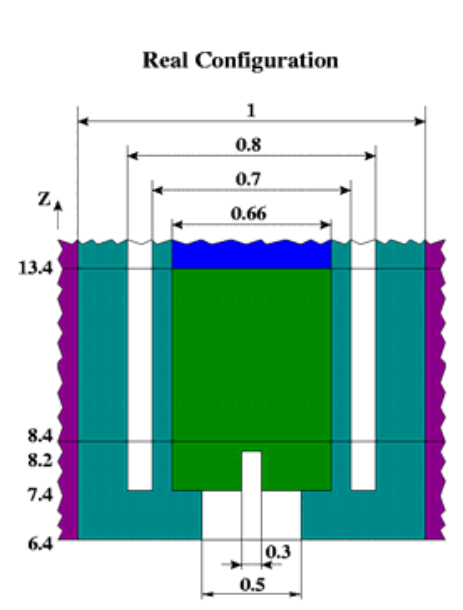
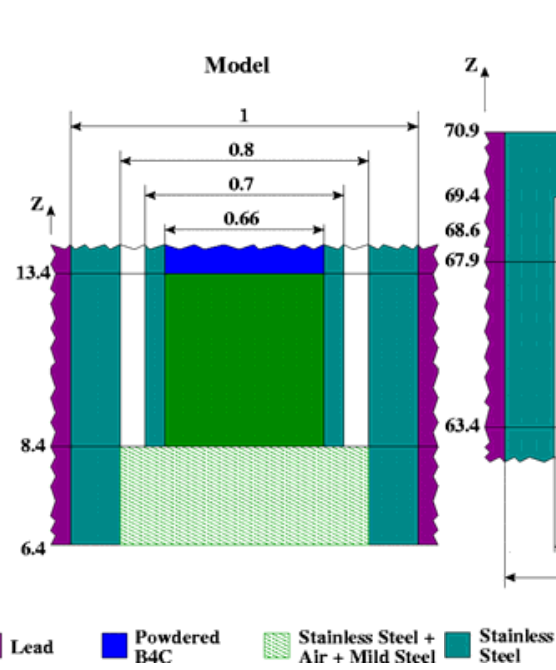

Real Configuration

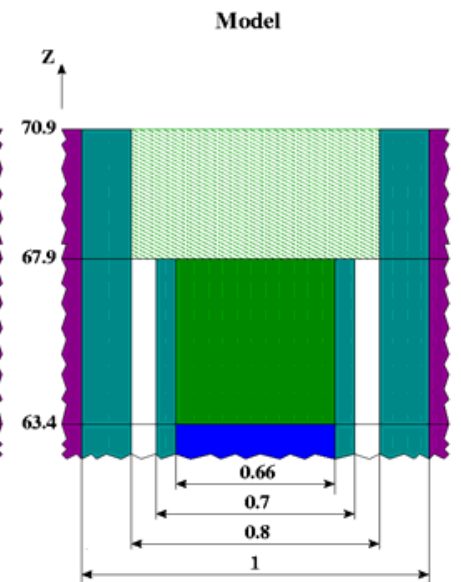

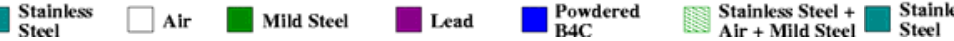
Figure 87. Bottom Part of $\mathrm{B}_{4} \mathrm{C}$ Rods

$\square$ Air $\square$ Mild Steel $\square$ Lead $\square$ B4C $\begin{aligned} & \text { Powdered } \\ & \text { Stainless Steel + } \\ & \text { Air + Mild Steel }\end{aligned}$ Figure 88. Top Part of $\mathrm{B}_{4} \mathrm{C}$ Rods 


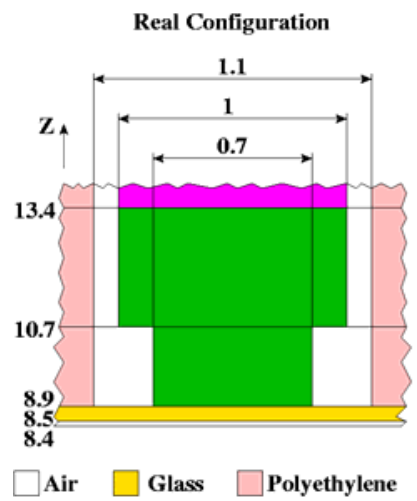

$\square$ Aluminium Alloy

$\square \mathrm{UO2}-\mathrm{MgO}$ (10\% U235)

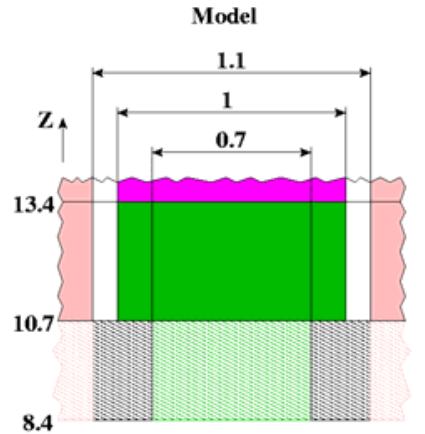
$\begin{array}{lll}\text { Mixture of } & \begin{array}{l}\text { Mixture } \\ \text { Mluminium }\end{array} & \begin{array}{l}\text { Mixture of } \\ \text { Polyethylene, }\end{array}\end{array}$ Alloy, Air and Air and Glass

Figure 89. Bottom Part of EK-10 Fuel Rods
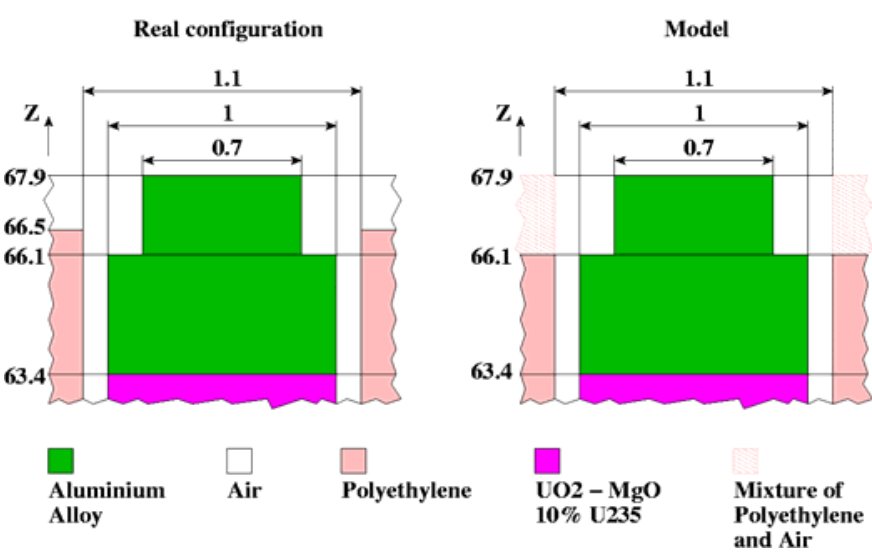

Figure 90. Top Part of EK-10 Fuel Rods
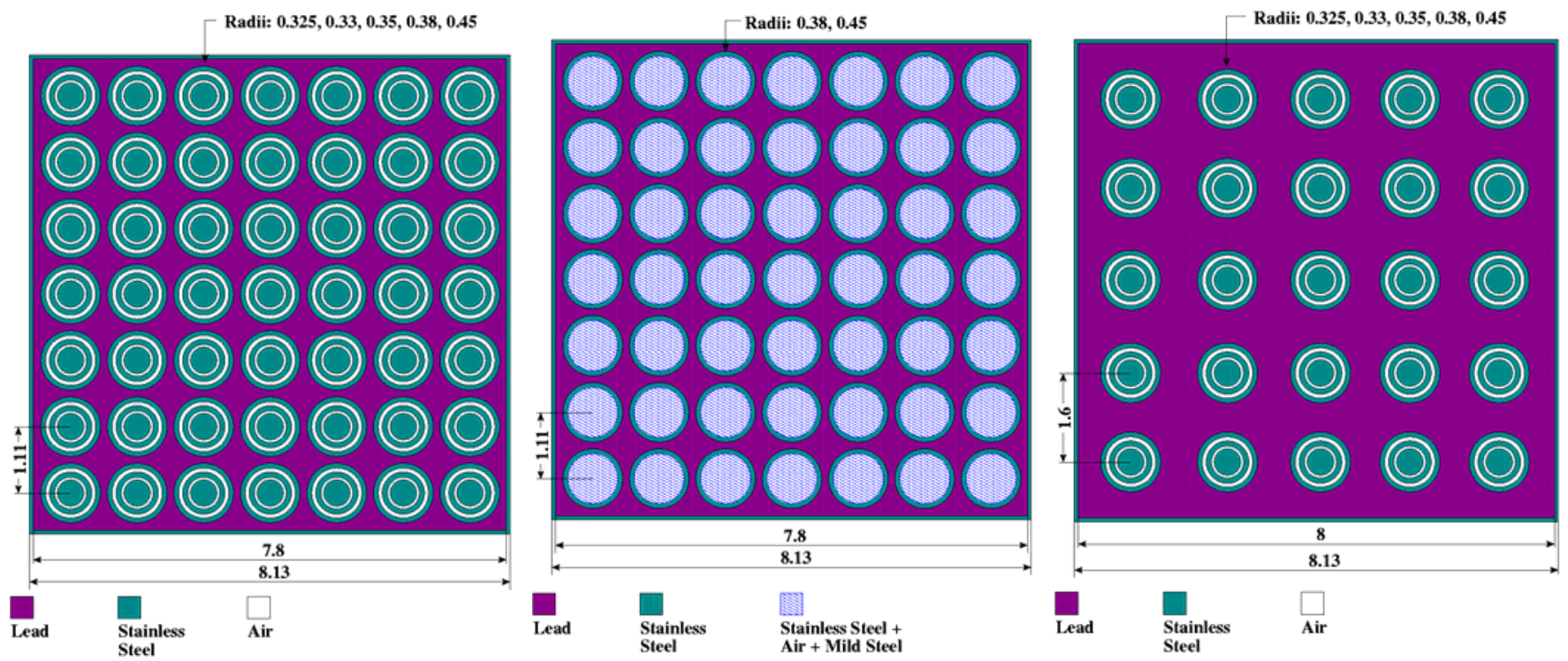

Figure 91. Cell Scheme for Zone 8 Figure 92. Cell Scheme for Zone 7 Fignure 93. Cell Scheme for Zone $(8.4<Z<13.4$ and $63.4<Z<67.9) \quad(6.4<Z<8.4)$ and $10(67.9<Z<70.9) 12(8.4<Z<13.4$ and $63.4<Z<67.9)$ 


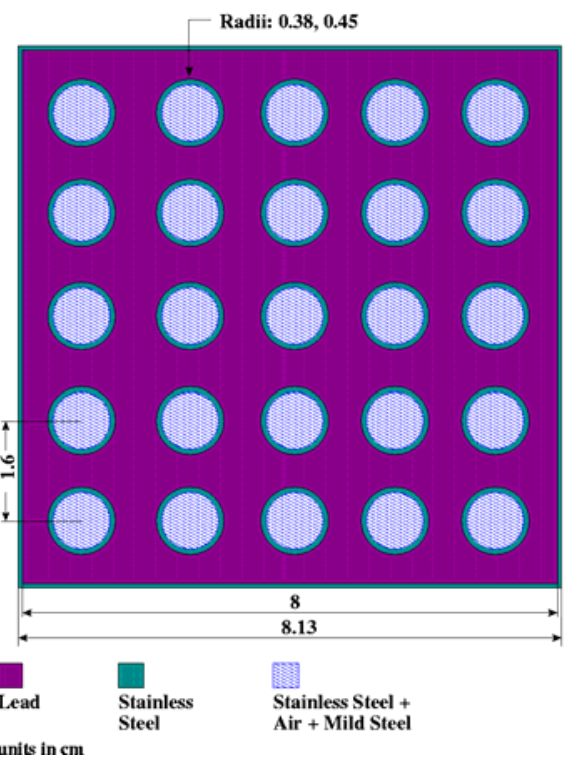

Figure 94. Cell Scheme for Zone $11(6.4<Z<8.4)$ and 14 $(67.9<Z<70.9)$

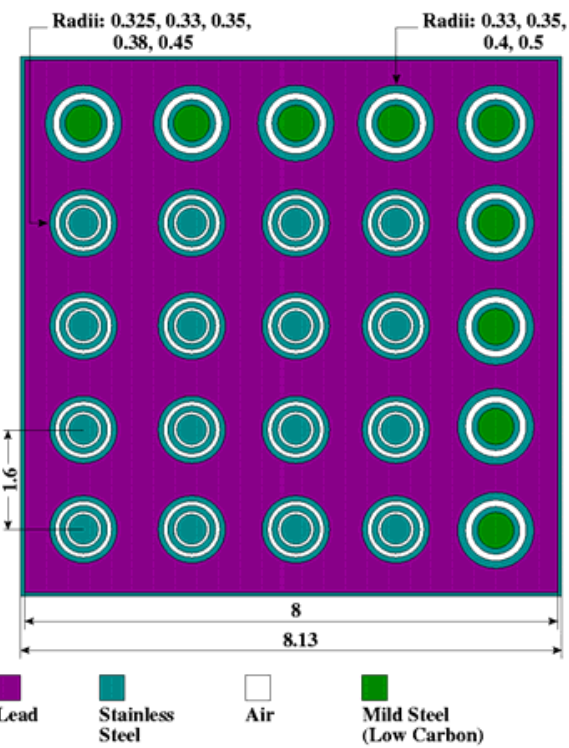

units incm
Figure 97. Cell Scheme for Zone $16(8.4<Z<13.4$ and $63.4<Z<67.9)$ at the Corner

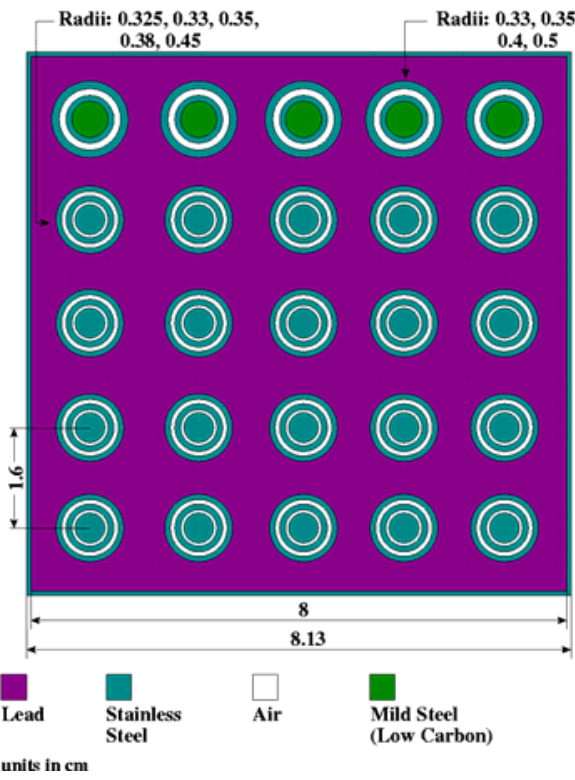

Figure 95. Cell Scheme for Zone $16(8.4<Z<13.4$ and $63.4<Z<67.9)$

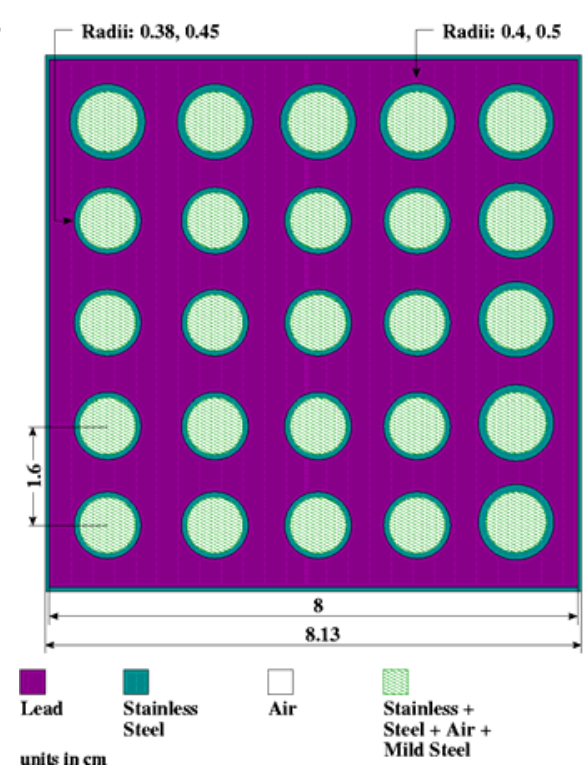

Figure 98. Cell Scheme for Zone $15(6.4<Z<8.4)$ and 18 $(67.9<Z<70.9)$ at the Corner

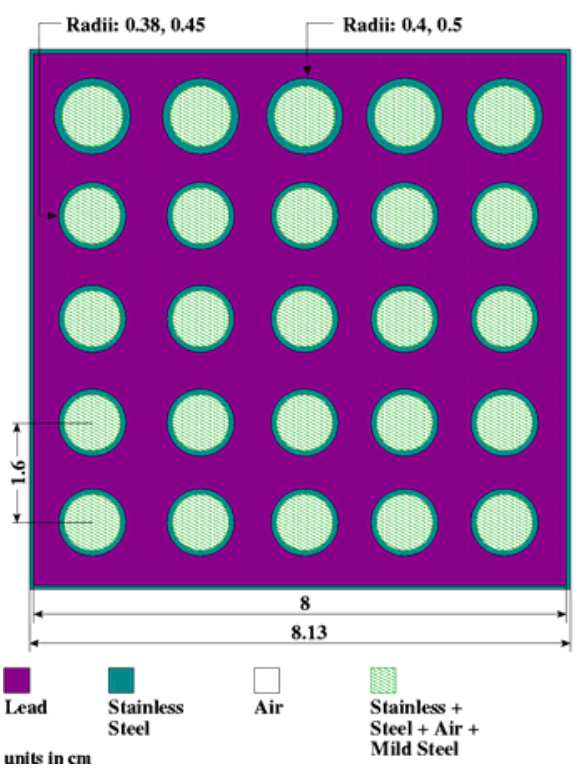

Figure 96. Cell Scheme for Zone $15(6.4<Z<8.4)$ and 18 $(67.9<Z<70.9)$

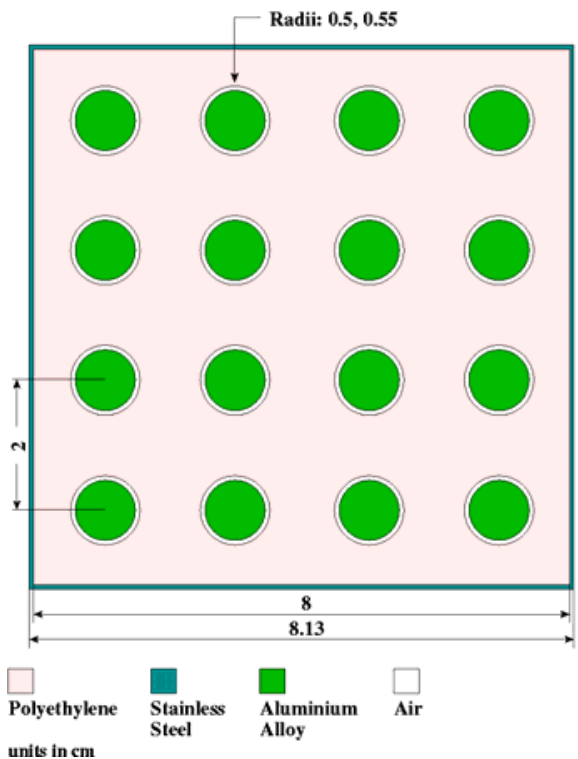

Figure 99. Cell Scheme for Zone $20(10.7<Z<13.4$ and $63.4<Z<66.1)$ 


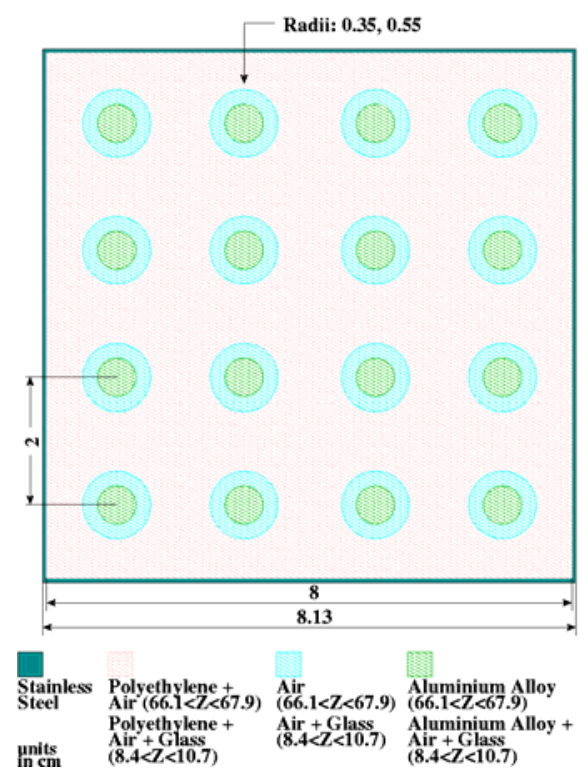

Figure 100. Cell Scheme for Zone $19(8.4<Z<10.7)$ and $22(66.1<Z<67.9)$

\section{Borated Polyethylene Region}

Cross-sections have been processed with a homogeneous cell calculation with homogenized borated polyethylene and stainless steel.

\section{Reflector Region}

Cross-section have been processed with a homogeneous cell calculation with homogenized graphite, stainless steel and glass.

\section{Deuteron Beam Duct and Target}

The central subassembly of the YALINA-Booster, including the deuteron beam duct and the target, has been modeled with six axial zones as shown in Figure 101. The XY views of the cells used for the cross-section processing are shown on the right side of Figure 101. The geometrical layout of these cells includes part of the lead material outside the beam duct and target area. The XY view of the YALINA-Booster shows the $8 \times 8 \mathrm{~cm}$ square central subassembly inside the fast zone with the highly enriched uranium. The fast zone extends for $15.6 \times 15.6 \mathrm{~cm}$. The space between the two squares [(15.6 - 8) / $2=3.8 \mathrm{~cm}]$ has three $90 \% \mathrm{U}-235$ enriched metallic uranium fuel rods. The fuel pitch is $1.114 \mathrm{~cm}$, which leaves $0.458 \mathrm{~cm}$ on each side of the $8-\mathrm{cm}$ deuteron beam duct and target. This space has lead material as shown in the YALINA-Booster configuration. To avoid the introduction of fine meshes in the deterministic model, this lead material is included with the deuteron beam duct and target in its heterogeneous geometrical model as shown in Figure 101. 


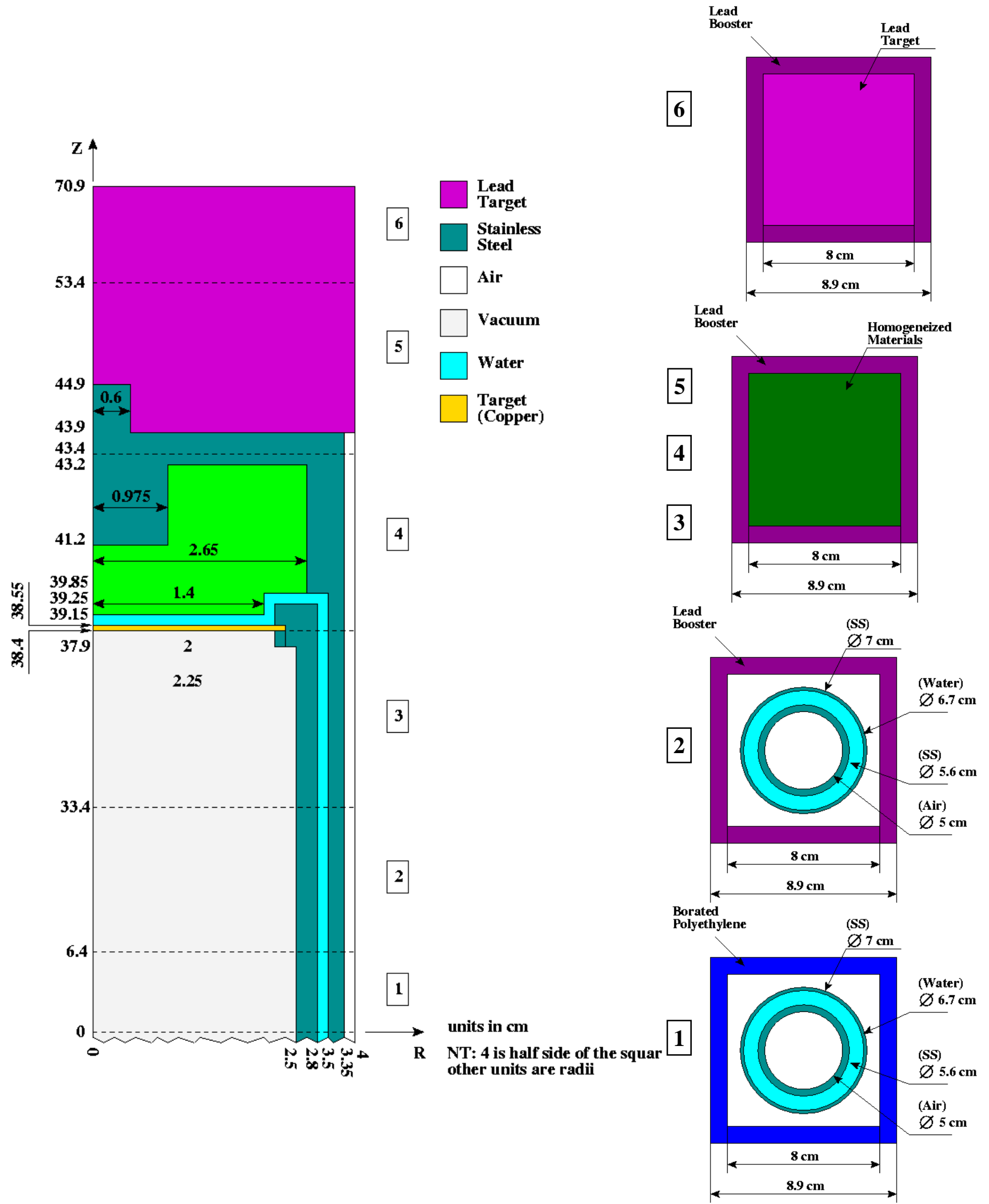

Figure 101. YALINA-Booster Calculational Models of the Central Assembly 


\section{Experimental Channels}

In order to avoid the presence of void regions and fine meshes in the deterministic model, the experimental channels have been homogenized with the regions where they are located. As consequence, the experimental channels located in the reflector are homogenized with an opportune volume of the reflector itself. The experimental channels located in the fuel zones are homogenized over the volume of the cell used to create the cross-section for the fuel region where they are located. Figure 102 shows the cell scheme adopted for the EC4B experimental channel. Additionally, due to the limitations imposed by the cell code in the geometry description, some simplifications were adopted to describe the presence of the experimental channels. For instance, Figure 103 shows the real geometry description of the cell containing the experimental channel EC1B, while Figure 104 shows its model. Similarly, Figures 105 and 106 show the real configuration and the model of the cell containing the experimental channels EC5T. Finally, Figures 107 and 108 show the solution adopted to represent the three void channels for the boron carbide rods in the thermal zone.

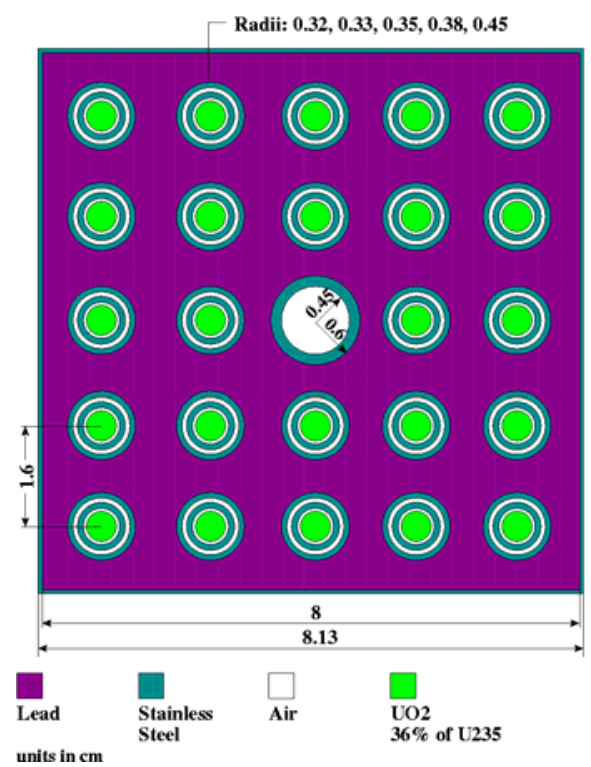

Figure 102. EC4B Experimental Channel

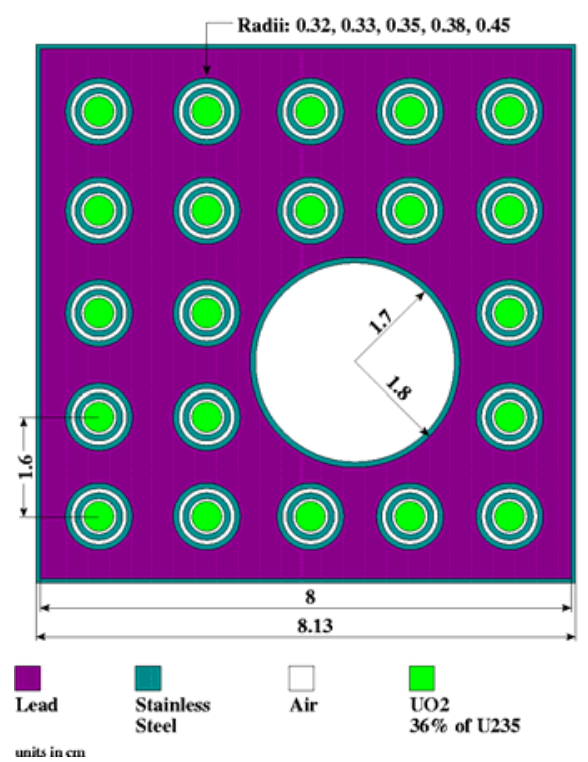

Figure 103. EC1B Experimental Channel

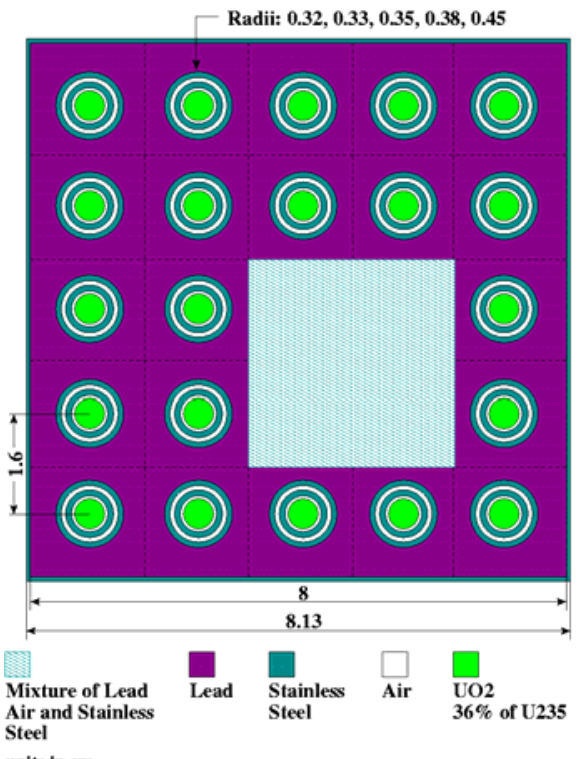

units in $\mathrm{cm}$

Figure 104. EC1B Calculational Model 


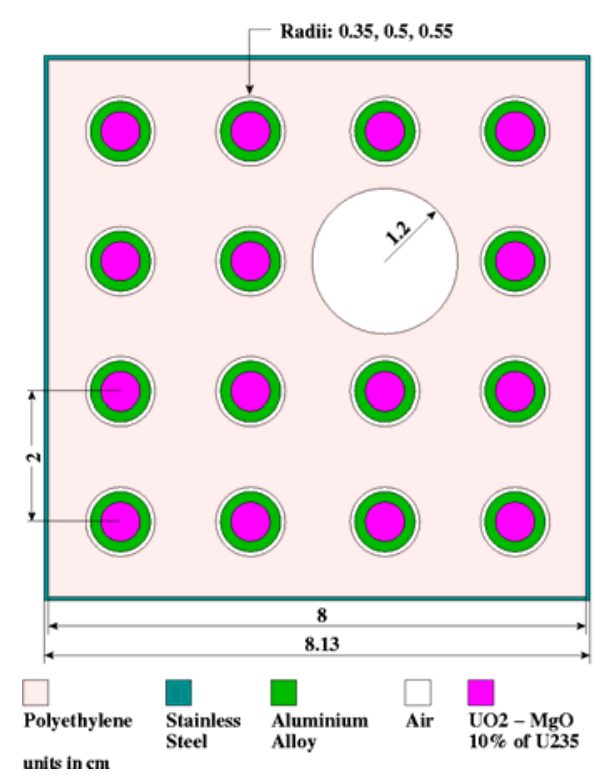

Figure 105. EC5T Experimental Channel

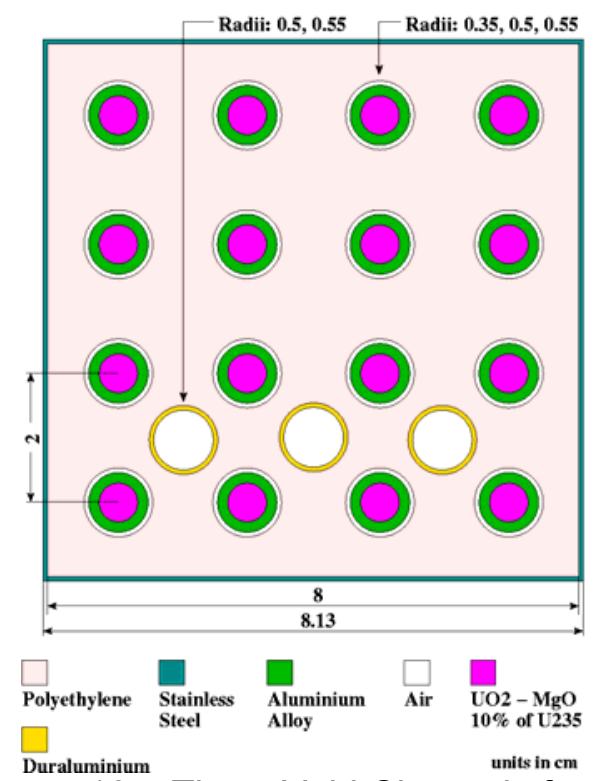

Figure 107. Three Void Channels for the Boron Carbide Rods

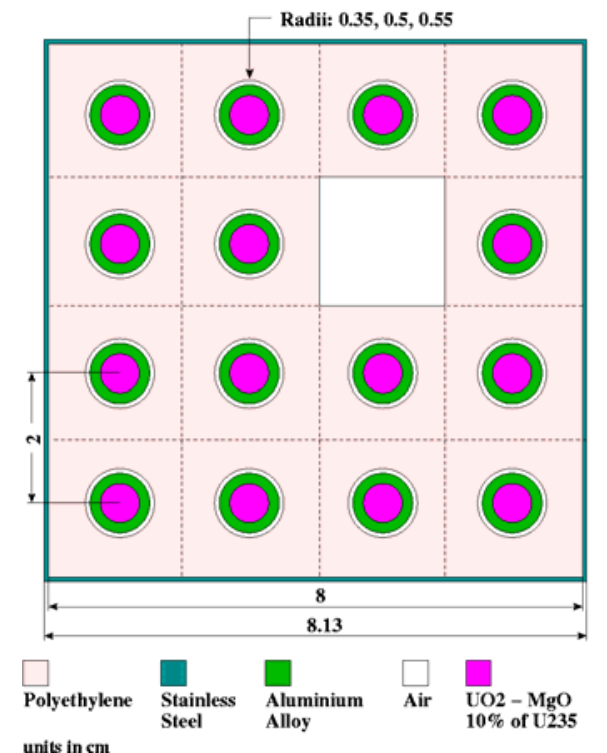

Figure 106. EC5T Calculational Model

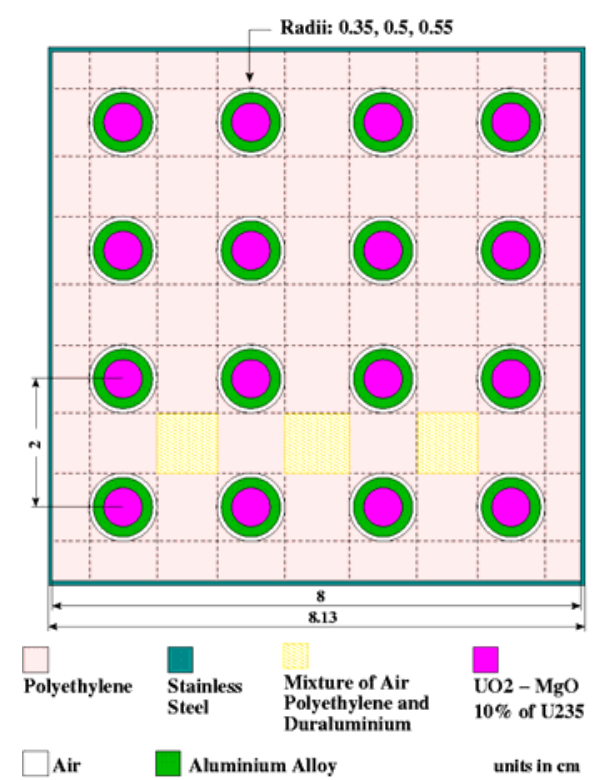

Figure 108. The calculational model of the three Void Channels for the Boron Carbide

Rods

\section{A.3. YALINA-Thermal}

The deterministic model developed for the YALINA-Thermal is shown in Figures 109 and 110 (the axial views), and in Figure 111 (the $X Y$ view). Figures 109 to 111 show the regions where the crosssections have been separately processed: e.g., a homogeneous set of cross-sections is associated to each zone number. The zones containing experimental channels are not presented in Figures 109 and 110. The number of cell calculations describing the deterministic model is 49 including the zones with experimental channels.

As the case for the YALINA-Booster, the void regions of the YALINA-thermal configuration were homogenized with the neighbor regions. For instance, the cross-sections of zone 12 were obtained by 
ANL-09-23

the homogenization of a section of the graphite reflector and the air gap as shown in Figure 112. In addition, homogenizations were performed for the end part of the fuel rods and the experimental channels.

Heterogeneous cell calculations were performed for the other regions to get their homogenized crosssections. Figures 113 to 115,118 and 119 , show the cell configuration used to process the crosssections of the different regions 


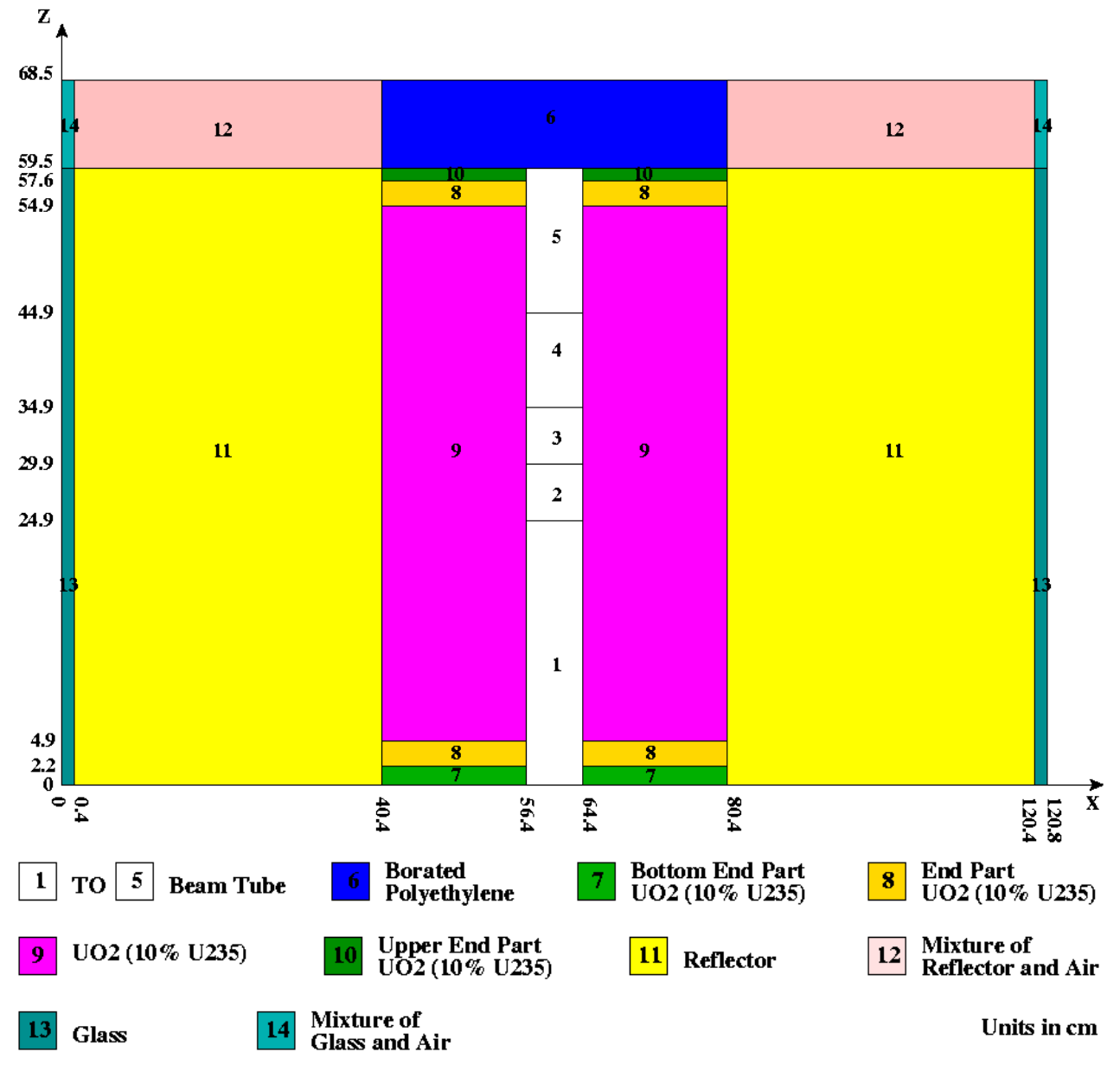

Figure 109. XZ Model for the YALINA-Thermal Deterministic Model (Experimental Channels are not Represented)

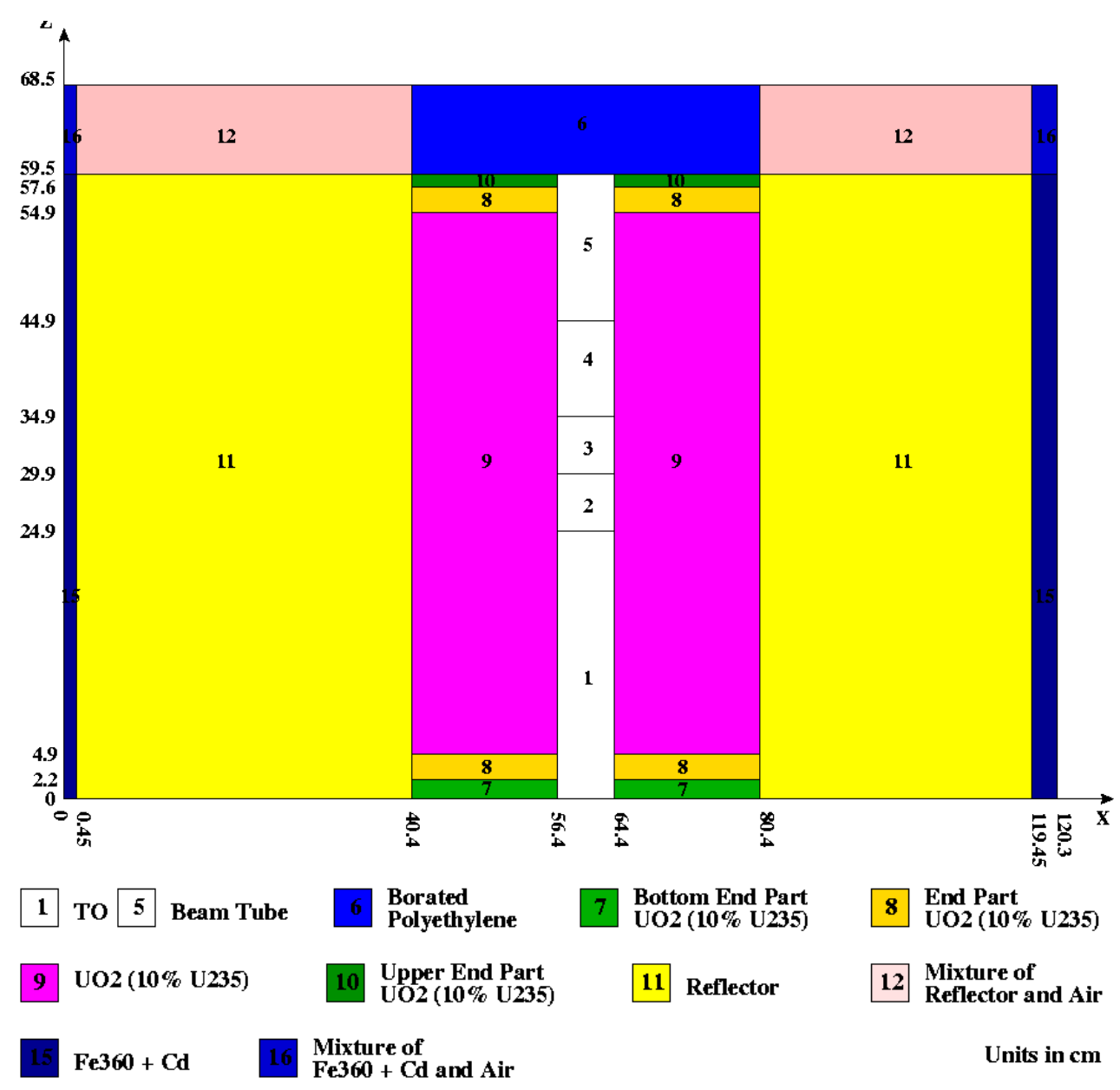

Figure 110. YZ Model for the YALINA-Thermal Deterministic Model (Experimental Channels are not Represented) 

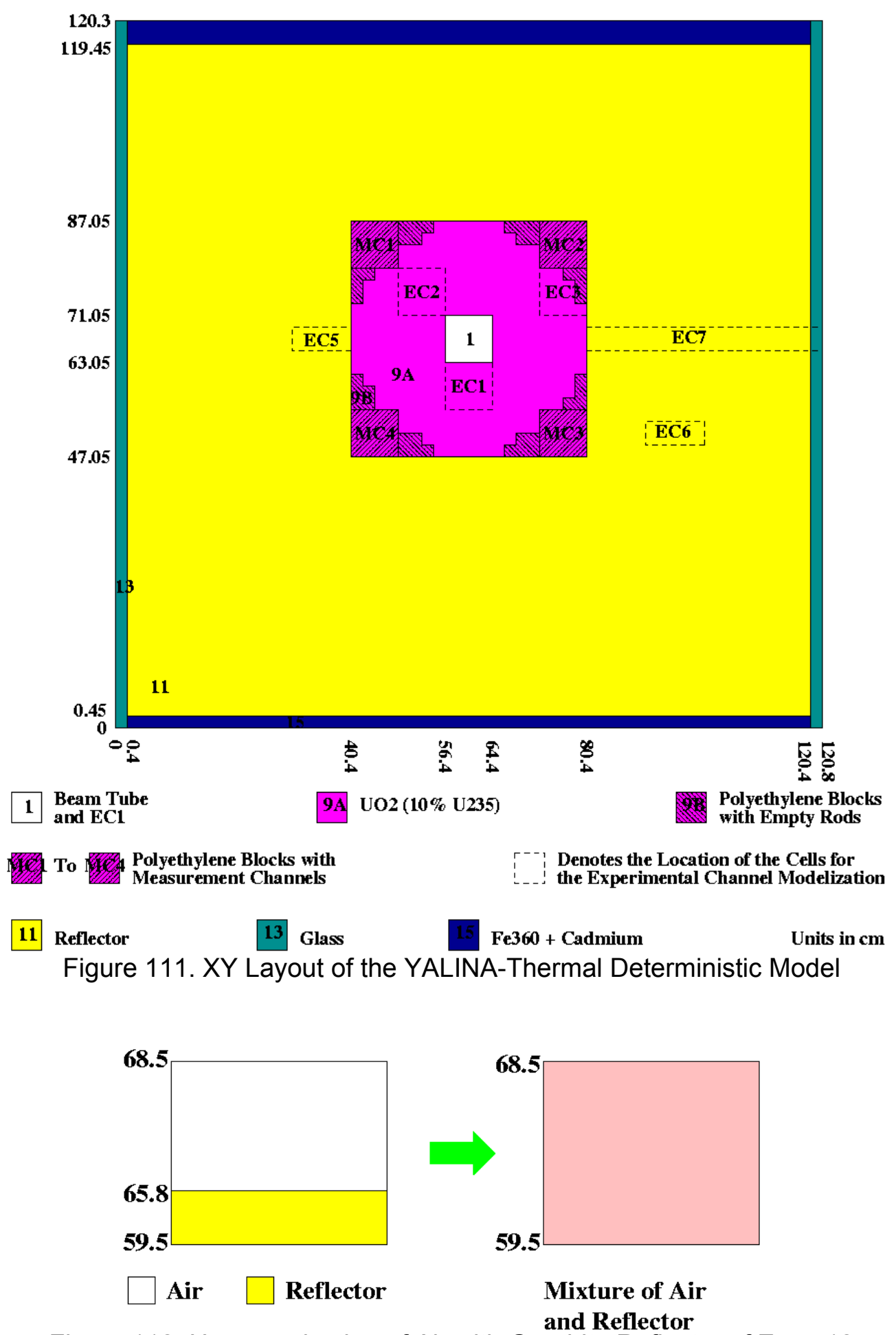

Figure 112. Homogenization of Air with Graphite Reflector of Zone 12

\section{Fuel Regions}

Generally, the cell is chosen with the purpose to represent the $X Y$ cut of the polyethylene subassemblies as shown in Figures 113 to 115. In the YALINA-Thermal the polyethylene blocks are assembled without any stainless steel frame around. As consequence, the cells used for the crosssection processing do not have the stainless steel frame represented in the corresponding cells of the YALINA-Booster. 

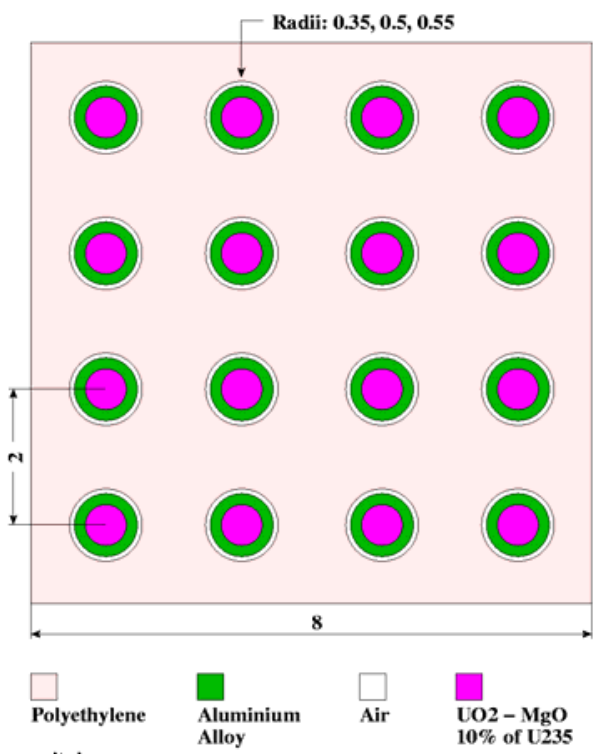

units in $\mathbf{c m}$

Figure 113. Cell Scheme for Zone
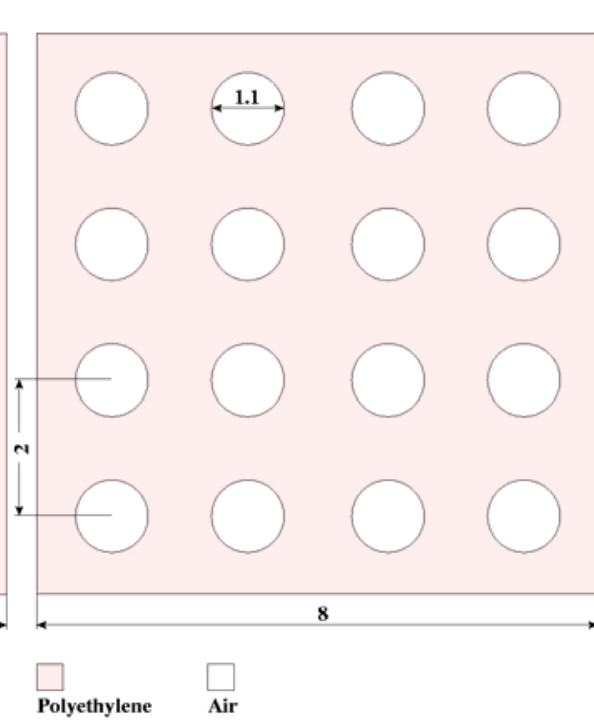

units in cm

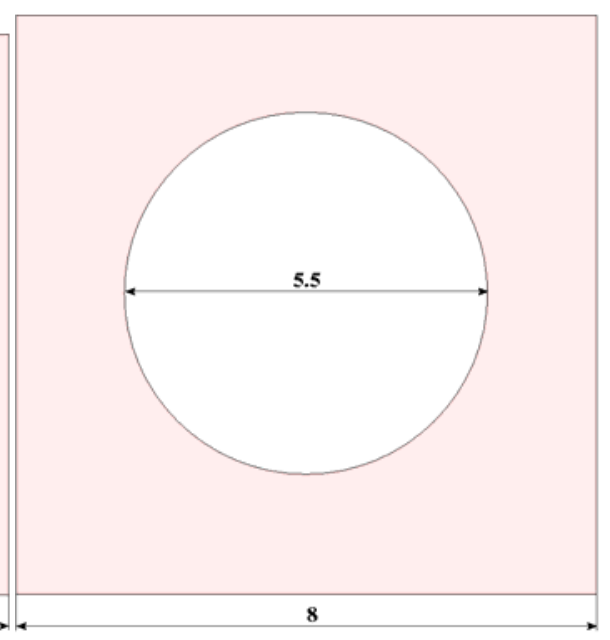

Polyethylene Air

units in $\mathrm{cm}$ 9A

9B

- MC4 Measurement Channels

\section{End Part of the Fuel Rods}

The selected axial meshes match the geometry of the fuel rod design shown in Figure 8 . The following are the axial boundaries used for each fuel rod design:

- Bottom part of EK-10 fuel rods: $Z=0,2.2$, and $4.9 \mathrm{~cm}$ as shown in Figure 116;

- Top part of EK-10 fuel rods: $Z=54.9,57.6$, and $59.5 \mathrm{~cm}$ as shown in Figure 117.

For these regions, the cross-sections have been obtained with heterogeneous geometry, as shown in Figures 118 and 119. However, for some zones material homogenization were used as shown in Figures 116 and 117.

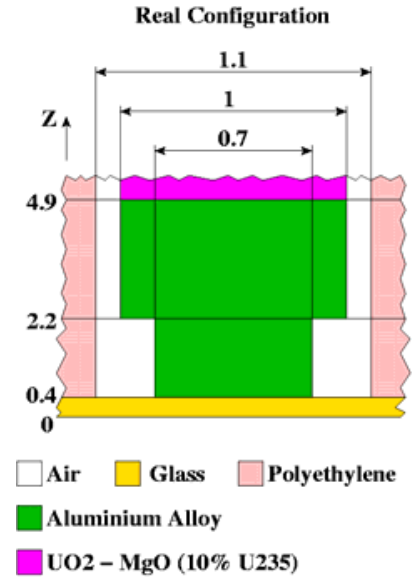
Figure 116. Bottom Part of EK-10 Fuel Rods iun
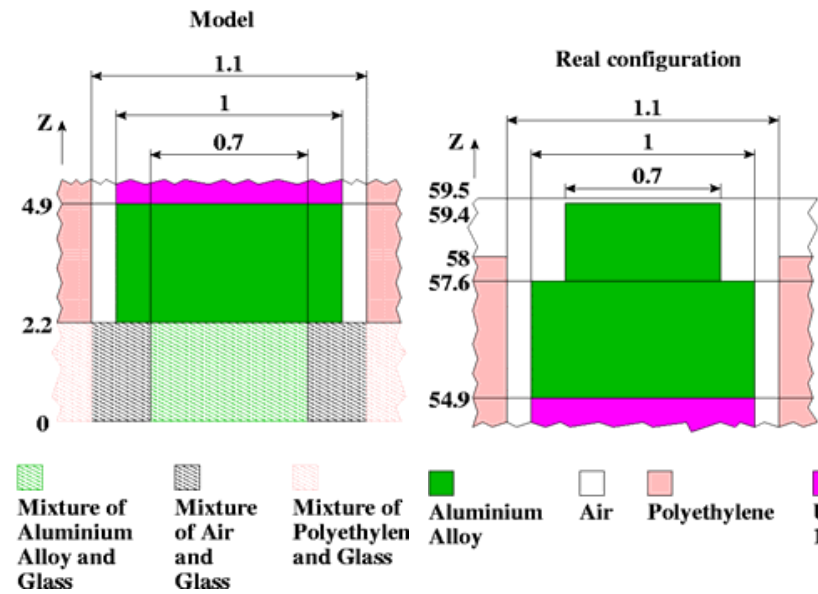

Figure 117. Top Part of EK-10 Fuel Rods 
ANL-09-23

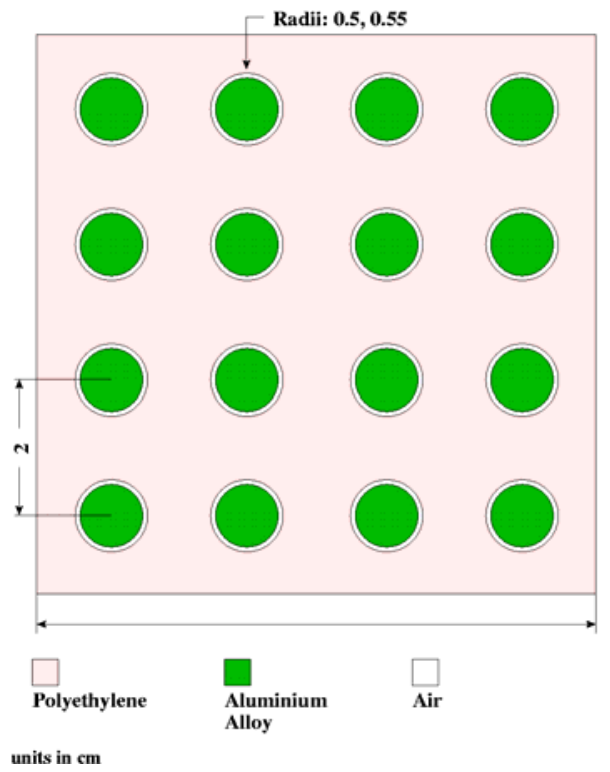

Figure 118. Cell Scheme for Zone 20 $(2.2<Z<4.9$ and $54.9<Z<57.6)$

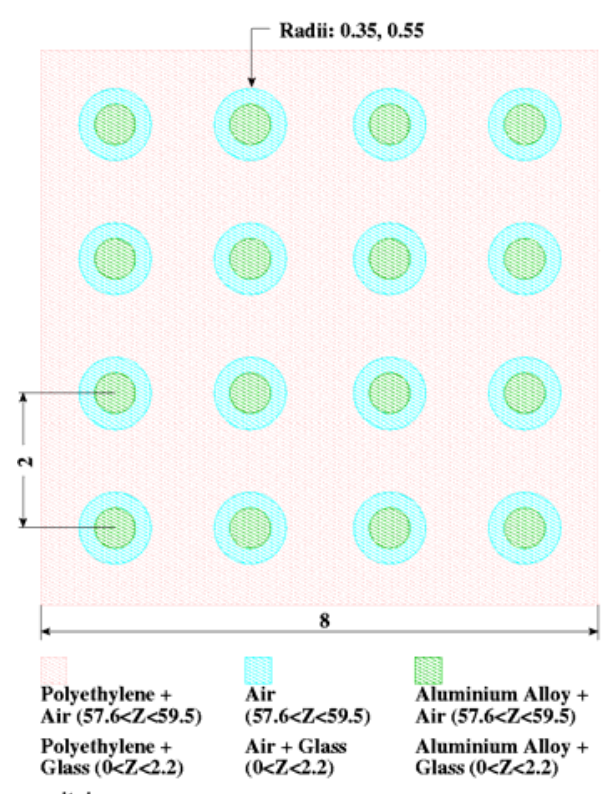

units in cm

Figure 119. Cell Scheme for Zone $19(0<Z<2.2)$ and $22(57.6<Z<59.5)$

\section{Borated polyethylene region}

Borated polyethylene and stainless steel cross-sections have been processed with a homogeneous cell calculation.

\section{Reflector region}

Graphite, stainless steel and glass cross-section have been processed with a homogeneous cell calculation.

\section{Deutron Beam Duct and Target}

The central subassembly of the YALINA-Thermal including the deuteron beam duct and the target has been presented with 5 axial zones as shown in Figure 120. The XY layout of the cells used for the cross-section processing is shown on the right side of Figure 120 for each axial zone. The deuteron beam duct and the target of the YALINA-Thermal has been modeled like the case of the YALINABooster. However, YALINA-Thermal has a stainless steel tube around the central assembly as shown in Figure 120. 


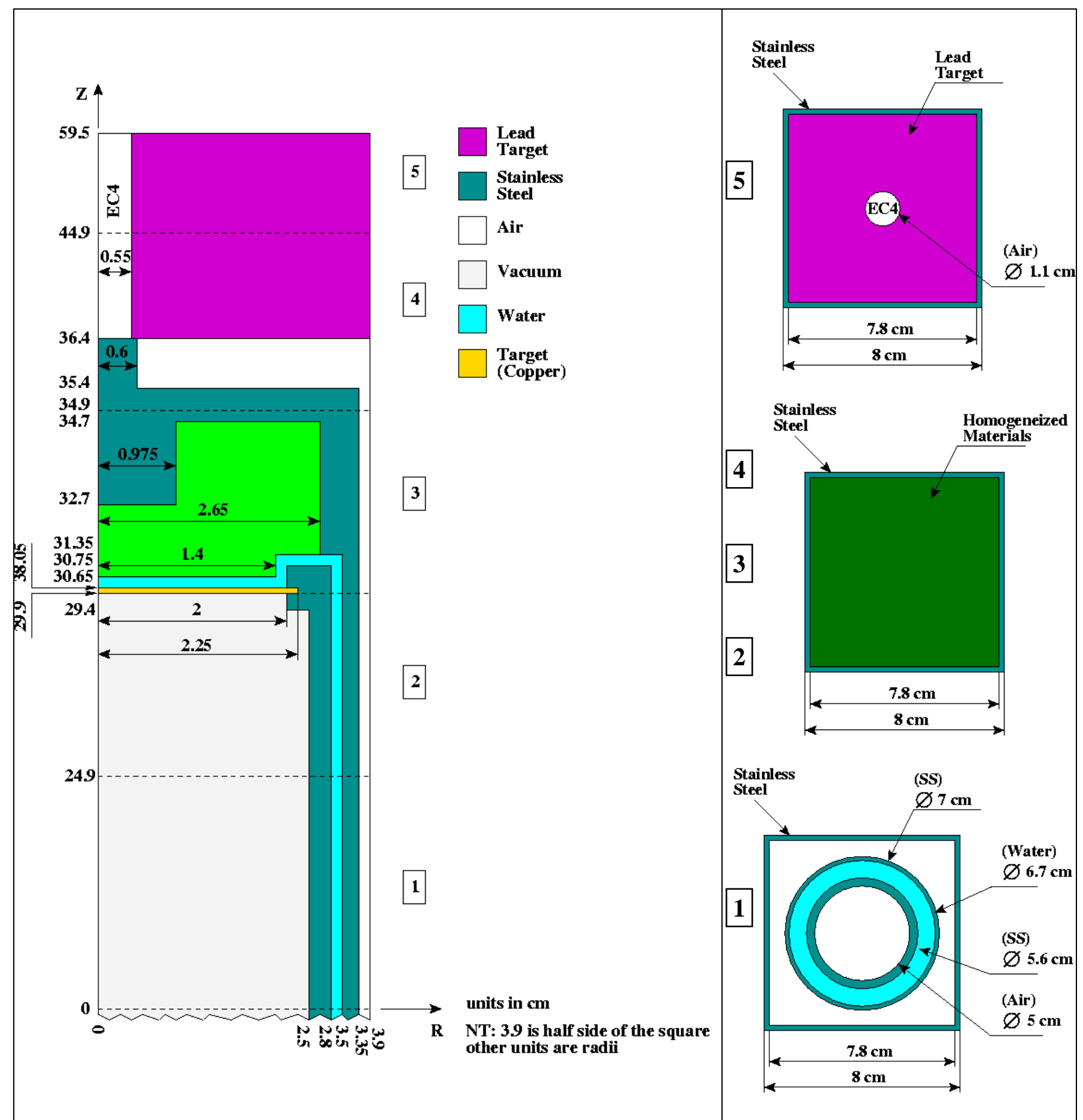

Figure 120. YALINA-Thermal Calculational Models of the Central Assembly

\section{Experimental Channels}

To avoid void regions and fine meshes in the calculational model, the experimental channels are homogenized with materials from the neighbor regions while conserving the material content of the assembly. The experimental channels of the reflector zone are homogenized with an opportune volume of the graphite reflector. The experimental channels located in the fuel zone are homogenized over the volume of the cell where they are located. Some simplifications were adopted to describe the presence of the experimental channels consistently with the cell lattice used to describe the fuel pins. Figure 121 shows the EC2 experimental channel inside the fuel zone and Figure 122 shows its 
calculational model. Figure 123 shows the exact geometry of the three channels of the boron carbide rods and Figure 124 shows the developed model for the three channels.

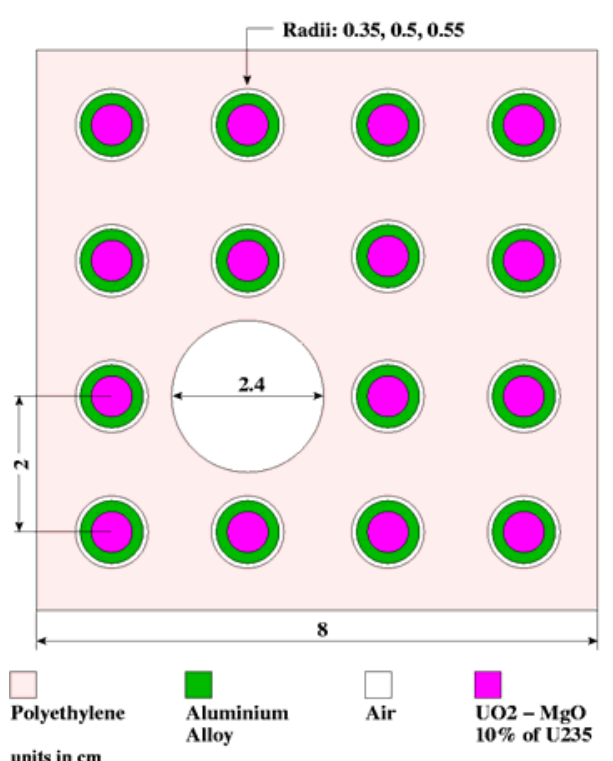

Figure 121. EC2 Experimental Channel

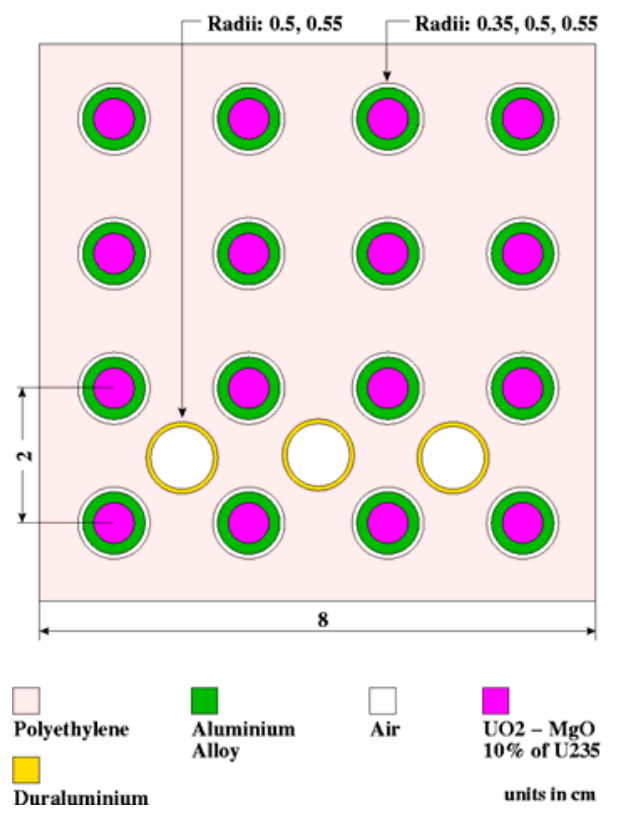

Figure 123. Three Channel for the $\mathrm{B}_{4} \mathrm{C}$ Rods

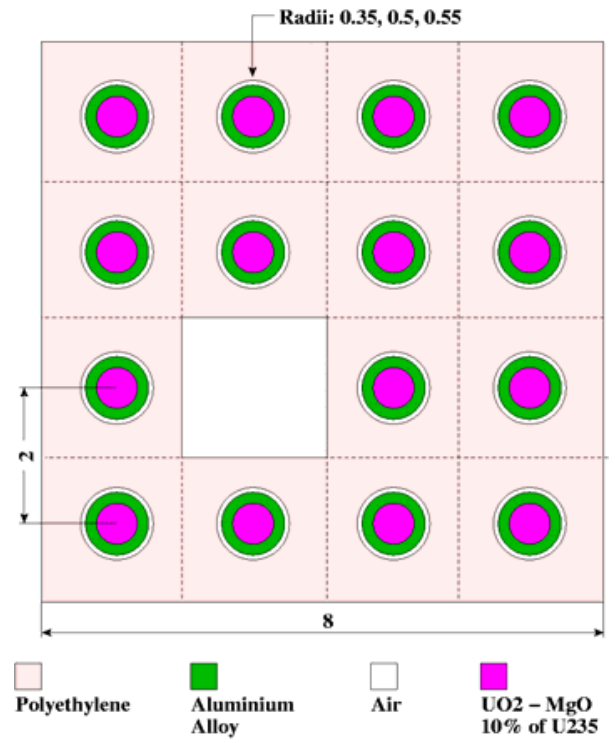

Figure 122.EC2 Experimental Channel Model

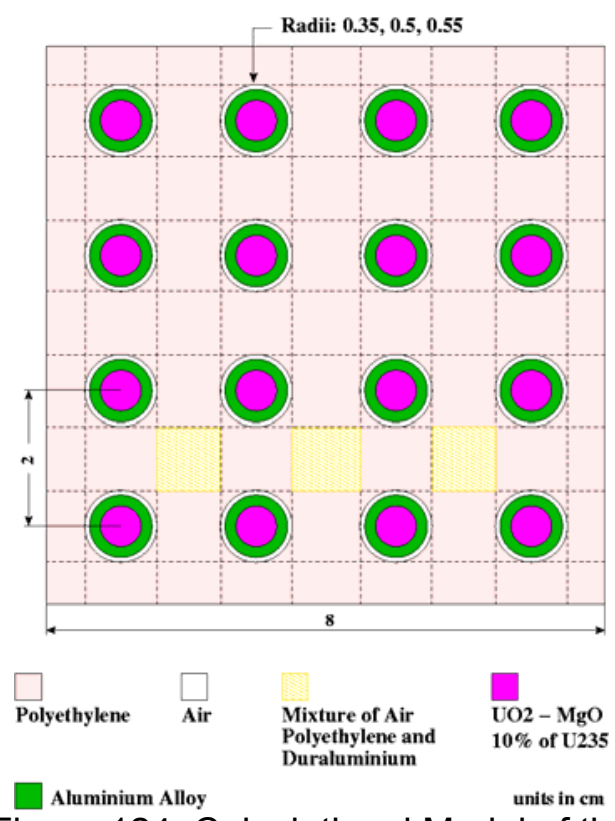

Figure 124. Calculational Model of the Three Channels for the $\mathrm{B}_{4} \mathrm{C}$ Rods 


\section{Appendix B}

\section{RZ Model}

The flux calculation with the BISTRO code requires the use of an RZ model. Figures 125 and 126 show the RZ models developed for the YALINA-Booster and -Thermal. The cross-section sets produced for the 3D models have been used for the corresponding zones of the RZ models.

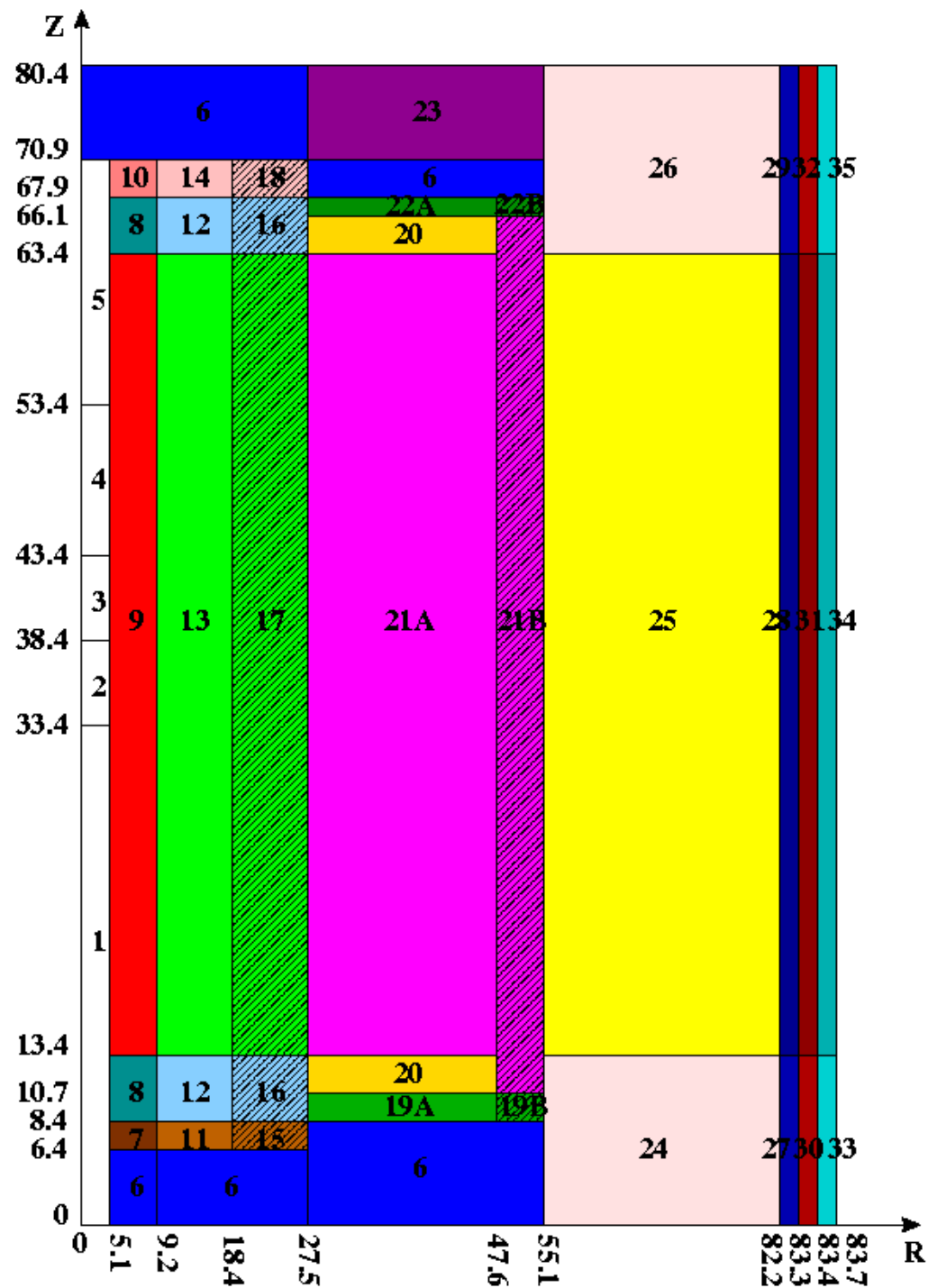

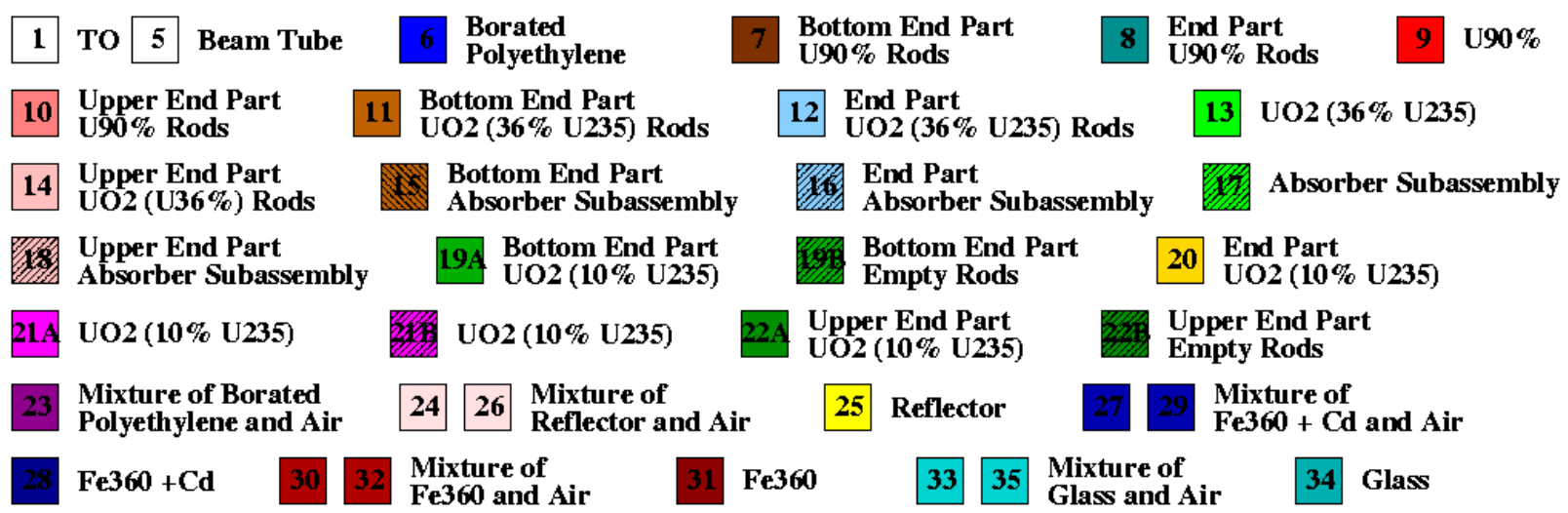

Figure 125. RZ Geometrical Model of the YALINA-Booster 


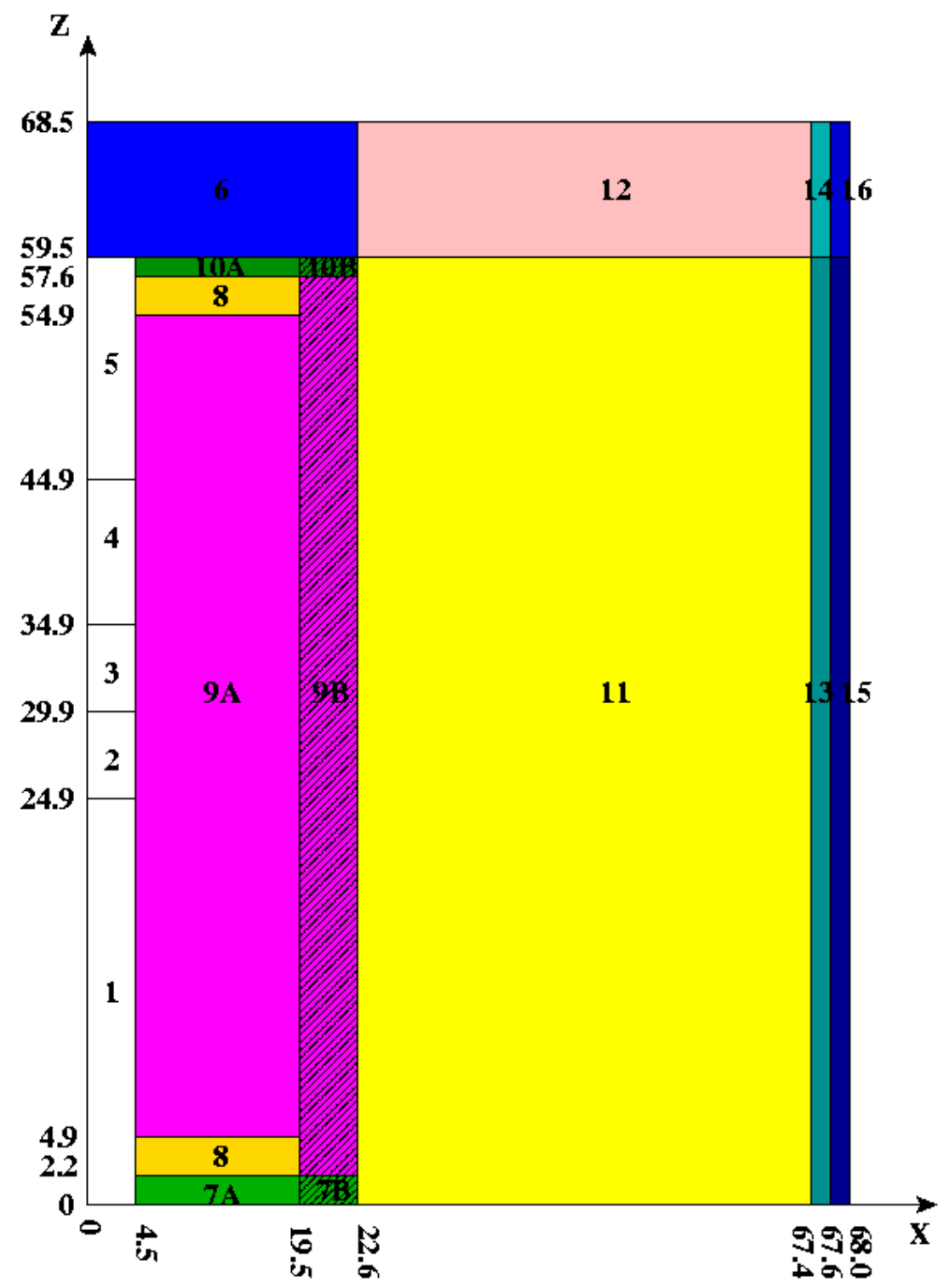

\begin{tabular}{llllll}
\hline 1 & To & 5 & Beam Tube & 6 & Borated
\end{tabular}

Polyethylene

7A Bottom End Part UO2 (10\% U235)

Bottom End Part Empty Rods

9A UO2 (10\% U235) UO2 (10\% U235) Upper End Part
UO2 (10\% U235)

8 End Part UO2 (10\% U235)

Upper End Part
Empty Rods

14 Mixture of Glass and Air

\section{Reflector}

12 Mixture of Reflector and Air

Mixture of

Fe360 + Cd and Air

Figure 126. RZ Geometrical Model of the YALINA-Thermal 
ANL-09-23

\section{Appendix C}

\section{Energy Group Structures}

The 172 and 53 energy group structures used for the deterministic calculations are presented in Tables 31 and 32 respectively.

Table 31. The 172-Energy Group Structure

\begin{tabular}{|c|c|c|c|c|c|c|c|}
\hline $\begin{array}{l}\text { Group } \\
\text { Number }\end{array}$ & Energy $^{(\mathrm{a})}[\mathrm{MeV}]$ & $\begin{array}{l}\text { Group } \\
\text { Number }\end{array}$ & Energy $^{(\mathrm{a})}[\mathrm{MeV}]$ & $\begin{array}{l}\text { Group } \\
\text { Number }\end{array}$ & Energy $^{(\mathrm{a})}[\mathrm{MeV}]$ & $\begin{array}{l}\text { Group } \\
\text { Number }\end{array}$ & Energy $^{(\mathrm{a})}[\mathrm{MeV}]$ \\
\hline 1 & $1.96403 E+01$ & 44 & $1.50344 \mathrm{E}-02$ & 87 & $8.31529 \mathrm{E}-06$ & 130 & $9.10000 \mathrm{E}-07$ \\
\hline 2 & $1.73325 \mathrm{E}+01$ & 45 & $1.11378 \mathrm{E}-02$ & 88 & $7.52398 \mathrm{E}-06$ & 131 & $8.60000 \mathrm{E}-07$ \\
\hline 3 & $1.49182 \mathrm{E}+01$ & 46 & $9.11882 \mathrm{E}-03$ & 89 & $6.16012 \mathrm{E}-06$ & 132 & $8.50000 \mathrm{E}-07$ \\
\hline 4 & $1.38403 \mathrm{E}+01$ & 47 & 7.46586E-03 & 90 & 5.34643E-06 & 133 & $7.90000 \mathrm{E}-07$ \\
\hline 5 & $1.16183 \mathrm{E}+01$ & 48 & 5.53084E-03 & 91 & $5.04348 \mathrm{E}-06$ & 134 & $7.80000 \mathrm{E}-07$ \\
\hline 6 & $1.00000 \mathrm{E}+01$ & 49 & $5.00451 \mathrm{E}-03$ & 92 & $4.12925 \mathrm{E}-06$ & 135 & $7.05000 \mathrm{E}-07$ \\
\hline 7 & $8.18731 \mathrm{E}+00$ & 50 & 3.52662E-03 & 93 & $4.00000 \mathrm{E}-06$ & 136 & $6.25000 \mathrm{E}-07$ \\
\hline 8 & $6.70320 \mathrm{E}+00$ & 51 & $3.35463 \mathrm{E}-03$ & 94 & $3.38075 \mathrm{E}-06$ & 137 & $5.40000 \mathrm{E}-07$ \\
\hline 9 & $6.06531 \mathrm{E}+00$ & 52 & $2.24867 \mathrm{E}-03$ & 95 & $3.30000 \mathrm{E}-06$ & 138 & $5.00000 \mathrm{E}-07$ \\
\hline 10 & $5.48812 \mathrm{E}+00$ & 53 & $2.03468 \mathrm{E}-03$ & 96 & 2.76792E-06 & 139 & $4.85000 \mathrm{E}-07$ \\
\hline 11 & $4.49329 \mathrm{E}+00$ & 54 & $1.50733 \mathrm{E}-03$ & 97 & $2.72000 \mathrm{E}-06$ & 140 & $4.33000 \mathrm{E}-07$ \\
\hline 12 & $3.67879 \mathrm{E}+00$ & 55 & 1.43382E-03 & 98 & $2.60000 \mathrm{E}-06$ & 141 & $4.00000 \mathrm{E}-07$ \\
\hline 13 & $3.01194 \mathrm{E}+00$ & 56 & $1.23410 \mathrm{E}-03$ & 99 & $2.55000 \mathrm{E}-06$ & 142 & $3.91000 \mathrm{E}-07$ \\
\hline 14 & $2.46597 \mathrm{E}+00$ & 57 & $1.01039 \mathrm{E}-03$ & 100 & $2.36000 \mathrm{E}-06$ & 143 & $3.50000 \mathrm{E}-07$ \\
\hline 15 & $2.23130 \mathrm{E}+00$ & 58 & $9.14242 \mathrm{E}-04$ & 101 & $2.13000 \mathrm{E}-06$ & 144 & $3.20000 \mathrm{E}-07$ \\
\hline 16 & $2.01897 \mathrm{E}+00$ & 59 & $7.48518 \mathrm{E}-04$ & 102 & $2.10000 \mathrm{E}-06$ & 145 & $3.14500 \mathrm{E}-07$ \\
\hline 17 & $1.65299 \mathrm{E}+00$ & 60 & $6.77287 \mathrm{E}-04$ & 103 & $2.02000 \mathrm{E}-06$ & 146 & $3.00000 \mathrm{E}-07$ \\
\hline 18 & $1.35335 \mathrm{E}+00$ & 61 & 4.53999E-04 & 104 & $1.93000 \mathrm{E}-06$ & 147 & $2.80000 \mathrm{E}-07$ \\
\hline 19 & $1.22456 \mathrm{E}+00$ & 62 & 3.71703E-04 & 105 & 1.84000E-06 & 148 & $2.48000 \mathrm{E}-07$ \\
\hline 20 & $1.10803 \mathrm{E}+00$ & 63 & $3.04325 \mathrm{E}-04$ & 106 & $1.75500 \mathrm{E}-06$ & 149 & $2.20000 \mathrm{E}-07$ \\
\hline 21 & $1.00259 \mathrm{E}+00$ & 64 & $2.03995 \mathrm{E}-04$ & 107 & 1.67000E-06 & 150 & $1.89000 \mathrm{E}-07$ \\
\hline 22 & $9.07180 \mathrm{E}-01$ & 65 & 1.48625E-04 & 108 & $1.59000 \mathrm{E}-06$ & 151 & $1.80000 \mathrm{E}-07$ \\
\hline 23 & $8.20850 \mathrm{E}-01$ & 66 & 1.36742E-04 & 109 & $1.50000 \mathrm{E}-06$ & 152 & $1.60000 \mathrm{E}-07$ \\
\hline 24 & 6.08101E-01 & 67 & $9.16609 \mathrm{E}-05$ & 110 & $1.47500 \mathrm{E}-06$ & 153 & $1.40000 \mathrm{E}-07$ \\
\hline 25 & $5.50232 \mathrm{E}-01$ & 68 & 7.56736E-05 & 111 & 1.44000E-06 & 154 & $1.34000 \mathrm{E}-07$ \\
\hline 26 & $4.97871 \mathrm{E}-01$ & 69 & $6.79041 \mathrm{E}-05$ & 112 & $1.37000 \mathrm{E}-06$ & 155 & $1.15000 \mathrm{E}-07$ \\
\hline 27 & $4.50492 \mathrm{E}-01$ & 70 & 5.55951E-05 & 113 & 1.33750E-06 & 156 & $1.00000 \mathrm{E}-07$ \\
\hline 28 & $4.07622 \mathrm{E}-01$ & 71 & $5.15780 \mathrm{E}-05$ & 114 & $1.30000 \mathrm{E}-06$ & 157 & $9.50000 \mathrm{E}-08$ \\
\hline 29 & $3.01974 \mathrm{E}-01$ & 72 & $4.82516 \mathrm{E}-05$ & 115 & $1.23500 \mathrm{E}-06$ & 158 & $8.00000 \mathrm{E}-08$ \\
\hline 30 & $2.73237 \mathrm{E}-01$ & 73 & 4.55174E-05 & 116 & $1.17000 \mathrm{E}-06$ & 159 & $7.70000 \mathrm{E}-08$ \\
\hline 31 & $2.47235 \mathrm{E}-01$ & 74 & 4.01690E-05 & 117 & $1.15000 \mathrm{E}-06$ & 160 & $6.70000 \mathrm{E}-08$ \\
\hline 32 & $1.83156 \mathrm{E}-01$ & 75 & $3.72665 \mathrm{E}-05$ & 118 & $1.12300 \mathrm{E}-06$ & 161 & $5.80000 \mathrm{E}-08$ \\
\hline 33 & $1.22773 \mathrm{E}-01$ & 76 & $3.37202 \mathrm{E}-05$ & 119 & $1.11000 \mathrm{E}-06$ & 162 & $5.00000 \mathrm{E}-08$ \\
\hline 34 & 1.11090E-01 & 77 & $3.05113 \mathrm{E}-05$ & 120 & 1.09700E-06 & 163 & $4.20000 \mathrm{E}-08$ \\
\hline 35 & $8.22975 \mathrm{E}-02$ & 78 & $2.76077 \mathrm{E}-05$ & 121 & $1.07100 \mathrm{E}-06$ & 164 & $3.50000 \mathrm{E}-08$ \\
\hline 36 & $6.73795 \mathrm{E}-02$ & 79 & $2.49805 \mathrm{E}-05$ & 122 & $1.04500 \mathrm{E}-06$ & 165 & $3.00000 \mathrm{E}-08$ \\
\hline 37 & $5.51656 \mathrm{E}-02$ & 80 & $2.26033 \mathrm{E}-05$ & 123 & $1.03500 \mathrm{E}-06$ & 166 & $2.50000 \mathrm{E}-08$ \\
\hline 38 & $4.08677 \mathrm{E}-02$ & 81 & 1.94548E-05 & 124 & $1.02000 \mathrm{E}-06$ & 167 & $2.00000 \mathrm{E}-08$ \\
\hline 39 & 3.69786E-02 & 82 & 1.59283E-05 & 125 & $9.96000 \mathrm{E}-07$ & 168 & $1.50000 \mathrm{E}-08$ \\
\hline 40 & $2.92830 \mathrm{E}-02$ & 83 & 1.37096E-05 & 126 & $9.86000 \mathrm{E}-07$ & 169 & $1.00000 \mathrm{E}-08$ \\
\hline 41 & $2.73945 \mathrm{E}-02$ & 84 & $1.12245 \mathrm{E}-05$ & 127 & $9.72000 \mathrm{E}-07$ & 170 & $6.90000 \mathrm{E}-09$ \\
\hline 42 & $2.47875 \mathrm{E}-02$ & 85 & $9.90556 \mathrm{E}-06$ & 128 & $9.50000 \mathrm{E}-07$ & 171 & $5.00000 \mathrm{E}-09$ \\
\hline 43 & 1.66156E-02 & 86 & $9.18981 \mathrm{E}-06$ & 129 & $9.30000 \mathrm{E}-07$ & 172 & $3.00000 \mathrm{E}-09$ \\
\hline
\end{tabular}

(a) Upper Energy boundary 
Table 32. The 53-Energy Group Structure

\begin{tabular}{|c|c||c|c||c|c||}
\hline $\begin{array}{c}\text { Group } \\
\text { Number }\end{array}$ & $\begin{array}{c}\text { Energy } \\
{[\mathrm{MeV}]}\end{array}$ & $\begin{array}{c}\text { Group } \\
\text { Number }\end{array}$ & $\begin{array}{c}\text { Energy } \\
{[\mathrm{MeV}]}\end{array}$ & $\begin{array}{c}\text { Group } \\
\text { Number }\end{array}$ & $\begin{array}{c}\text { Energy } \\
{[\mathrm{MeV}]}\end{array}$ \\
\hline \hline 1 & $1.96403 \mathrm{E}+01$ & 19 & $5.53084 \mathrm{E}-03$ & 37 & $9.10000 \mathrm{E}-07$ \\
\hline 2 & $1.41907 \mathrm{E}+01$ & 20 & $3.35463 \mathrm{E}-03$ & 38 & $8.50000 \mathrm{E}-07$ \\
\hline 3 & $1.39561 \mathrm{E}+01$ & 21 & $2.03468 \mathrm{E}-03$ & 39 & $7.90000 \mathrm{E}-07$ \\
\hline 4 & $1.00000 \mathrm{E}+01$ & 22 & $1.23410 \mathrm{E}-03$ & 40 & $7.05000 \mathrm{E}-07$ \\
\hline 5 & $6.06531 \mathrm{E}+00$ & 23 & $7.48518 \mathrm{E}-04$ & 41 & $6.25000 \mathrm{E}-07$ \\
\hline 6 & $3.67879 \mathrm{E}+00$ & 24 & $4.53999 \mathrm{E}-04$ & 42 & $5.40000 \mathrm{E}-07$ \\
\hline 7 & $2.23130 \mathrm{E}+00$ & 25 & $3.04325 \mathrm{E}-04$ & 43 & $4.85000 \mathrm{E}-07$ \\
\hline 8 & $1.35335 \mathrm{E}+00$ & 26 & $1.48625 \mathrm{E}-04$ & 44 & $4.33000 \mathrm{E}-07$ \\
\hline 9 & $8.20850 \mathrm{E}-01$ & 27 & $9.16609 \mathrm{E}-05$ & 45 & $3.20000 \mathrm{E}-07$ \\
\hline 10 & $4.97871 \mathrm{E}-01$ & 28 & $6.79041 \mathrm{E}-05$ & 46 & $2.48000 \mathrm{E}-07$ \\
\hline 11 & $3.01974 \mathrm{E}-01$ & 29 & $4.01690 \mathrm{E}-05$ & 47 & $1.60000 \mathrm{E}-07$ \\
\hline 12 & $1.83156 \mathrm{E}-01$ & 30 & $2.26033 \mathrm{E}-05$ & 48 & $1.40000 \mathrm{E}-07$ \\
\hline 13 & $1.11090 \mathrm{E}-01$ & 31 & $1.37096 \mathrm{E}-05$ & 49 & $1.00000 \mathrm{E}-07$ \\
\hline 14 & $6.73795 \mathrm{E}-02$ & 32 & $8.31529 \mathrm{E}-06$ & 50 & $5.00000 \mathrm{E}-08$ \\
\hline 15 & $4.08677 \mathrm{E}-02$ & 33 & $4.00000 \mathrm{E}-06$ & 51 & $3.50000 \mathrm{E}-08$ \\
\hline 16 & $2.47875 \mathrm{E}-02$ & 34 & $2.76792 \mathrm{E}-06$ & 52 & $2.50000 \mathrm{E}-08$ \\
\hline 17 & $1.50344 \mathrm{E}-02$ & 35 & $1.37000 \mathrm{E}-06$ & 53 & $1.50000 \mathrm{E}-08$ \\
\hline 18 & $9.11882 \mathrm{E}-03$ & 36 & $9.50000 \mathrm{E}-07$ & \multicolumn{1}{|c}{} \\
\hline
\end{tabular}

(a) Upper Energy boundary 
ANL-09-23

\section{Appendix D}

\section{Cf-252 Source Energy Distribution}

The 172 and 53 energy group distributions of the Cf-252 source used for the deterministic calculations are presented in Tables 33 and 34 respectively.

Table 33. 172 Energy Group Distribution of the Cf-252 Source

\begin{tabular}{|c|c|c|c|c|c|c|c|c|c|c|c|}
\hline $\mathrm{Gr}$ & $\begin{array}{c}\text { Energy }{ }^{(a)} \\
{[\mathrm{MeV}]}\end{array}$ & $\begin{array}{l}\text { Cf-252 } \\
\text { Source } \\
\end{array}$ & $\mathrm{Gr}$. & $\begin{array}{c}\text { Energy }^{(a)} \\
{[\mathrm{MeV}]}\end{array}$ & $\begin{array}{l}\text { Cf-252 } \\
\text { Source } \\
\end{array}$ & $\mathrm{Gr}$ & $\begin{array}{c}\text { Energy }{ }^{(a)} \\
{[\mathrm{MeV}]}\end{array}$ & $\begin{array}{l}\text { Cf-252 } \\
\text { Source } \\
\end{array}$ & Gr. & $\begin{array}{c}\text { Energy }^{(a)} \\
{[\mathrm{MeV}]}\end{array}$ & $\begin{array}{l}\text { Cf-252 } \\
\text { Source } \\
\end{array}$ \\
\hline 1 & $E+1$ & 15397E-5 & 44 & $1.50344 \mathrm{E}-2$ & .78323E-4 & 6 & & & & & \\
\hline 2 & $5 E+1$ & 337E-4 & 5 & $78 \mathrm{E}-2$ & 186E-4 & 8 & & & & & \\
\hline 3 & $2 \mathrm{E}+1$ & $2529 E-4$ & 46 & 1882E-3 & 383E-5 & 9 & & & & & \\
\hline 4 & $3 \mathrm{E}+1$ & $63875 E-4$ & 47 & 46586E-3 & E-5 & 0 & & & & & \\
\hline 5 & $E+1$ & $2.28808 \mathrm{E}-3$ & 48 & 53084E-3 & 7E-5 & 1 & & & & & \\
\hline 6 & $E+1$ & 7.59485E-3 & 49 & 51E-3 & 4E-5 & 2 & & & & & \\
\hline 7 & $E+0$ & $68971 \mathrm{E}-2$ & 50 & $62 \mathrm{E}-3$ & E-6 & 3 & & & & & \\
\hline 8 & $E+0$ & $1.34418 \mathrm{E}-2$ & 51 & 5463E-3 & $875 E-5$ & 4 & & & & & \\
\hline 9 & $E+0$ & 1.74494E-2 & 52 & $2.24867 \mathrm{E}-3$ & $6.23691 \mathrm{E}-6$ & 5 & & & & & \\
\hline 10 & $E+0$ & $80426 \mathrm{E}-2$ & 53 & $2.03468 \mathrm{E}-3$ & E-5 & 96 & & & & & \\
\hline 11 & & $6.54085 \mathrm{E}-2$ & 54 & 733E-3 & $77722 \mathrm{E}-6$ & 17 & & & & & \\
\hline 12 & $E+0$ & 7.98244E-2 & 55 & $1.43382 \mathrm{E}-3$ & 4.59877E-6 & 8 & 2 & 12 & & 4.00 & 10 \\
\hline 13 & $E+0$ & 90453E-2 & 56 & $1.23410 \mathrm{E}-3$ & 4.72617E-6 & 9 & E-6 & 1 & 42 & & Tד \\
\hline 14 & $E+0$ & $60985 \mathrm{E}-2$ & 57 & $9 \mathrm{E}-3$ & $1.88261 \mathrm{E}-6$ & & & $1.000 \mathrm{~s}$ & 43 & & \\
\hline 15 & $E+0$ & 61686E-2 & 58 & $9.14242 \mathrm{E}-4$ & $3.01673 \mathrm{E}-6$ & & 2 & 191505 & 44 & E-7 & (1) \\
\hline 16 & $E+0$ & $99886 \mathrm{E}-2$ & 59 & 7.48518E-4 & 38E-6 & & 2 & OYZYUC & 45 & E- -1 & $.009 / 95$ \\
\hline 17 & $E+0$ & 47E-2 & 60 & $6.77287 \mathrm{E}-4$ & $3.35507 \mathrm{E}-6$ & & & 12 & 46 & FE-1 & Juoz \\
\hline 18 & $5 E+0$ & $84492 \mathrm{E}-2$ & 61 & 4.53999E-4 & $9 \mathrm{E}-6$ & & & $5801 \mathrm{E}-12$ & $4 I$ & JE-1 & . \\
\hline 19 & E +0 & $59645 \mathrm{E}-2$ & 62 & 3.71703E-4 & $7.86832 \mathrm{E}-7$ & & E- -6 & 45277E-12 & 48 & E-7 & $.56 / \angle 4 \mathrm{E}-1$ \\
\hline 20 & $E+0$ & $33760 \mathrm{E}-2$ & 63 & $5 E-4$ & 2 E-6 & & & -12 & 49 & E-7 & $38<94$ E- 1 \\
\hline 21 & $9 \mathrm{E}+0$ & 19E-2 & 64 & 15E-4 & 1E-7 & & & -12 & 50 & E-7 & $1.63866 \mathrm{E}-1$ \\
\hline 22 & OE-1 & $2.81517 \mathrm{E}-2$ & 65 & $1.48625 \mathrm{E}-4$ & 5 E-8 & & E-6 & 09590E-12 & 151 & E-7 & $3.78551 \mathrm{E}-1$ \\
\hline 23 & $\mathrm{E}-1$ & $9 \mathrm{E}-2$ & 66 & 12E-4 & 8E-7 & & E-6 & $\mathrm{E}-12$ & 152 & E-7 & $81 \mathrm{E}-1$ \\
\hline 24 & E-1 & $1.87442 \mathrm{E}-2$ & 67 & 9E-5 & SE-8 & & E-6 & 308E-12 & 53 & E-7 & $1.25756 \mathrm{E}-1$ \\
\hline 25 & $50232 \mathrm{E}-1$ & 31E-2 & 68 & $6 \mathrm{E}-5$ & E-8 & & E-6 & $396 \mathrm{E}-12$ & 154 & E-7 & $1 \mathrm{E}-12$ \\
\hline 26 & & 4E-2 & 69 & E-5 & E-8 & & & & 55 & E-7 & $70 \mathrm{E}-1$ \\
\hline 27 & $2 \mathrm{E}-1$ & 35E-2 & 70 & E-5 & $6 \mathrm{E}-8$ & & & & 56 & E-7 & $18 \mathrm{E}-12$ \\
\hline 28 & $2 \mathrm{E}-1$ & 47E-2 & 71 & E-5 & E-8 & & & & 157 & E-8 & $3.90531 \mathrm{E}-1$ \\
\hline 29 & $\mathrm{E}-1$ & 7.99448E-3 & 72 & $E-5$ & E-8 & & & $55 \mathrm{E}-12$ & 58 & E-8 & $3.22734 \mathrm{E}-13$ \\
\hline 30 & 7E-1 & $7.00992 \mathrm{E}-3$ & 73 & $4 \mathrm{E}-5$ & E-8 & & E-6 & 12 & 159 & E-8 & $2.86222 \mathrm{E}-1 \mathrm{a}$ \\
\hline 31 & $5 \mathrm{E}-1$ & $0 \mathrm{E}-2$ & 74 & $0 \mathrm{E}-5$ & E-8 & 1 & & 2.3 & 160 & E-8 & $2.76092 \mathrm{E}-1$ \\
\hline 32 & $6 \mathrm{E}-1$ & $.33950 \mathrm{E}-2$ & 75 & $5 \mathrm{E}-5$ & $2 \mathrm{E}-8$ & & & E-12 & 161 & E-8 & $97 \mathrm{~F}-12$ \\
\hline 33 & 22773E-1 & $2.32704 \mathrm{E}-3$ & 76 & $2 \mathrm{E}-5$ & 9E-8 & & E-6 & 42E-12 & 162 & 5.00 & $2.85448 \mathrm{E}-12$ \\
\hline 34 & $90 \mathrm{E}-1$ & $5.28161 \mathrm{E}-3$ & 77 & $3 \mathrm{E}-5$ & $E-8$ & 120 & & & 163 & OE-8 & $2.72748 \mathrm{E}-1$ \\
\hline 35 & E-2 & $2.44504 \mathrm{E}-3$ & 78 & $7 E-5$ & $3 \mathrm{E}-9$ & 121 & & 401F-12 & 164 & $E-8$ & 11807E-1 \\
\hline 36 & $5 \mathrm{E}-2$ & $82809 E-3$ & 79 & $5 E-5$ & 15E-9 & 12 & & 7299F-13 & 165 & $\mathrm{E}-8$ & $2.30178 \mathrm{E}-12$ \\
\hline 37 & $5.51656 \mathrm{E}-2$ & 91047E-3 & 80 & $3 \mathrm{E}-5$ & $1.08932 \mathrm{E}-8$ & 123 & E-6 & $1.33629 \mathrm{E}-12$ & 166 & 2.50 & $2.54446 \mathrm{E}-1$ \\
\hline 38 & 7E-2 & 71193E-4 & 81 & 48E-5 & 5620E-8 & & & & 167 & $\mathrm{~F}-8$ & $288647 \mathrm{~F}-1$ \\
\hline 39 & 6E-2 & 8E-4 & 82 & & & & & $706 \mathrm{~F}-13$ & $16 \varepsilon$ & E-8 & $3.42222 \mathrm{E}-12$ \\
\hline 40 & JE-2 & $96655 \mathrm{E}-4$ & 83 & & & & & & 169 & $\mathrm{~F}-8$ & $2.57774 \mathrm{E}-1$ \\
\hline 41 & & $60851 \mathrm{E}-4$ & 84 & & & & & & & & \\
\hline 42 & & 7.29832E-4 & 85 & & & & & & 17 & & 36E-1 \\
\hline 43 & E-2 & 24073E-4 & & & & & & & & & \\
\hline
\end{tabular}


Table 34. 53 Energy Group Distribution of the Cf-252 Source

\begin{tabular}{|c|c|c||c|c|c|c|c|c||}
\hline \hline Gr. & Energy $^{(\mathrm{a})}[\mathrm{MeV}]$ & Cf-252 Source & Gr. & Energy $^{(\mathrm{a})}[\mathrm{MeV}]$ & Cf-252 Source & Gr. & Energy $^{(\mathrm{a})}[\mathrm{MeV}]$ & Cf-252 Source \\
\hline \hline 1 & $1.96403 \mathrm{E}+01$ & $1.51377 \mathrm{E}-4$ & 19 & $5.53084 \mathrm{E}-03$ & $9.09571 \mathrm{E}-5$ & 37 & $9.10000 \mathrm{E}-07$ & $5.63753 \mathrm{E}-12$ \\
\hline 2 & $1.41907 \mathrm{E}+01$ & $1.52529 \mathrm{E}-4$ & 20 & $3.35463 \mathrm{E}-03$ & $4.30244 \mathrm{E}-5$ & 38 & $8.50000 \mathrm{E}-07$ & $5.78197 \mathrm{E}-12$ \\
\hline 3 & $1.39561 \mathrm{E}+01$ & $3.25195 \mathrm{E}-3$ & 21 & $2.03468 \mathrm{E}-03$ & $2.03477 \mathrm{E}-5$ & 39 & $7.90000 \mathrm{E}-07$ & $8.47667 \mathrm{E}-12$ \\
\hline 4 & $1.00000 \mathrm{E}+01$ & $3.79338 \mathrm{E}-2$ & 22 & $1.23410 \mathrm{E}-03$ & $9.62551 \mathrm{E}-6$ & 40 & $7.05000 \mathrm{E}-07$ & $8.34103 \mathrm{E}-12$ \\
\hline 5 & $6.06531 \mathrm{E}+00$ & $1.30901 \mathrm{E}-1$ & 23 & $7.48518 \mathrm{E}-04$ & $4.55694 \mathrm{E}-6$ & 41 & $6.25000 \mathrm{E}-07$ & $9.33793 \mathrm{E}-12$ \\
\hline 6 & $3.67879 \mathrm{E}+00$ & $2.14968 \mathrm{E}-1$ & 24 & $4.53999 \mathrm{E}-04$ & $1.84692 \mathrm{E}-6$ & 42 & $5.40000 \mathrm{E}-07$ & $6.36252 \mathrm{E}-12$ \\
\hline 7 & $2.23130 \mathrm{E}+00$ & $2.19672 \mathrm{E}-1$ & 25 & $3.04325 \mathrm{E}-04$ & $1.48988 \mathrm{E}-6$ & 43 & $4.85000 \mathrm{E}-07$ & $6.29790 \mathrm{E}-12$ \\
\hline 8 & $1.35335 \mathrm{E}+00$ & $1.66693 \mathrm{E}-1$ & 26 & $1.48625 \mathrm{E}-04$ & $4.04072 \mathrm{E}-7$ & 44 & $4.33000 \mathrm{E}-07$ & $1.49289 \mathrm{E}-11$ \\
\hline 9 & $8.20850 \mathrm{E}-01$ & $1.05202 \mathrm{E}-1$ & 27 & $9.16609 \mathrm{E}-05$ & $1.39799 \mathrm{E}-7$ & 45 & $3.20000 \mathrm{E}-07$ & $1.07693 \mathrm{E}-11$ \\
\hline 10 & $4.97871 \mathrm{E}-01$ & $5.92896 \mathrm{E}-2$ & 28 & $6.79041 \mathrm{E}-05$ & $1.37368 \mathrm{E}-7$ & 46 & $2.48000 \mathrm{E}-07$ & $1.53744 \mathrm{E}-11$ \\
\hline 11 & $3.01974 \mathrm{E}-01$ & $3.11814 \mathrm{E}-2$ & 29 & $4.01690 \mathrm{E}-05$ & $6.98790 \mathrm{E}-8$ & 47 & $1.60000 \mathrm{E}-07$ & $4.01681 \mathrm{E}-12$ \\
\hline 12 & $1.83156 \mathrm{E}-01$ & $1.57221 \mathrm{E}-2$ & 30 & $2.26033 \mathrm{E}-05$ & $2.26292 \mathrm{E}-8$ & 48 & $1.40000 \mathrm{E}-07$ & $8.96267 \mathrm{E}-12$ \\
\hline 13 & $1.11090 \mathrm{E}-01$ & $7.72665 \mathrm{E}-3$ & 31 & $1.37096 \mathrm{E}-05$ & $3.95261 \mathrm{E}-10$ & 49 & $1.00000 \mathrm{E}-07$ & $1.42223 \mathrm{E}-11$ \\
\hline 14 & $6.73795 \mathrm{E}-02$ & $3.73856 \mathrm{E}-3$ & 32 & $8.31529 \mathrm{E}-06$ & $2.93744 \mathrm{E}-10$ & 50 & $5.00000 \mathrm{E}-08$ & $5.58196 \mathrm{E}-12$ \\
\hline 15 & $4.08677 \mathrm{E}-02$ & $1.79187 \mathrm{E}-3$ & 33 & $4.00000 \mathrm{E}-06$ & $8.44012 \mathrm{E}-11$ & 51 & $3.50000 \mathrm{E}-08$ & $4.41985 \mathrm{E}-12$ \\
\hline 16 & $2.47875 \mathrm{E}-02$ & $8.53906 \mathrm{E}-4$ & 34 & $2.76792 \mathrm{E}-06$ & $1.03836 \mathrm{E}-10$ & 52 & $2.50000 \mathrm{E}-08$ & $5.43093 \mathrm{E}-12$ \\
\hline 17 & $1.50344 \mathrm{E}-02$ & $4.05509 \mathrm{E}-4$ & 35 & $1.37000 \mathrm{E}-06$ & $3.609222 \mathrm{E}-11$ & 53 & $1.50000 \mathrm{E}-08$ & $1.86456 \mathrm{E}-11$ \\
\hline 18 & $9.11882 \mathrm{E}-03$ & $1.92169 \mathrm{E}-4$ & 36 & $9.50000 \mathrm{E}-07$ & $3.68614 \mathrm{E}-12$ & \multicolumn{3}{|l}{} \\
\hline
\end{tabular}




\section{Appendix E}

\section{ENDF Delayed Neutron Data}

This delayed neutron data used in the analyses from ENDF/B nuclear data files are tabulated in Tables 35, 36, 37, and 38.

Table 35. ENDF/B Delayed Time Constants [sec. ${ }^{-1}$ ]

\begin{tabular}{|l||c|c|c|c|c|c|}
\hline $\mathrm{U} 235$ & $1.33360 \mathrm{E}-2$ & $3.27390 \mathrm{E}-2$ & $1.20780 \mathrm{E}-1$ & $3.02780 \mathrm{E}-1$ & $8.49490 \mathrm{E}-1$ & $2.85300 \mathrm{E}+0$ \\
\hline $\mathrm{U} 238$ & $1.36300 \mathrm{E}-2$ & $3.13340 \mathrm{E}-2$ & $1.23340 \mathrm{E}-1$ & $3.23730 \mathrm{E}-1$ & $9.05970 \mathrm{E}-1$ & $3.04870 \mathrm{E}+0$ \\
\hline
\end{tabular}

Table 36. ENDF/B $\beta^{v}$

\begin{tabular}{|c||c|c|c|c|c|c|c||}
\hline Family Group & 1 & 2 & 3 & 4 & 5 & 6 & Total \\
\hline \hline U235 & $5.84666 \mathrm{E}-4$ & $3.01753 \mathrm{E}-3$ & $2.88051 \mathrm{E}-3$ & $6.45923 \mathrm{E}-3$ & $2.64878 \mathrm{E}-3$ & $1.10928 \mathrm{E}-3$ & $1.67000 \mathrm{E}-2$ \\
\hline U238 & $6.13371 \mathrm{E}-4$ & $4.96323 \mathrm{E}-3$ & $5.76393 \mathrm{E}-3$ & $1.69455 \mathrm{E}-2$ & $1.11779 \mathrm{E}-2$ & $4.53606 \mathrm{E}-3$ & $4.40000 \mathrm{E}-2$ \\
\hline
\end{tabular}


Table 37. Calculated ENDF/B Delayed Neutron Spectra for the YALINA-Booster

\begin{tabular}{|c|c|c|c|c|c|c|c|}
\hline \multicolumn{2}{|c|}{ Family Group } & \multirow[t]{2}{*}{1} & \multirow[t]{2}{*}{2} & \multirow[t]{2}{*}{3} & \multirow[t]{2}{*}{4} & \multirow[t]{2}{*}{5} & \multirow[t]{2}{*}{6} \\
\hline Group & En. [eV] & & & & & & \\
\hline 1 & $1.964 \mathrm{E}+7$ & $0.000 \mathrm{E}+0$ & $0.000 \mathrm{E}+0$ & $0.000 \mathrm{E}+0$ & $0.000 \mathrm{E}+0$ & $0.000 \mathrm{E}+0$ & $0.000 \mathrm{E}+0$ \\
\hline 2 & $1.419 \mathrm{E}+7$ & $0.000 \mathrm{E}+0$ & $0.000 \mathrm{E}+0$ & $0.000 \mathrm{E}+0$ & $0.000 \mathrm{E}+0$ & $0.000 \mathrm{E}+0$ & $0.000 \mathrm{E}+0$ \\
\hline 3 & $1.396 \mathrm{E}+7$ & $0.000 \mathrm{E}+0$ & $0.000 \mathrm{E}+0$ & $0.000 \mathrm{E}+0$ & $0.000 \mathrm{E}+0$ & $0.000 \mathrm{E}+0$ & $0.000 \mathrm{E}+0$ \\
\hline 4 & $1.000 \mathrm{E}+7$ & $0.000 \mathrm{E}+0$ & $0.000 \mathrm{E}+0$ & $0.000 \mathrm{E}+0$ & $0.000 \mathrm{E}+0$ & $0.000 \mathrm{E}+0$ & $0.000 \mathrm{E}+0$ \\
\hline 5 & $6.065 E+6$ & $0.000 \mathrm{E}+0$ & $0.000 \mathrm{E}+0$ & $0.000 \mathrm{E}+0$ & $0.000 \mathrm{E}+0$ & $0.000 \mathrm{E}+0$ & $0.000 \mathrm{E}+0$ \\
\hline 6 & $3.679 \mathrm{E}+6$ & $0.000 \mathrm{E}+0$ & $0.000 \mathrm{E}+0$ & 3.793E-4 & $4.424 \mathrm{E}-3$ & $8.661 \mathrm{E}-3$ & $1.528 \mathrm{E}-2$ \\
\hline 7 & $2.231 E+6$ & 9.904E-3 & $1.274 \mathrm{E}-2$ & 1.620E-2 & 5.643E-2 & $5.122 \mathrm{E}-2$ & 5.860E-2 \\
\hline 8 & $1.353 \mathrm{E}+6$ & 1.237E-1 & $1.534 \mathrm{E}-1$ & 8.771E-2 & 1.617E-1 & $1.235 \mathrm{E}-1$ & 1.217E-1 \\
\hline 9 & $8.209 E+5$ & $1.691 \mathrm{E}-1$ & $2.236 \mathrm{E}-1$ & $2.698 \mathrm{E}-1$ & $2.350 \mathrm{E}-1$ & $2.140 \mathrm{E}-1$ & $2.154 \mathrm{E}-1$ \\
\hline 10 & $4.979 \mathrm{E}+5$ & $2.117 \mathrm{E}-1$ & $2.628 \mathrm{E}-1$ & $2.291 \mathrm{E}-1$ & $2.132 \mathrm{E}-1$ & $2.159 \mathrm{E}-1$ & $2.018 \mathrm{E}-1$ \\
\hline 11 & $3.020 \mathrm{E}+5$ & $1.961 \mathrm{E}-1$ & $1.295 \mathrm{E}-1$ & 1.624E-1 & 1.410E-1 & 1.635E-1 & $1.548 \mathrm{E}-1$ \\
\hline 12 & $1.832 \mathrm{E}+5$ & $1.234 \mathrm{E}-1$ & $8.235 \mathrm{E}-2$ & $1.071 \mathrm{E}-1$ & $9.009 \mathrm{E}-2$ & $1.023 \mathrm{E}-1$ & $9.366 \mathrm{E}-2$ \\
\hline 13 & $1.111 \mathrm{E}+5$ & $5.972 \mathrm{E}-2$ & $6.409 \mathrm{E}-2$ & $5.598 \mathrm{E}-2$ & $4.348 \mathrm{E}-2$ & $5.644 \mathrm{E}-2$ & $5.964 \mathrm{E}-2$ \\
\hline 14 & $6.738 \mathrm{E}+4$ & $4.966 \mathrm{E}-2$ & $2.797 \mathrm{E}-2$ & $2.985 \mathrm{E}-2$ & $2.242 \mathrm{E}-2$ & $2.733 \mathrm{E}-2$ & $2.745 \mathrm{E}-2$ \\
\hline 15 & $4.087 \mathrm{E}+4$ & $2.186 \mathrm{E}-2$ & $1.721 \mathrm{E}-2$ & $1.786 \mathrm{E}-2$ & $1.398 \mathrm{E}-2$ & $1.410 \mathrm{E}-2$ & $1.519 \mathrm{E}-2$ \\
\hline 16 & $2.479 E+4$ & $2.182 \mathrm{E}-2$ & $1.049 \mathrm{E}-2$ & $1.072 \mathrm{E}-2$ & $8.978 \mathrm{E}-3$ & $1.224 \mathrm{E}-2$ & $1.975 \mathrm{E}-2$ \\
\hline 17 & $1.503 E+4$ & $1.085 \mathrm{E}-2$ & $6.329 \mathrm{E}-3$ & $6.131 \mathrm{E}-3$ & $5.037 \mathrm{E}-3$ & 7.996E-3 & $1.450 \mathrm{E}-2$ \\
\hline 18 & $9.119 \mathrm{E}+3$ & $8.465 \mathrm{E}-4$ & $3.765 \mathrm{E}-3$ & 2.646E-3 & 1.690E-3 & 1.127E-3 & 8.529E-4 \\
\hline 19 & $5.531 \mathrm{E}+3$ & $5.134 \mathrm{E}-4$ & $2.284 \mathrm{E}-3$ & $1.605 \mathrm{E}-3$ & $1.025 \mathrm{E}-3$ & $6.837 \mathrm{E}-4$ & $5.173 \mathrm{E}-4$ \\
\hline 20 & $3.355 E+3$ & $3.114 \mathrm{E}-4$ & 1.385E-3 & 9.734E-4 & $6.217 \mathrm{E}-4$ & 4.147E-4 & $3.138 \mathrm{E}-4$ \\
\hline 21 & $2.035 E+3$ & $1.889 \mathrm{E}-4$ & $8.401 \mathrm{E}-4$ & $5.904 \mathrm{E}-4$ & $3.771 \mathrm{E}-4$ & $2.515 \mathrm{E}-4$ & $1.903 \mathrm{E}-4$ \\
\hline 22 & $1.234 \mathrm{E}+3$ & $1.146 \mathrm{E}-4$ & $5.096 \mathrm{E}-4$ & $3.581 \mathrm{E}-4$ & $2.287 \mathrm{E}-4$ & $1.526 \mathrm{E}-4$ & $1.154 \mathrm{E}-4$ \\
\hline 23 & $7.485 \mathrm{E}+2$ & $6.949 \mathrm{E}-5$ & $3.091 \mathrm{E}-4$ & $2.172 \mathrm{E}-4$ & 1.387E-4 & $9.253 \mathrm{E}-5$ & $7.001 \mathrm{E}-5$ \\
\hline 24 & $4.540 \mathrm{E}+2$ & $3.531 \mathrm{E}-5$ & $1.571 \mathrm{E}-4$ & $1.104 \mathrm{E}-4$ & $7.050 \mathrm{E}-5$ & $4.703 \mathrm{E}-5$ & $3.558 \mathrm{E}-5$ \\
\hline 25 & $3.043 E+2$ & $3.674 \mathrm{E}-5$ & $1.634 \mathrm{E}-4$ & $1.148 \mathrm{E}-4$ & $7.334 \mathrm{E}-5$ & $4.892 \mathrm{E}-5$ & $3.701 \mathrm{E}-5$ \\
\hline 26 & $1.486 \mathrm{E}+2$ & $1.344 \mathrm{E}-5$ & $5.978 \mathrm{E}-5$ & $4.201 \mathrm{E}-5$ & $2.683 \mathrm{E}-5$ & 1.790E-5 & $1.354 \mathrm{E}-5$ \\
\hline 27 & $9.166 \mathrm{E}+1$ & $5.605 \mathrm{E}-6$ & $2.493 E-5$ & $1.752 \mathrm{E}-5$ & $1.119 \mathrm{E}-5$ & $7.464 \mathrm{E}-6$ & $5.647 \mathrm{E}-6$ \\
\hline 28 & $6.790 \mathrm{E}+1$ & $6.544 \mathrm{E}-6$ & $2.911 \mathrm{E}-5$ & $2.045 \mathrm{E}-5$ & $1.306 \mathrm{E}-5$ & $8.714 \mathrm{E}-6$ & $6.593 \mathrm{E}-6$ \\
\hline 29 & $4.017 \mathrm{E}+1$ & 4.144E-6 & 1.843E-5 & $1.295 \mathrm{E}-5$ & $8.274 \mathrm{E}-6$ & $5.519 \mathrm{E}-6$ & $4.175 \mathrm{E}-6$ \\
\hline 30 & $2.260 \mathrm{E}+1$ & $2.098 \mathrm{E}-6$ & $9.333 \mathrm{E}-6$ & $6.559 \mathrm{E}-6$ & $4.189 \mathrm{E}-6$ & $2.794 \mathrm{E}-6$ & $2.114 \mathrm{E}-6$ \\
\hline 31 & $1.371 \mathrm{E}+1$ & $1.273 \mathrm{E}-6$ & $5.661 \mathrm{E}-6$ & $3.978 \mathrm{E}-6$ & $2.541 \mathrm{E}-6$ & $1.695 \mathrm{E}-6$ & $1.282 \mathrm{E}-6$ \\
\hline 32 & $8.315 \mathrm{E}+0$ & $1.018 \mathrm{E}-6$ & $4.529 \mathrm{E}-6$ & $3.182 \mathrm{E}-6$ & 2.033E-6 & $1.356 \mathrm{E}-6$ & $1.026 \mathrm{E}-6$ \\
\hline 33 & $4.000 \mathrm{E}+0$ & $2.907 \mathrm{E}-7$ & $1.293 \mathrm{E}-6$ & $9.086 \mathrm{E}-7$ & $5.803 \mathrm{E}-7$ & $3.871 \mathrm{E}-7$ & $2.929 \mathrm{E}-7$ \\
\hline 34 & $2.768 \mathrm{E}+0$ & $3.298 \mathrm{E}-7$ & $1.467 \mathrm{E}-6$ & $1.031 \mathrm{E}-6$ & $6.584 \mathrm{E}-7$ & $4.392 \mathrm{E}-7$ & $3.323 \mathrm{E}-7$ \\
\hline 35 & $1.370 \mathrm{E}+0$ & $9.909 \mathrm{E}-8$ & $4.408 \mathrm{E}-7$ & $3.097 \mathrm{E}-7$ & $1.978 \mathrm{E}-7$ & $1.320 \mathrm{E}-7$ & $9.983 \mathrm{E}-8$ \\
\hline 36 & $9.500 \mathrm{E}-1$ & $9.437 \mathrm{E}-9$ & $4.198 \mathrm{E}-8$ & $2.950 \mathrm{E}-8$ & $1.884 \mathrm{E}-8$ & $1.257 \mathrm{E}-8$ & $9.508 \mathrm{E}-9$ \\
\hline 37 & $9.100 \mathrm{E}-1$ & $1.416 \mathrm{E}-8$ & $6.297 \mathrm{E}-8$ & $4.425 \mathrm{E}-8$ & $2.826 \mathrm{E}-8$ & $1.885 \mathrm{E}-8$ & $1.426 \mathrm{E}-8$ \\
\hline 38 & $8.500 \mathrm{E}-1$ & $1.416 \mathrm{E}-8$ & $6.297 \mathrm{E}-8$ & $4.425 \mathrm{E}-8$ & $2.826 \mathrm{E}-8$ & $1.885 \mathrm{E}-8$ & 1.426E-8 \\
\hline 39 & $7.900 \mathrm{E}-1$ & $2.005 \mathrm{E}-8$ & $8.920 \mathrm{E}-8$ & $6.268 \mathrm{E}-8$ & $4.004 \mathrm{E}-8$ & $2.671 \mathrm{E}-8$ & $2.020 \mathrm{E}-8$ \\
\hline 40 & $7.050 \mathrm{E}-1$ & $1.888 \mathrm{E}-8$ & $8.395 \mathrm{E}-8$ & $5.900 \mathrm{E}-8$ & $3.768 \mathrm{E}-8$ & $2.514 \mathrm{E}-8$ & $1.902 \mathrm{E}-8$ \\
\hline 41 & $6.250 \mathrm{E}-1$ & $2.005 \mathrm{E}-8$ & $8.920 \mathrm{E}-8$ & $6.268 \mathrm{E}-8$ & $4.004 \mathrm{E}-8$ & $2.671 \mathrm{E}-8$ & $2.020 \mathrm{E}-8$ \\
\hline 42 & $5.400 \mathrm{E}-1$ & $1.298 \mathrm{E}-8$ & $5.772 \mathrm{E}-8$ & $4.056 \mathrm{E}-8$ & $2.591 \mathrm{E}-8$ & $1.728 \mathrm{E}-8$ & 1.307E-8 \\
\hline 43 & $4.850 \mathrm{E}-1$ & $1.227 \mathrm{E}-8$ & $5.457 \mathrm{E}-8$ & $3.835 \mathrm{E}-8$ & $2.449 \mathrm{E}-8$ & 1.634E-8 & $1.236 \mathrm{E}-8$ \\
\hline 44 & $4.330 \mathrm{E}-1$ & $2.666 \mathrm{E}-8$ & $1.186 \mathrm{E}-7$ & 8.333E-8 & $5.322 \mathrm{E}-8$ & $3.550 \mathrm{E}-8$ & $2.686 \mathrm{E}-8$ \\
\hline 45 & $3.200 \mathrm{E}-1$ & 1.699E-8 & $7.556 \mathrm{E}-8$ & $5.310 \mathrm{E}-8$ & $3.391 \mathrm{E}-8$ & $2.262 \mathrm{E}-8$ & $1.711 \mathrm{E}-8$ \\
\hline 46 & $2.480 \mathrm{E}-1$ & $2.076 \mathrm{E}-8$ & $9.235 \mathrm{E}-8$ & $6.490 \mathrm{E}-8$ & $4.145 \mathrm{E}-8$ & $2.765 \mathrm{E}-8$ & $2.092 \mathrm{E}-8$ \\
\hline 47 & $1.600 \mathrm{E}-1$ & $4.719 \mathrm{E}-9$ & $2.099 \mathrm{E}-8$ & $1.475 \mathrm{E}-8$ & $9.420 \mathrm{E}-9$ & $6.284 \mathrm{E}-9$ & $4.754 \mathrm{E}-9$ \\
\hline 48 & $1.400 \mathrm{E}-1$ & 9.437E-9 & $4.198 \mathrm{E}-8$ & $2.950 \mathrm{E}-8$ & $1.884 \mathrm{E}-8$ & $1.257 \mathrm{E}-8$ & $9.508 \mathrm{E}-9$ \\
\hline 49 & $1.000 \mathrm{E}-1$ & $1.180 \mathrm{E}-8$ & $5.247 \mathrm{E}-8$ & $3.687 \mathrm{E}-8$ & $2.355 \mathrm{E}-8$ & $1.571 \mathrm{E}-8$ & $1.189 \mathrm{E}-8$ \\
\hline 50 & $5.000 \mathrm{E}-2$ & $3.539 \mathrm{E}-9$ & $1.574 \mathrm{E}-8$ & 1.106E-8 & 7.065E-9 & $4.713 \mathrm{E}-9$ & $3.566 \mathrm{E}-9$ \\
\hline 51 & $3.500 \mathrm{E}-2$ & $2.359 \mathrm{E}-9$ & $1.049 \mathrm{E}-8$ & 7.375E-9 & $4.710 \mathrm{E}-9$ & $3.142 \mathrm{E}-9$ & $2.377 \mathrm{E}-9$ \\
\hline 52 & $2.500 \mathrm{E}-2$ & $2.359 \mathrm{E}-9$ & $1.049 \mathrm{E}-8$ & 7.375E-9 & $4.710 \mathrm{E}-9$ & $3.142 \mathrm{E}-9$ & $2.377 \mathrm{E}-9$ \\
\hline 53 & $1.500 \mathrm{E}-2$ & 3.539E-9 & 1.574E-8 & 1.106E-8 & $7.065 \mathrm{E}-9$ & 4.713E-9 & 3.566E-9 \\
\hline
\end{tabular}


Table 38. Calculated ENDF/B Delayed Neutron Spectra for the YALINA-Thermal

\begin{tabular}{|c|c|c|c|c|c|c|c|}
\hline \multicolumn{2}{|c|}{ Family Group } & \multirow[t]{2}{*}{1} & \multirow[t]{2}{*}{2} & \multirow[t]{2}{*}{3} & \multirow[t]{2}{*}{4} & \multirow[t]{2}{*}{5} & \multirow[t]{2}{*}{6} \\
\hline Group & En. $[\mathrm{eV}]$ & & & & & & \\
\hline 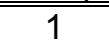 & $1.964 \mathrm{E}+7$ & $0.000 \mathrm{E}+0$ & $0.000 \mathrm{E}+0$ & $0.000 \mathrm{E}+0$ & $0.000 \mathrm{E}+0$ & $0.000 \mathrm{E}+0$ & $0.000 \mathrm{E}+\mathrm{C}$ \\
\hline 2 & $1.419 \mathrm{E}+7$ & $0.000 \mathrm{E}+0$ & $0.000 \mathrm{E}+0$ & $0.000 \mathrm{E}+0$ & $0.000 \mathrm{E}+0$ & $0.000 \mathrm{E}+0$ & $0.000 \mathrm{E}+\mathrm{C}$ \\
\hline 3 & $1.396 \mathrm{E}+7$ & $0.000 \mathrm{E}+0$ & $0.000 \mathrm{E}+0$ & $0.000 \mathrm{E}+0$ & $0.000 \mathrm{E}+0$ & $0.000 \mathrm{E}+0$ & $0.000 \mathrm{E}+\mathrm{C}$ \\
\hline 4 & $1.000 \mathrm{E}+7$ & $0.000 \mathrm{E}+0$ & $0.000 \mathrm{E}+0$ & $0.000 \mathrm{E}+0$ & $0.000 \mathrm{E}+0$ & $0.000 \mathrm{E}+0$ & $0.000 \mathrm{E}+\mathrm{C}$ \\
\hline 5 & $6.065 E+6$ & $0.000 \mathrm{E}+0$ & $0.000 \mathrm{E}+0$ & $0.000 \mathrm{E}+0$ & $0.000 \mathrm{E}+0$ & $0.000 \mathrm{E}+0$ & $0.000 \mathrm{E}+0$ \\
\hline 6 & $3.679 \mathrm{E}+6$ & $0.000 \mathrm{E}+0$ & $0.000 \mathrm{E}+0$ & 3.793E-4 & $4.419 \mathrm{E}-3$ & 8.653E-3 & 1.527E-2 \\
\hline 7 & $2.231 \mathrm{E}+6$ & $9.896 \mathrm{E}-3$ & $1.273 \mathrm{E}-2$ & $1.621 \mathrm{E}-2$ & $5.641 \mathrm{E}-2$ & $5.123 \mathrm{E}-2$ & $5.858 \mathrm{E}-2$ \\
\hline 8 & $1.353 \mathrm{E}+6$ & $1.236 \mathrm{E}-1$ & 1.533E-1 & 8.772E-2 & 1.617E-1 & $1.236 \mathrm{E}-1$ & 1.217E-1 \\
\hline 9 & $8.209 E+5$ & $1.690 \mathrm{E}-1$ & $2.235 \mathrm{E}-1$ & $2.699 \mathrm{E}-1$ & $2.351 \mathrm{E}-1$ & $2.140 \mathrm{E}-1$ & $2.155 \mathrm{E}-1$ \\
\hline 10 & $4.979 \mathrm{E}+5$ & $2.116 \mathrm{E}-1$ & $2.627 \mathrm{E}-1$ & $2.291 \mathrm{E}-1$ & $2.132 \mathrm{E}-1$ & $2.159 \mathrm{E}-1$ & $2.017 \mathrm{E}-1$ \\
\hline 11 & $3.020 \mathrm{E}+5$ & 1.962E-1 & 1.295E-1 & 1.624E-1 & 1.410E-1 & $1.635 \mathrm{E}-1$ & 1.548E-1 \\
\hline 12 & $1.832 \mathrm{E}+5$ & $1.235 \mathrm{E}-1$ & $8.243 \mathrm{E}-2$ & $1.071 \mathrm{E}-1$ & $9.007 \mathrm{E}-2$ & $1.023 \mathrm{E}-1$ & $9.366 \mathrm{E}-2$ \\
\hline 13 & $1.111 \mathrm{E}+5$ & $5.975 \mathrm{E}-2$ & $6.411 \mathrm{E}-2$ & $5.597 \mathrm{E}-2$ & $4.347 \mathrm{E}-2$ & $5.641 \mathrm{E}-2$ & $5.963 \mathrm{E}-2$ \\
\hline 14 & $6.738 \mathrm{E}+4$ & $4.969 \mathrm{E}-2$ & $2.799 \mathrm{E}-2$ & $2.984 \mathrm{E}-2$ & $2.242 \mathrm{E}-2$ & $2.732 \mathrm{E}-2$ & $2.745 \mathrm{E}-2$ \\
\hline 15 & $4.087 \mathrm{E}+4$ & $2.187 \mathrm{E}-2$ & $1.722 \mathrm{E}-2$ & $1.785 \mathrm{E}-2$ & $1.398 \mathrm{E}-2$ & $1.410 \mathrm{E}-2$ & $1.519 \mathrm{E}-2$ \\
\hline 16 & $2.479 E+4$ & $2.183 \mathrm{E}-2$ & $1.050 \mathrm{E}-2$ & $1.072 \mathrm{E}-2$ & $8.974 \mathrm{E}-3$ & $1.224 \mathrm{E}-2$ & 1.977E-2 \\
\hline 17 & $1.503 \mathrm{E}+4$ & $1.086 \mathrm{E}-2$ & $6.335 \mathrm{E}-3$ & $6.129 \mathrm{E}-3$ & $5.034 \mathrm{E}-3$ & $7.999 \mathrm{E}-3$ & 1.452E-2 \\
\hline 18 & $9.119 \mathrm{E}+3$ & $8.471 \mathrm{E}-4$ & $3.768 \mathrm{E}-3$ & $2.645 \mathrm{E}-3$ & $1.688 \mathrm{E}-3$ & $1.126 \mathrm{E}-3$ & $8.530 \mathrm{E}-4$ \\
\hline 19 & $5.531 \mathrm{E}+3$ & $5.138 \mathrm{E}-4$ & $2.285 \mathrm{E}-3$ & $1.604 \mathrm{E}-3$ & $1.024 \mathrm{E}-3$ & $6.832 \mathrm{E}-4$ & $5.174 \mathrm{E}-4$ \\
\hline 20 & $3.355 E+3$ & $3.116 \mathrm{E}-4$ & 1.386E-3 & 9.729E-4 & $6.208 \mathrm{E}-4$ & 4.144E-4 & 3.138E-4 \\
\hline 21 & $2.035 E+3$ & $1.890 \mathrm{E}-4$ & $8.407 \mathrm{E}-4$ & $5.901 \mathrm{E}-4$ & $3.766 \mathrm{E}-4$ & $2.513 \mathrm{E}-4$ & $1.903 \mathrm{E}-4$ \\
\hline 22 & $1.234 \mathrm{E}+3$ & $1.146 \mathrm{E}-4$ & $5.099 \mathrm{E}-4$ & $3.579 \mathrm{E}-4$ & $2.284 \mathrm{E}-4$ & $1.525 \mathrm{E}-4$ & $1.154 \mathrm{E}-4$ \\
\hline 23 & $7.485 \mathrm{E}+2$ & $6.954 \mathrm{E}-5$ & $3.093 \mathrm{E}-4$ & $2.171 \mathrm{E}-4$ & $1.385 \mathrm{E}-4$ & $9.246 \mathrm{E}-5$ & $7.002 \mathrm{E}-5$ \\
\hline 24 & $4.540 \mathrm{E}+2$ & $3.534 \mathrm{E}-5$ & $1.572 \mathrm{E}-4$ & $1.103 \mathrm{E}-4$ & $7.040 \mathrm{E}-5$ & $4.699 \mathrm{E}-5$ & $3.558 \mathrm{E}-5$ \\
\hline 25 & $3.043 E+2$ & $3.676 \mathrm{E}-5$ & $1.635 \mathrm{E}-4$ & $1.148 \mathrm{E}-4$ & $7.323 \mathrm{E}-5$ & $4.888 \mathrm{E}-5$ & $3.702 \mathrm{E}-5$ \\
\hline 26 & $1.486 \mathrm{E}+2$ & $1.345 \mathrm{E}-5$ & $5.982 \mathrm{E}-5$ & 4.199E-5 & $2.679 \mathrm{E}-5$ & $1.788 \mathrm{E}-5$ & $1.354 \mathrm{E}-5$ \\
\hline 27 & $9.166 \mathrm{E}+1$ & $5.609 \mathrm{E}-6$ & $2.495 \mathrm{E}-5$ & $1.751 \mathrm{E}-5$ & $1.117 \mathrm{E}-5$ & $7.459 \mathrm{E}-6$ & $5.648 \mathrm{E}-6$ \\
\hline 28 & $6.790 \mathrm{E}+1$ & $6.548 \mathrm{E}-6$ & $2.913 \mathrm{E}-5$ & $2.044 \mathrm{E}-5$ & $1.305 \mathrm{E}-5$ & $8.707 \mathrm{E}-6$ & $6.594 \mathrm{E}-6$ \\
\hline 29 & $4.017 \mathrm{E}+1$ & $4.147 \mathrm{E}-6$ & $1.845 \mathrm{E}-5$ & $1.295 \mathrm{E}-5$ & $8.262 \mathrm{E}-6$ & $5.515 \mathrm{E}-6$ & $4.176 \mathrm{E}-6$ \\
\hline 30 & $2.260 \mathrm{E}+1$ & $2.100 \mathrm{E}-6$ & $9.340 \mathrm{E}-6$ & $6.555 \mathrm{E}-6$ & $4.183 \mathrm{E}-6$ & $2.792 \mathrm{E}-6$ & $2.114 \mathrm{E}-6$ \\
\hline 31 & $1.371 \mathrm{E}+1$ & $1.274 \mathrm{E}-6$ & $5.665 \mathrm{E}-6$ & $3.976 \mathrm{E}-6$ & $2.537 \mathrm{E}-6$ & $1.694 \mathrm{E}-6$ & $1.282 \mathrm{E}-6$ \\
\hline 32 & $8.315 \mathrm{E}+0$ & $1.019 \mathrm{E}-6$ & $4.532 \mathrm{E}-6$ & $3.181 \mathrm{E}-6$ & $2.030 \mathrm{E}-6$ & $1.355 \mathrm{E}-6$ & $1.026 \mathrm{E}-6$ \\
\hline 33 & $4.000 \mathrm{E}+0$ & $2.909 \mathrm{E}-7$ & $1.294 \mathrm{E}-6$ & $9.081 \mathrm{E}-7$ & $5.795 \mathrm{E}-7$ & $3.868 \mathrm{E}-7$ & $2.929 \mathrm{E}-7$ \\
\hline 34 & $2.768 \mathrm{E}+0$ & $3.301 \mathrm{E}-7$ & $1.468 \mathrm{E}-6$ & $1.030 \mathrm{E}-6$ & $6.575 \mathrm{E}-7$ & $4.389 \mathrm{E}-7$ & $3.323 \mathrm{E}-7$ \\
\hline 35 & $1.370 \mathrm{E}+0$ & $9.916 \mathrm{E}-8$ & $4.411 \mathrm{E}-7$ & $3.096 \mathrm{E}-7$ & $1.975 \mathrm{E}-7$ & $1.319 \mathrm{E}-7$ & $9.985 \mathrm{E}-8$ \\
\hline 36 & $9.500 \mathrm{E}-1$ & $9.444 \mathrm{E}-9$ & $4.201 \mathrm{E}-8$ & $2.948 \mathrm{E}-8$ & $1.881 \mathrm{E}-8$ & $1.256 \mathrm{E}-8$ & $9.509 \mathrm{E}-9$ \\
\hline 37 & $9.100 \mathrm{E}-1$ & 1.417E-8 & $6.301 \mathrm{E}-8$ & $4.422 \mathrm{E}-8$ & $2.822 \mathrm{E}-8$ & $1.884 \mathrm{E}-8$ & $1.426 \mathrm{E}-8$ \\
\hline 38 & $8.500 \mathrm{E}-1$ & 1.417E-8 & $6.301 \mathrm{E}-8$ & $4.422 \mathrm{E}-8$ & $2.822 \mathrm{E}-8$ & 1.884E-8 & $1.426 \mathrm{E}-8$ \\
\hline 39 & $7.900 \mathrm{E}-1$ & $2.007 \mathrm{E}-8$ & $8.926 \mathrm{E}-8$ & $6.265 \mathrm{E}-8$ & $3.998 \mathrm{E}-8$ & $2.669 \mathrm{E}-8$ & $2.021 \mathrm{E}-8$ \\
\hline 40 & $7.050 \mathrm{E}-1$ & $1.889 \mathrm{E}-8$ & $8.401 \mathrm{E}-8$ & $5.896 \mathrm{E}-8$ & $3.763 \mathrm{E}-8$ & $2.512 \mathrm{E}-8$ & $1.902 \mathrm{E}-8$ \\
\hline 41 & $6.250 \mathrm{E}-1$ & $2.007 \mathrm{E}-8$ & 8.926E-8 & $6.265 \mathrm{E}-8$ & $3.998 \mathrm{E}-8$ & $2.669 \mathrm{E}-8$ & $2.021 \mathrm{E}-8$ \\
\hline 42 & $5.400 \mathrm{E}-1$ & $1.299 \mathrm{E}-8$ & $5.776 \mathrm{E}-8$ & $4.054 \mathrm{E}-8$ & $2.587 \mathrm{E}-8$ & $1.727 \mathrm{E}-8$ & $1.308 \mathrm{E}-8$ \\
\hline 43 & $4.850 \mathrm{E}-1$ & $1.228 \mathrm{E}-8$ & $5.461 \mathrm{E}-8$ & $3.833 \mathrm{E}-8$ & $2.446 \mathrm{E}-8$ & $1.633 \mathrm{E}-8$ & $1.236 \mathrm{E}-8$ \\
\hline 44 & $4.330 \mathrm{E}-1$ & $2.668 \mathrm{E}-8$ & 1.187E-7 & 8.329E-8 & $5.315 \mathrm{E}-8$ & $3.548 \mathrm{E}-8$ & $2.686 \mathrm{E}-8$ \\
\hline 45 & $3.200 \mathrm{E}-1$ & $1.700 \mathrm{E}-8$ & $7.561 \mathrm{E}-8$ & $5.307 \mathrm{E}-8$ & $3.387 \mathrm{E}-8$ & $2.260 \mathrm{E}-8$ & $1.712 \mathrm{E}-8$ \\
\hline 46 & $2.480 \mathrm{E}-1$ & $2.078 \mathrm{E}-8$ & $9.241 \mathrm{E}-8$ & $6.486 \mathrm{E}-8$ & $4.139 \mathrm{E}-8$ & $2.763 \mathrm{E}-8$ & $2.092 \mathrm{E}-8$ \\
\hline 47 & $1.600 \mathrm{E}-1$ & $4.722 \mathrm{E}-9$ & $2.100 \mathrm{E}-8$ & $1.474 \mathrm{E}-8$ & 9.407E-9 & $6.279 \mathrm{E}-9$ & $4.755 \mathrm{E}-9$ \\
\hline 48 & $1.400 \mathrm{E}-1$ & $9.444 \mathrm{E}-9$ & $4.201 \mathrm{E}-8$ & $2.948 \mathrm{E}-8$ & $1.881 \mathrm{E}-8$ & $1.256 \mathrm{E}-8$ & 9.509E-9 \\
\hline 49 & $1.000 \mathrm{E}-1$ & $1.181 \mathrm{E}-8$ & $5.251 \mathrm{E}-8$ & $3.685 \mathrm{E}-8$ & $2.352 \mathrm{E}-8$ & $1.570 \mathrm{E}-8$ & $1.189 \mathrm{E}-8$ \\
\hline 50 & $5.000 \mathrm{E}-2$ & $3.542 \mathrm{E}-9$ & $1.575 \mathrm{E}-8$ & $1.106 \mathrm{E}-8$ & $7.055 \mathrm{E}-9$ & $4.709 \mathrm{E}-9$ & $3.566 \mathrm{E}-9$ \\
\hline 51 & $3.500 \mathrm{E}-2$ & $2.361 \mathrm{E}-9$ & $1.050 \mathrm{E}-8$ & 7.370E-9 & $4.704 \mathrm{E}-9$ & $3.140 \mathrm{E}-9$ & $2.377 \mathrm{E}-9$ \\
\hline 52 & $2.500 \mathrm{E}-2$ & $2.361 \mathrm{E}-9$ & $1.050 \mathrm{E}-8$ & $7.370 \mathrm{E}-9$ & $4.704 \mathrm{E}-9$ & $3.140 \mathrm{E}-9$ & $2.377 \mathrm{E}-9$ \\
\hline 53 & $1.500 \mathrm{E}-2$ & $3.542 \mathrm{E}-9$ & $1.575 \mathrm{E}-8$ & 1.106E-8 & $7.055 \mathrm{E}-9$ & $4.709 \mathrm{E}-9$ & $3.566 \mathrm{E}-9$ \\
\hline
\end{tabular}




\section{Appendix F}

\section{Comparison of Neutron Spectra Calculated with Different Nuclear Data Libraries}

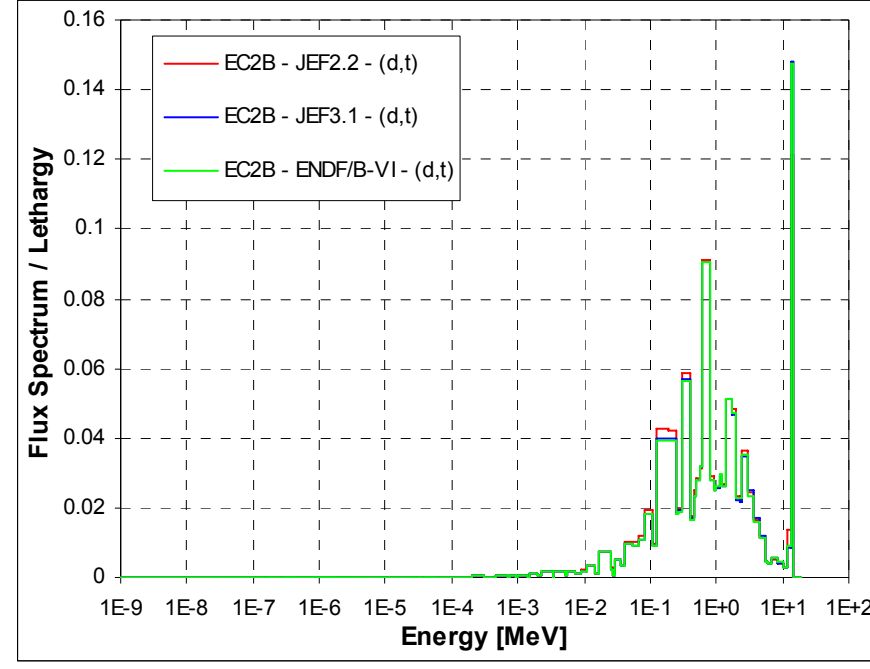

Figure 127. EC2B Neutron Spectra of the YALINABooster with $(d, t)$ Neutron Source

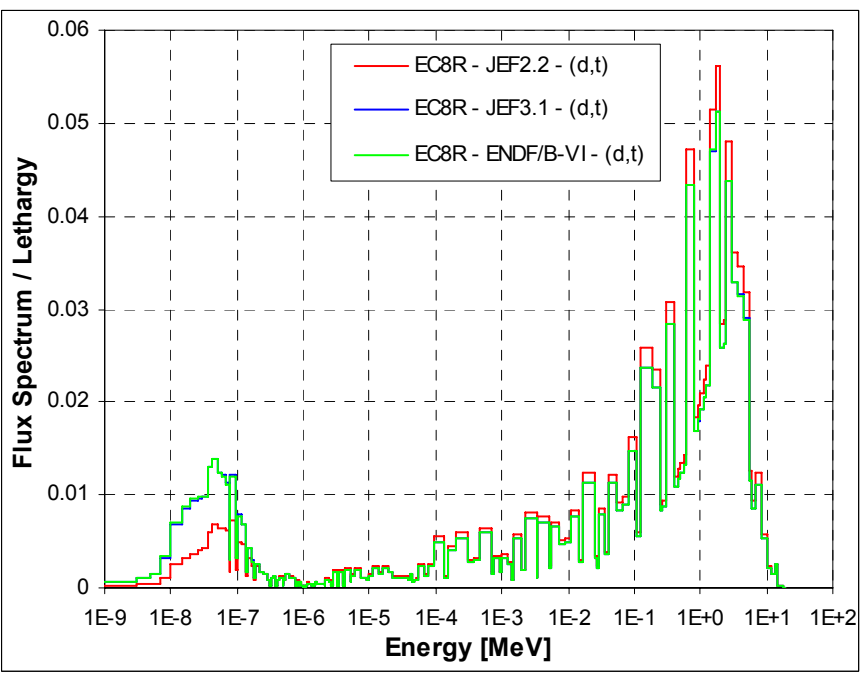

Figure 129. EC8R Neutron Spectra of the YALINABooster with $(d, t)$ Neutron Source

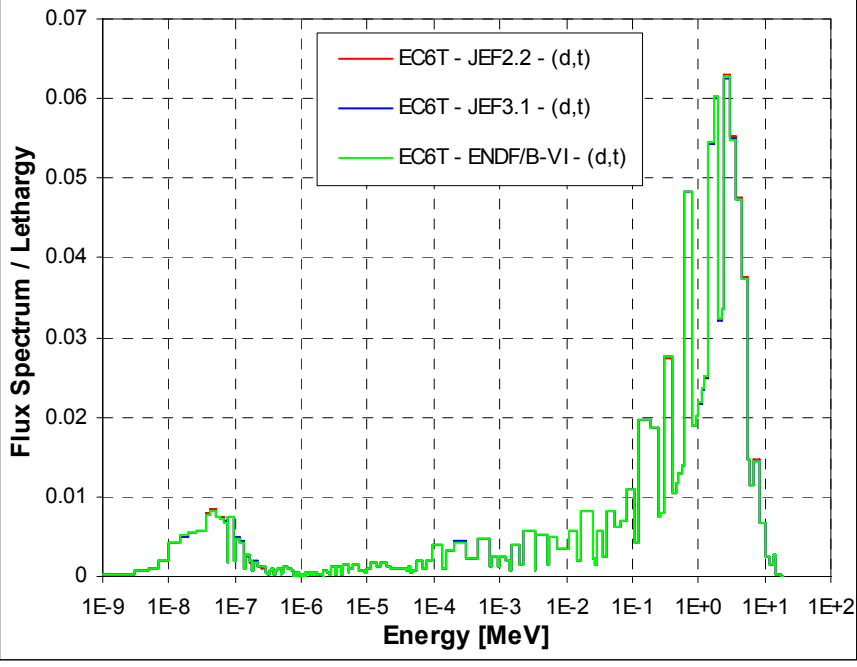

Figure 128. EC6T Neutron Spectra of the YALINABooster with $(d, t)$ Neutron Source

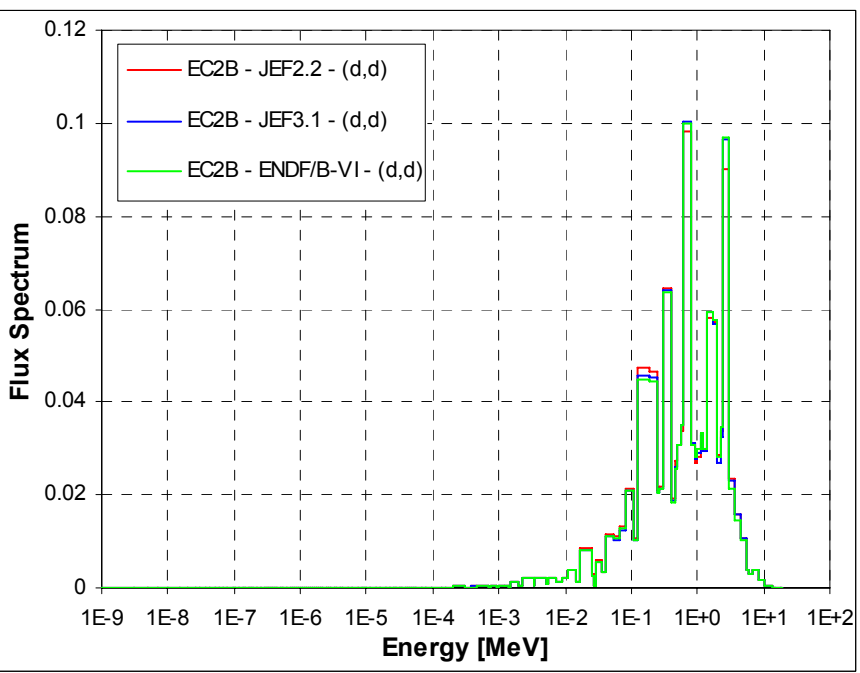

Figure 130. EC2B Neutron Spectra of the YALINABooster with $(d, d)$ Neutron Source 
ANL-09-23

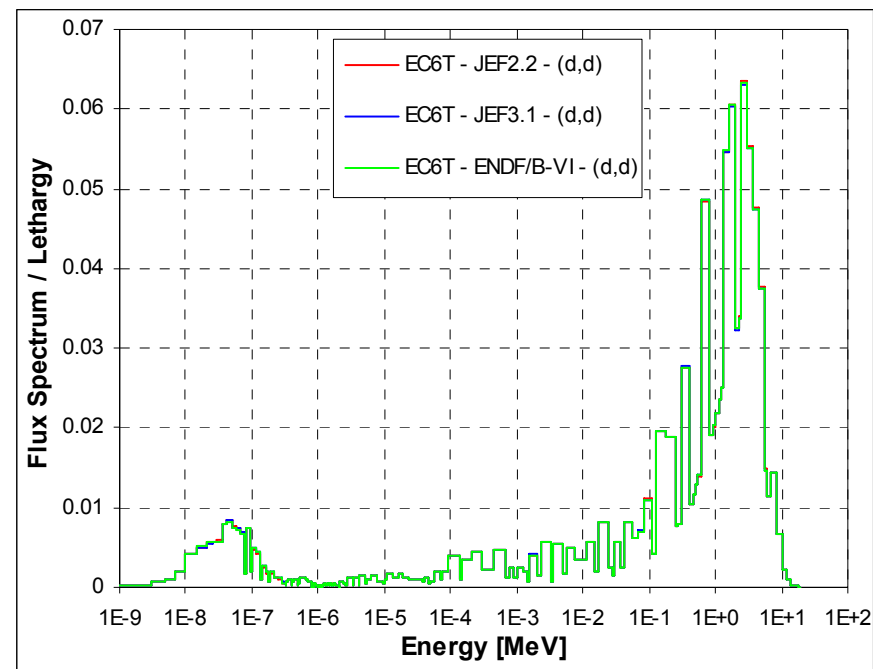

Figure 131. EC6T Neutron Spectra of the YALINABooster with (d,d) Neutron Source

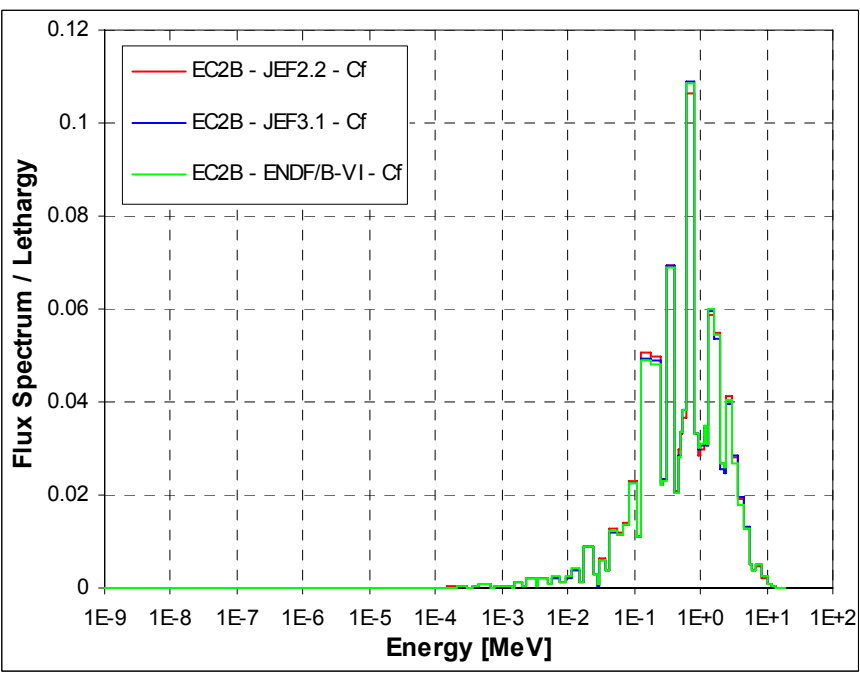

Figure 133. EC2B Neutron Spectra of the YALINABooster with Cf Neutron Source

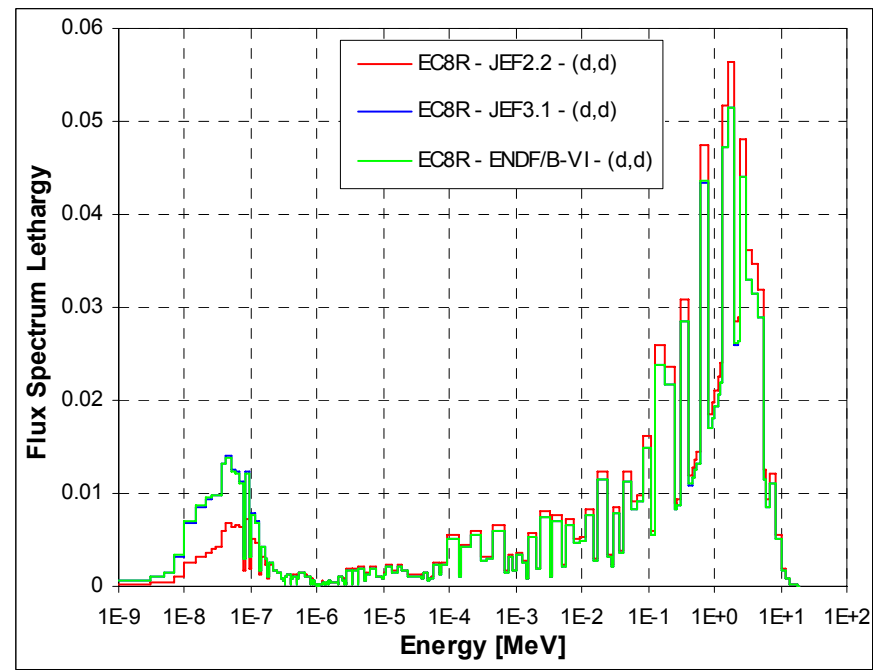

Figure 132. EC8R Neutron Spectra of the YALINABooster with $(d, d)$ Neutron Source

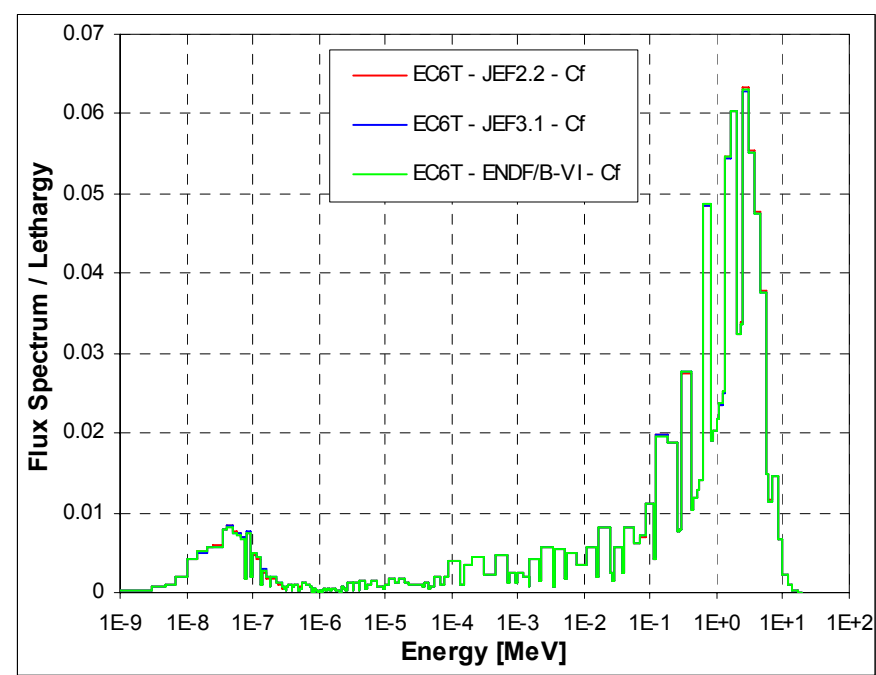

Figure 134. EC6T Neutron Spectra of the YALINABooster with Cf Neutron Source

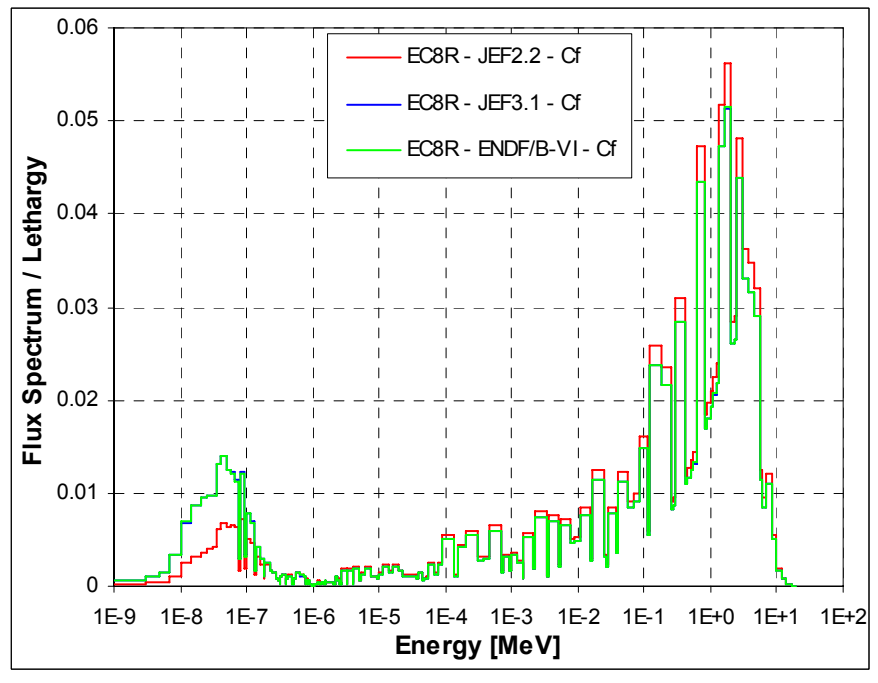

Figure 135. EC8R Neutron Spectra of the YALINA-Booster with Cf Neutron Source 
ANL-09-23
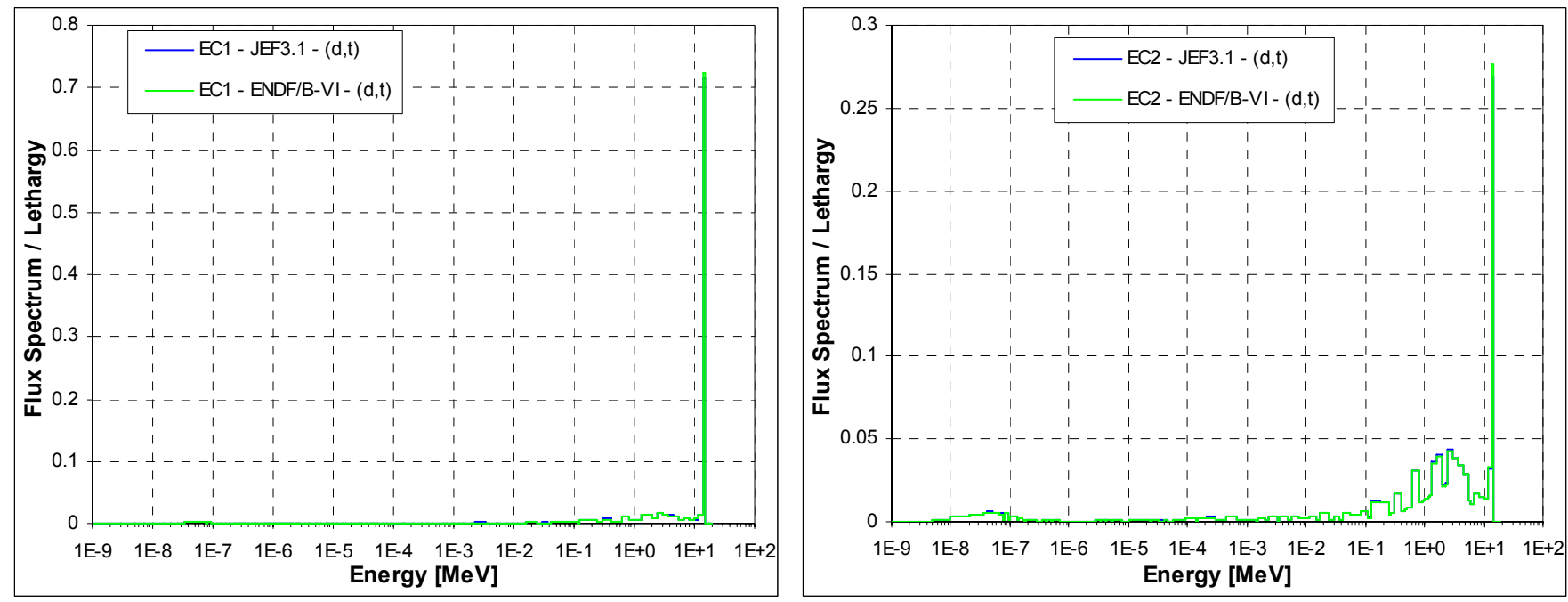

Figure 136. EC1 Neutron Spectra of the YALINA-ThermalFigure 137. EC2 Neutron Spectra of the YALINA-Thermal with $(d, t)$ Neutron Source with $(\mathrm{d}, \mathrm{t})$ Neutron Source
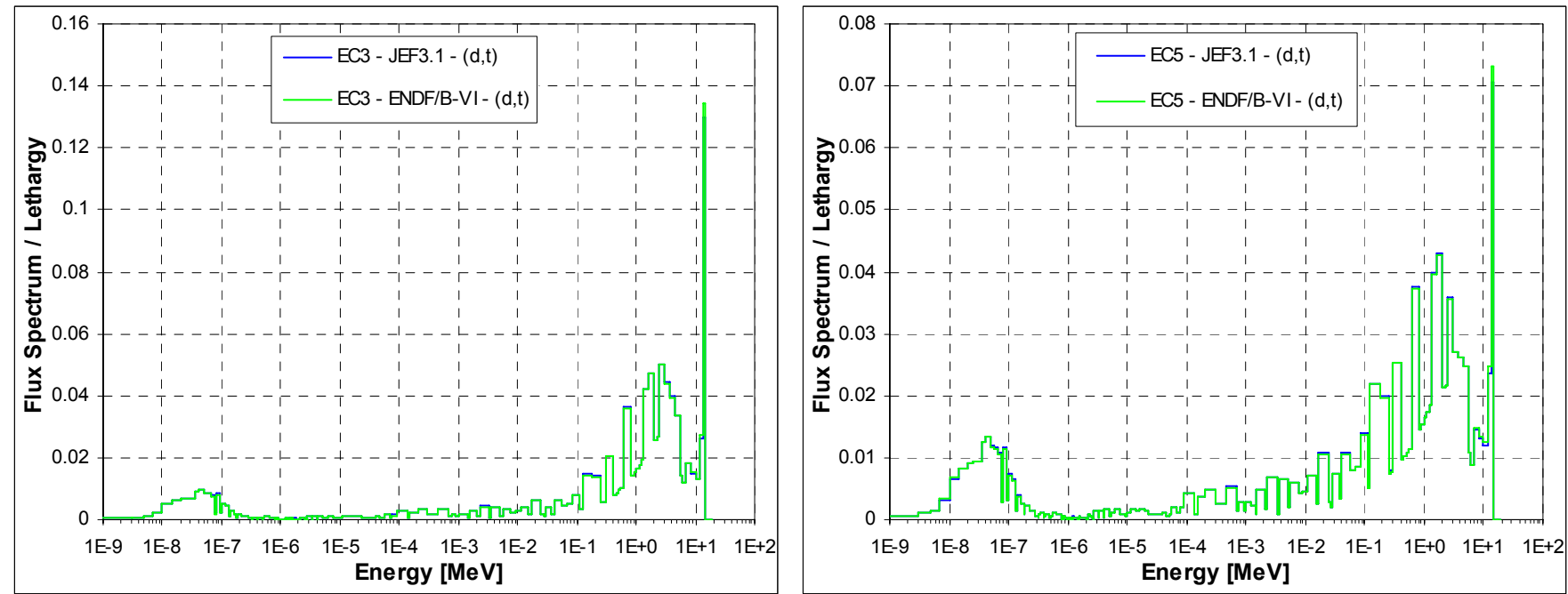

Figure 138. EC3 Neutron Spectra of the YALINA-ThermalFigure 139. EC5 Neutron Spectra of the YALINA-Thermal with $(d, t)$ Neutron Source
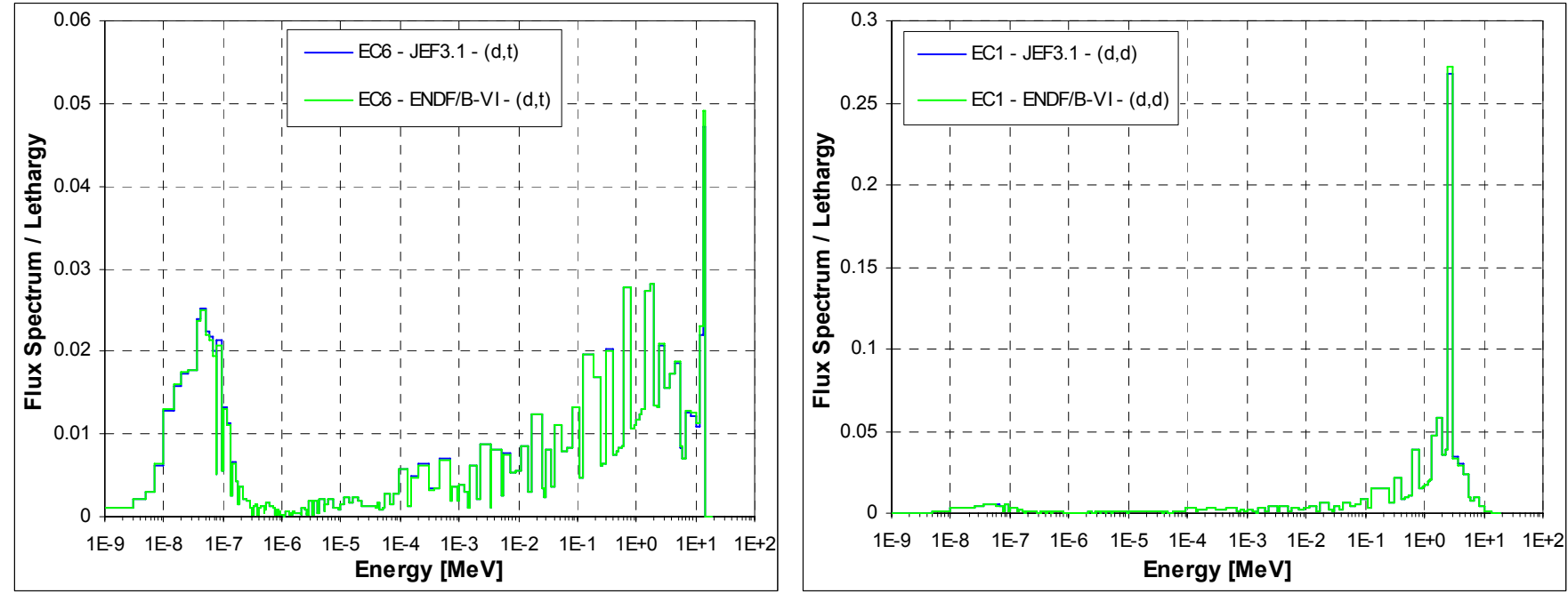

Figure 140. EC6 Neutron Spectra of the YALINA-ThermalFigure 141. EC1 Neutron Spectra of the YALINA-Thermal with $(d, t)$ Neutron Source with $(d, d)$ Neutron Source 

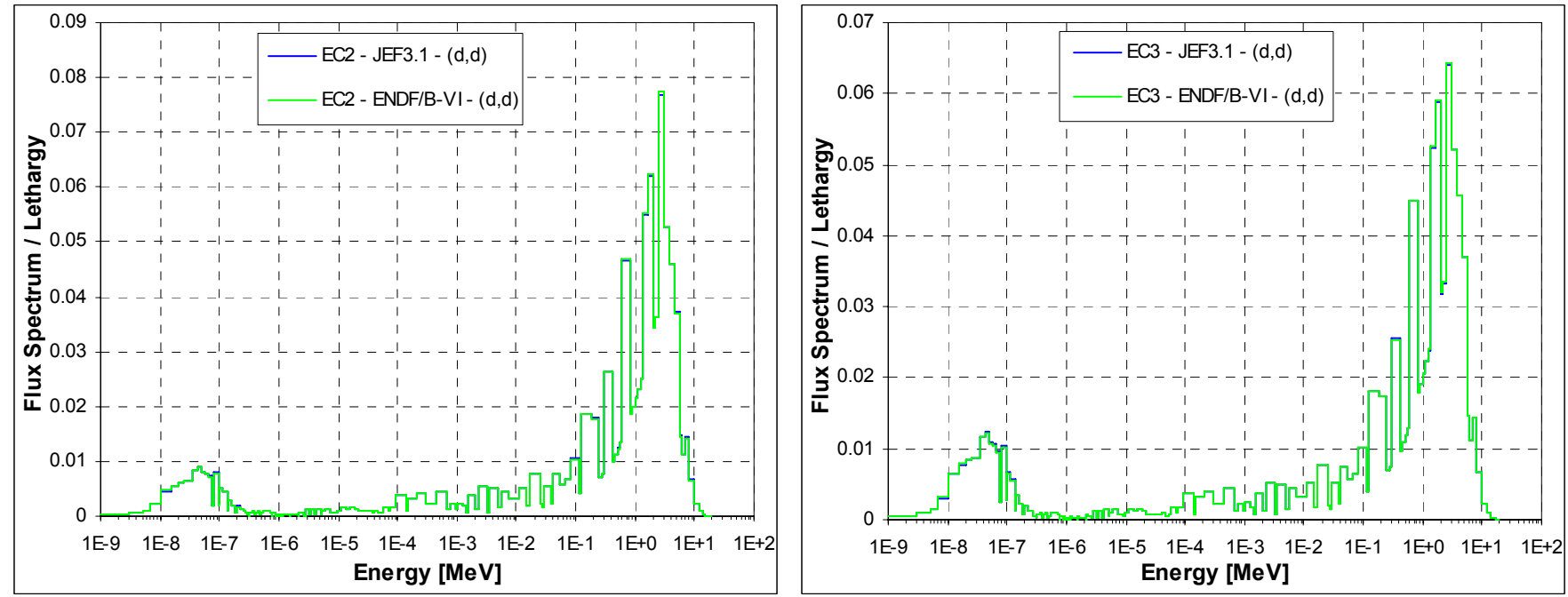

Figure 142. EC2 Neutron Spectra of the YALINA-ThermalFigure 143. EC3 Neutron Spectra of the YALINA-Thermal with $(d, d)$ Neutron Source with $(d, d)$ Neutron Source
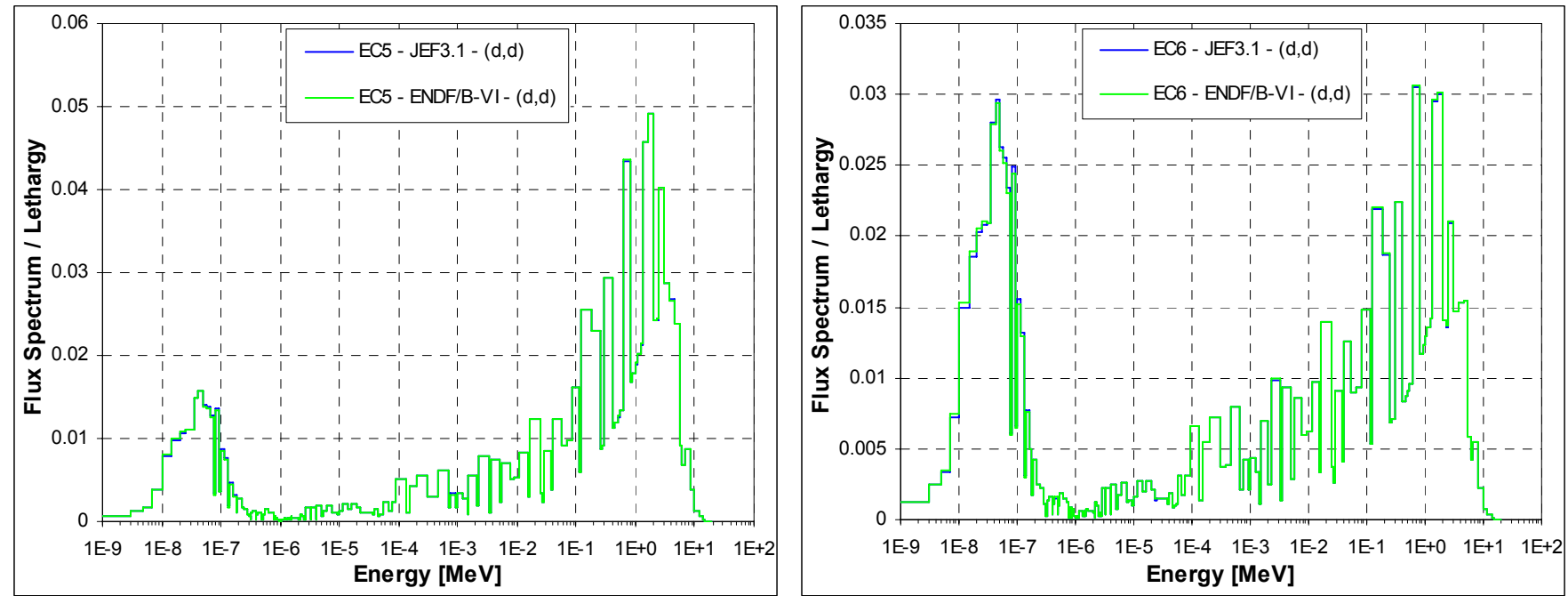

Figure 144. EC5 Neutron Spectra of the YALINA-ThermalFigure 145. EC6 Neutron Spectra of the YALINA-Thermal with $(d, d)$ Neutron Source with $(d, d)$ Neutron Source
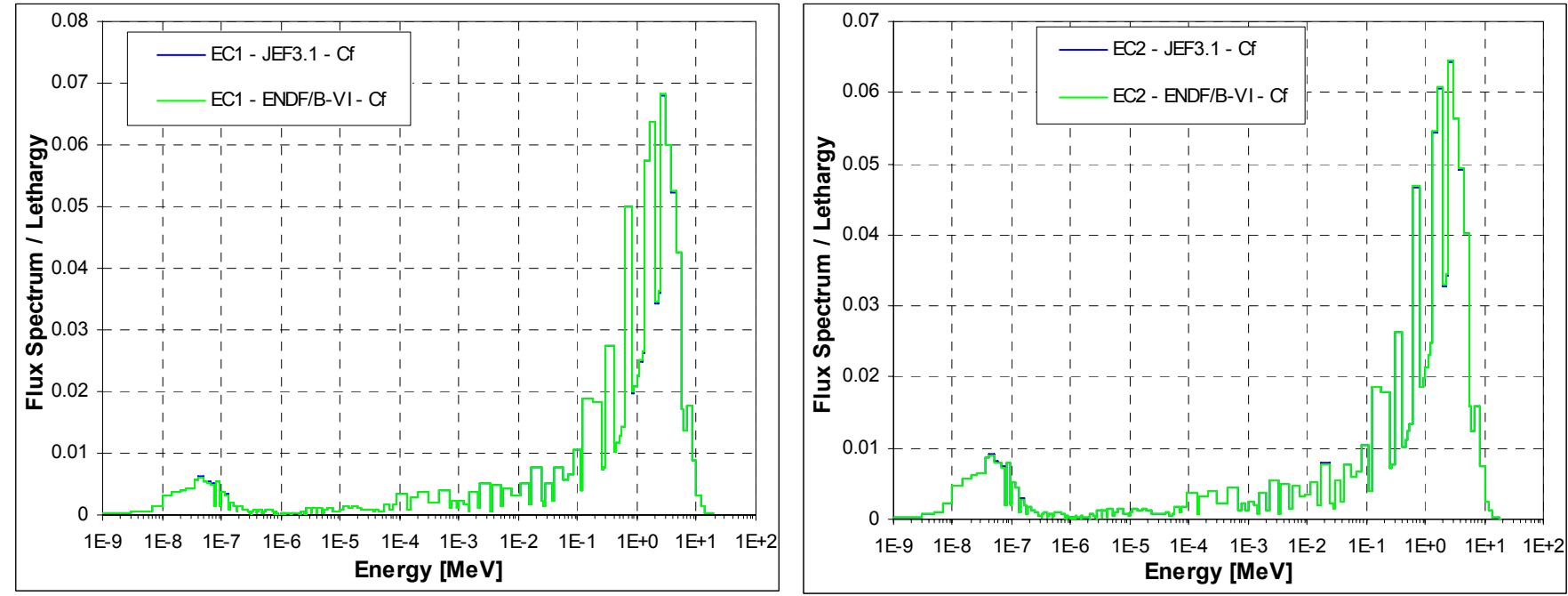

Figure 146. EC1 Neutron Spectra of the YALINA-ThermalFigure 147. EC2 Neutron Spectra of the YALINA-Thermal with Cf Neutron Source with Cf Neutron Source 
ANL-09-23
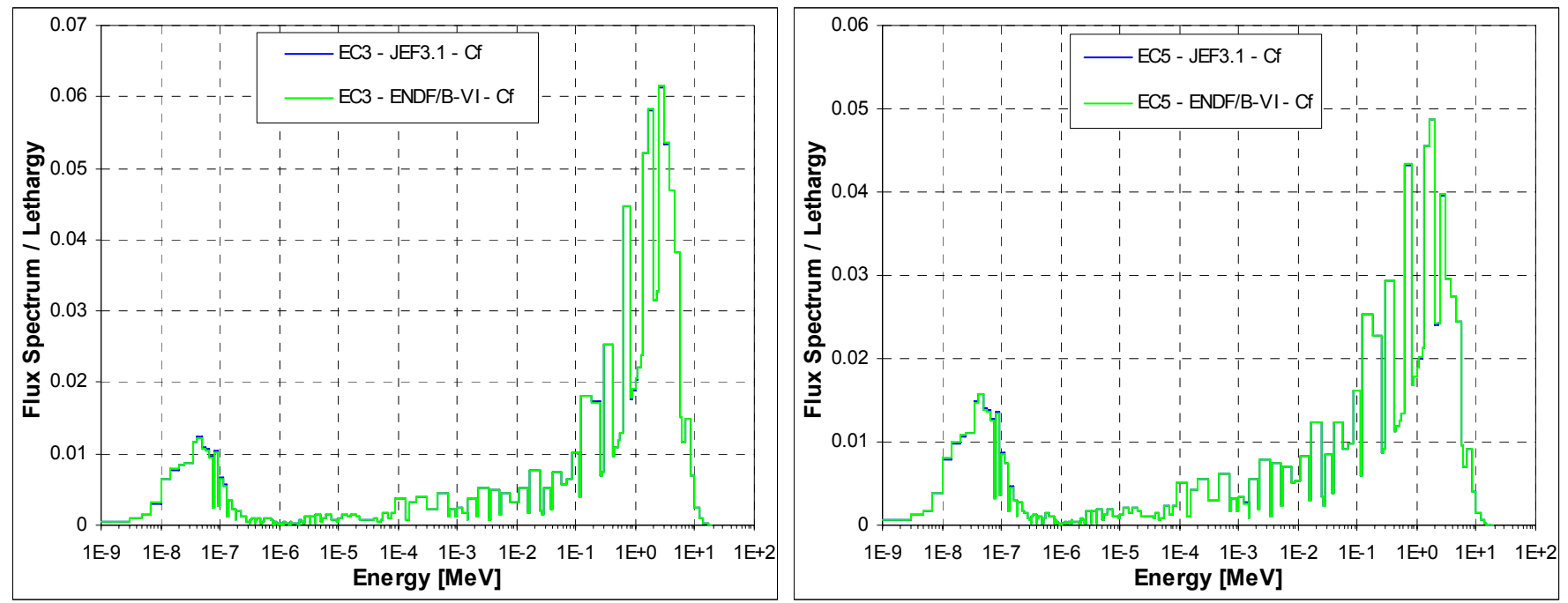

Figure 148. EC3 Neutron Spectra of the YALINA-ThermalFigure 149. EC5 Neutron Spectra of the YALINA-Thermal with Cf Neutron Source with Cf Neutron Source

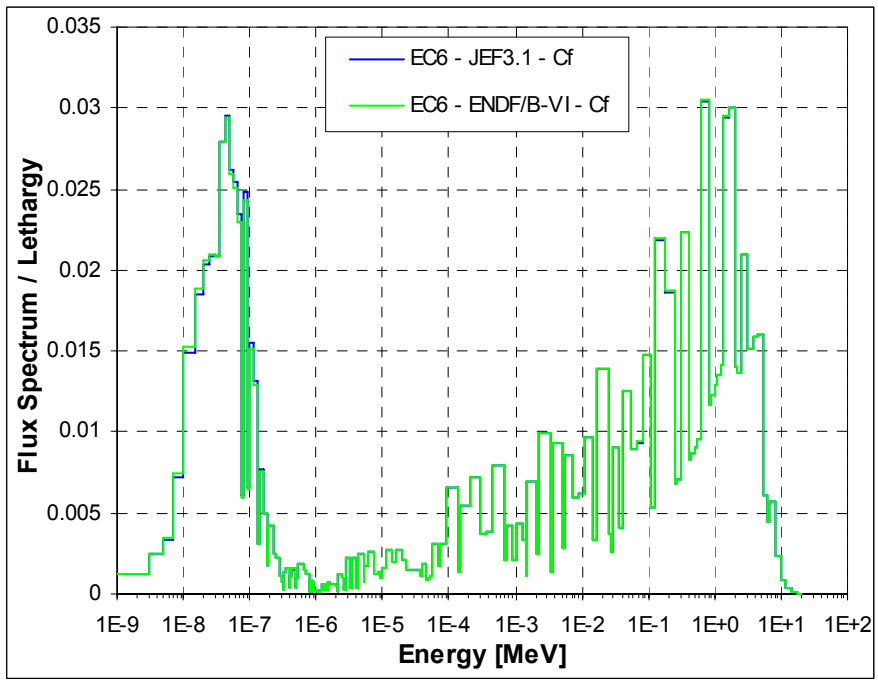

Figure 150. EC6 Neutron Spectra of the YALINA-Thermal with Cf Neutron Source 


\section{Appendix G}

\section{Comparison of Reaction Rates Calculated with Different Nuclear Data Libraries}

\section{G.1. YALINA-Booster}

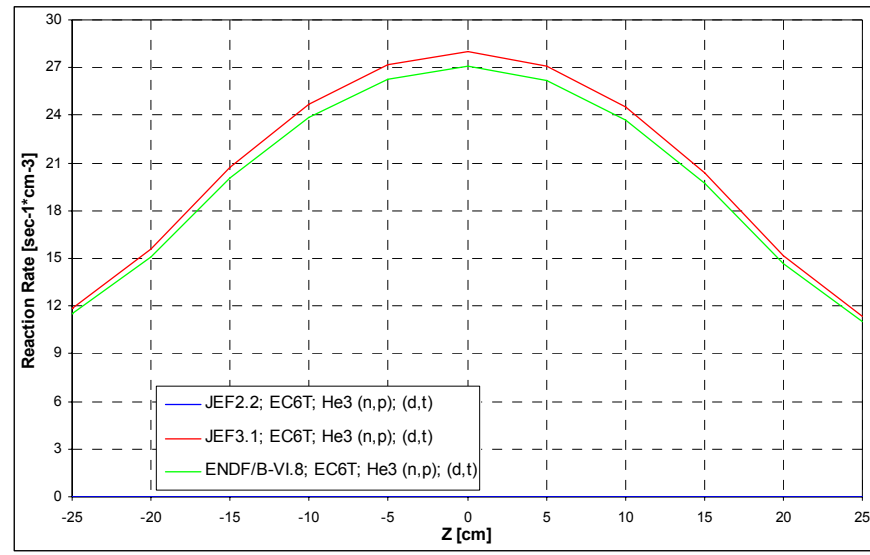

Figure 151. He-3(n,p) Reaction Rate in EC6T Experimental Channel of the YALINA-Booster with $(\mathrm{d}, \mathrm{t})$ Source

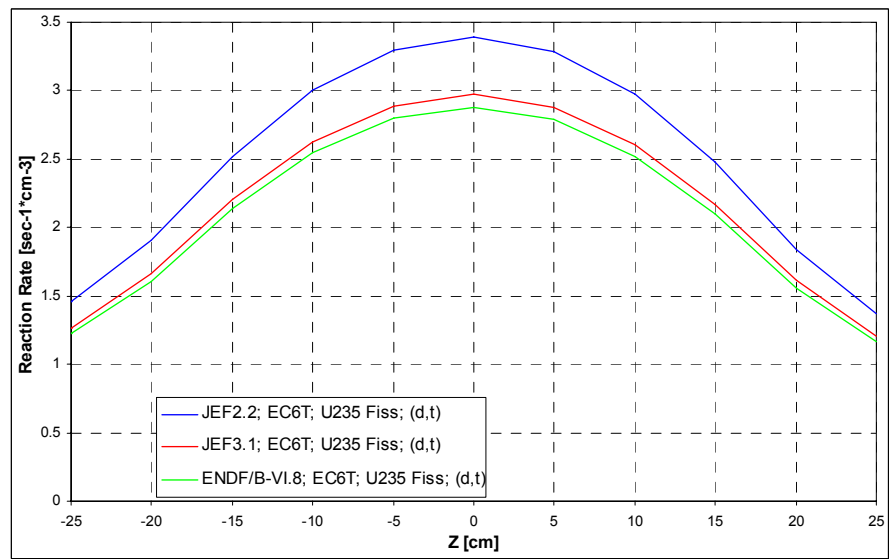

Figure 153. U-235 Fission Reaction Rate in EC6T Experimental Channel of the YALINA-Booster with $(\mathrm{d}, \mathrm{t})$ Source

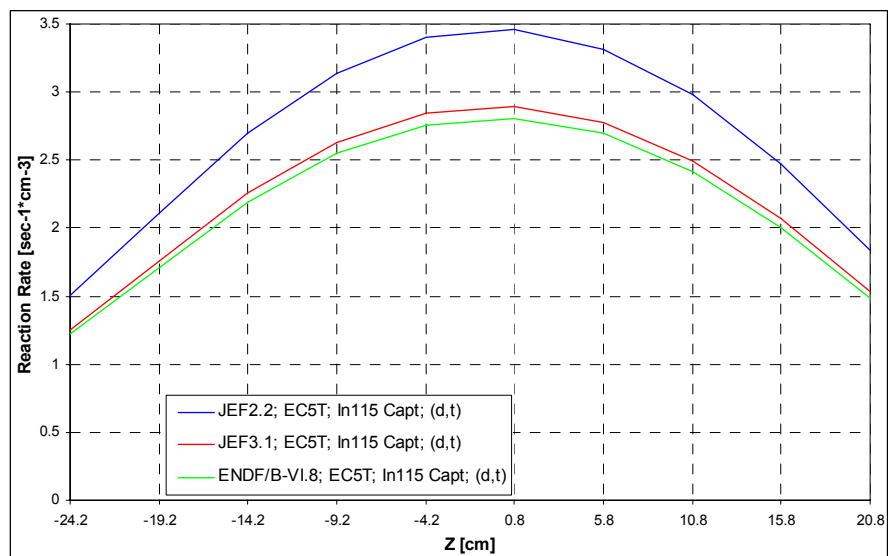

Figure 155. In-115 Capture Reaction Rate in EC5T Experimental Channel of the YALINA-Booster with $(\mathrm{d}, \mathrm{t})$ Source. Polyethylene Holder is Modeled

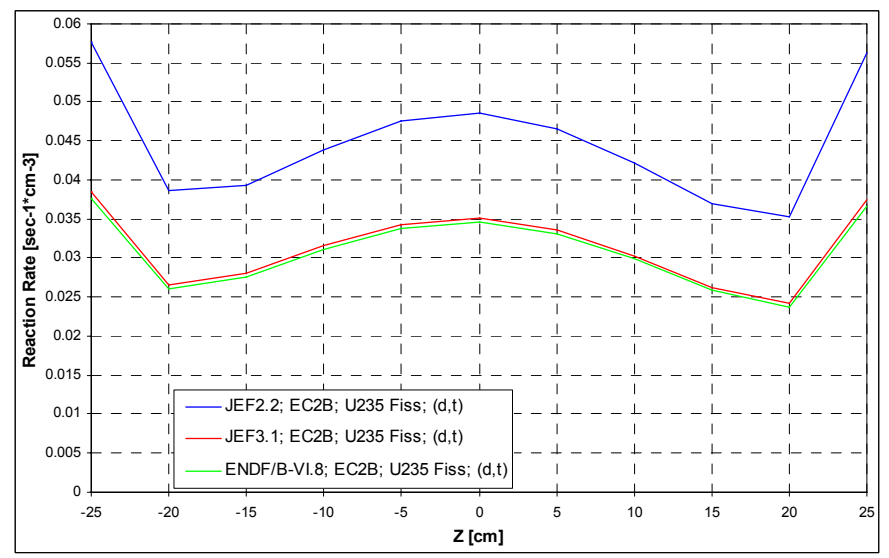

Figure 152. U-235 Fission Reaction Rate in EC2B Experimental Channel of the YALINA-Booster with $(\mathrm{d}, \mathrm{t})$ Source

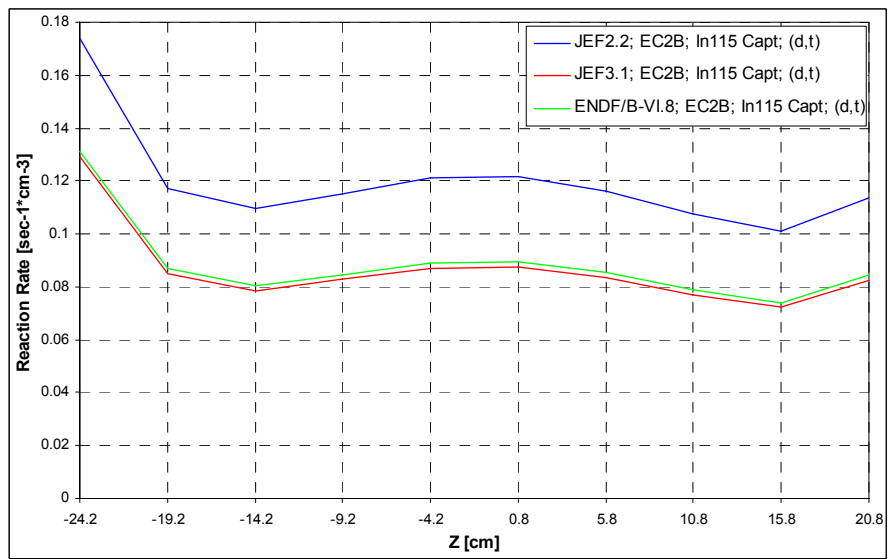

Figure 154. In-115 Capture Reaction Rate in EC2B Experimental Channel of the YALINA-Booster with $(\mathrm{d}, \mathrm{t})$ Source. Lead Holder is Modeled

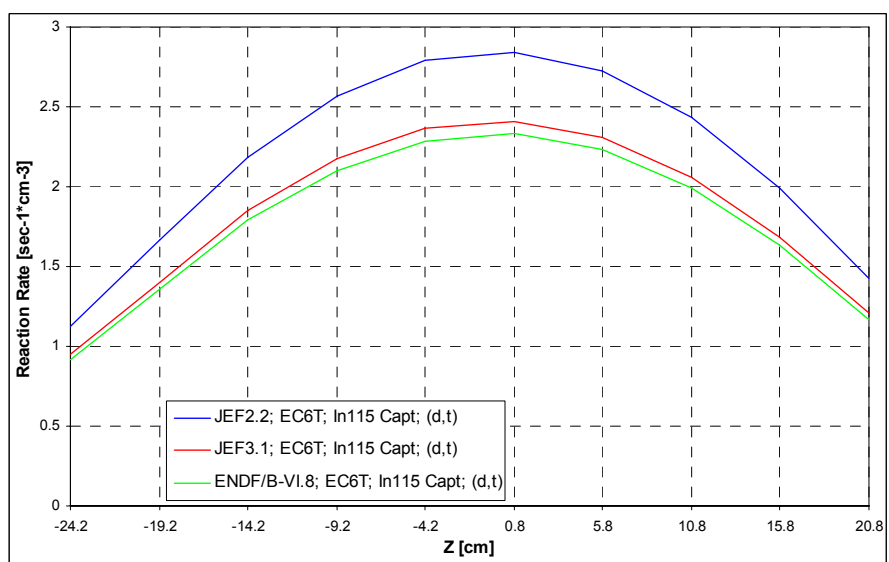

Figure 156. In-115 Capture Reaction Rate in EC6T Experimental Channel of the YALINA-Booster with $(d, t)$ Source. Polyethylene Holder is Modeled 
ANL-09-23

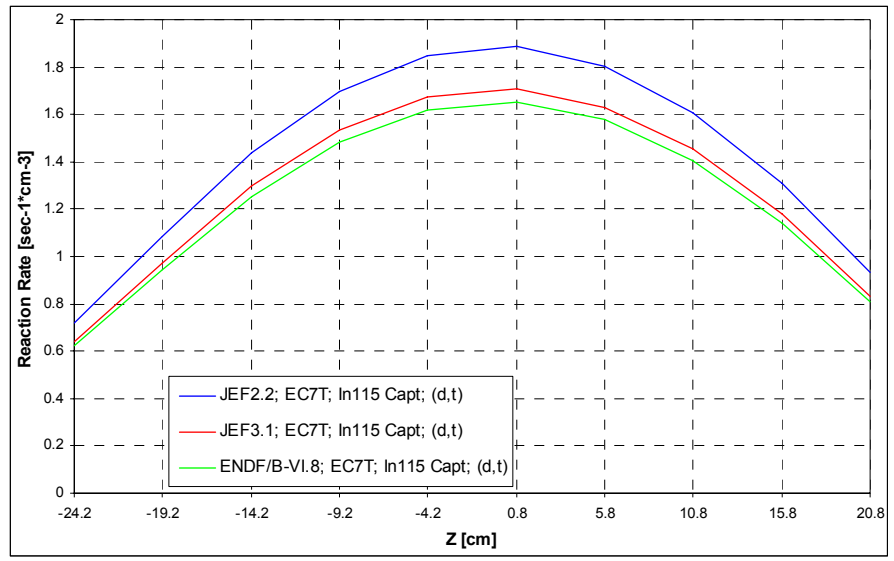

Figure 157. In-115 Capture Reaction Rate in EC7T Experimental Channel of the YALINA-Booster with $(\mathrm{d}, \mathrm{t})$ Source. Polyethylene Holder is Modeled

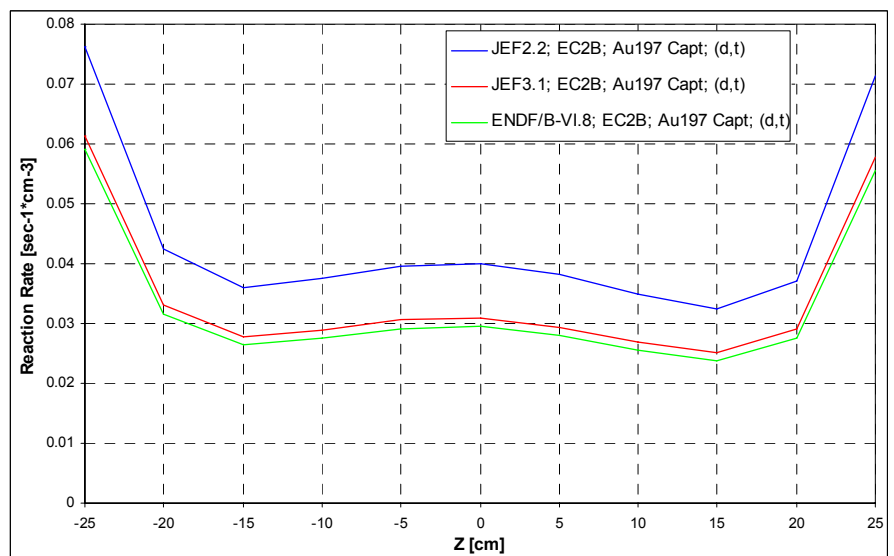

Figure 159. Au-197 Capture Reaction Rate in EC2B Experimental Channel of the YALINA-Booster with $(\mathrm{d}, \mathrm{t})$ Source. Lead Holder is Modeled

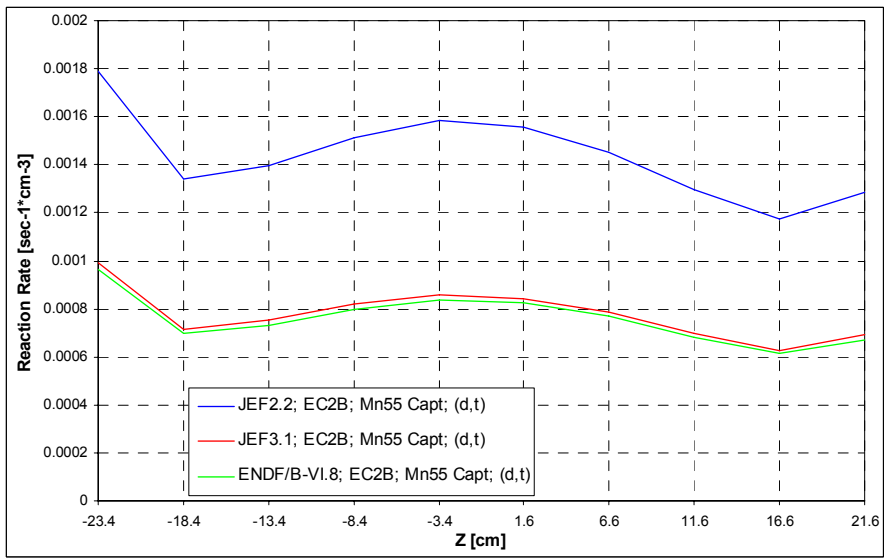

Figure 161. Mn-55 Capture Reaction Rate in EC2B Experimental Channel of the YALINA-Booster with $(d, t)$ Source. Lead Holder is Modeled

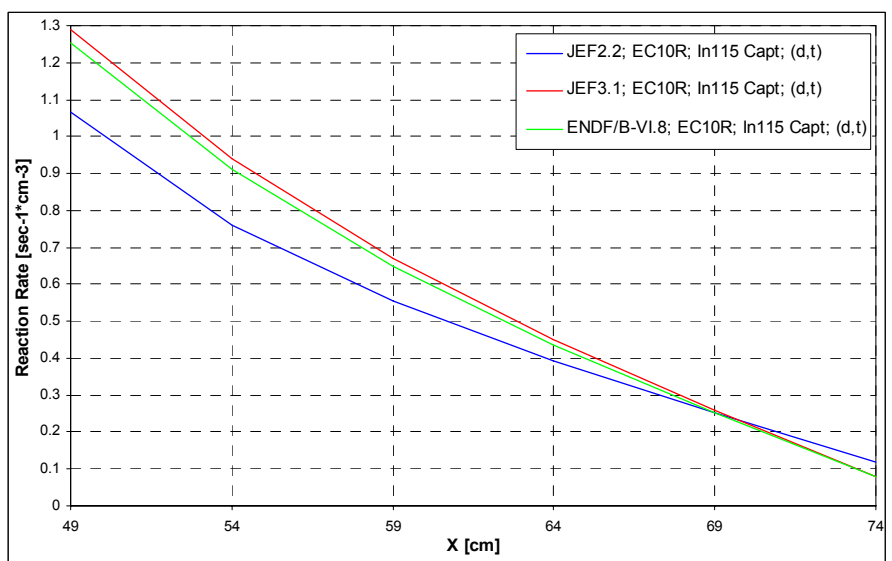

Figure 158. In-115 Capture Reaction Rate in EC10R Experimental Channel of the YALINA-Booster with $(\mathrm{d}, \mathrm{t})$ Source. Polyethylene Holder is Modeled

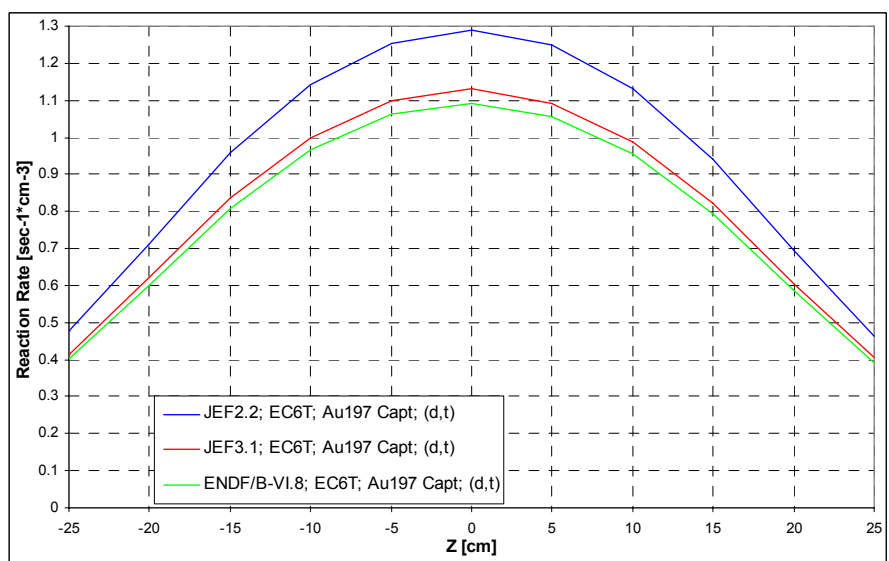

Figure 160. Au-197 Capture Reaction Rate in EC6T Experimental Channel of the YALINA-Booster with $(\mathrm{d}, \mathrm{t})$ Source. Polyethylene Holder is Modeled

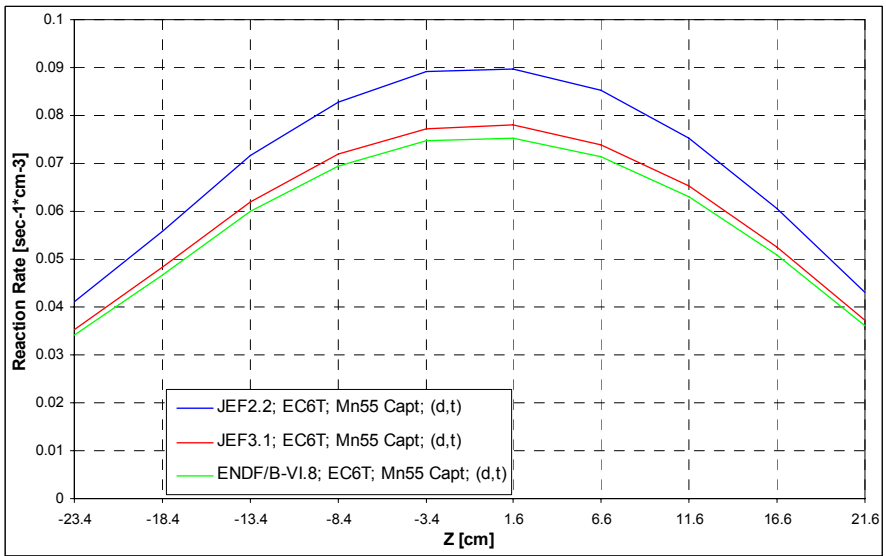

Figure 162. Mn-55 Capture Reaction Rate in EC6T Experimental Channel of the YALINA-Booster with $(\mathrm{d}, \mathrm{t})$ Source. Polyethylene Holder is Modeled 


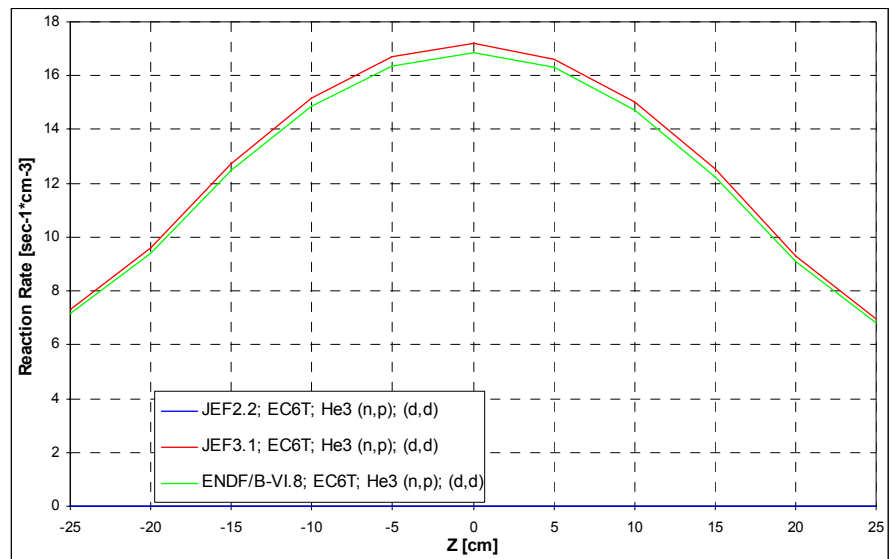

Figure 163. He-3(n,p) Capture Reaction Rate in EC6T Experimental Channel of the YALINA-Booster with $(d, d)$ Source

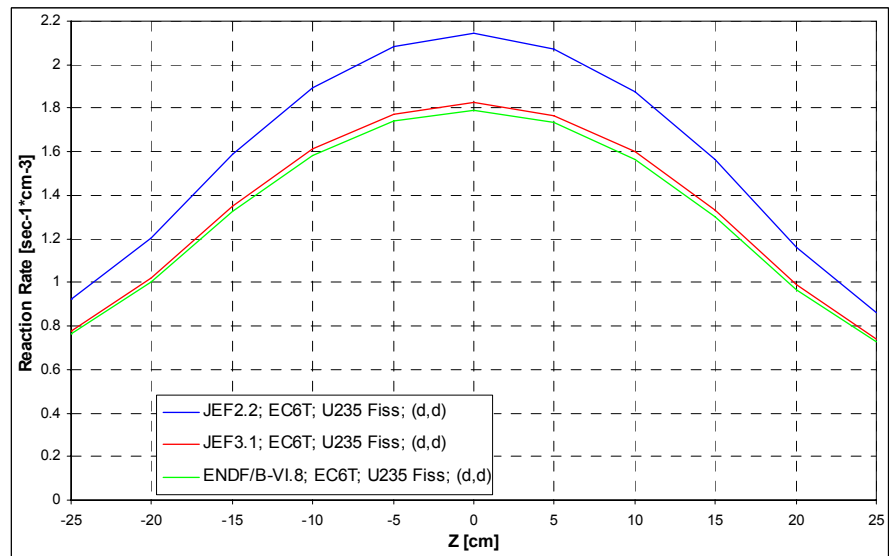

Figure 165. U-235 Fission Capture Reaction Rate in EC6T Experimental Channel of the YALINA-Booster with $(d, d)$ Source

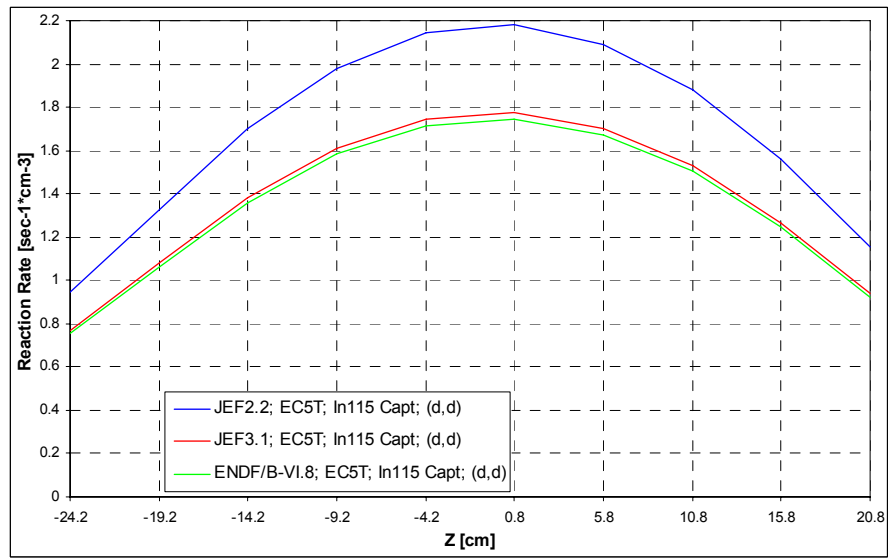

Figure 167. In-115 Capture Reaction Rate in EC5T Experimental Channel of the YALINA-Booster with $(d, d)$ Source. Polyethylene Holder is Modeled

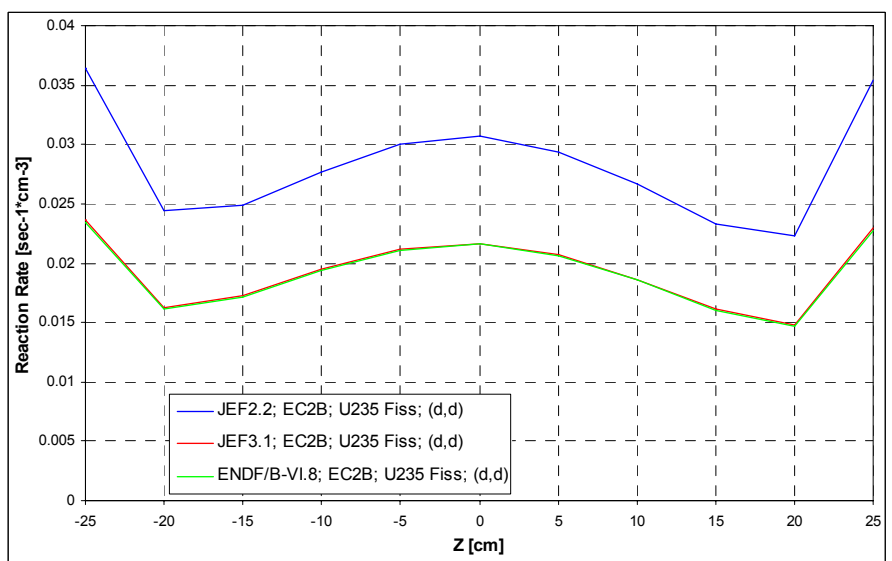

Figure 164. U-235 Fission Capture Reaction Rate in EC2B Experimental Channel of the YALINA-Booster with $(d, d)$ Source

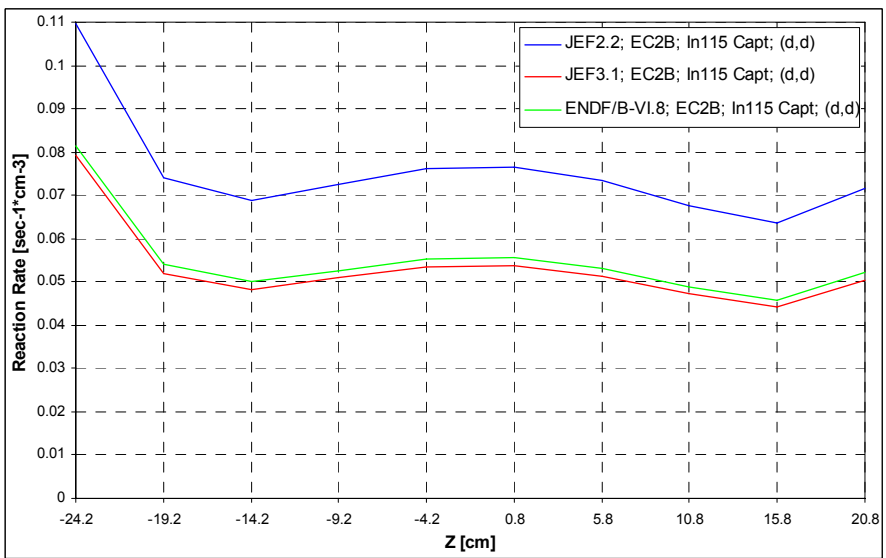

Figure 166. In-115 Capture Reaction Rate in EC2B Experimental Channel of the YALINA-Booster with $(\mathrm{d}, \mathrm{d})$ Source. Lead Holder is Modeled

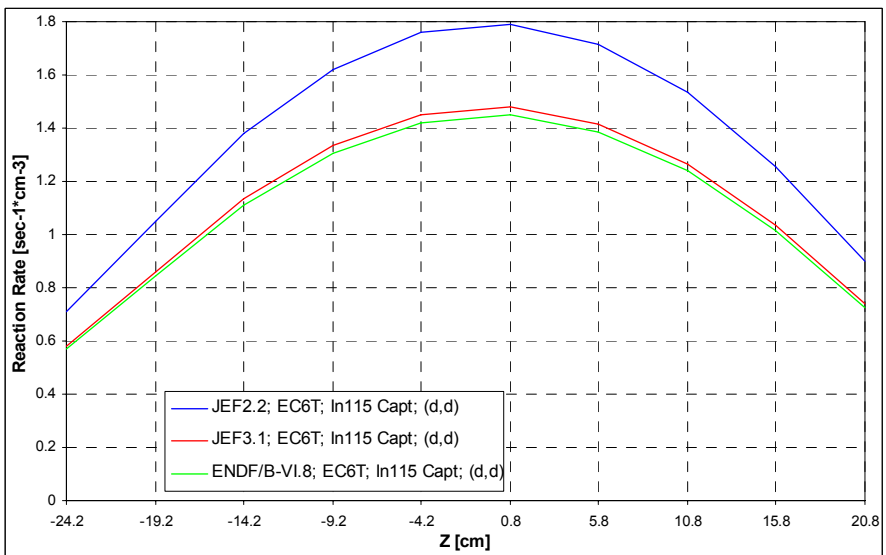

Figure 168. In-115 Capture Reaction Rate in EC6T Experimental Channel of the YALINA-Booster with $(d, d)$ Source. Polyethylene Holder is Modeled 
ANL-09-23

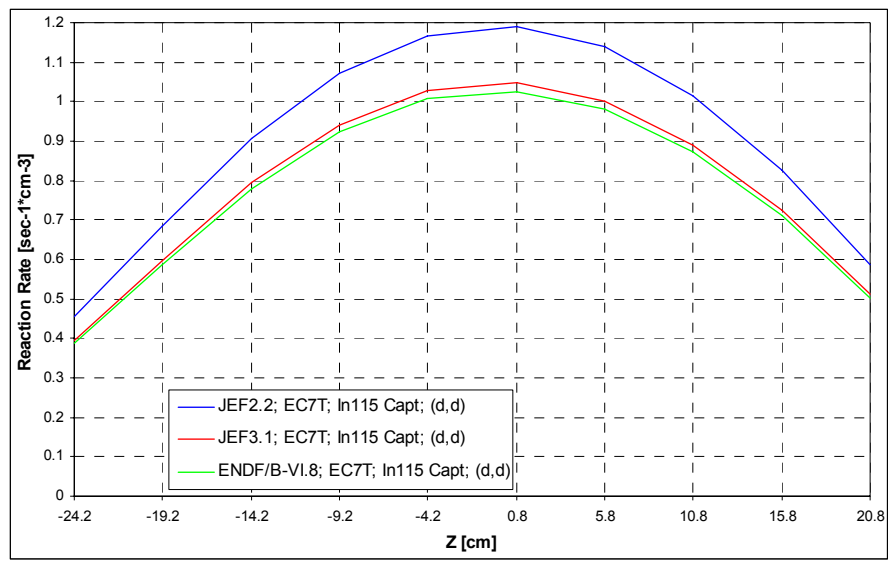

Figure 169. In-115 Capture Reaction Rate in EC7T Experimental Channel of the YALINA-Booster with $(d, d)$ Source. Polyethylene Holder is Modeled

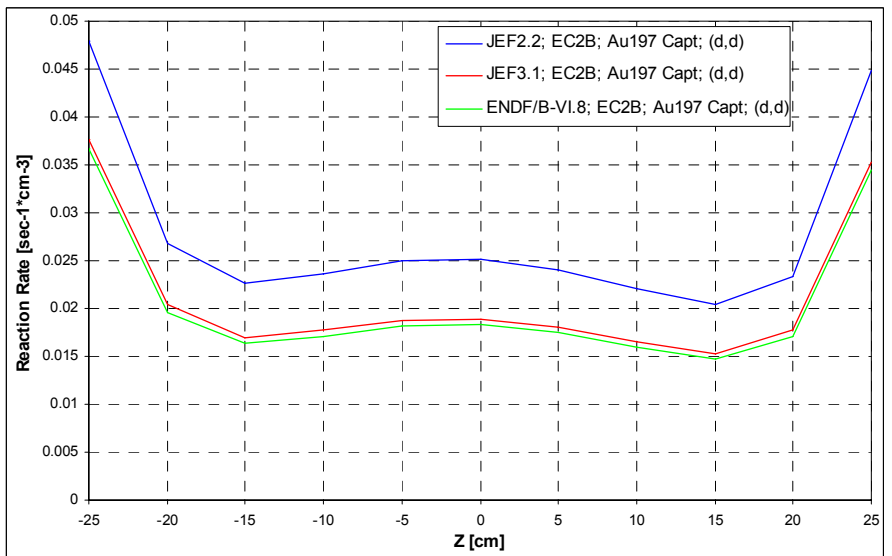

Figure 171. Au-197 Capture Reaction Rate in EC2B Experimental Channel of the YALINA-Booster with $(d, d)$ Source. Lead Holder is Modeled

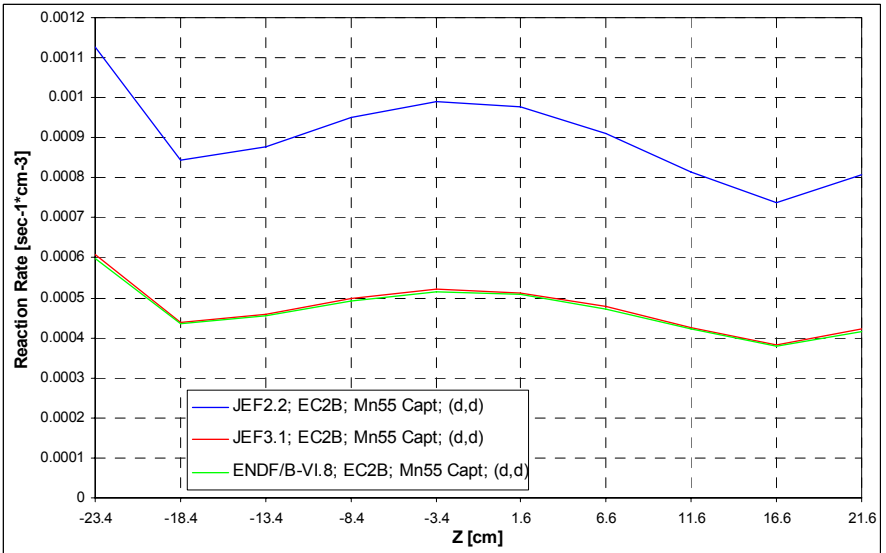

Figure 173. Mn-55 Capture Reaction Rate in EC2B Experimental Channel of the YALINA-Booster with $(\mathrm{d}, \mathrm{d})$ Source. Lead Holder is Modeled

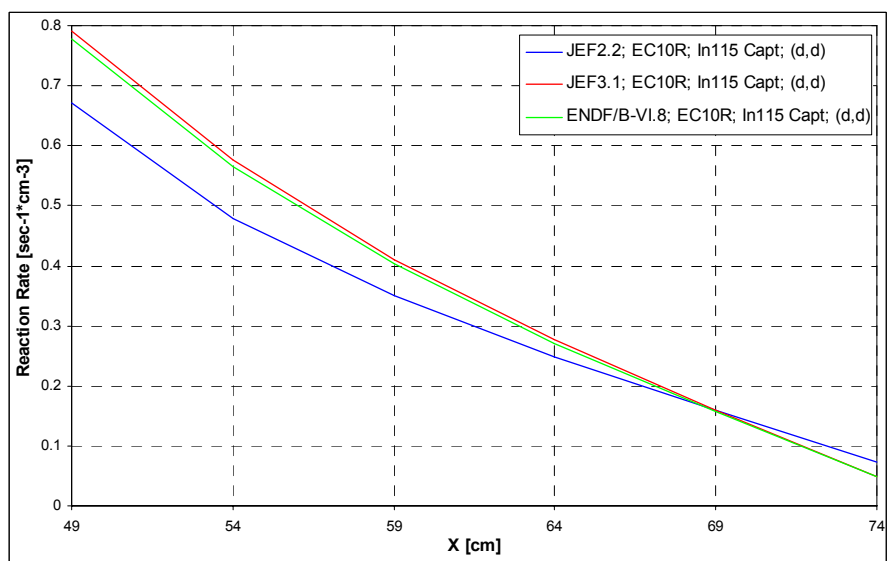

Figure 170. In-115 Capture Reaction Rate in EC10R Experimental Channel of the YALINA-Booster with $(d, d)$ Source. Polyethylene Holder is Modeled

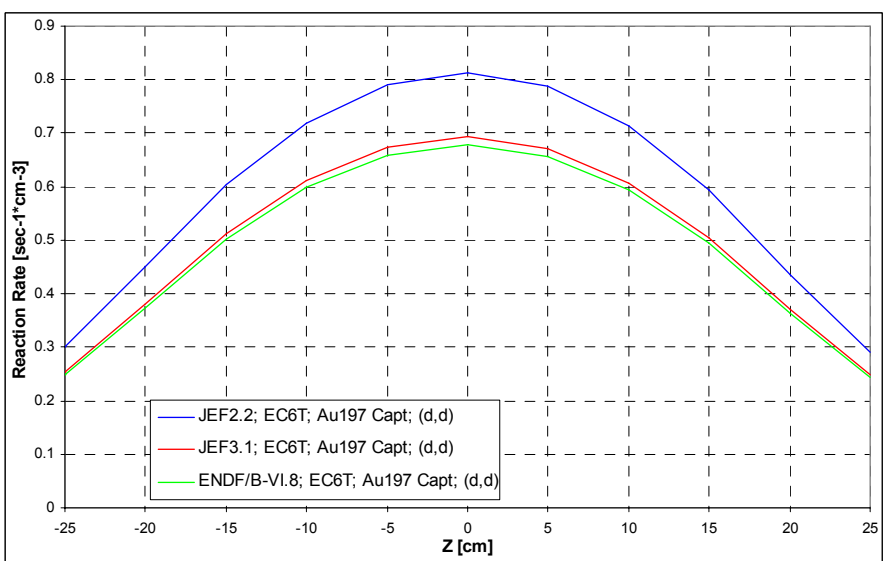

Figure 172. Au-197 Capture Reaction Rate in EC6T Experimental Channel of the YALINA-Booster with $(d, d)$ Source. Polyethylene Holder is Modeled

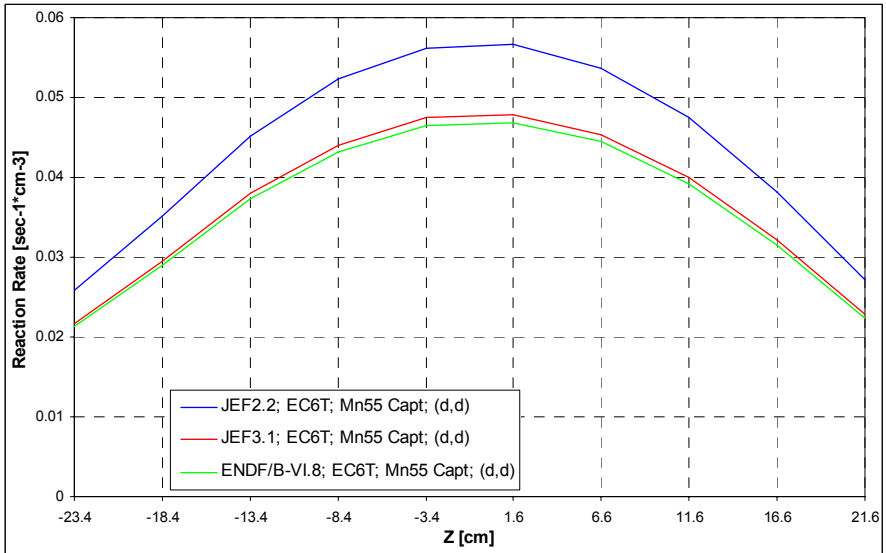

Figure 174. Mn-55 Capture Reaction Rate in EC6T Experimental Channel of the YALINA-Booster with $(d, d)$ Source. Polyethylene Holder is Modeled 


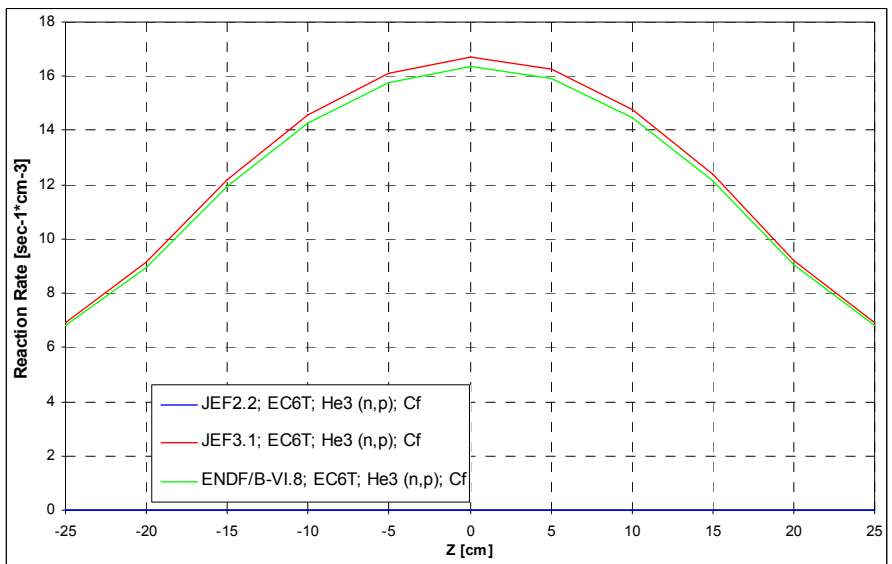

Figure 175. He-3(n,p) Reaction Rate in EC6T Experimental Channel of the YALINA-Booster with Cf Neutron Source

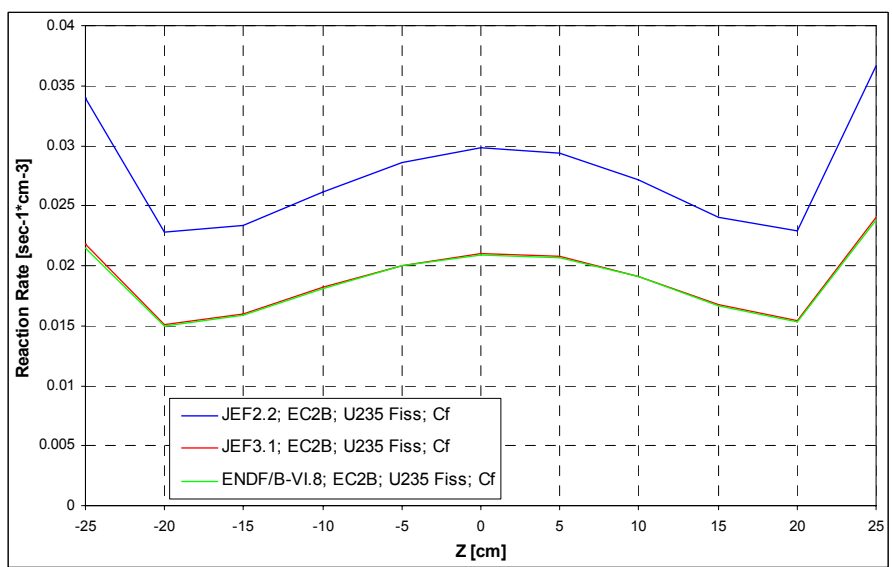

Figure 176. U-235 Fission Reaction Rate in EC2B Experimental Channel of the YALINA-Booster with Cf Neutron Source

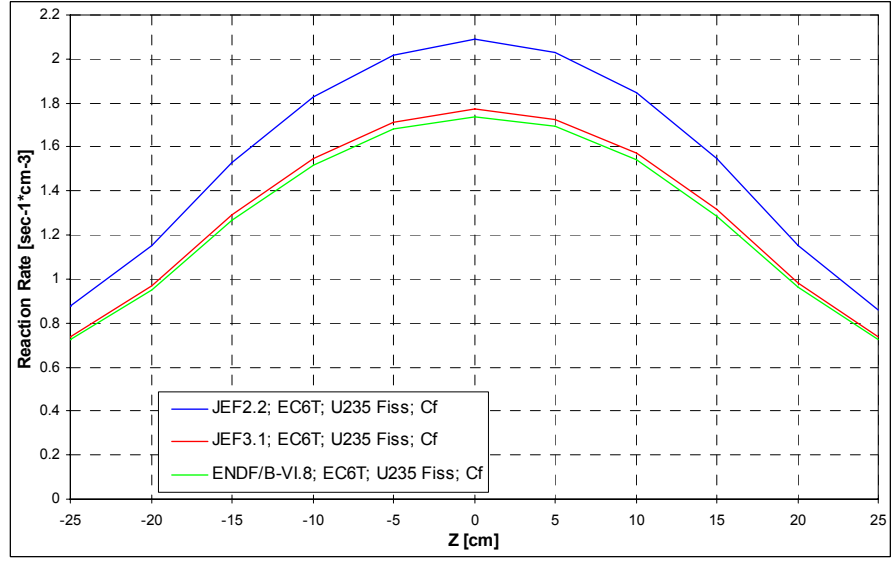

Figure 177. U-235 Fission Reaction Rate in EC6T Experimental Channel of the YALINA-Booster with Cf Neutron Source

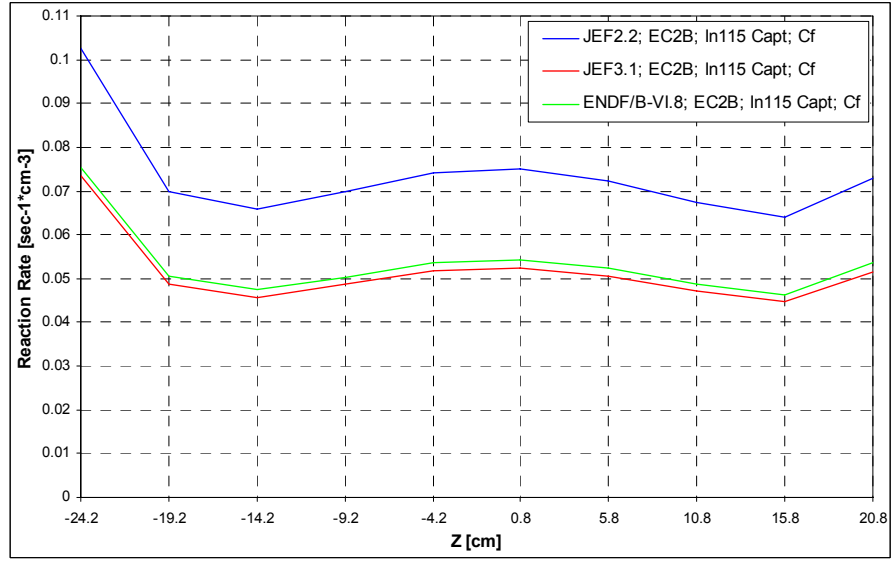

Figure 178. In-115 Capture Reaction Rate in EC2B Experimental Channel of the YALINA-Booster with Cf Neutron Source. Lead Holder is Modeled

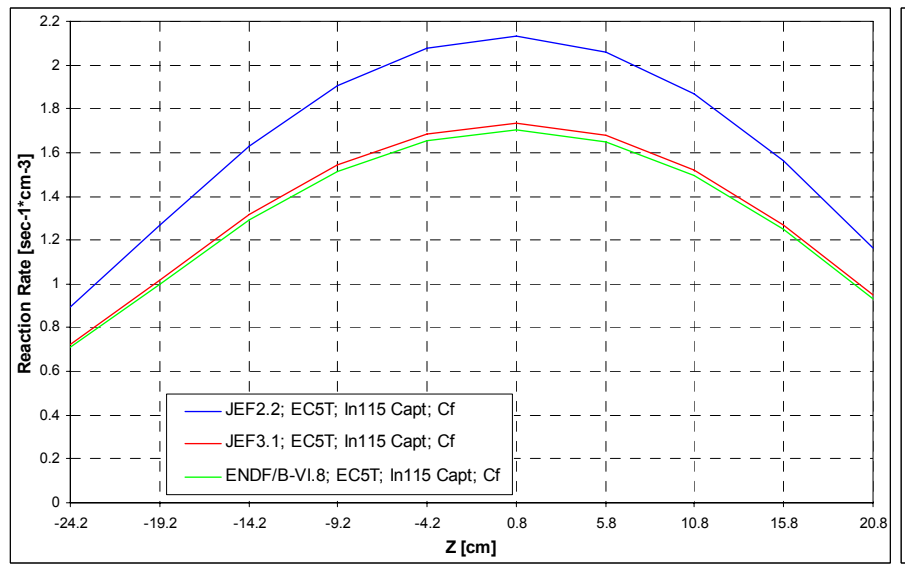

Figure 179. In-115 Capture Reaction Rate in EC5T Experimental Channel of the YALINA-Booster with Cf Neutron Source. Polyethylene Holder is Modeled

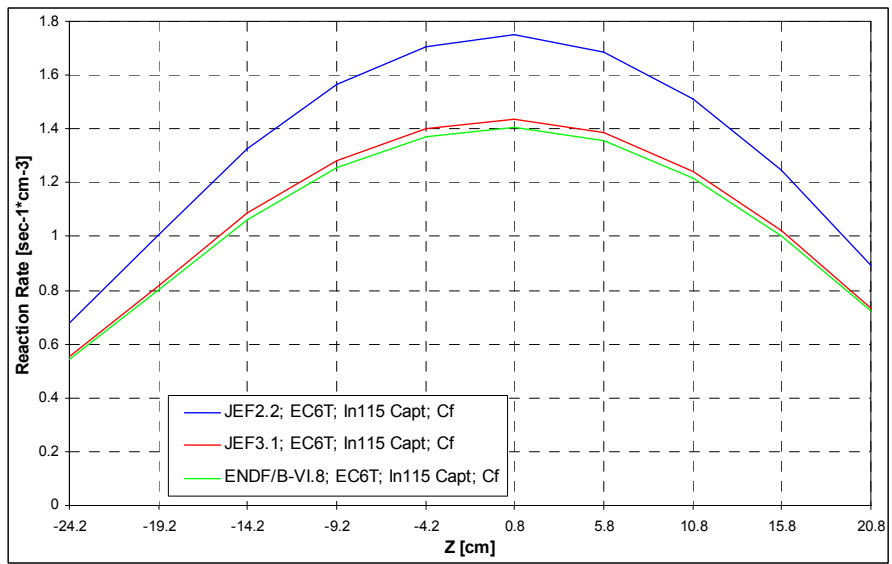

Figure 180. In-115 Capture Reaction Rate in EC6T Experimental Channel of the YALINA-Booster with Cf Neutron Source. Polyethylene Holder is Modeled 
ANL-09-23

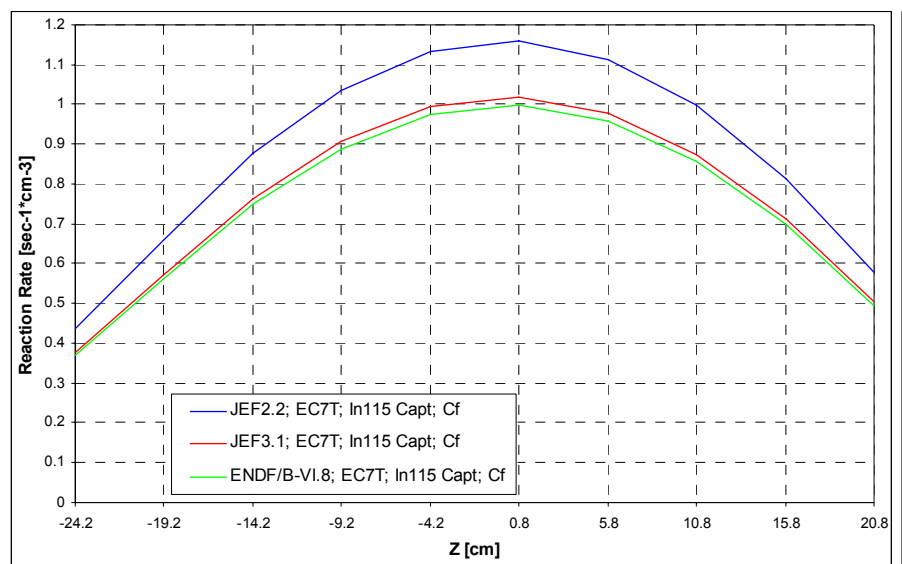

Figure 181. In-115 Capture Reaction Rate in EC7T Experimental Channel of the YALINA-Booster with Cf Neutron Source. Polyethylene Holder is Modeled

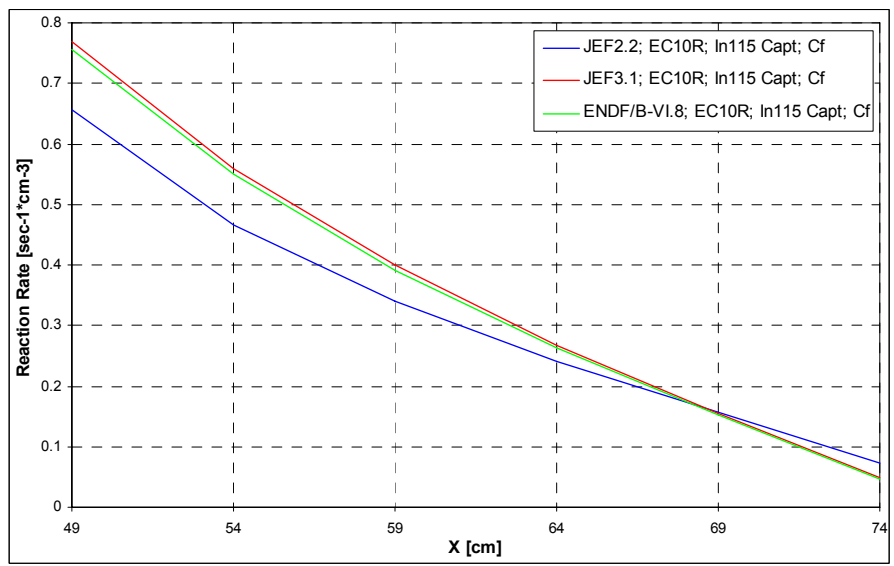

Figure 182. In-115 Capture Reaction Rate in EC10R Experimental Channel of the YALINA-Booster with Cf Neutron Source. Polyethylene Holder is Modeled

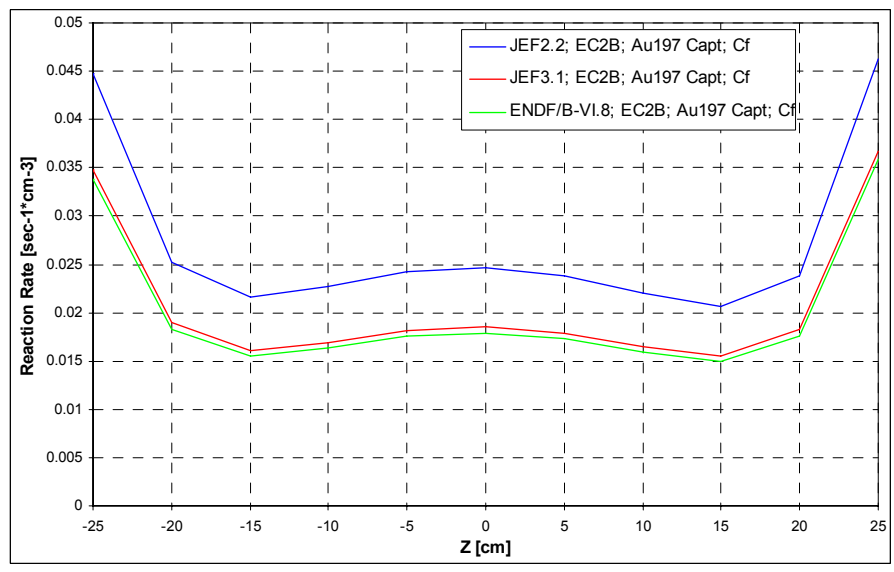

Figure 183. Au-197 Capture Reaction Rate in EC2B Experimental Channel of the YALINA-Booster with Cf Neutron Source. Lead Holder is Modeled

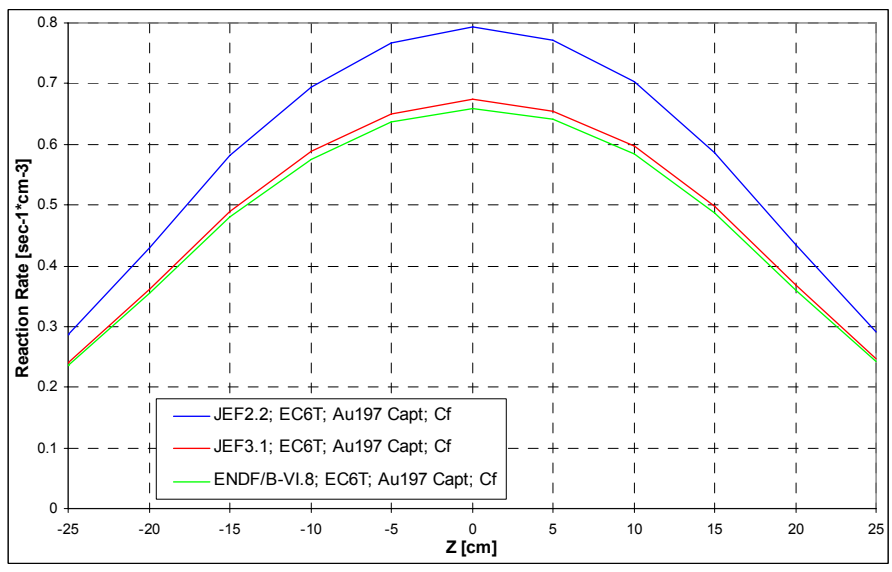

Figure 184. Au-197 Capture Reaction Rate in EC6T Experimental Channel of the YALINA-Booster with Cf Neutron Source. Polyethylene Holder is Modeled

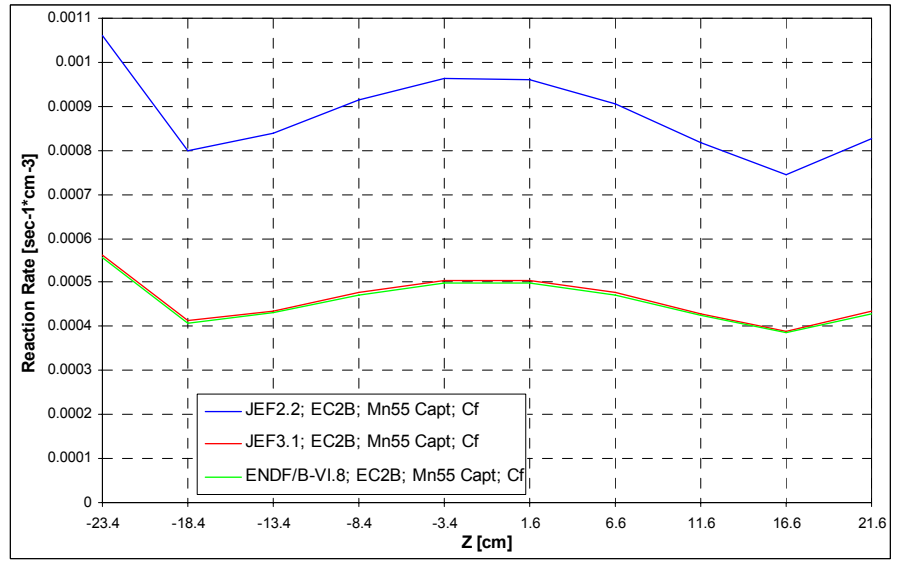

Figure 185. Mn-55 Capture Reaction Rate in EC2B Experimental Channel of the YALINA-Booster with Cf Neutron Source. Lead Holder is Modeled

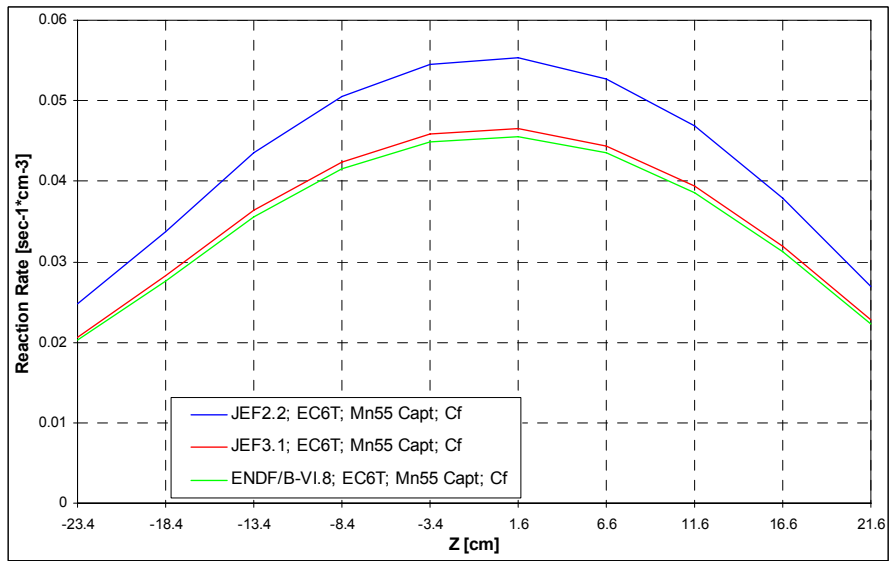

Figure 186. Mn-55 Capture Reaction Rate in EC6T Experimental Channel of the YALINA-Booster with Cf Neutron Source. Polyethylene Holder is Modeled 


\section{G.2. YALINA-Thermal}
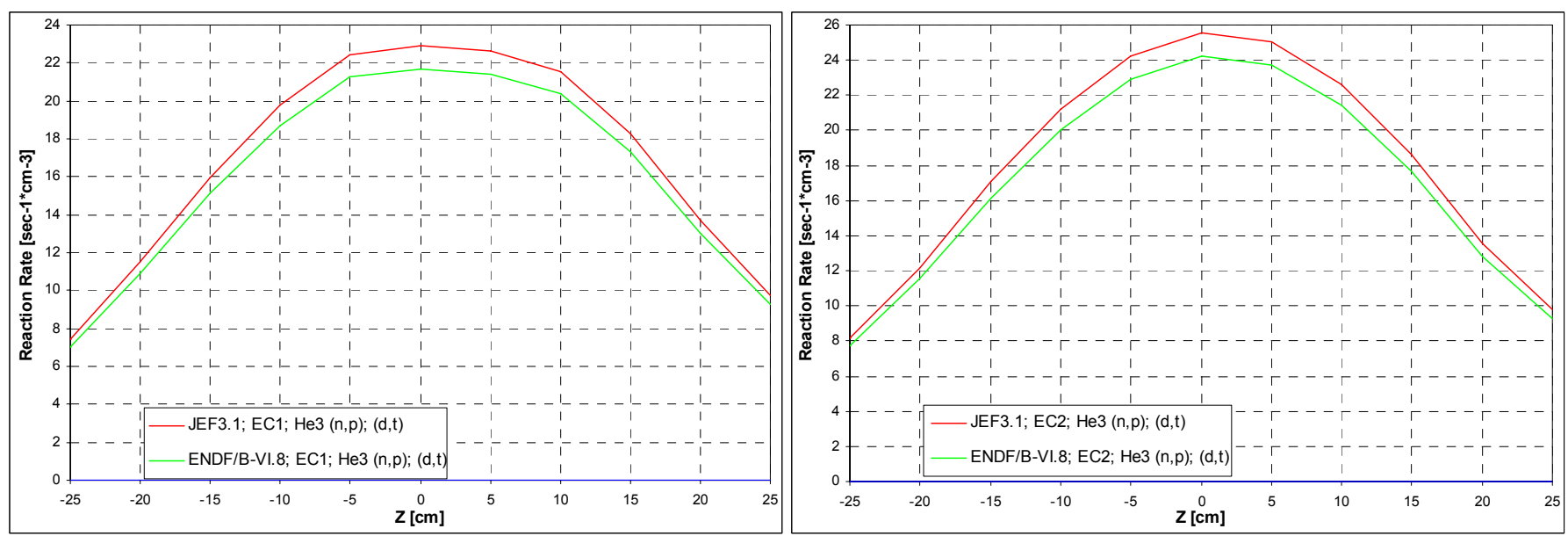

Figure 187. He-3(n,p) Reaction Rate in EC1 ExperimentalFigure 188. He-3(n,p) Reaction Rate in EC2 Experimental Channel of the YALINA-Thermal with $(d, t)$ Neutron Source

Channel of the YALINA-Thermal with $(\mathrm{d}, \mathrm{t})$ Neutron Source

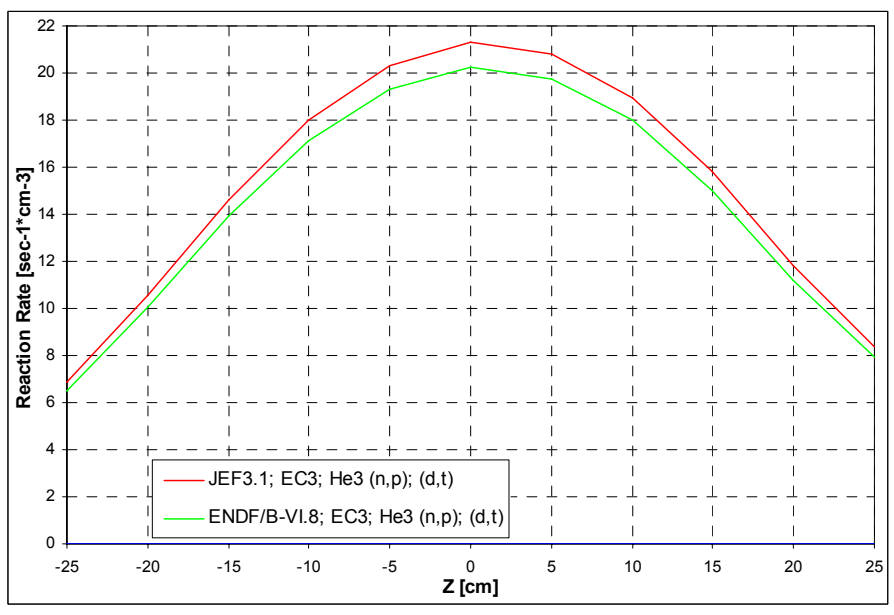

Figure 189. He-3(n,p) Reaction Rate in EC3 Experimental Channel of the YALINA-Thermal with $(d, t)$ Neutron Source

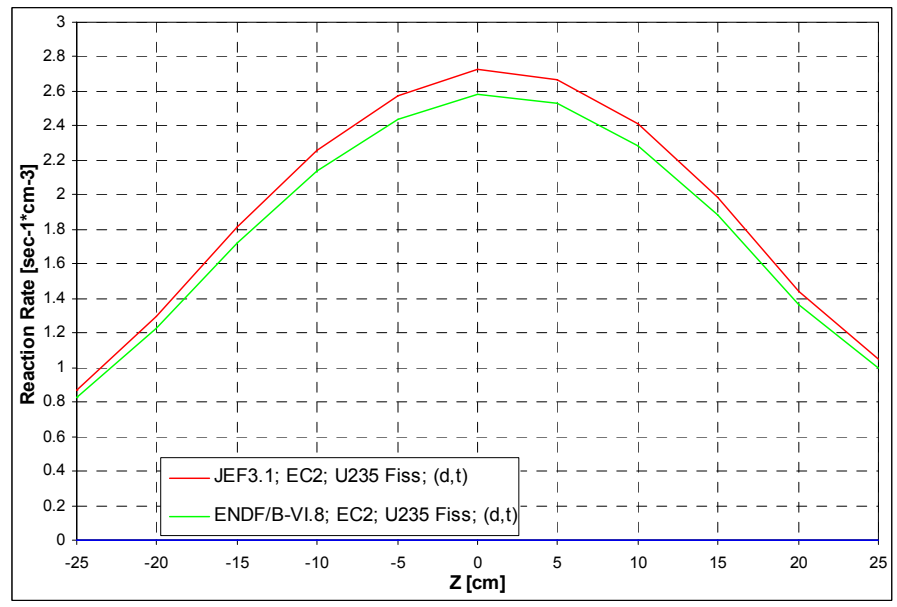

Figure 191. U-235 Fission Reaction Rate in EC2 Experimental Channel of the YALINA-Thermal with $(\mathrm{d}, \mathrm{t})$ Neutron Source

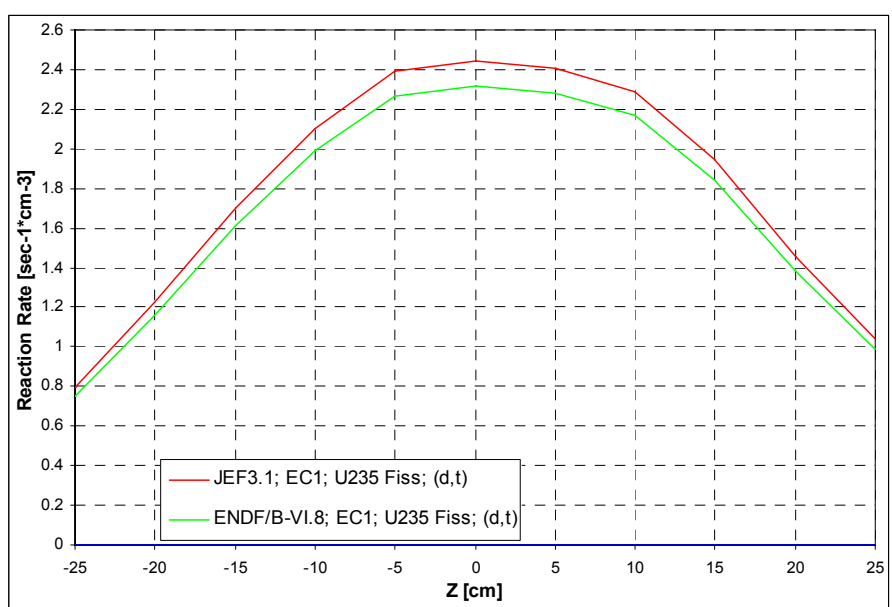

Figure 190. U-235 Fission Reaction Rate in EC1 Experimental Channel of the YALINA-Thermal with $(d, t)$ Neutron Source

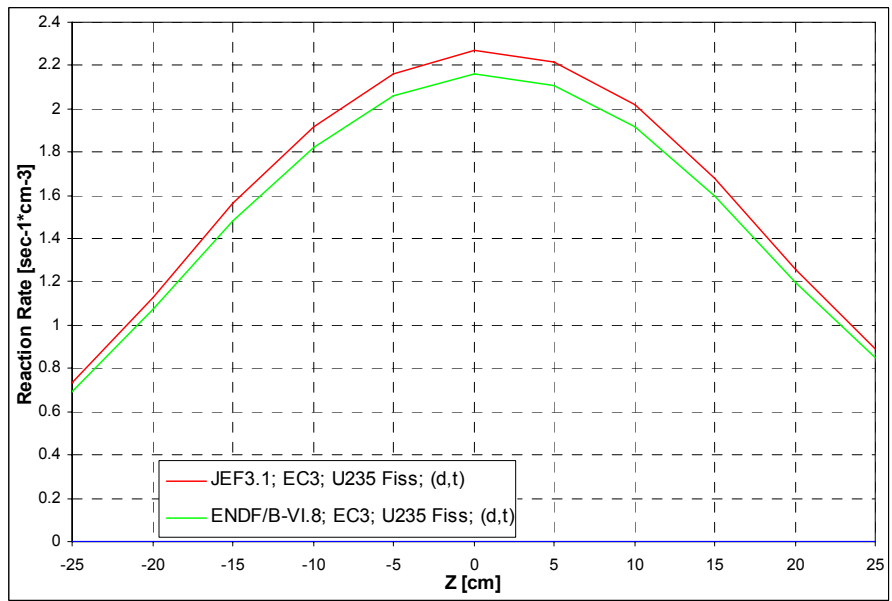

Figure 192. U-235 Fission Reaction Rate in EC3 Experimental Channel of the YALINA-Thermal with $(d, t)$ Neutron Source 


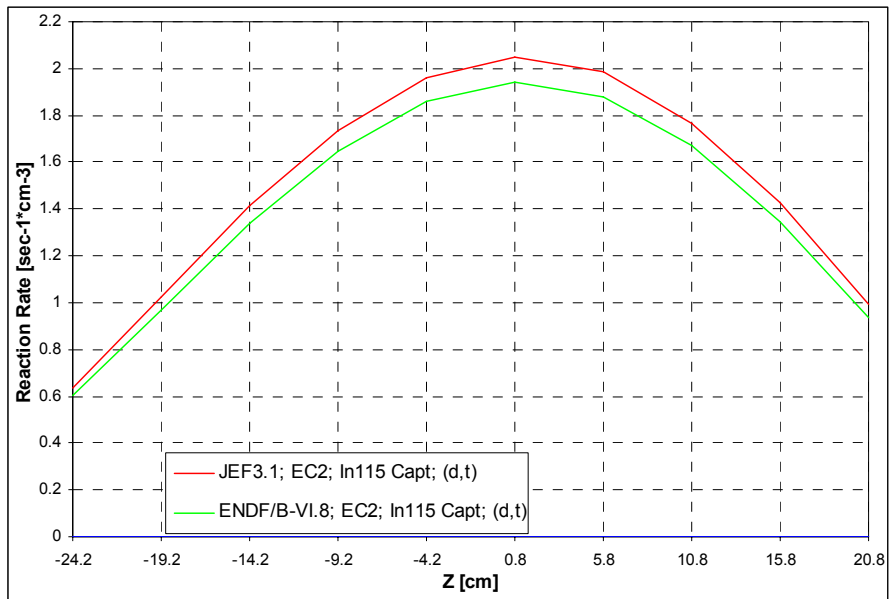

Figure 193. In-115 Capture Reaction Rate in EC2

Experimental Channel of the YALINA-Thermal with $(\mathrm{d}, \mathrm{t})$ Neutron Source. Polyethylene Holder is Modeled

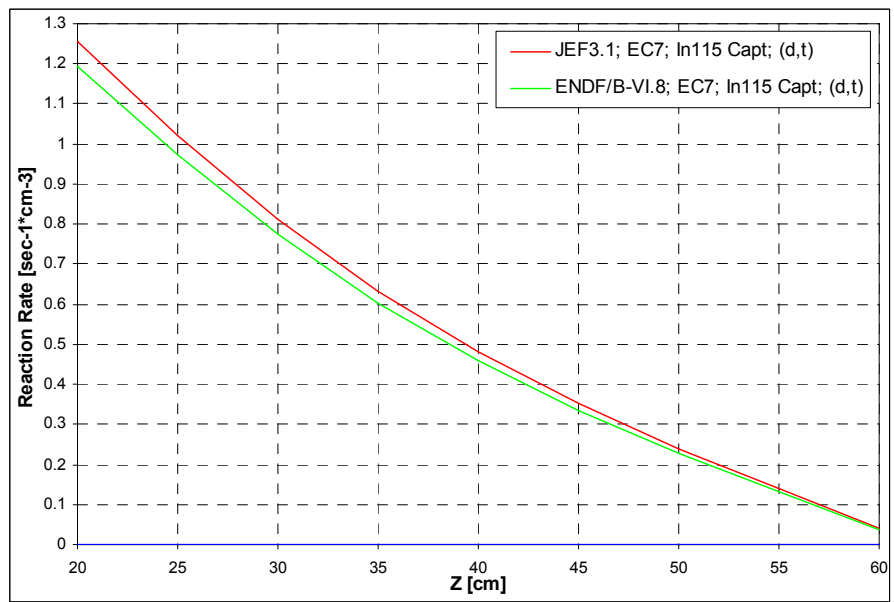

Figure 194. In-115 Capture Reaction Rate in EC7 Experimental Channel of the YALINA-Thermal with $(d, t)$ Neutron Source. Polyethylene Holder is Modeled

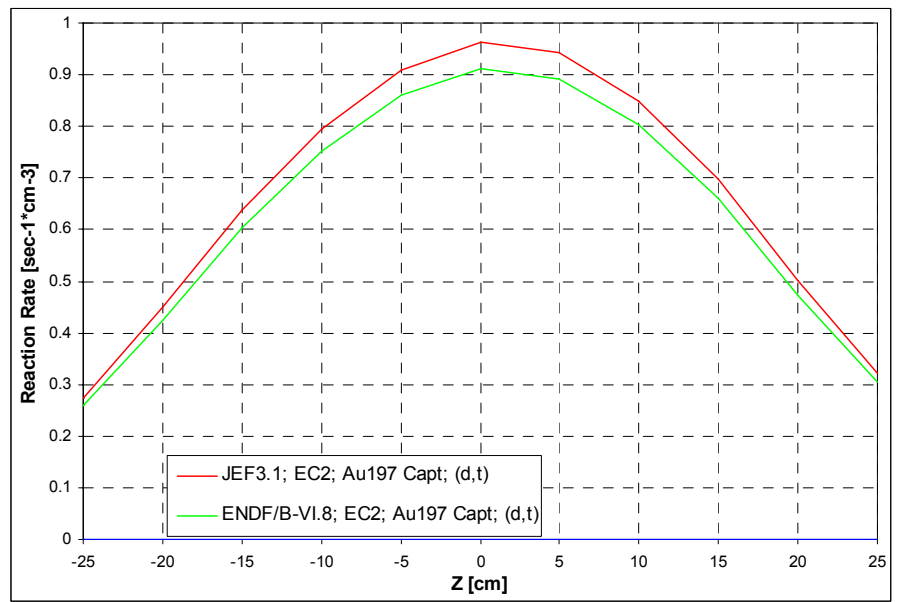

Figure 195. Au-197 Capture Reaction Rate in EC2 Experimental Channel of the YALINA-Thermal with $(\mathrm{d}, \mathrm{t})$ Neutron Source. Polyethylene Holder is Modeled

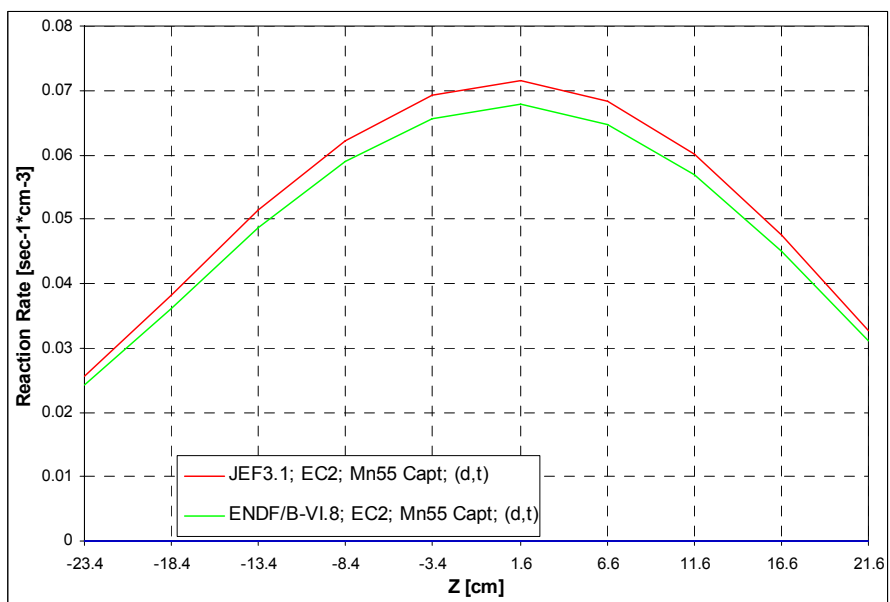

Figure 196. Mn-55 Capture Reaction Rate in EC2 Experimental Channel of the YALINA-Thermal with $(d, t)$ Neutron Source. Polyethylene Holder is Modeled
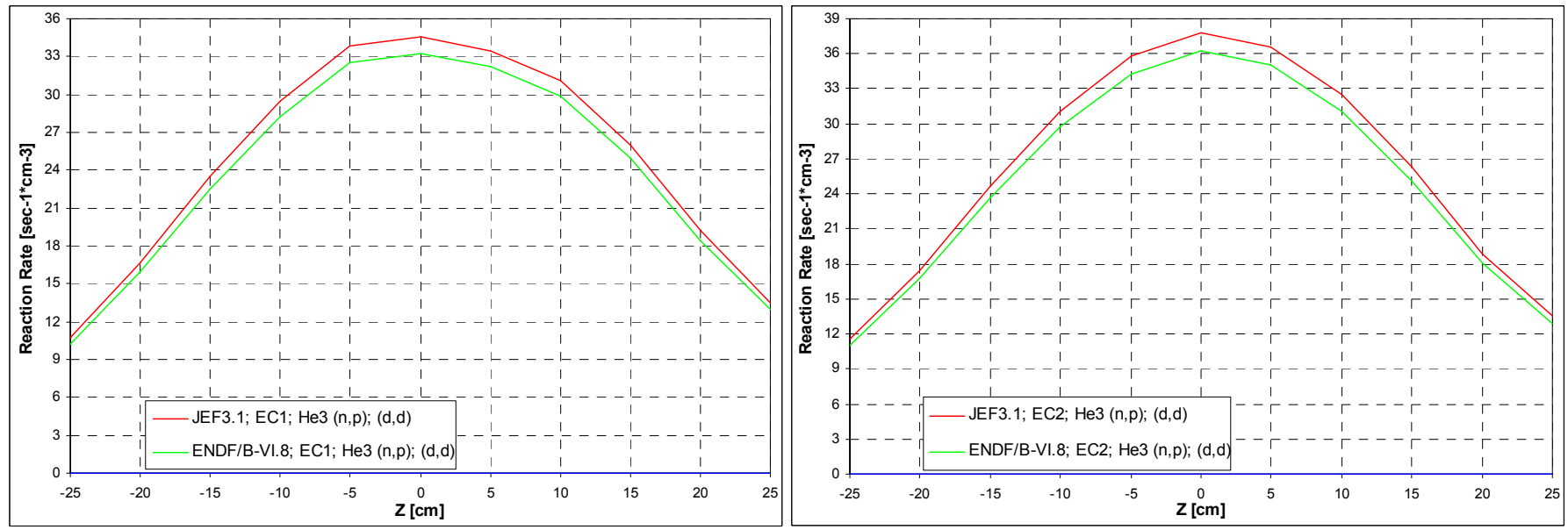

Figure 197. He-3(n,p) Reaction Rate in EC1 ExperimentalFigure 198. He-3(n,p) Reaction Rate in EC2 Experimental Channel of the YALINA-Thermal with $(d, d)$ Neutron Source

Channel of the YALINA-Thermal with (d,d) Neutron Source 
ANL-09-23

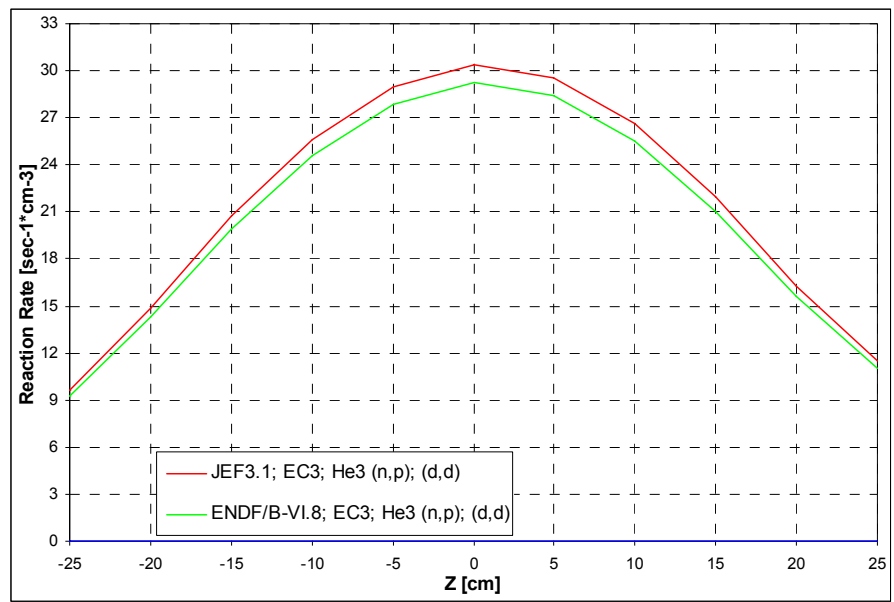

Figure 199. He-3(n,p) Reaction Rate in EC3 Experimental Channel of the YALINA-Thermal with $(d, d)$ Neutron Source

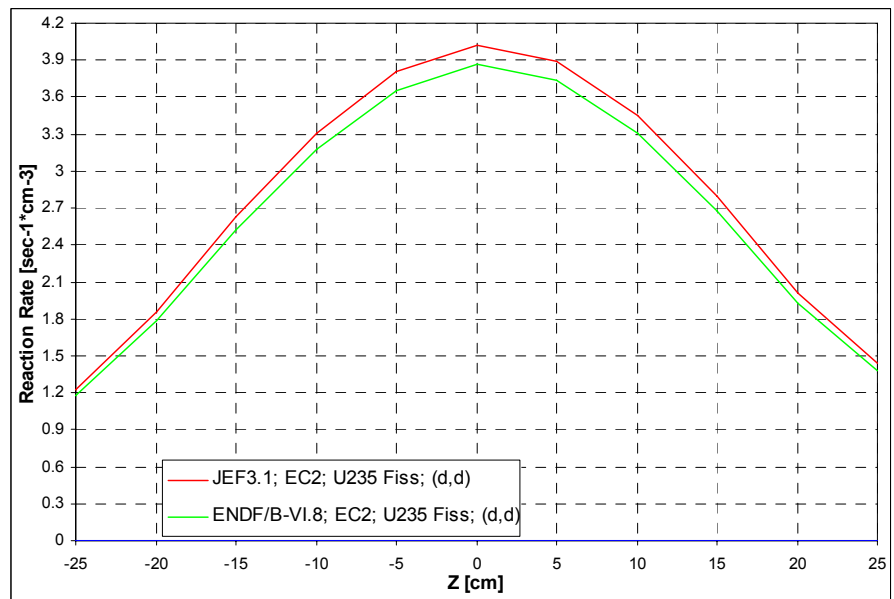

Figure 201. U-235 Fission Reaction Rate in EC2 Experimental Channel of the YALINA-Thermal with $(d, d)$ Neutron Source

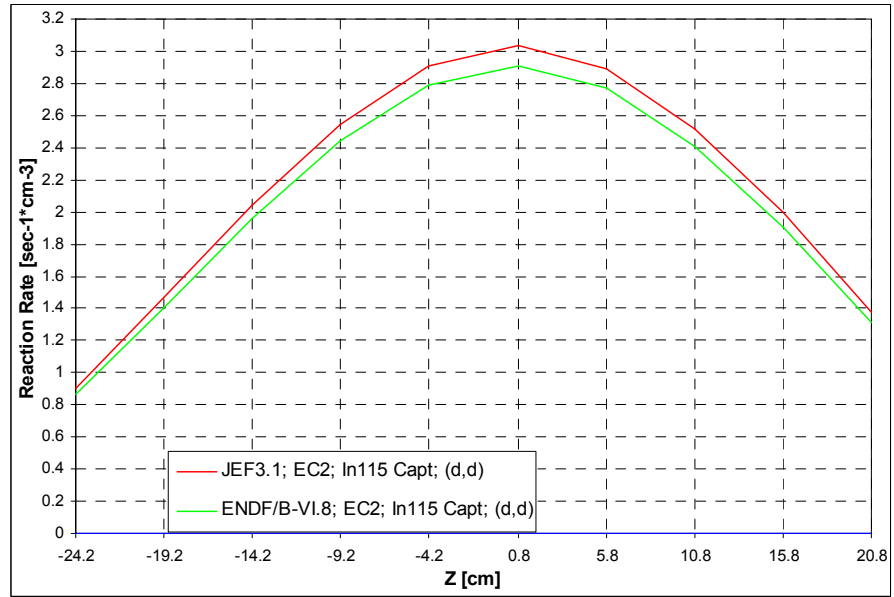

Figure 203. In-115 Capture Reaction Rate in EC2 Experimental Channel of the YALINA-Thermal with $(d, d)$ Neutron Source. Polyethylene Holder is modeled

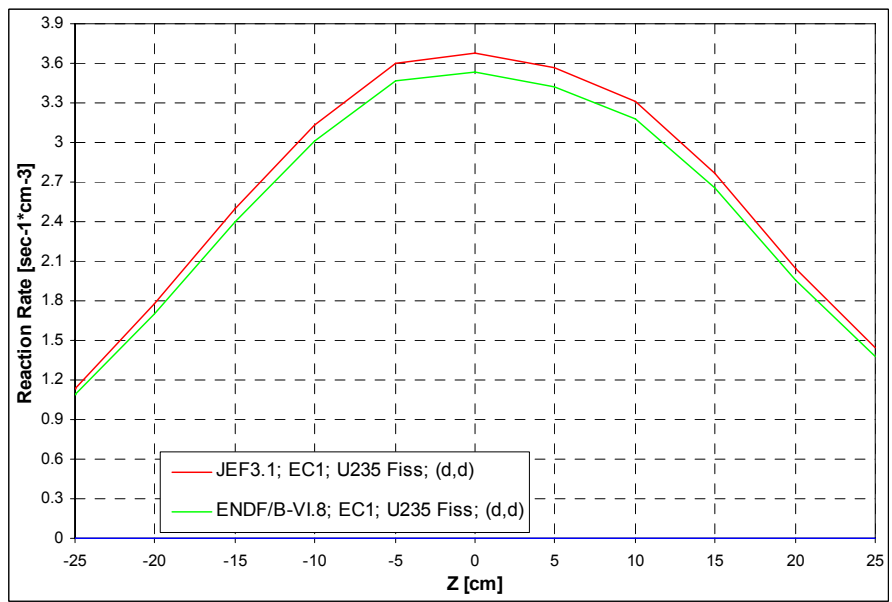

Figure 200. U-235 Fission Reaction Rate in EC1 Experimental Channel of the YALINA-Thermal with $(d, d)$ Neutron Source

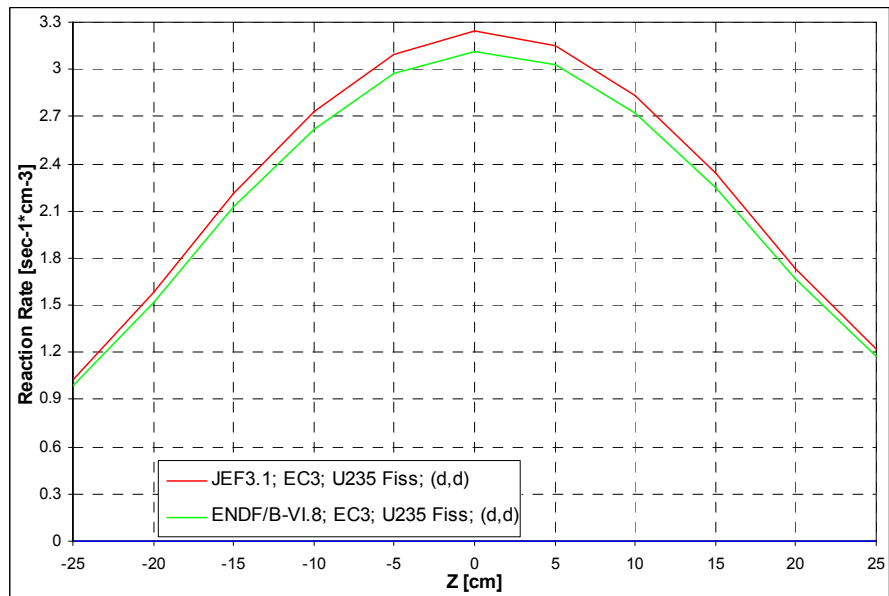

Figure 202. U-235 Fission Reaction Rate in EC3 Experimental Channel of the YALINA-Thermal with $(d, d)$ Neutron Source

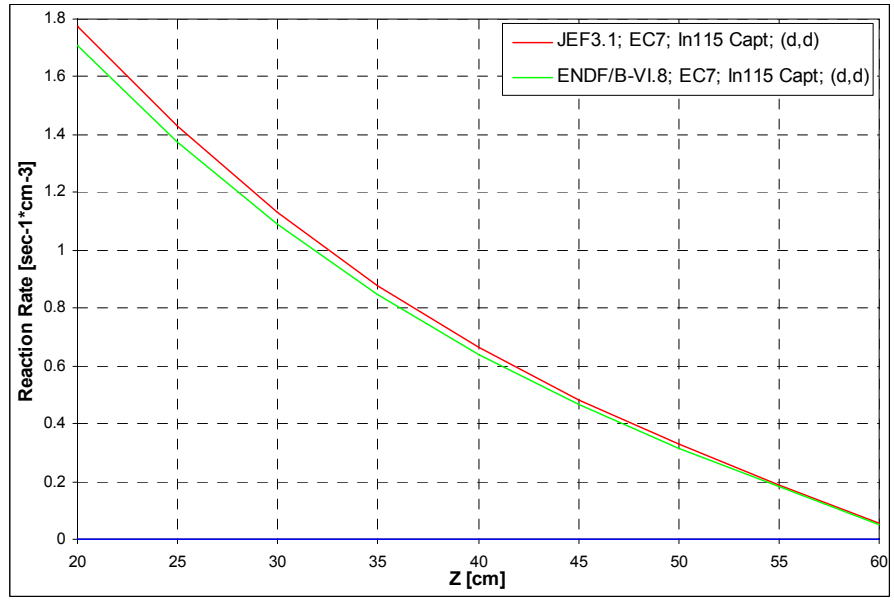

Figure 204. In-115 Capture Reaction Rate in EC7 Experimental Channel of the YALINA-Thermal with $(d, d)$ Neutron Source. Polyethylene Holder is modeled 


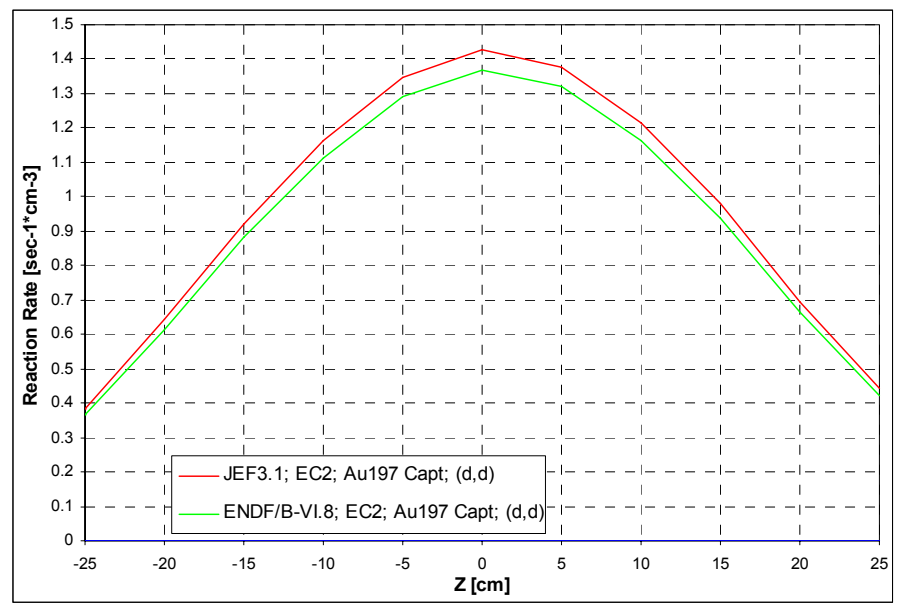

Figure 205. Au-197 Capture Reaction Rate in EC2 Experimental Channel of the YALINA-Thermal with $(d, d)$ Neutron Source. Polyethylene Holder is modeled

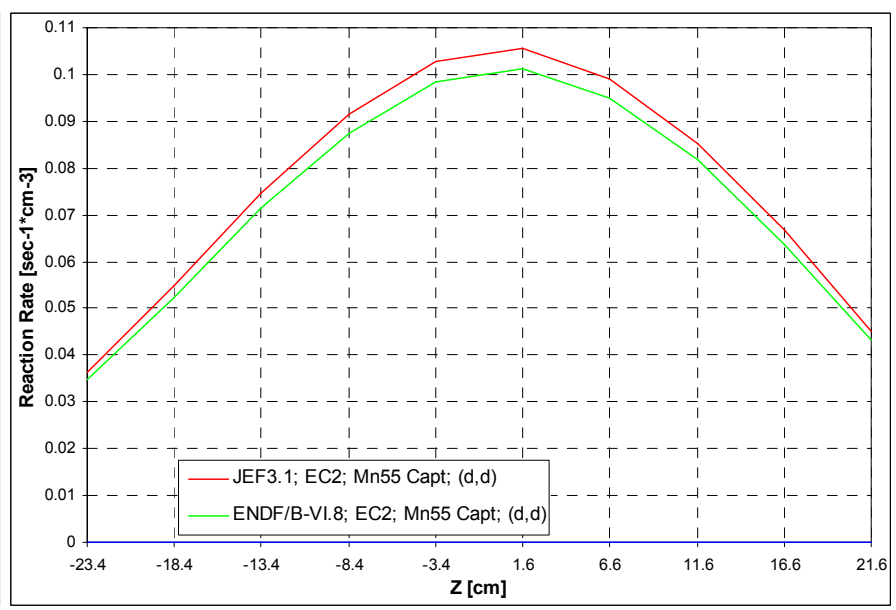

Figure 206. Mn-55 Capture Reaction Rate in EC2 Experimental Channel of the YALINA-Thermal with $(d, d)$ Neutron Source. Polyethylene Holder is modeled
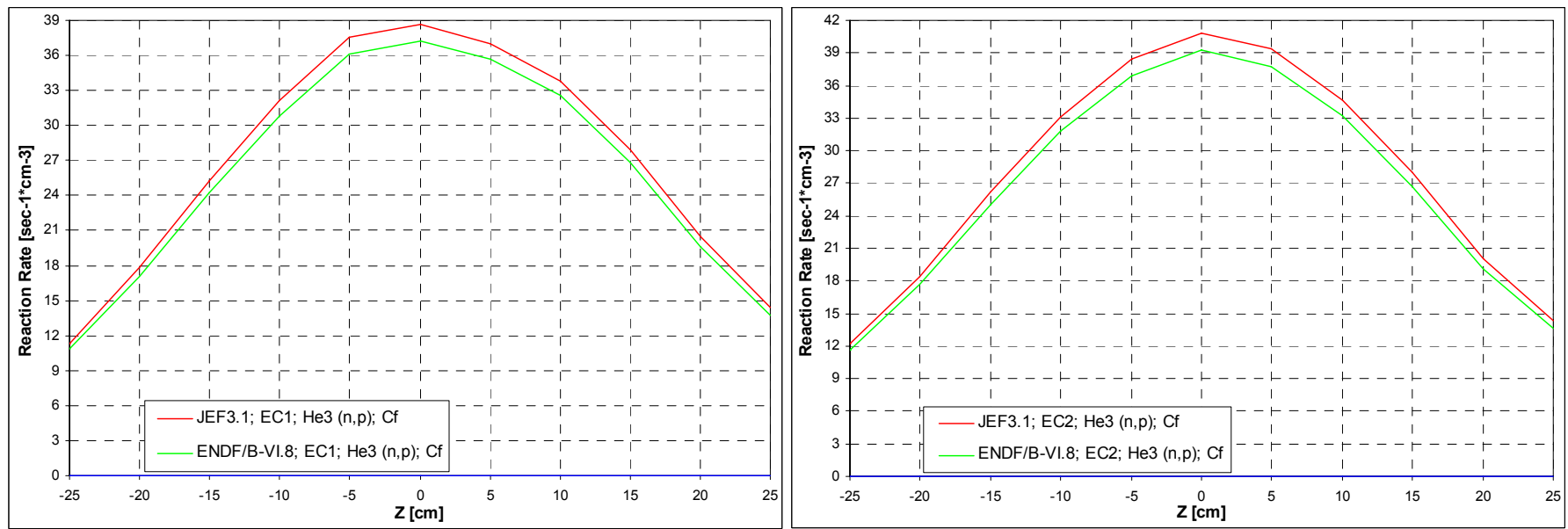

Figure 207. He-3(n,p) Reaction Rate in EC1 ExperimentalFigure 208. He-3(n,p) Reaction Rate in EC2 Experimental Channel of the YALINA-Thermal with Cf Neutron Source Channel of the YALINA-Thermal with Cf Neutron Source

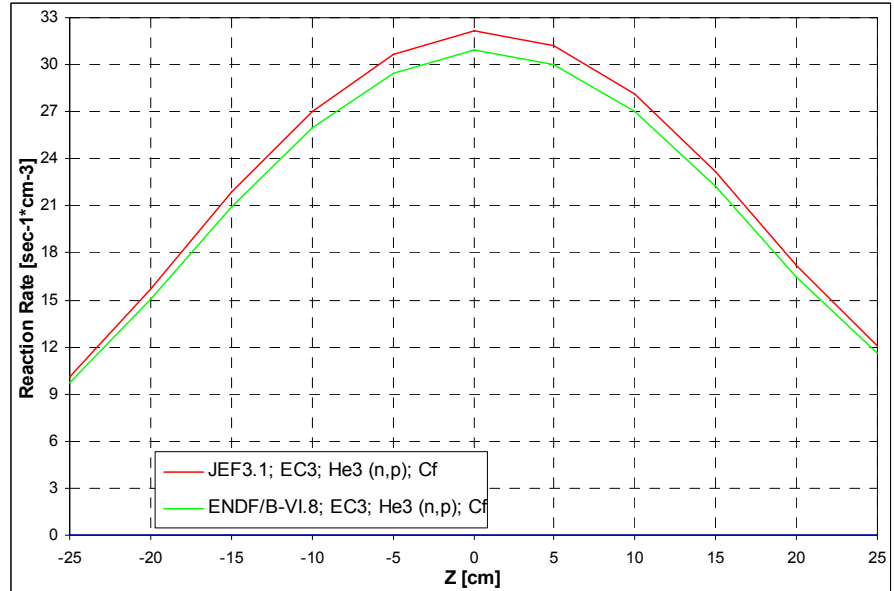

Figure 209. He-3(n,p) Reaction Rate in EC3 Experimental Channel of the YALINA-Thermal with Cf Neutron Source

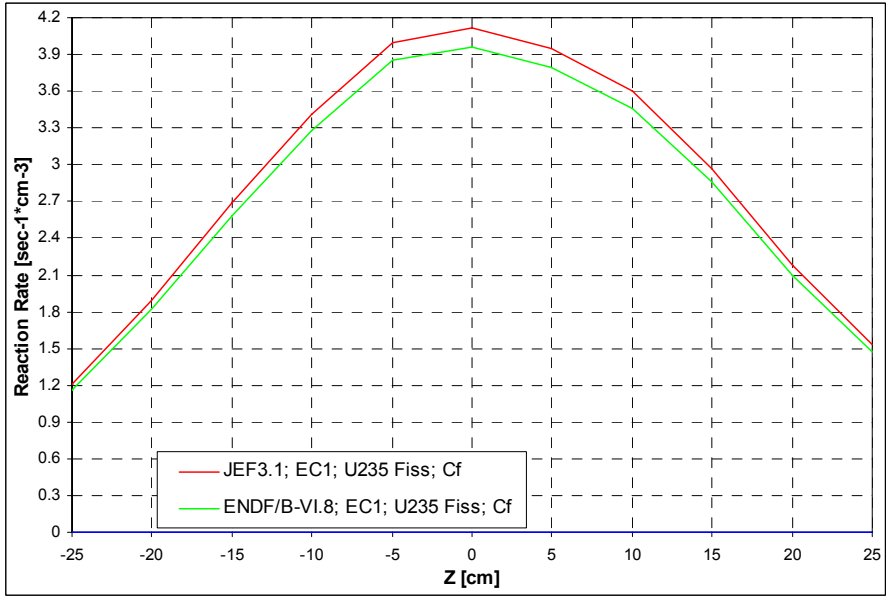

Figure 210. U-235 Fission Reaction Rate in EC1 Experimental Channel of the YALINA-Thermal with Cf Neutron Source 


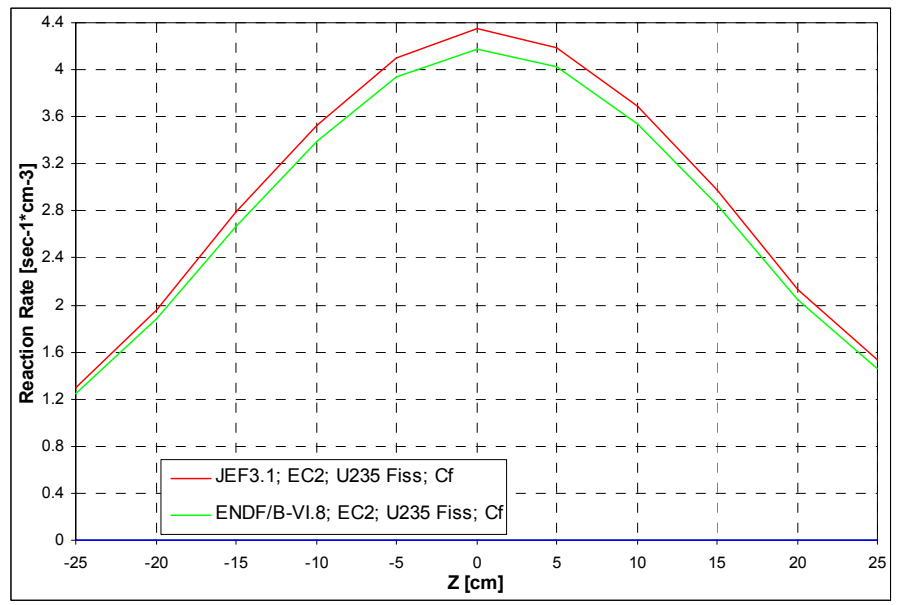

Figure 211. U-235 Fission Reaction Rate in EC2 Experimental Channel of the YALINA-Thermal with Cf Neutron Source

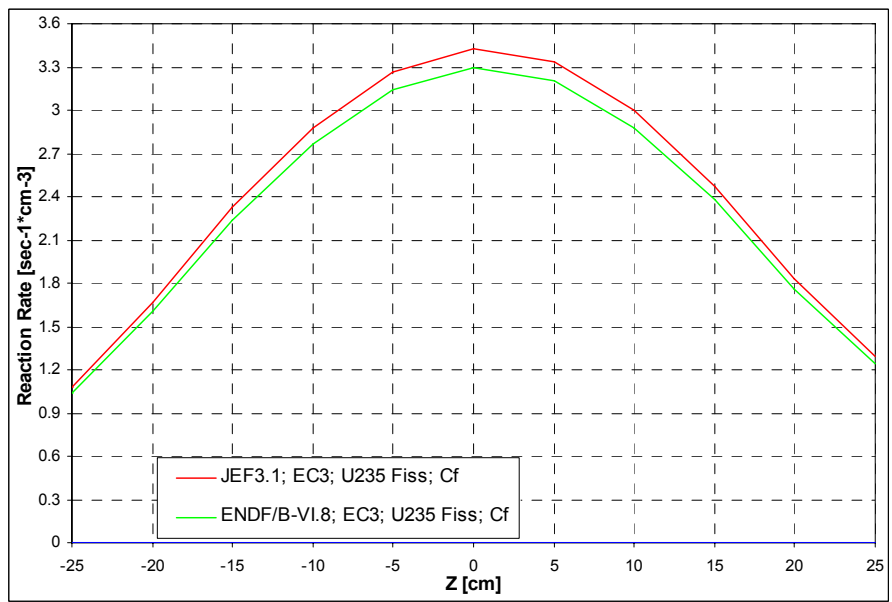

Figure 212. U-235 Fission Reaction Rate in EC3 Experimental Channel of the YALINA-Thermal with Cf Neutron Source

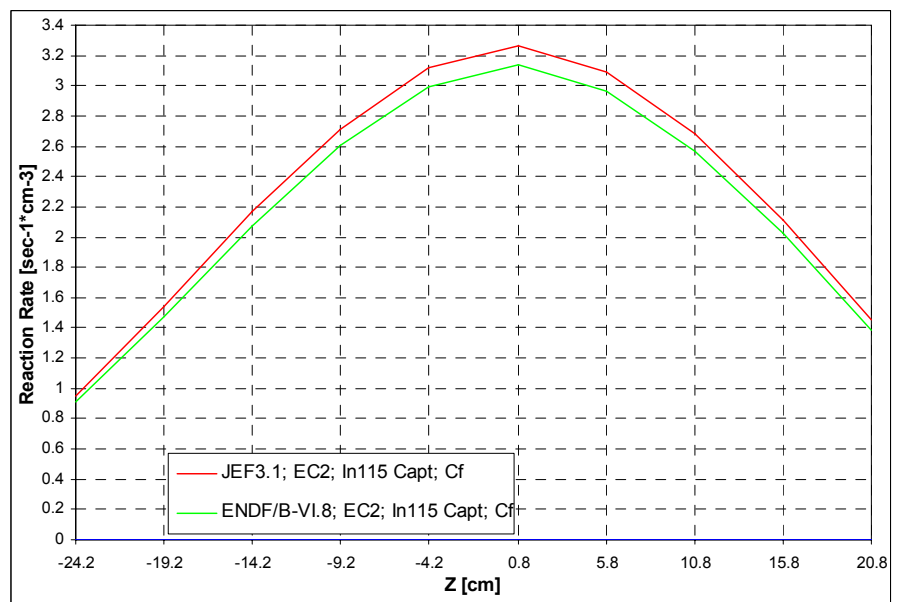

Figure 213. In-115 Capture Reaction Rate in EC2 Experimental Channel of the YALINA-Thermal with Cf Neutron Source. Polyethylene Holder is modeled

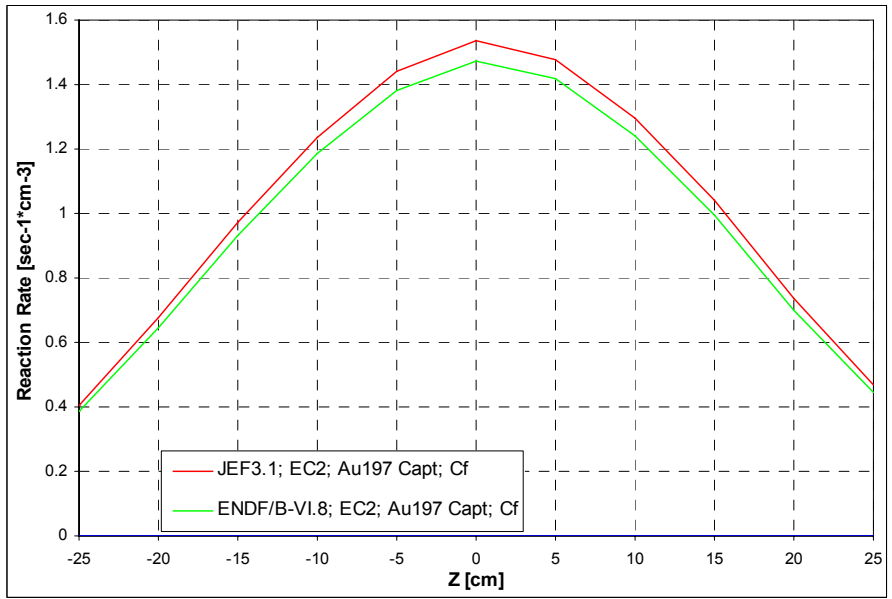

Figure 215. Au-197 Capture Reaction Rate in EC2 Experimental Channel of the YALINA-Thermal with Cf Neutron Source. Polyethylene Holder is modeled

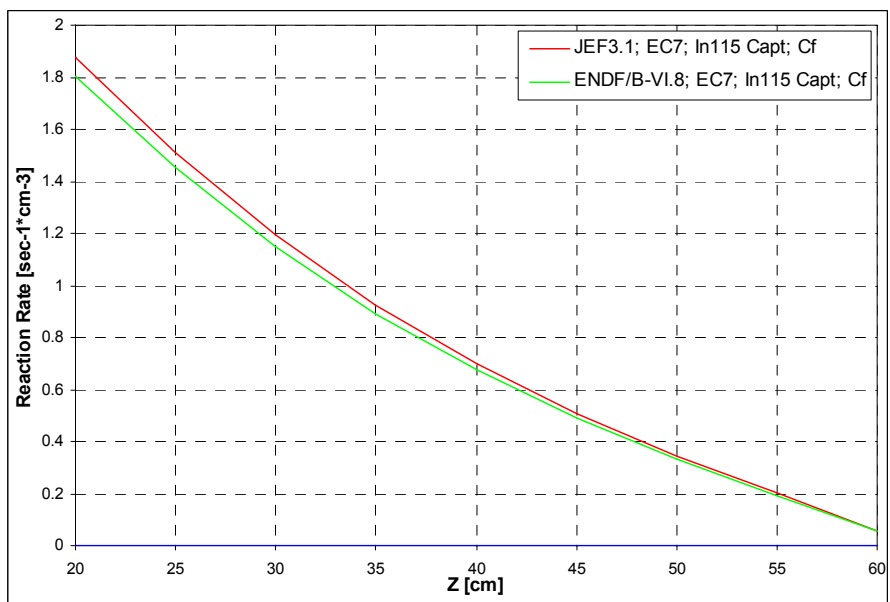

Figure 214. In-115 Capture Reaction Rate in EC7 Experimental Channel of the YALINA-Thermal with Cf Neutron Source. Polyethylene Holder is modeled

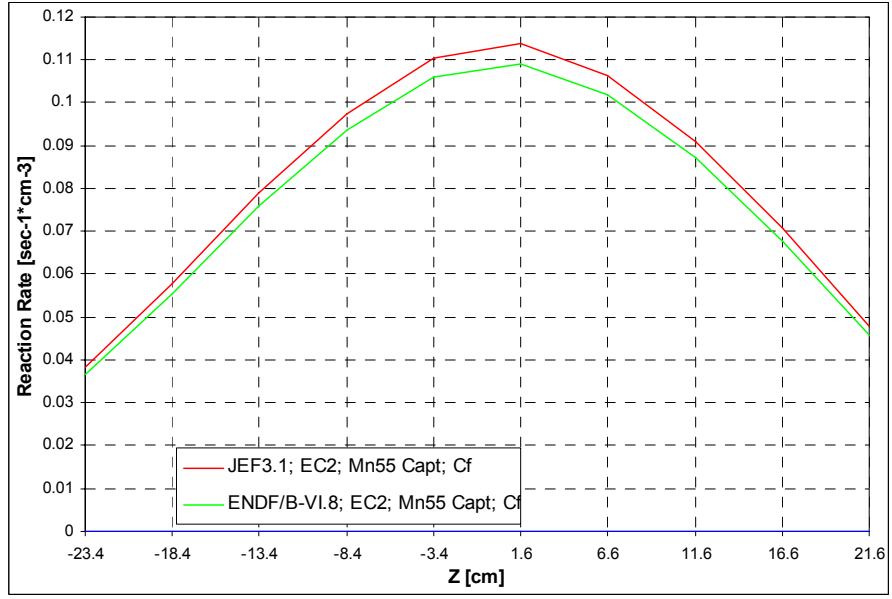

Figure 216. Mn-55 Capture Reaction Rate in EC2 Experimental Channel of the YALINA-Thermal with Cf Neutron Source. Polyethylene Holder is modeled 


\section{Appendix H}

\section{Comparison with Different Libraries}

\section{H.1. ENDF/B-VI.8 Results}

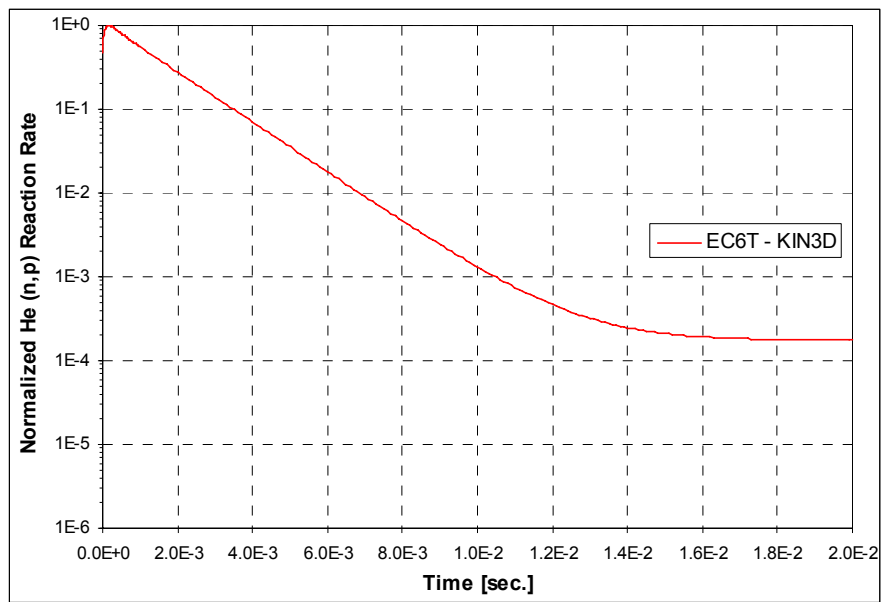

Figure 217. He-3 Detector Response in EC6T Experimental Channel of the YALINA-Booster with $(d, t)$ Neutron Source

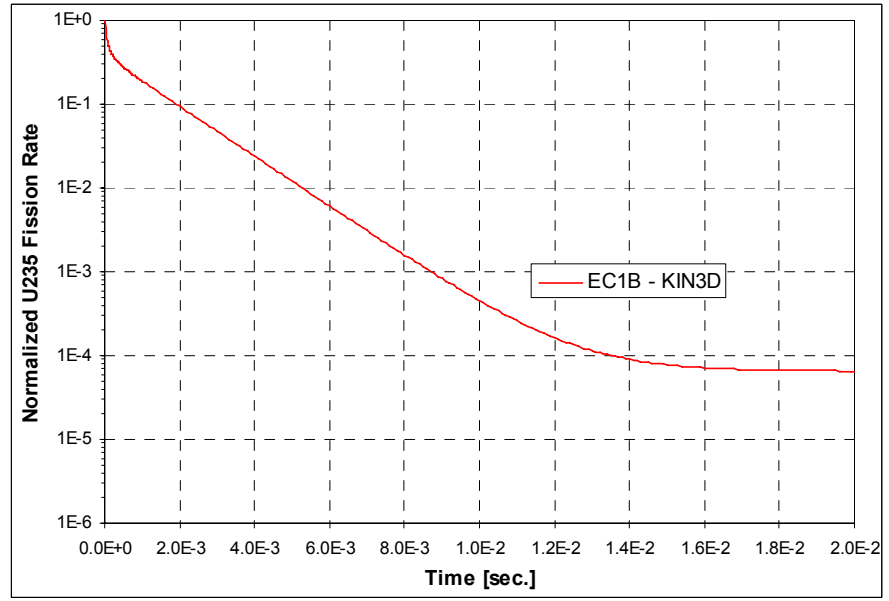

Figure 219. He-3 Detector Response in EC1B Experimental Channel of the YALINA-Booster with $(d, t)$ Neutron Source

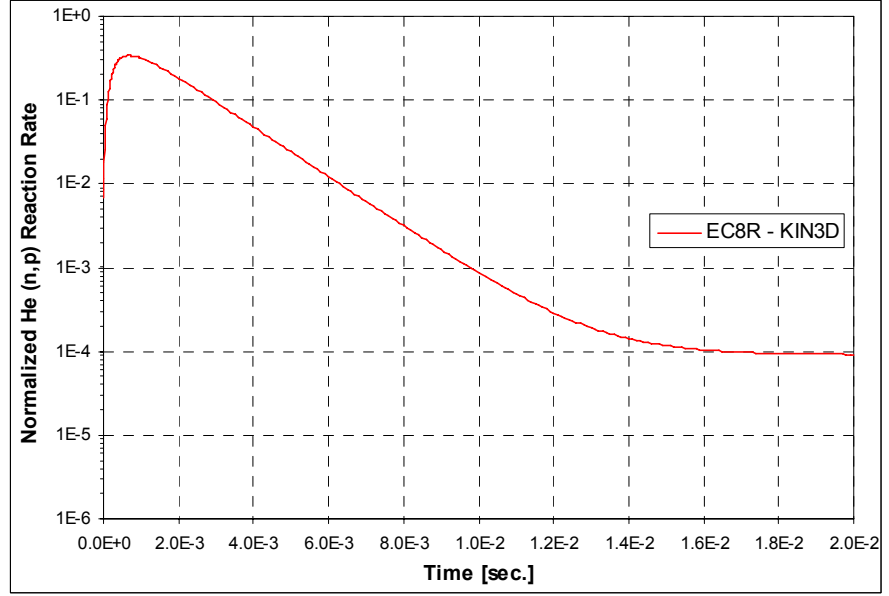

Figure 218. He-3 Detector Response in EC8R Experimental Channel of the YALINA-Booster with $(\mathrm{d}, \mathrm{t})$ Neutron Source

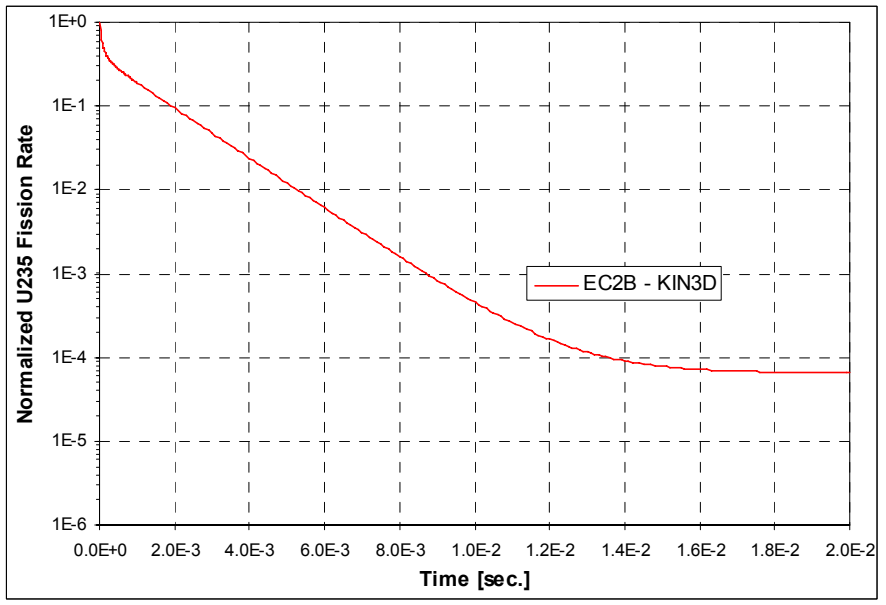

Figure 220. He-3 Detector Response in EC2B Experimental Channel of the YALINA-Booster with $(d, t)$ Neutron Source 


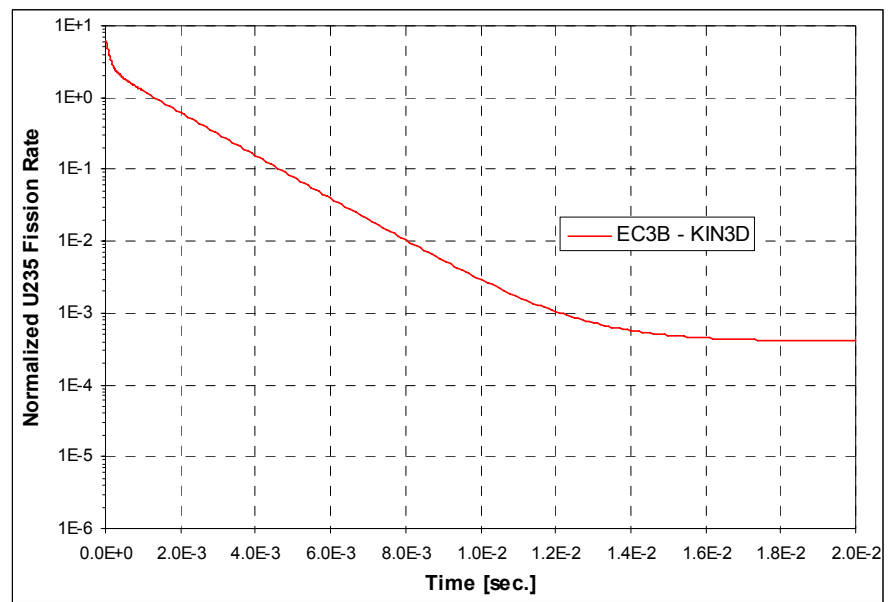

Figure 221. He-3 Detector Response in EC3B Experimental Channel of the YALINA-Booster with $(d, t)$ Neutron Source

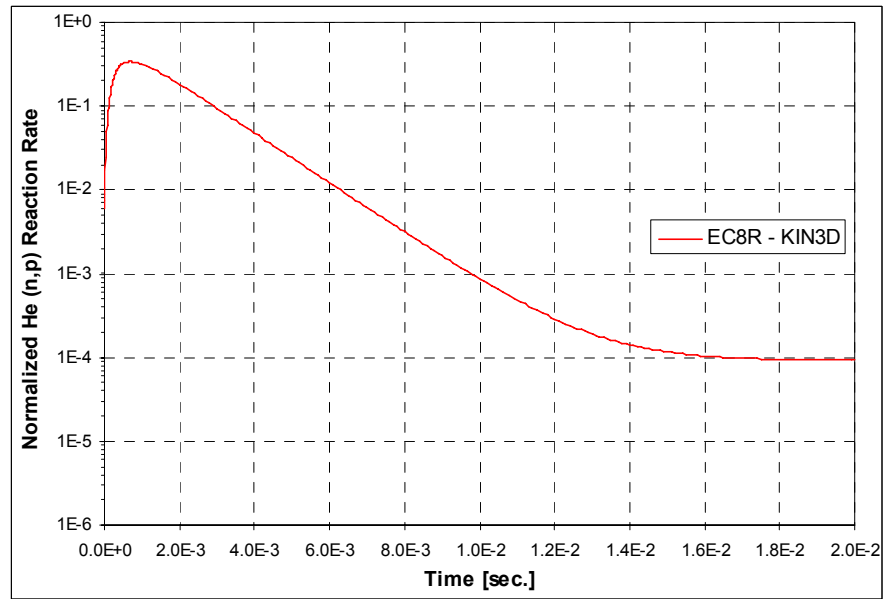

Figure 223. He-3 Detector Response in EC8R

Experimental Channel of the YALINA-Booster with $(d, d)$ Neutron Source

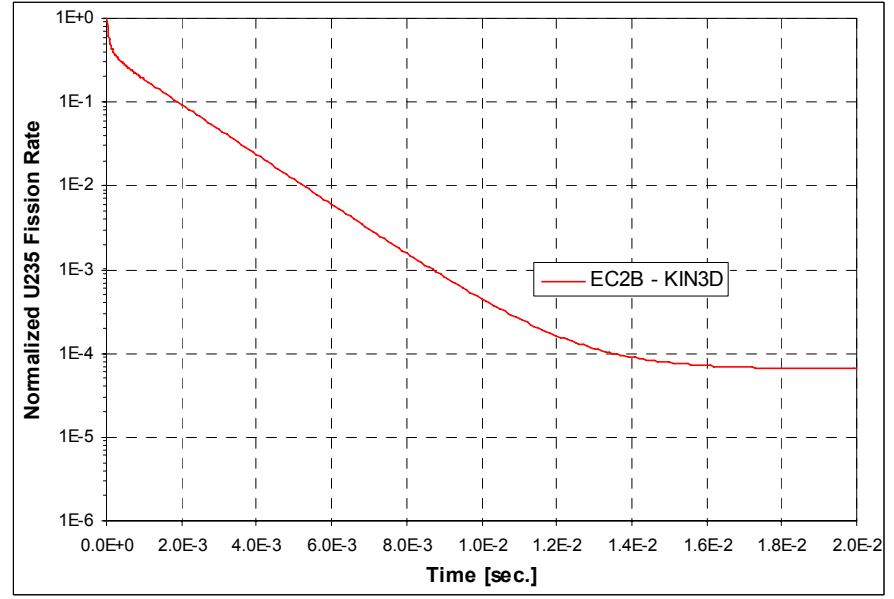

Figure 225. He-3 Detector Response in EC2B

Experimental Channel of the YALINA-Booster with $(d, d)$ Neutron Source

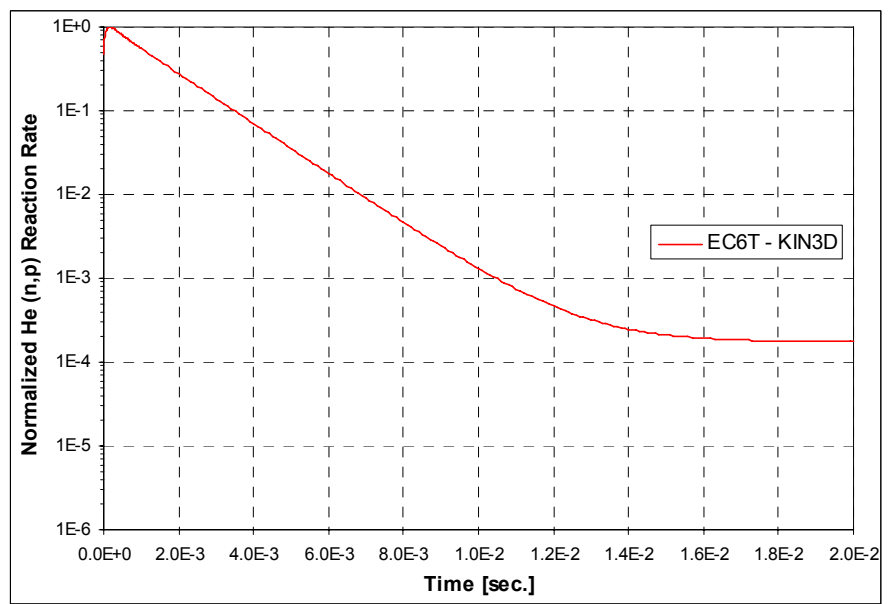

Figure 222. He-3 Detector Response in EC6T Experimental Channel of the YALINA-Booster with $(d, d)$ Neutron Source

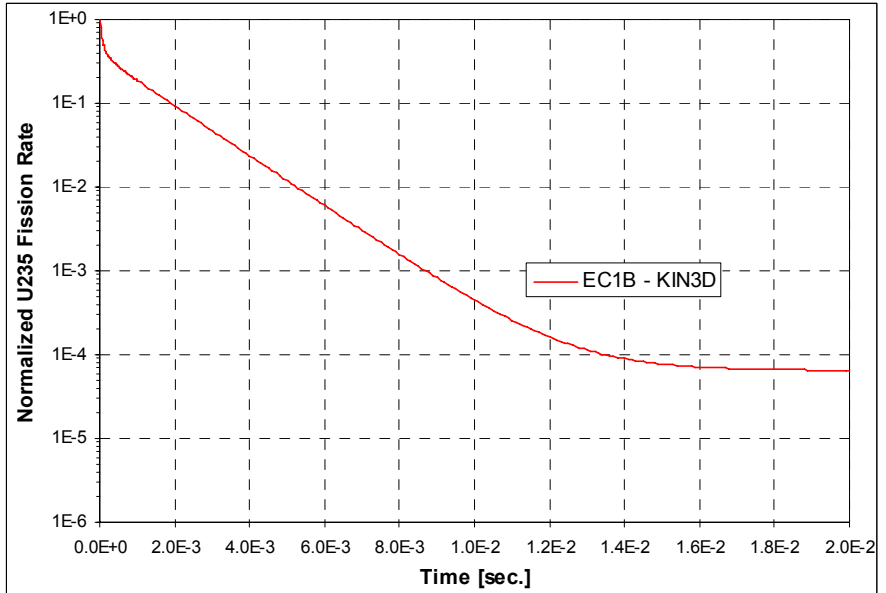

Figure 224. He-3 Detector Response in EC1B Experimental Channel of the YALINA-Booster with $(d, d)$ Neutron Source

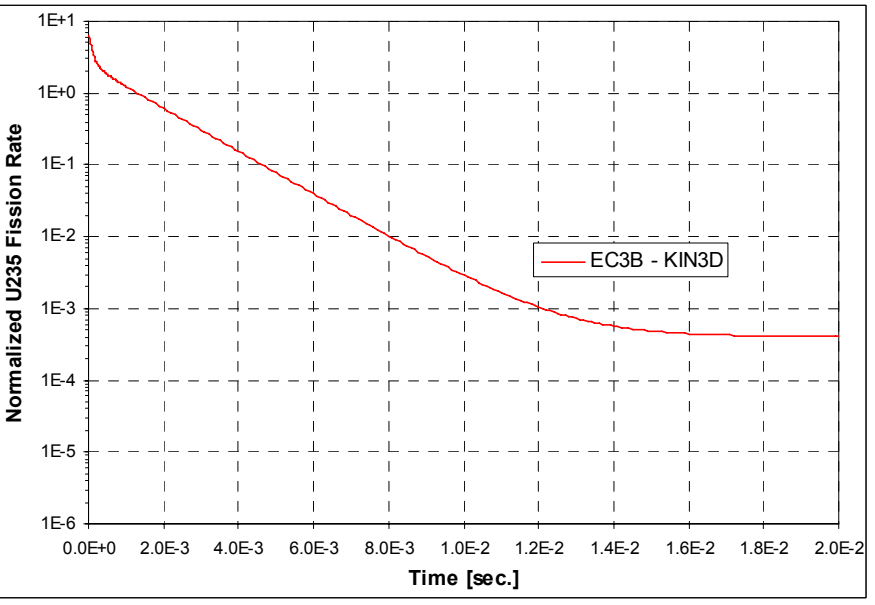

Figure 226. He-3 Detector Response in EC3B Experimental Channel of the YALINA-Booster with $(d, d)$ Neutron Source 


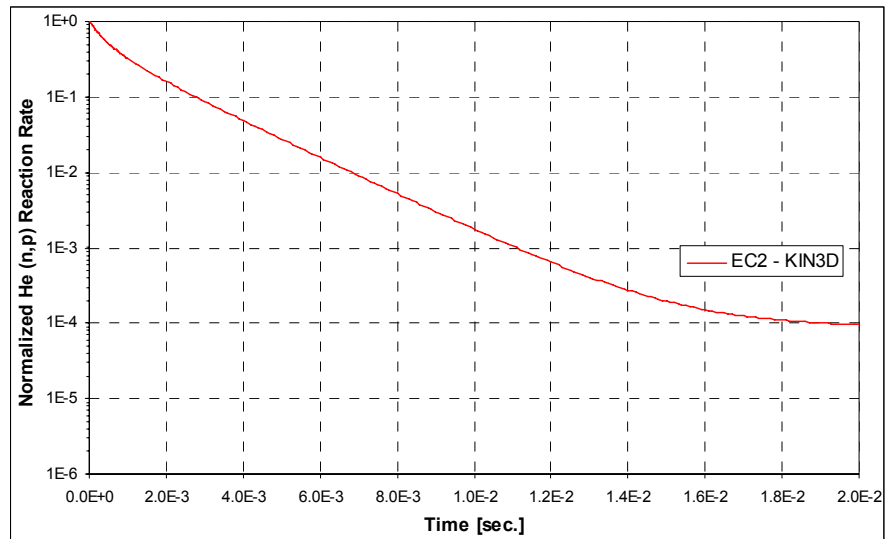

Figure 227. He-3 Detector Response in EC2

Experimental Channel of the YALINA-Thermal with $(d, t)$ Neutron Source

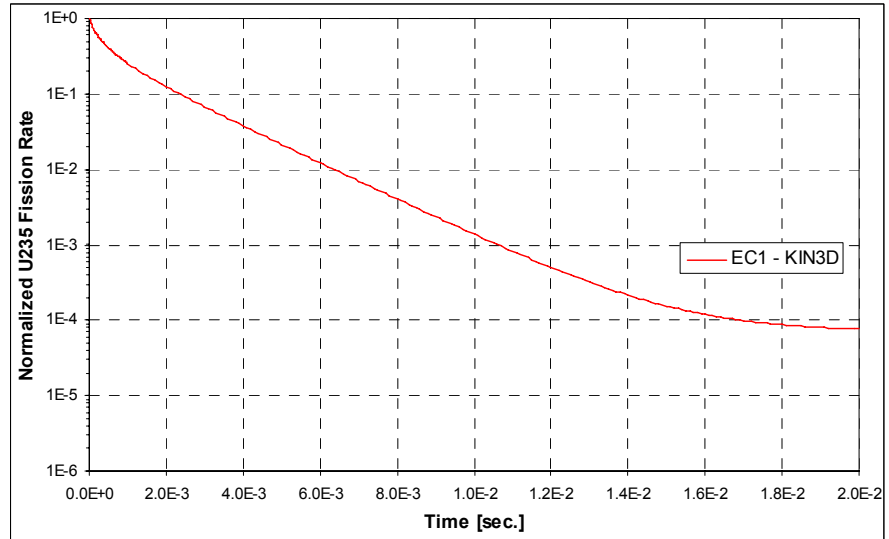

Figure 229. He-3 Detector Response in EC1 Experimental Channel of the YALINA-Thermal with $(d, t)$ Neutron Source

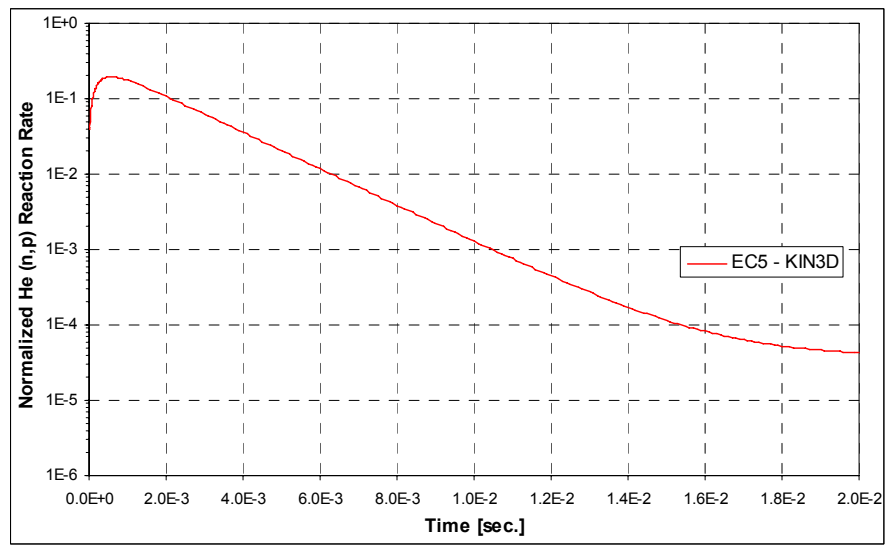

Figure 231. He-3 Detector Response in EC5

Experimental Channel of the YALINA-Thermal with $(d, d)$ Neutron Source

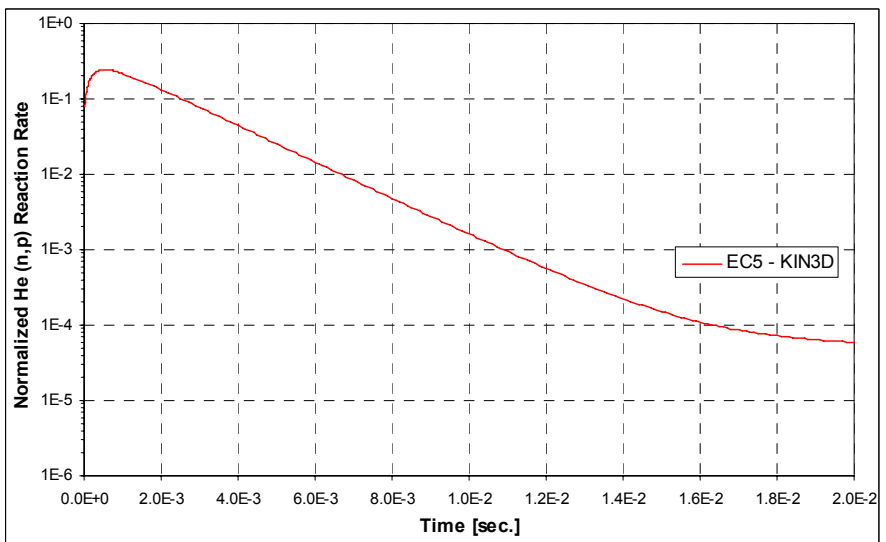

Figure 228. He-3 Detector Response in EC5 Experimental Channel of the YALINA-Thermal with $(d, t)$ Neutron Source

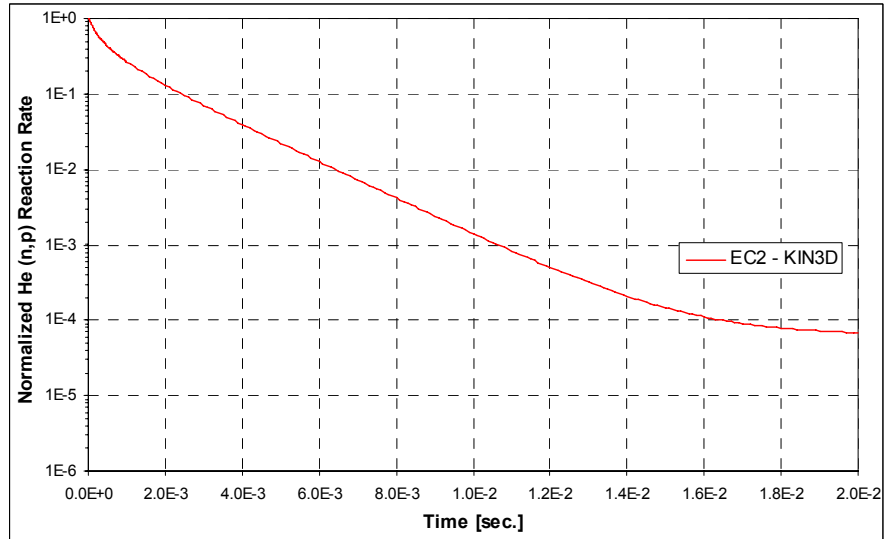

Figure 230. He-3 Detector Response in EC2 Experimental Channel of the YALINA-Thermal with $(d, t)$ Neutron Source

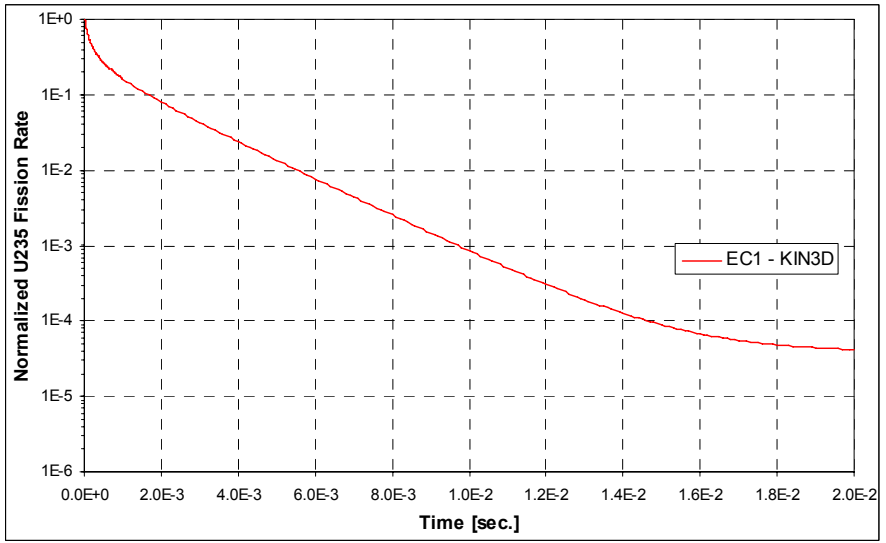

Figure 232. He-3 Detector Response in EC1 Experimental Channel of the YALINA-Thermal with $(d, d)$ Neutron Source 
H.2. Use of JEF2.2

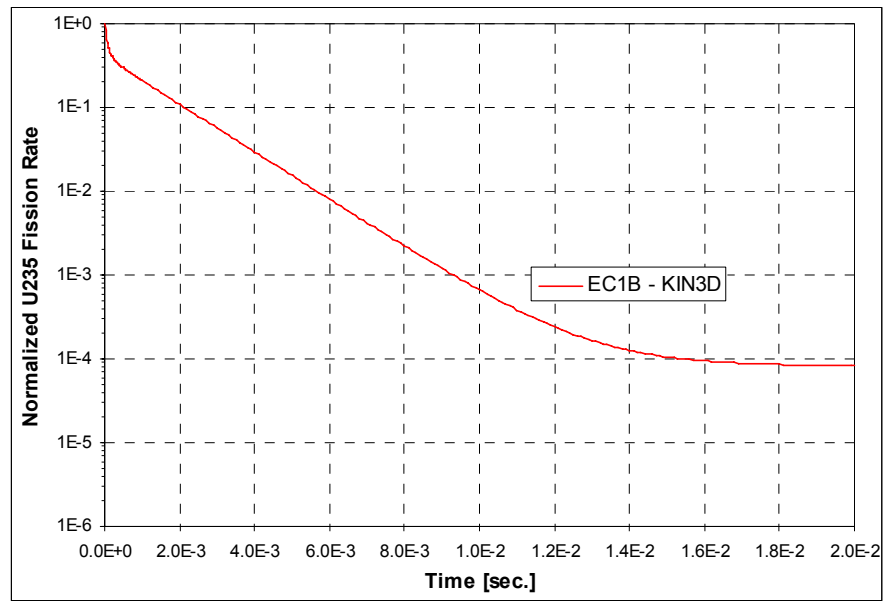

Figure 233. He-3 Detector Response in EC1B Experimental Channel of the YALINA-Booster with $(\mathrm{d}, \mathrm{t})$ Neutron Source

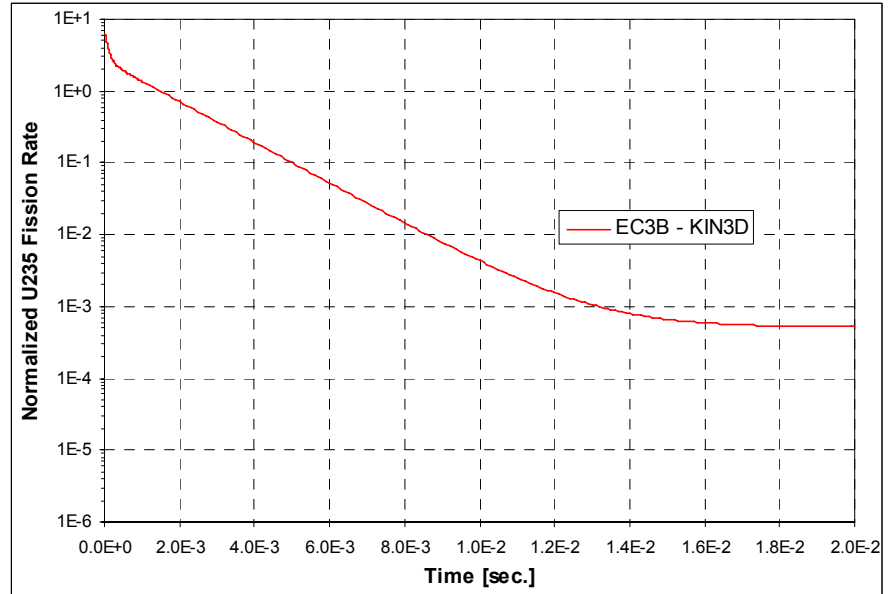

Figure 235. He-3 Detector Response in EC3B Experimental Channel of the YALINA-Booster with $(d, t)$ Neutron Source

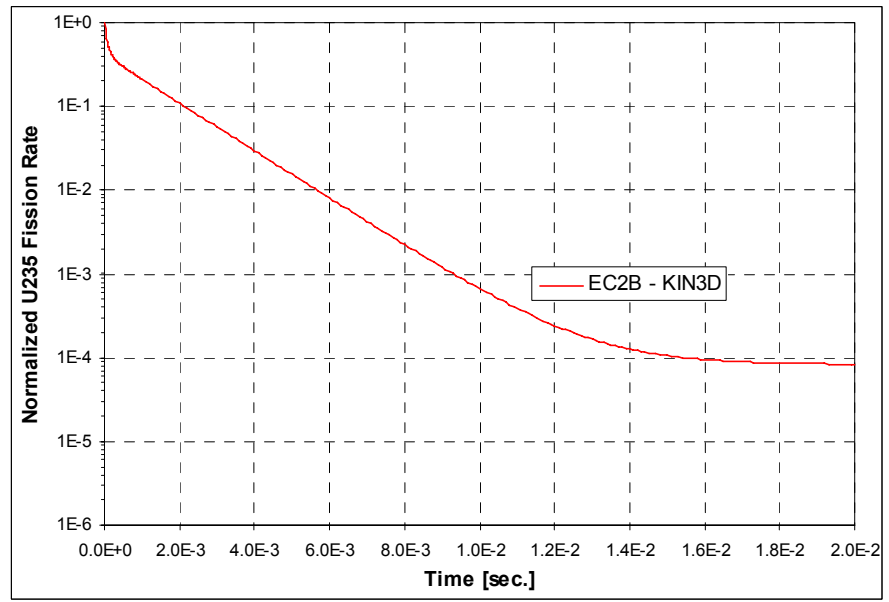

Figure 237. He-3 Detector Response in EC2B Experimental Channel of the YALINA-Booster with $(d, d)$ Neutron Source

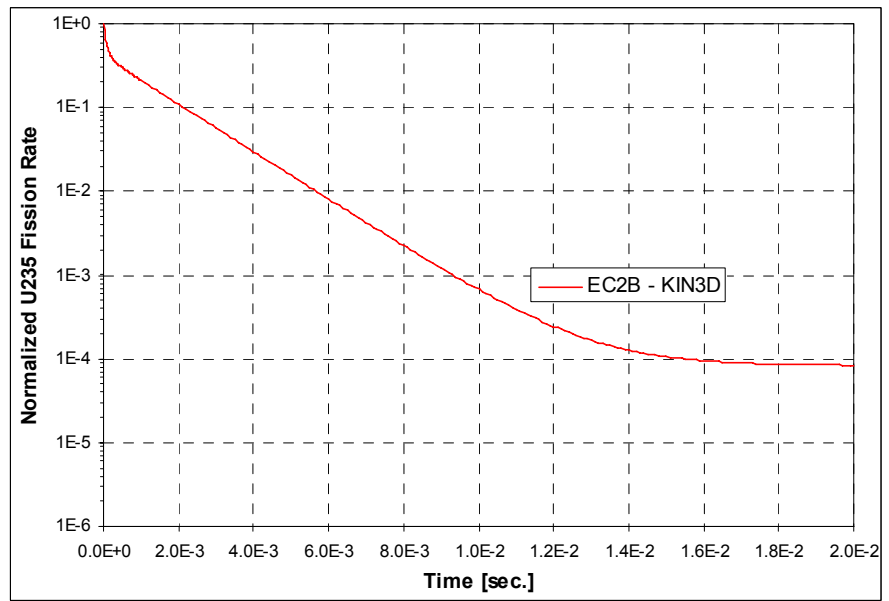

Figure 234. He-3 Detector Response in EC2B Experimental Channel of the YALINA-Booster with $(d, t)$ Neutron Source

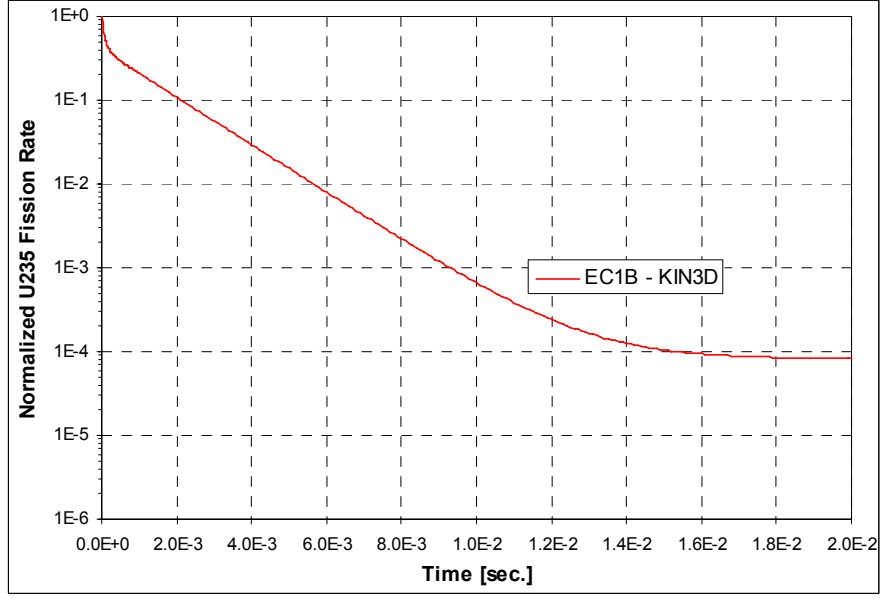

Figure 236. He-3 Detector Response in EC1B Experimental Channel of the YALINA-Booster with $(d, d)$ Neutron Source

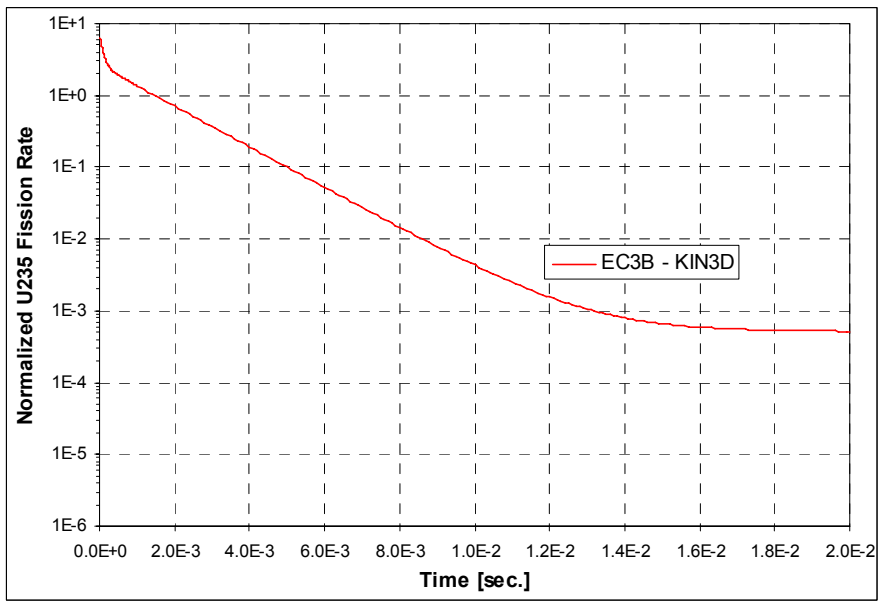

Figure 238. He-3 Detector Response in EC3B Experimental Channel of the YALINA-Booster with $(d, d)$ Neutron Source 


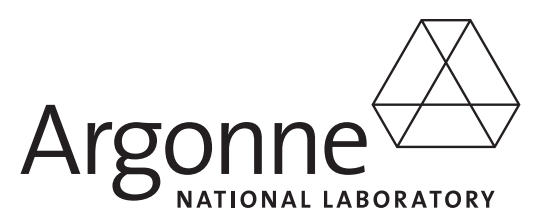

Nuclear Engineering Division

Argonne National Laboratory

9700 South Cass Avenue, Bldg. 208

Argonne, IL 60439-4842

www.anl.gov

U.S. DEPARTMENT OF

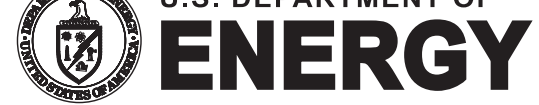

Argonne National Laboratory is a U.S. Department of Energy

laboratory managed by UChicago Argonne, LLC 